\title{
Persistence of corals in marginal habitats: the role of the environment, and symbiont diversity and ecophysiology
}

\section{Laura Caroline Wicks}

\author{
A thesis submitted to \\ Victoria University of Wellington \\ in fulfillment of the requirements for the degree of \\ Doctor of Philosophy in Science
}

2009

VICTORIA UNIVERSITY OF WELLINGTON

Te Whare Wānanga o te Ūpoko o te Ika a Māui

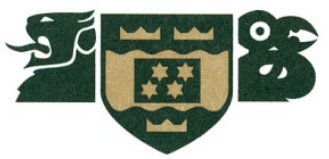




\begin{abstract}
Many corals live in marginal habitats, close to their survival thresholds of water temperature, light penetration and aragonite saturation. Living under these highly variable and extreme conditions is likely facilitated by specific physiological adaptations and/or the presence of unique species of coral and their symbionts but data on these factors are limited.

The specific objectives of the study were to: (1) examine the diversity and distribution patterns of corals in marginal environments, (2) investigate the diversity, distribution patterns and host specificity of symbionts in corals in marginal environments, (3) assess the influence of environmental variables on host and symbiont distribution in marginal environments, in comparison to 'optimal' environments, and (4) examine the physiological responses to changing environmental conditions and stress of corals and their symbionts in marginal environments.
\end{abstract}

Surveys of coral community patterns were conducted at the Kermadec Islands (KI), New Zealand, and Palmyra Atoll, USA, with local scale environmental parameters (i.e. wave exposure and sedimentation) found to control the diversity and distribution of the coral communities. Symbiodinium types were identified to subcladal level in a range of coral species at each of the survey sites, using ITS2-DGGE. A high diversity of $\mathrm{C}$ type symbionts (19 types in 13 host genera), and reduced host specificity was observed at the high latitude site of Lord Howe Island (LHI), Australia, with similarly high diversity at the KI (10 types in 9 genera). Thirteen novel clade C types were identified in corals at LHI, with two of these types also present in hosts at the KI. The reduced host specificity of symbionts at LHI, 
compared to tropical sites, implies that the evolution of novel holobionts may be an important mechanism whereby corals can cope with variable and stressful conditions. Further, physiological assessment of the novel LHI symbionts led to the suggestion that Symbiodinium at LHI may be specialised for cooler and more variable temperatures, so contributing to the success of corals at this marginal location.

In contrast, a low diversity of generalist symbionts (C and D types) were uncovered at the equatorial site of Palmyra Atoll (10 types in 13 genera), attributed to the stressful environmental regime resulting in a reduced population of stresstolerant symbionts. The variation in environmental parameters, particularly sedimentation, around Palmyra Atoll has led to diversification of coral communities, however this environmental variation has not affected the symbiont communities.

While it has been suggested that marginal coral communities might be better adapted for survival in an environment modified by global climate change, the local scale environmental factors are also important drivers of both coral and symbiont distributions, and should be considered when making predictions for the future. Further, assessment of the physiological tolerance ranges of both the multiple, novel symbionts at high latitudes, and the few, potentially stress-tolerant symbionts at Palmyra should be conducted, to help determine whether they have the ability to adjust to new environmental conditions. 


\section{Contributions and publications}

This thesis is written as a series of manuscripts, which are in the review process or to be submitted in the near future. All field-work, lab-work and writing were conducted by the Author, with expections as below.

\section{Chapter 2}

This chapter has been submitted for publication to the Marine Ecology Progress Series, and is in review. Sample collection was undertaken by JPA Gardner and J Long, of Victoria University of Wellington.

\section{Chapter 3}

The molecular work in this chapter was assisted by Dr Eugenia Sampayo, of The University of Queensland. Figure 3.3 was designed by Dr Sampayo, and made editorial comments on the text.

\section{Chapter 5}

The design and implementation of this study was aided by Dr Ross Hill of The University of Technology, Sydney. Dr Hill also made editorial comments on the text 


\section{Acknowledgements}

There are many people that I would like to thank for their invaluable support, both academically and personally, that made the completion of this thesis possible. I would like to thank everyone that has aided me in this journey; if I have forgotten anyone I apologise.

Foremost, I would like to thank my supervisor Dr Simon Davy for his continual support and insightful suggestions in the last three and a half years. Simon was always there to listen and give feedback, despite his busy schedule, and this thesis would not have existed without him. I would also like to thank my second supervisor Dr Jonathan Gardner, who not only was there with help and support when required, but also gave me the amazing opportunity to conduct research at Palmyra Atoll, an indescribable experience.

I am also grateful to the collaborators on two of my projects, Dr Eugenia Sampayo and Dr Ross Hill, and their supervisors, Prof Ove Hoegh-Guldberg and Dr Peter Ralph for allowing me to work in their labs and monopolise their post-docs' time. Additionally, I am indebted to all the people who lent me support and expertise in the lab, namely Dr Tyrone Ridgway, Dr Jo Zuccarello. Dr Ann Wood, Kristen Westfall, and Pelayo Salinas de Leon.

I wish to thank my lab group, for both their support and the constant reminder that, although my lab-work was testing at the best of times, I could have been cleaning anemones! In particular, for their kind assistance with fieldwork, I wish to thank Dr Jo Davy, Dan Logan and Gareth Williams. Additional thanks goes to Gareth for his stats advice and expertise, and his true gentlemanly behaviour in the face of a tiger shark. 
Many people outside VUW assisted with the fieldwork component of my studies. For their contribution to my Lord Howe Island work, thanks go to Ian Kerr and Sallyann Gudge of Lord Howe Island Marine Parks Authority, Tas Douglass, Lauren Gatherer, Brian 'Busty’ Busteed, Dr Peter Harrison and Dr Carden Wallace. For field assistance at Palmyra Atoll, I thank the staff of The Nature Conservancy, particularly Roseanne for her quick thinking in the tiger shark episode.

For permits I wish to thank NSW Marine Parks Authority, US Fish and Wildlife Services, and the Department of Conservation, New Zealand. For funding, I acknowledge the Commonwealth Scholarship scheme, New Zealand Postgraduate Study Abroad, Project Aware, Australian Geographic, the British Ecological Society, and finally Victoria University of Wellington for their research funding, faculty grant and submission scholarship.

During my $\mathrm{PhD}$, I have appreciated the presence of many good friends, in particular Anna Smith who shared with me the ups and downs, and many bottles of wine. I also wish to thank Jade Berman, Emily Dicks and the rest of my office buddies, for their support through the hard times, and fun times beside. Jessie and Peter Bakker receive special thanks for providing me with a happy home on multiple occasions, with many memorable nights out and in.

The writing up period was always going to be a challenge, but Chrissie and Brian Stuart-Nairne made the experience an enjoyable one, giving me a home in beautiful surroundings, and thus enabling me to keep my sanity at the same time as writing my thesis. I have to mention the mischievous antics of their Goldies, Bobby and Madge; Bobby especially made me laugh on more occasions than I thought possible during my $\mathrm{PhD}$. 
Lastly, and most importantly I need to thank the people to whom I dedicate this thesis, my parents and sisters, and Brett. Thank you mum and dad, not only for your financial support in times of crisis (and non-crisis!), but mainly for your emotional support and your faith in me over these long years. Despite the time difference, those weekly phone calls from home, and sporadic texts from Soph made me feel part of a wonderful family, even at such a distance. And finally to my partner Brett, I owe the greatest thanks. It cannot have been easy to have a girlfriend in a different country, let alone one doing a $\mathrm{PhD}$, but you stuck with me through the hard times, made me smile when times were bad, and I am looking forward to all the good times yet to come.

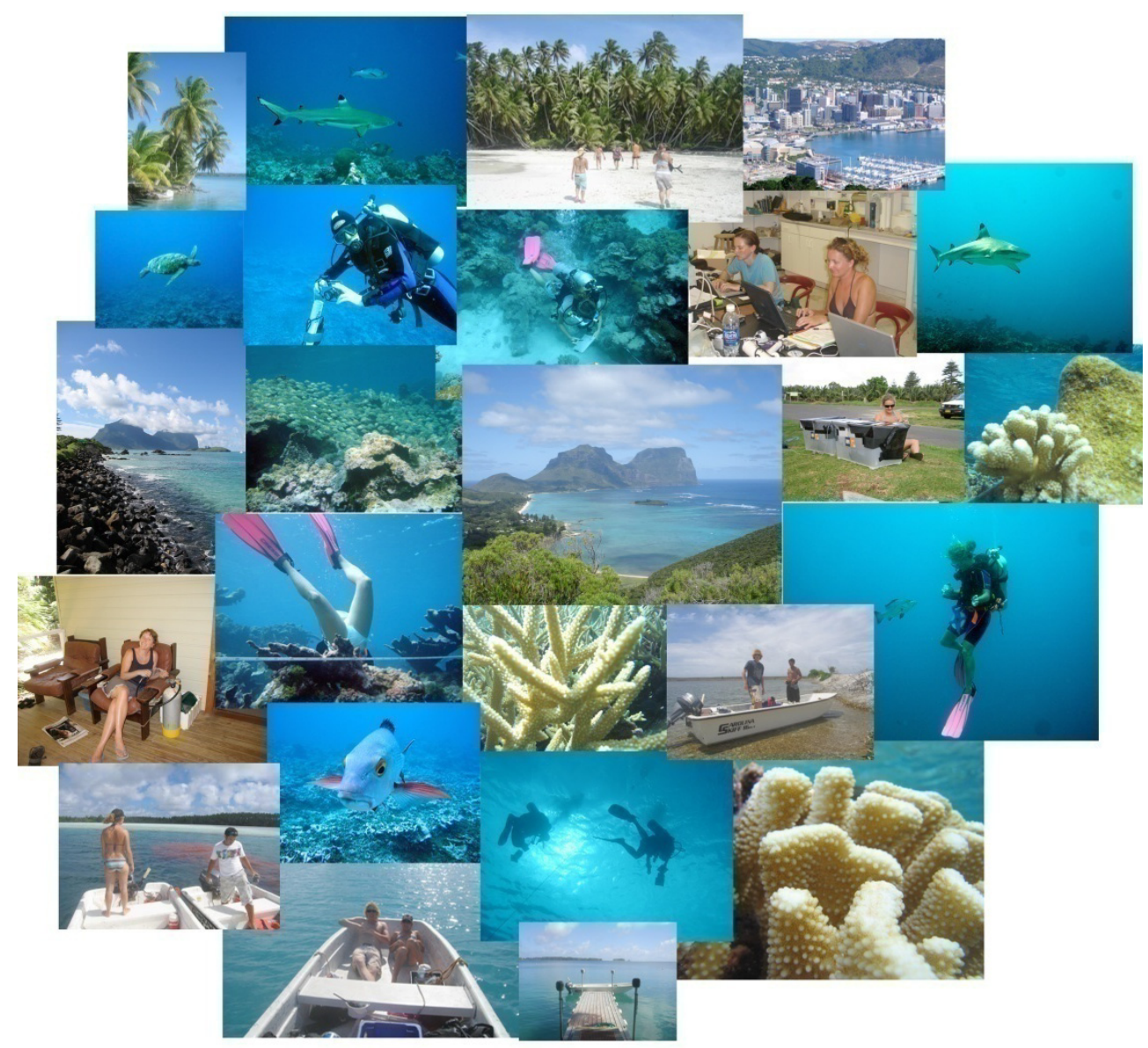




\section{Table of contents}

Abstract

Contributions and publications

$\begin{array}{lll}\text { Acknowledgements } & \text { III }\end{array}$

$\begin{array}{lll}\text { Table of contents } & \text { VI }\end{array}$

$\begin{array}{ll}\text { List of Figures } & \text { XI }\end{array}$

$\begin{array}{ll}\text { List of Tables } & \text { XIV }\end{array}$

$\begin{array}{ll}\text { List of abbreviations } & \text { XVI }\end{array}$

$\begin{array}{ll}\text { Glossary of terms } & \text { XVIII }\end{array}$

Chapter $1+1$ -

General Introduction $\quad$ - 1 -

1.1 Corals and symbiosis -1 -

1.2 Genetic diversity of Symbiodinium - 4 -

1.3 Host-symbiont specificity and flexibility $\quad-9$ -

1.4 Biogeographic and ecological variability of Cnidarian-Symbiodinium

partnerships -12 -

1.5 Physiological variability and susceptibility to environmental stress $\quad$ - 14 -

1.6 Photophysiology of Symbiodinium - 17 -

1.7 Corals in marginal environments -20 -

1.8 Symbiodinium in marginal environments $\quad-25$ -

1.9 Objectives $-26-$ 
Chapter 2

Spatial patterns and regional affinities of coral communities at the Kermadec

Islands Marine Reserve (New Zealand), a marginal high-latitude site $\quad$ - 30 ABSTRACT - 30 -

2.1 INTRODUCTION - 31 -

2.2 Materials and Methods $\quad 35$ -

2.2.1 Study area -35 -

2.2.2 Sampling - 35 -

2.2.3 Regional affinities 37 -

2.2.4 Data analysis $\quad-38$ -

Kermadec Islands $\quad-38$ -

Regional affinities $\quad$ - 39 -

2.3 RESULTS -40 -

2.3.1 Kermadec Islands $\quad-40$ -

2.3.2 Regional affinities -45 -

2.4. DISCUSSION - 49 -

2.4.1 Kermadec Islands

2.4.2. Wider implications 54 -

Chapter $3+\mathbf{5 6}$ -

Local endemicity and high diversity characterise high latitude coral-

Symbiodinium partnerships $\quad-56$ -

ABSTRACT -56 -

3.1 INTRODUCTION

3.2 MATERIALS AND METHODS - 61 -

3.2.1 Sampling and oceanographic parameters $\quad 61-$ 
3.2.2 DNA extraction and Symbiodinium identification

3.2.3 Data analysis

$-64-$

3.3 RESULTS

$-66-$

3.3.1 Symbiont community diversity and phylogenetic analysis

$-66-$

3.3.2 Environmental variability and symbiont diversity

3.4 DISCUSSION

3.4.1 Biogeographic distribution patterns of Symbiodinium

$-76-$

3.4.2 Endemicity and diversity

$-78-$

3.4.3 Ecological implications

Chapter 4

Effect of sedimentation on the community structure and resilience of corals and their symbionts

ABSTRACT

$-84-$

4.1 INTRODUCTION

$-85-$

4.2 METHOD

$-88-$

4.2.1 Study site

$-88-$

4.2.2 Coral sampling and community surveys

$-89-$

4.2.2 Symbiont identification

$-89-$

4.2.3 Environmental variables

$-92-$

4.2.4 Statistical analyses

4.3 RESULTS

$-96-$

4.3.1 Coral community structure

$-96-$

4.3.2 Symbiont identification

$-97-$

4.3.3 Environmental variables

$-100-$

4.4 DISCUSSION

- 106 - 
4.4.1 Symbiodinium at Palmyra Atoll

4.4.2 Environmental variability

4.4.3 Future plans for Palmyra Atoll

$-113-$

4.4.4 Ecological implications

$-114-$

Chapter 5

Photophysiology of Symbiodinium in response to environmental stress at a high

latitude, seasonally variable site

- 116 -

ABSTRACT

$-116-$

5.1 INTRODUCTION

- $117-$

5.2 MATERIALS AND METHODS

5.2.1 Sampling

5.2.2 Experimental procedure

$-122-$

5.2.3 Physiological measurements

$-123-$

5.2.4 Genetic data

$-125-$

5.2.5 Data analysis

$-126-$

5.3 RESULTS

$-127-$

5.3.1 Symbiont identification

$-127-$

5.3.2 Bleaching thresholds

$-127-$

5.3.3 Photochemical efficiency

$-128-$

5.3.4 Fast induction kinetics

$-133-$

5.3.5 Symbiont density and chlorophyll concentrations

$-138-$

5.4 DISCUSSION

$-142-$

Chapter 6

-150 -

General Discussion

- 150 - 
6.1 Marginal vs. optimal sites $\quad$ - 151 -

6.2 Marginality - a variable term $\quad 154$ -

6.3 Future of 'marginal' reefs and communities -155 -

References $\quad-161$ -

Appendix $1 \quad$ - 204 -

Kermadec Islands coral community analysis $\quad-204$ -

Appendix $2+205-$

Physiological capacity of Symbiodinium to facilitate survival of scleractinian

corals at environmentally marginal sites $\quad-205$ -

A2.1 INTRODUCTION - 205 -

A2.2 METHODS 208 -

A2.2.1 Study site and experimental setup $\quad 208$ -

A2.2.2 Environmental parameters $\quad-210$ -

A2.2.3 Genetic identification and physiological characteristics of Symbiodinium - 210

A2.3 RESULTS

Appendix 3

Symbiodinium diversity by sampling effort

Appendix 4

Palmyra Atoll coral diversity, distribution and photosynthetic health

A.4.1 Coral diversity at Palmyra Atoll 


\section{List of Figures}

\section{Chapter 1: General Introduction}

1.1 Freshly isolated zooxanthellae (Symbiodinium sp.) 3

1.2 Symbiodinium clade phylogeny inferred using rDNA 5

$\begin{array}{ll}\text { 1.3 Photosynthesis under ambient and stressed conditions } & 18\end{array}$

1.4 Distribution of marginal coral reefs and communities, as determined by Kleypas

et al. (1999) 22

1.5 Landscape of a typical high latitude coral reef 24

Chapter 2: Spatial patterns and regional affinities of coral communities at the Kermadec Islands

2.1 Algae competing for space with encrusting coral 32

2.2 New Zealand and Australian sites 36

2.3 Mean percent coral cover $( \pm \mathrm{SD})$ of hard and soft corals and numbers of species at nine sites at the Kermadec Islands, New Zealand. 43

2.4 Cluster analysis of coral community structure patterns of the Kermadec Islands, and other marginal sites $\quad 46$

Chapter 3: Reduced host specificity of Symbiodinium at high latitudes - a means of survival at seasonally variable reef sites?

3.1 Location of sampling sites at Lord Howe Island and the Kermadec Islands 62 3.2 PCR-DGGE fingerprints of ITS2 and ITS1 Symbiodinium types identified in various coral species at Lord Howe Island (Australia) and the Kermadec Islands (New Zealand) 
3.3 Most parsimonious tree of the ITS rDNA of Symbiodinium isolated from various coral hosts identified by ITS1 and ITS2 DGGE

3.4 Mean $( \pm$ SD) of environmental parameters measured at sites around Lord Howe Island, Australia

3.5 Distance based RDA ordination relating environmental variables to symbiont distributions at Lord Howe Island, Australia

Chapter 4: Effect of sedimentation on the community patterns and resilience of corals and their symbionts.

4.1 Location of Palmyra Atoll, USA, and sampling sites

4.2 Variation in coral cover, diversity and sediment regimes between sites at Palmyra Atoll USA

4.3 Symbiodinium types identified in corals at Palmyra Atoll, USA based on ITS2 DGGE

4.4 MDS plots showing dissimilarities in benthic cover, coral species presence/absence, holobiont presence/absence, and environmental variables at five sites at Palmyra Atoll, USA

4.5 LINKTREE classification and regression tree analysis showing major splits in coral species assemblages between sites by most significant environmental variables

Chapter 5: Do corals survive at marginal sites because of the specialised physiology of their dinoflagellate symbionts?

5.1 Lord Howe Island, Australia, with locations of sample collection 
5.3 ФPSII in Pocillopora damicornis over 72h in temperature/light treatments 132

5.4 PSII excitation pressure $\left(\mathrm{Q}_{\mathrm{m}}\right)$ in Pocillopora damicornis nubbins over 3 day thermal treatment period at high and low light.

5.5 Fast kinetic induction curves of thermal treatments on Pocillopora damicornis at 7 timepoints over a $72 \mathrm{~h}$ period at high and low light

5.6 Amplitude of the O, J, I and P steps along fast induction curves (FICs) in Pocillopora damicornis over a $72 \mathrm{~h}$ thermal treatment period at high and low light

5.7 Relative change of symbiont density in Pocillopora damicornis following $72 \mathrm{~h}$ exposure to temperature treatments at two light levels

5.8 Relative change of chl-a concentration in Pocillopora damicornis following $72 \mathrm{~h}$ exposure to temperature treatments at two light levels

\section{Chapter 6: General Discussion}

6.1 Factors/processes affecting the ability of marginal sites to act as refuges 


\section{List of Tables}

\section{Chapter 1: General Introduction}

1.1 Overview of costs, limitations, and solutions of various analysis techniques used to detect diversity in Symbiodinium communities

1.2 Characteristics of coral communities existing under optimal and marginal settings

Chapter 2: Spatial patterns and regional affinities of coral communities at the

\section{Kermadec Islands}

2.1 Benthic and coral species cover at the Kermadec Islands

2.2 Coral genera contributing to SIMPROF groupings of similarities in coral assemblages between Australasian and marginal sites

Chapter 3: Reduced host specificity of Symbiodinium at high latitudes - a means of survival at seasonally variable reef sites?

3.1 Sample list of host specimens and identified Symbiodinium type from sites (and depths) around Lord Howe Island, Australia, and the Kermadec Islands, New Zealand, using ITS2-DGGE

Chapter 4: Effect of sedimentation on the community patterns and resilience of corals and their symbionts.

4.1 Coral community measures and environmental parameters recorded at five backreef sites around Palmyra Atoll, USA

4.2 Symbiodinium types identified in coral species from five backreef sites at 
4.3 Summary of ANOVA/Kruskal-Wallis tests of difference in measured variables between sites at Palmyra Atoll, USA

Chapter 5: Do corals survive at marginal sites because of the specialised physiology of their dinoflagellate symbionts?

5.1. $p$ values of the rmANOVA analyses of physiological parameters between temperature and light treatments

5.2 Symbiont density and chl- $a$ concentrations in Pocillopora damicornis nubbins pre- and post-treatment

$5.3 p$ values of one-way ANOVA which tested for changes in symbiont density and chl-a concentration in Pocillopora damicornis nubbins over a $72 \mathrm{~h}$ thermal treatment period 


\section{List of abbreviations}

ФPSII = Effective photosynthetic yield

$18 \mathrm{~S}$ or SSU $=$ Small subunit of the rDNA

23S $=$ Chloroplast large subunit

$28 \mathrm{~S}$ or LSU $=$ Large subunit of the rDNA

$\mathrm{APX}=$ ascorbate peroxidase

ATP $=$ Adenosine triphosphate

chl- $a=$ chlorophyll a

COX $1=$ Cytochrome oxidase subunit 1

cprDNA $=$ Chloroplast ribosomal DNA

DGGE $=$ Denaturing gradient gel electrophoresis

DNA $=$ Deoxyribonucleic acid

FIC $=$ Fast induction curve

FTU $=$ Formazin turbidity unit

$\mathrm{F}_{\mathrm{v}} / \mathrm{F}_{\mathrm{m}}=$ Dark adapted photosynthetic yield

GBR $=$ Great Barrier Reef

ITS $=$ Internal transcribed spacer region of the rDNA

$\mathrm{KI}=$ Kermadec Islands

LHC $=$ Light harvesting complexes

LHI $=$ Lord Howe Island

$\mathrm{MAA}=$ mycosporine-like amino acids

$\mathrm{NADPH}=$ Oxidized nicotinamide adenine dinucleotide phosphate

$\mathrm{NPQ}=$ Non photochemical quenching

PAM $=$ Pulse amplitude modulation 
PCOM $=$ Percent organic matter

$\mathrm{PCR}=$ Polymerase chain reaction

PEA $=$ Plant efficiency analyser

$\mathrm{POM}=$ Particulate organic matter

PSII $=$ Photosystem II

rmANOVA $=$ Repeat measures analysis of variance

$\mathrm{Q}_{\mathrm{A}}=$ Primary electron acceptor

$\mathrm{Q}_{\mathrm{B}}=$ Secondary electron acceptor

$\mathrm{Q}_{\mathrm{m}}=$ Maximum excitation pressure over PSII

rDNA $=$ Ribosomal DNA

ROS $=$ Reactive oxygen species

$\mathrm{SOD}=$ superoxide dismutase

$\mathrm{SSCP}=$ Single strand conformation polymorphism

$\mathrm{SST}=$ Sea surface temperature

$\mathrm{TPM}=$ Total particulate matter

$\mathrm{UVR}=$ Ultraviolet radiation 


\section{Glossary of terms}

Environmental specialist: A symbiont specialised for a particular environment, recognisable by their patterns of distribution

Flexibility: Ability of a host to associate with multiple Symbiodinium types

Holobiont: Unit defined by the host species and symbiont type.

Host generalist: A symbiont which associates with a range of host species or genera Host specialist: A symbiont that only associates with one host species or genera ITS2 type: Genetic ITS2 variant, lower taxonomic level than a clade. Taxonomic status as yet unresolved but may represent a species or a genetic variant within a species (strain).

Marginal reefs/communities: those that occur where conditions are close to the environmental thresholds for coral survival (Kleypas et al 1999, Harriott \& Banks, 2002). These thresholds include high or low temperatures, salinities or nutrient levels, low light penetration or low aragonite saturation state (Kleypas et al 1999). Selective sweep: reduction or elimination of variation among the nucleotides in neighbouring DNA of a mutation as the result of recent and strong positive natural selection.

Specificity: Members of the same host taxa harbouring specific symbiont types, e.g. Pocillopora damicornis with C41 


\section{Chapter 1}

\section{General Introduction}

Marginal coral communities are viewed as those that exist close to the environmental thresholds for coral survival (Kleypas et al. 1999). Given that most of the world's coral reefs will become marginalised as our climate rapidly changes (HoeghGuldberg et al. 2007), study of marginal corals and their dinoflagellate symbionts (zooxanthellae) may provide useful analogues for understanding the ecology of coral reefs subjected to deteriorating conditions (Perry \& Larcombe 2003). Moreover, it has been suggested that marginal coral communities might be better adapted for survival in an environment modified by global climate change, as a result of their existence in already stressed conditions (Glynn 1996, Riegl \& Piller 2003). Knowledge of the environmental parameters driving coral and symbiont distributions, and the physiological tolerances of these symbionts to environmental stressors, are central to understanding how reefs or coral communities persist in marginal conditions.

\subsection{Corals and symbiosis}

Dinoflagellates of the genus Symbiodinium are phototrophic unicellular algae ('symbionts') that form mutualistic relationships with a wide variety of marine invertebrates and protists ('hosts'), in both tropical and temperate waters (Trench 1979, 1987, Banaszak et al. 1993). These hosts include members of various phyla, 
including the Cnidaria, Platyhelminthes, Mollusca, Porifera, and Foraminifera (Trench 1979, Pawlowski et al. 2001). In the relationship between scleractinian (hard) corals and Symbiodinium spp., the algae live intracellularly, residing in hostderived vacuoles in the endodermal cells of the host that line the gastrovascular cavity (Fig 1.1a, Colley \& Trench 1983, Lewin \& Chang 1989, Farmer et al. 2001). These microscopic golden-brown algae (size $\sim 5 \mu \mathrm{m}$, Fig. 1.1b), commonly known as zooxanthellae, are present at extremely high densities in their host (greater than $10^{6}$ $\mathrm{cm}^{-2}$, Muscatine \& Porter 1977). Densities of symbionts may fluctuate over time in response to seasonal variables such as irradiance and temperature (Fagoonee et al. 1999, Fitt et al. 2000). Internally, Symbiodinium cells possess a large nucleus containing permanently condensed chloroplast(s) with a spiked pyrenoid (housing enzymes for $\mathrm{CO}_{2}$ fixation), and pigments including chlorophylls $a$ and $c$, peridinin and diadinoxanthin. Zooxanthellae reproduce asexually, by mitotic division when in the coccoid state only; growing evidence also suggests that sexual recombination can occur (Stat et al. 2006).

The host relies on its dinoflagellate symbionts for survival; they release substantial amounts of photosynthetically-fixed organic compounds ('photosynthate'), meeting up to $95 \%$ of the hosts energy requirements (Muscatine 1990, Wang \& Douglas 1998). Photosynthate consists largely of low molecular weight, energy rich compounds such as glycerol and glucose, almost all essential amino acids, organic acids, and, arguably, lipids (Markell \& Trench 1993, Trench 1993, Muscatine et al. 1994). In return, the host provides carbon dioxide for photosynthesis and supplies metabolic waste products (containing nitrogen and other elements including phosphorus) to the symbiont. The symbionts recycle the nitrogen by incorporating it into amino acids, which are then translocated back to the coral for 
use in respiration. Additionally, by hosting Symbiodinium cells, the host conserves nitrogen by preferentially using the low molecular weight nitrogen produced by the symbiont for its own respiration, rather than host-derived amino acids (Wang \& Douglas 1998). These nutritional interactions promote the growth and development of coral reefs in nutrient-poor tropical seas (Muscatine \& Porter 1977), with energy from the symbiont also assisting in coral calcification and hence formation of the reef framework (Pearse \& Muscatine 1971, Hoegh-Guldberg et al. 2004). The lack of coral reefs in temperate waters, and the reduced framework of coral communities at high latitudes, is in a large part related to the reduced capacity of the dinoflagellate symbionts to photosynthesise in cooler waters, leading to a reduced capacity for net reef accretion (Glynn \& Stewart 1973, Crossland 1981).

(a)

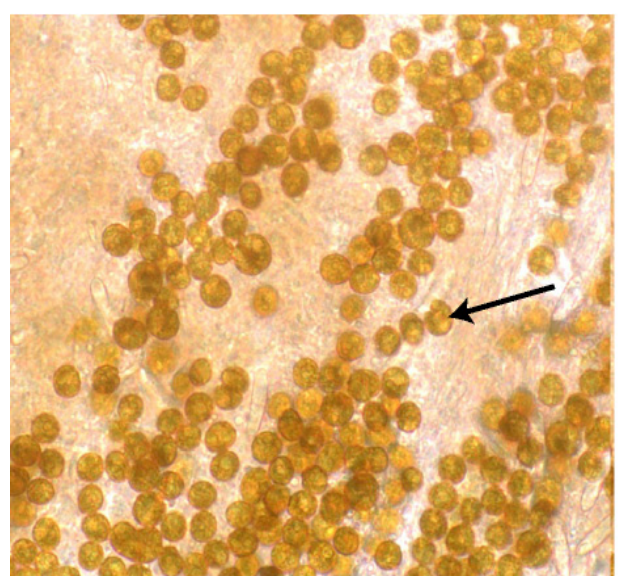

(b)

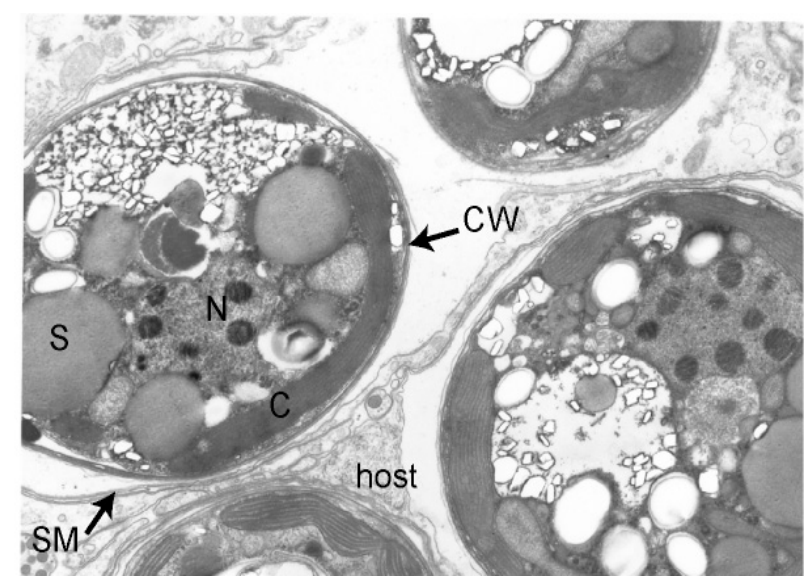

Figure 1.1 Freshly isolated zooxanthellae (Symbiodinium sp.). (a) light microscope of zooxanthellae cells, each cell $\sim 5 \mu \mathrm{m}$. Arrow points to single zooxanthella. Courtesy of Ove Hoegh-Guldberg. (b) transmission electron micrograph of zooxanthellae in a thin section of the sea anemone Aiptasia pallida showing cellular structure and host symbiont arrangement. CW, cell wall; SM, symbiosome membrane; S, starch storage granule; C, chloroplast; N, nucleus containing dark, permanently condensed chromosomes. Courtesy of Giselle Muller-Parker and Kit Lee. 


\subsection{Genetic diversity of Symbiodinium}

The lack of distinct morphological differences between Symbiodinium types led to the initial belief that the genus consisted of a single species, Symbiodinium microadriaticum. However, over the past several decades, molecular, microscopic and physiological analyses of various Symbiodinium spp. have repeatedly shown that considerable genetic, morphological, biochemical and physiological diversity exists within the genus (Freundenthal, 1962, Schoenberg \& Trench 1980a, b, c, Chang et al. 1983, Tytler \& Trench 1986, Trench \& Blank 1987, Markell \& Trench 1993, Trench 1993, reviewed by Coffroth \& Santos 2005).

Current knowledge on the evolution, biogeography and ecology of Symbiodinium stems from our ability to, with the aid of molecular techniques, distinguish members of this highly diverse group of microorganisms. Thus far, 8 clades (A-H) and numerous sub-cladal types of Symbiodinium have been identified, with six of these clades (A-D, F and G) known to form associations with scleractinian corals (reviewed in Rowan 1998, Baker 2003, Coffroth \& Santos 2005). Symbiodinium clades represent divergent lineages, with the sub-clades representing closely related molecular 'types' (Fig. 1.2). A 'type' refers to the genetic lineage of Symbiodinium defined by a unique ITS2 sequence. The greatest number of types has thus far been identified in clade $\mathrm{C}$, which is found in association with most marine invertebrate hosts that harbour Symbiodinium cells and is particularly prevalent in the Pacific Ocean (Baker \& Rowan 1997, Veron 2000, LaJeunesse et al. 2003, 2004a, b). Symbiont types C3 and C1 (identified by the internal transcribed spacer region, ITS2) have been called the 'living ancestors' of the clade C lineage (LaJeunesse 2005), from which all other known types diverge. The diversity within clade C Symbiodinium has been postulated to have resulted from a selective sweep of these 
types or their ancestor before the closure of the Central American Isthmus. This was followed by allopatric evolution, resulting in different molecular types found in conspecific hosts between the two Oceans (LaJeunesse 2001, 2005). Recently it has been proposed that these multiple sub-cladal types represent intraspecific sequence variations, as they are only minimally divergent from each other (i.e. 1 basepair) (Correa \& Baker 2008), however issues have arisen with that study (see LaJeunesse et al 2008, Sampayo et al 2008). The lack of agreement on sub-cladal distinction remains an ongoing issue, with attempts to develop multiple, independent markers continuing (Coffroth \& Santos 2005, Correa \& Baker 2009).

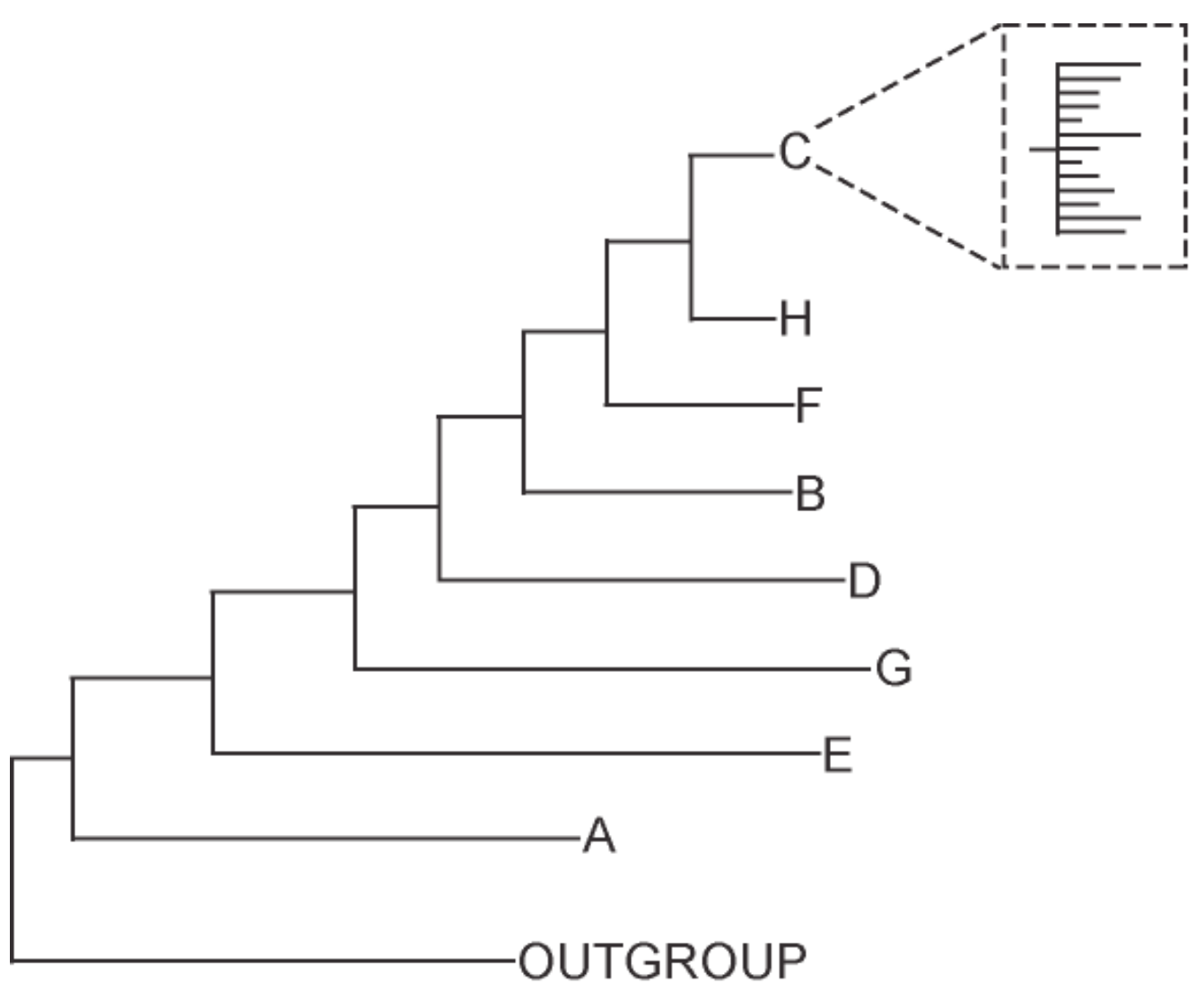

Figure 1.2 Symbiodinium clade phylogeny inferred using rDNA. The subcladal diversity is represented for clade C only. Adapted from Pochon et al. (2004). 
Although initial studies used the small subunit (n18s) rDNA for taxonomic identification of Symbiodinium (Rowan \& Powers 1991), recent studies have largely been based on multi-copy ribosomal RNA genes, including the large subunit region (28S) (Rowan 1998, Baker 1999), and the more rapidly evolving, noncoding ITS1 and ITS2 (Hunter et al. 1997, Baillie et al. 2000, LaJeunesse 2001, van Oppen et al. 2001), in addition to the chloroplast large subunit (23S) (Santos et al. 2002), and mitochondrial protein-coding gene (cytochrome oxidase subunit I (COX1); Takabayashi et al. 2004).

For the rapid resolution of distinct Symbiodinium types, molecular screening techniques have been used, including denaturing gradient gel electrophoresis (DGGE; e.g. LaJeunesse et al. 2003, 2004a), restriction fragment length polymorphism (RFLP) analysis of small (SSU) and large subunit (LSU) nrDNA (Baker 1999), temperature gradient gel electrophoresis (TGGE, Carlos et al. 2000), single strand conformational polymorphism (SSCP) analysis of ITS nrDNA (van Oppen et al. 2001, Ulstrup \& van Oppen 2003, van Oppen 2004), length heteroplasmy of LSU cprDNA (Santos et al. 2003) and phylogenetic analysis of microsatellite flanking regions (Santos et al. 2004). Although efforts to uncover the true diversity of Symbiodinium communities have been confused due to the application of different screening techniques in different laboratories, several independent approaches have been shown to uncover the same level of diversity within a community survey (Sampayo et al. 2009). Population level studies of Symbiodinium diversity and distribution have recently been developed, using microsatellites, with this technique likely increase in usage in the future.

Over the past 5 years, DGGE of the ribosomal ITS1 and ITS2 regions has been widely used to characterise the symbionts found in cnidarian hosts (Diekmann 
et al. 2002, LaJeunesse 2002, LaJeunesse et al. 2003, LaJeunesse et al. 2004a, Sampayo et al. 2007). Both ITS1 and ITS2 have provided insight into sub-cladal classification ('types'), with ITS2 being the most widely used marker. DGGE can be used to distinguish differences in the primary sequence (e.g. ITS2) based on disparities in electrophoretic mobility of the sequence. DGGE was originally developed to detect specific mutations within genomic genes due to one base mismatch (Myers et al. 1985). Since Muyzer et al. (1993) applied this method to environmental microorganisms, analyses of microbial communities using DGGE have become increasingly popular.

The use of DGGE in cnidarian hosts began with LaJeunesse and Trench (2000) and has since been used with ITS1 and ITS2 rDNA to distinguish genetically and ecologically distinct symbionts (e.g. LaJeunesse 2001, Sampayo et al. 2007, LaJeunesse et al. 2008). The advantages of DGGE are that it allows the simultaneous analysis of multiple samples and the comparison of Symbiodinium communities both within a single coral colony and within an environment. Further, excision of the bands enables sequence data to be obtained on dominant Symbiodinium types. As with all molecular screening techniques, disadvantages also exist, mainly in relation to sequence co-migration and heteroduplexes (Apprill \& Gates 2007, LaJeunesse \& Pinzon 2007, Thornhill et al. 2007, Sampayo et al. 2009). However, when applied correctly and interpreted conservatively, ITS1 and ITS2 DGGE remain the most appropriate techniques available at present for identifying Symbiodinium diversity among cnidarian hosts. The benefits and disadvantages of multiple screening techniques of Symbiodinium communities are outlined in Table 1.1. 


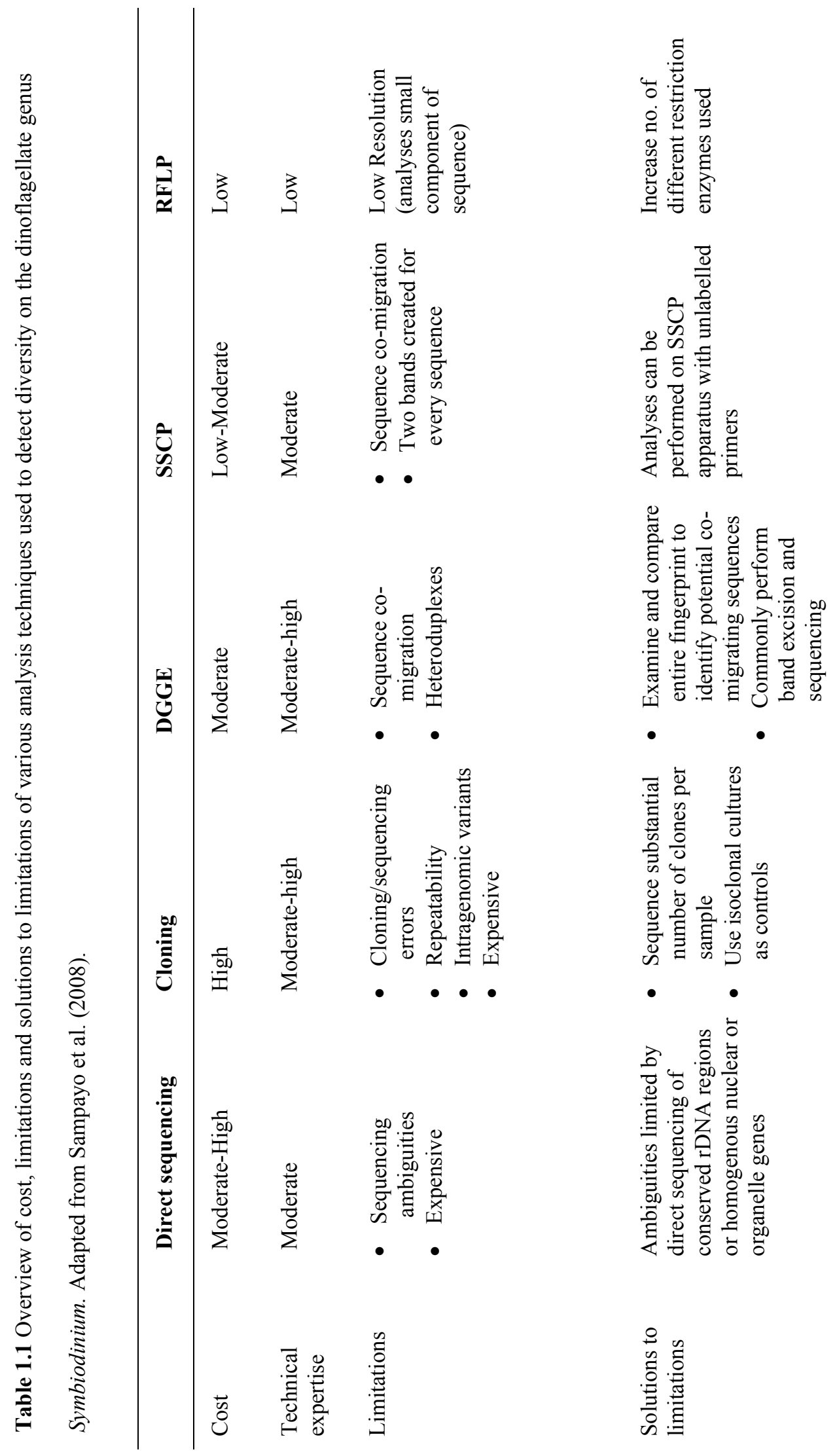




\subsection{Host-symbiont specificity and flexibility}

The current understanding of Symbiodinium diversity and host specificity reveals a great deal of complexity in the relationship. The host symbiont partnership can exhibit specificity and flexibility i.e. some members of the same host species generally harbour the same Symbiodinium type, or clade at least (Rowan and Powers 1991, Baker et al. 1997), whereas some host species can harbour numerous types of Symbiodinium (LaJeunesse 2002, Baker 2003). Single coral colonies can also harbour multiple Symbiodinium types, on both a cladal (Baker 2003, Mieog et al. 2007) and sub-cladal level (Ulstrup \& van Oppen 2003). Typically, one or two types are numerically dominant (Baker 2003, LaJeunesse 2005, Baker \& Romanski 2007, Goulet 2007), with a recent study, using highly sensitive real-time PCR, showing that the presence of multiple cryptic types at low densities within a single colony is common (Mieog et al. 2007).

Specificity also varies between symbiont types; many are known to associate with numerous host taxa ('host generalists'), whilst copious others are specialized to particular host species or genera ('host specialists'; LaJeunesse et al. 2003). For example, type $\mathrm{C} 8 / \mathrm{a}$ has only been found to associate with the scleractinian pocilloporid Stylophora pistillata (Sampayo et al. 2007), whereas C3 associates with a broad array of coral families, including Acroporidae, Faviidae and Pocilloporidae (e.g. LaJeunesse 2001, LaJeunesse et al. 2003, LaJeunesse 2005).

Although a much debated issue, studies have suggested that the presence of a host-generalist $v s$. a host-specialist symbiont may be strongly linked to the mode of symbiont transmission in the host. Symbionts are acquired by their hosts in one of two ways; either from the water column (horizontal transmission) or via maternal inheritance (vertical transmission). Corals that brood their larvae reproduce by 
internal fertilisation and develop their planktonic larvae before release into the water column. As these larvae already contain their symbionts, faithful transmission of symbionts from parents to the next generation is maintained (Barneah et al. 2004). Additionally, corals that reproduce asexually directly pass their symbionts to the new coral colony in the parental tissues. Vertical transmission can be beneficial since it maintains fidelity with a well-suited symbiont, however horizontal transmission allows a shift to a new symbiont pool (Douglas 1998, Rowan 1998). Alternatively, corals that broadcast spawn their larvae, by releasing their gametes into the water column for external fertilisation (Harrison et al. 1984, Harrison \& Wallace 1990), can acquire their symbionts in a number of ways, including from the surrounding water column and by infection of the ova prior to their release (Davy \& Turner 2003). Broadcast spawning is the dominant reproductive mechanism of corals, ( 85\%) (Schwarz et al. 2002) and occurs as a synchronous event (Harrison et al. 1984).

The specificity of the host-symbiont relationship has further been suggested to result in co-evolution of specific symbionts types with their vertically transmitting hosts (LaJeunesse 2002, LaJeunesse 2002, Diekmann et al. 2003, LaJeunesse 2005), evident in the proportionally high number of specific, unique symbiont types in vertical transmitters. However there are conflicting data on whether this symbiont acquisition strategy does influence the final host-symbiont assemblage (Loh et al. 2001, van Oppen 2004, Stat et al. 2009). Recent comparative analysis by Stat et al. (2009) found that the majority of vertical transmitting corals associated with distinct species- or genus-specific Symbiodinium types, but that some could also associate with the generalist types more common to horizontal transmitters. Host-specific lineages have so far only been detected in one horizontal strategist, Fungia scutaria, 
which hosts specialist C1f in Hawaii (Weis et al. 2001, Rodriguez-Lanetty et al. 2004).

Specificity between a host and its symbiont also depends heavily on the host, particularly in regards to recognition mechanisms involved in the establishment of symbiosis. While much remains to be learnt of the mechanisms involved (Weis 2008), it is understood that the identity of the symbiont is a key factor in the onset of symbiosis, with variation in the algal cell structure affecting phagocytosis triggers in the host (Markell et al. 1992, Lin et al. 2000). After a symbiont enters a host, the host will have some way to regulate the symbiont population, either through controlling reproduction rates of, selectively destroying, or expelling unwanted symbionts (Gates et al. 1992, Falkowski et al. 1993, Baghdasarian \& Muscatine 2000, Dunn et al. 2002, Dunn \& Weis 2009). Furthermore, within the host cell, competition between symbionts will determine which symbiont types will be found in the host, with certain types competing more successfully within a particular host or region within a host (Sachs \& Wilcox 2006, Fay et al. 2009). Finally, the fitness of the holobiont (host and symbiont; Rohwer et al. 2002), will determine the abundance of a particular host-symbiont pair; as the fitness interests of both partners are aligned, the holobiont will have a fitness advantage over holobionts with mismatched fitness interests. 


\subsection{Biogeographic and ecological variability of Cnidarian-Symbiodinium}

\section{partnerships}

Variability in the Symbiodinium type harboured by a host is seen on both a local and biogeographic scale, in response to the environment in which the holobiont lives (e.g. LaJeunesse \& Trench 2000, Rodriguez-Lanetty et al. 2004). For instance, clade C tends to dominate in 'normal' stable conditions, while clade B tends to be more prevalent in harsher colder conditions (Baker 2003, LaJeunesse et al. 2003). Latitudinal shifts in host-symbiont pairings have been observed for a number of host species, with a transition from clade $\mathrm{C}$ in tropical zones to clade $\mathrm{A}, \mathrm{B}$ or D recorded by different studies on invertebrate hosts from Japan, the north-eastern Atlantic and Mediterranean Sea (Loh et al. 2001, Rodriguez-Lanetty et al. 2001, Savage et al. 2002). Specifically, LaJeunesse \& Trench (2000) found that the sea anemone Anthopleura elegantissima from the temperate northern sites of Washington and Oregon contained a different symbiont (clade B) in comparison to southern Californian sites (clade E). This latitudinal pattern was mirrored in the coral species Plesiastrea versipora (Rodriguez-Lanetty et al. 2001) along the East Australian coast, whereby a cladal transition occurs from clade $\mathrm{C}$ in the tropics and sub-tropics, to clade $\mathrm{B}$ in the cooler, high-latitude communities. A recent study in southeast Africa indicates that similar patterns of latitudinal zonation between clades exist at the sub-cladal level, with a transition of clade C Symbiodinium types in Stylophora pistillata in relation to a latitudinal temperature gradient (Macdonald et al. 2008).

Niche partitioning of host-symbiont partnerships can be seen on a local scale, with irradiance and temperature the two most common environmental variables to correlate with their distribution. Initial observations of the zonation of symbionts according to depth, and associated irradiance, were on the coral Montastraea spp. 
located on reefs in the Caribbean (Rowan \& Knowlton 1995, Rowan et al. 1997, Baker 2003). Clade A Symbiodinium was found in Montastraea spp. in shallow waters $(<6 \mathrm{~m})$ while clade C Symbiodinium was restricted to deeper colonies. Further studies of the zonation of symbionts within a single colony of Montastraea sp. found that clades A and B were present in the top of the colony subject to high irradiance, clades $\mathrm{A}$ to $\mathrm{C}$ at intermediate depths within the colony, and clade $\mathrm{C}$ only in the most shaded portions of the colony (Rowan et al. 1997). Depth-related patterns were also observed in scleractinian corals on the GBR: LaJeunesse et al. (2003) identified nine coral species in which the symbiotic partner varied according to host depth. Many of the patterns identified by LaJeunesse et al. (2003) featured variation at a sub-cladal level and these have been corroborated by numerous other studies (LaJeunesse et al. 2004a, LaJeunesse et al. 2004b, Sampayo et al. 2007, Macdonald et al. 2008). In the Caribbean, Frade et al. (2008a,b) found that the depth stratification of clade B Symbiodinium types in Madracis sp. had associated functional variability: type B15, which was predominantly found at deeper sites, occurs with lower cell densities, larger cell sizes, higher photosynthetic pigment concentrations, and higher peridinin to chlorophyll (chl) $a$ ratios than does type B7. These attributes would make B15 better adapted to darker environments. Type B7, on the other hand, was found in shallow colonies and exhibited functional differences consistent with the high irradiance environment, such as a larger dinoxanthin to $\operatorname{chl} a$ ratio and larger xanthophyll-pool size, suggesting that it is probably more competent in quenching excess of energy.

In terms of the impact of irradiance of symbiont distribution, sedimentation in the water column is a further influential factor. Toller et al. (2001a) found that clade D dominated hosts in areas subject to high sedimentation and suggested that this 
clade was more 'stress tolerant' than other clades. Similarly, Garren et al. (2006) found a lack of clade B Symbiodinium in Montastraea annularis in environments characterised by high sedimentation in Panama where irradiance levels were reduced, whereas clade B was dominant in the waters of Belize with enhanced irradiance levels. Finer scale patterns were suggested to exist, with further examination required using higher resolution molecular techniques. To date, no studies have addressed the sub-cladal distribution of symbionts in response to sediment regime.

The ability of a coral to associate with different symbiont types has ecological implications and has been suggested to delineate the tolerance range of the host. In a genetic and physiological study, Iglesias-Prieto et al. (2004) showed that symbionts may directly influence the vertical distribution of a host species. These authors found that, in two coral species on eastern Pacific reefs, the efficiency of light capture by their symbionts correlated with the depth at which they were found and, following depth transplantation, photosynthetic measurements of the symbionts continued to show the same 'sun-loving' or 'shade-loving' qualities. However, the symbionts may have evolved with the host, to live in the hosts' restricted distribution. The fact that the external environment can lead to specific pairings of hosts and physiologically distinct symbionts will play a key role in the evolutionary success of coral reefs.

\subsection{Physiological variability and susceptibility to environmental stress}

The physiological variability between Symbiodinium types is evident in their local and biogeographic distributions, as has been described in the previous sections, and importantly, can also dictate the tolerance of the holobiont to environmental stress. Coral bleaching involves the breakdown of the symbiotic relationship, whereby the 
symbionts and/or their pigments are lost as a stress response (see next section for details of the mechanism). Stressors that induce bleaching include high or low seawater temperature or light levels, reduced salinity, and sedimentation (e.g. Rowan 2004, Tchernov et al. 2004, Berkelmans \& van Oppen 2006, Jones 2008). Elevated sea surface temperature (SST) is the main driver of mass coral bleaching and has led to the decimation of reefs worldwide (Hoegh-Guldberg 1999, Donner et al. 2005).

Highly variable patterns of bleaching have been observed between and within geographic regions (Hoegh-Guldberg 1999, Marshall \& Baird 2000), as well as between single coral species (Edmunds 1994, Glynn et al. 2001, Brown et al. 2002). This variation has been linked to both host-related factors (i.e. tissue behaviour, Brown et al. 2002; tissue thickness, Fitt et al. 2009), and/or the presence of physiologically distinct symbionts (Rowan et al. 1997, Glynn et al. 2001, Baker et al. 2004, Rowan 2004, Berkelmans \& van Oppen 2006). For example, Pocillopora damicornis colonies which harboured clade D Symbiodinium were less susceptible to bleaching than those containing clade C (Rowan 2004). Clade D Symbiodinium have been suggested to be more resistant to thermal stress than other clades (Rowan 2004) and evidence has shown that some coral reefs which have been subject to repeated bleaching episodes harbour a greater proportion of D-type symbionts (Glynn et al. 2001, Toller et al. 2001a, Baker et al. 2004, Fabricius et al. 2004, Rowan 2004). Variability in thermal tolerance has also been observed between sub-cladal types. For example, colonies of the coral Stylophora pistillata hosting C78 and C8/a were more thermally tolerant than those containing C79 and C35/a, which suffered significant bleaching and post-bleaching mortality (Sampayo et al. 2008).

It has been hypothesised that some coral species have the potential to adapt to a particular environment by 'switching' or 'shuffling' their stress-vulnerable 
symbionts to stress-resistant Symbiodinium types (Buddemeier \& Fautin 1993, Baker 2001, Baker 2003, Fautin \& Buddemeier 2004). Switching refers to the uptake of a novel symbiont from the external environment as an adaptation to the new conditions. Conversely, shuffling refers to the increase in abundance of a 'cryptic' symbiont in the host, better adapted to the new conditions. This much debated issue is known as the 'Adaptive Bleaching Hypothesis' (ABH: Buddemeier \& Fautin 1993). Berkelmans and van Oppen (2006) found that transplanting Acropora millepora from cooler to warmer sites on the Great Barrier Reef resulted in a change in their symbiont communities to favour Symbiodinium in clade D and that this transition increased their thermal tolerance by up to $1.5^{\circ} \mathrm{C}$. Jones et al. (2008) corroborated this evidence of a change in symbiont populations in A. millepora, with shuffling of pre-existing symbiont types observed following a natural bleaching event.

It is important to note that coping with thermal or other stressors is also dependent on the flexibility of a host to associate with multiple physiologically distinct symbiont types, whether by shuffling or switching its symbionts. It is still unknown if the specific host-symbiont combinations found in nature can switch or shuffle with time, and do so rapidly enough to keep pace with the changing conditions associated with climate change. To understand how and why bleaching occurs, and how this varies between different coral-host partnerships, first we must understand the photosynthetic system involved. 


\subsection{Photophysiology of Symbiodinium}

Under normal conditions, Symbiodinium cells can exhibit very high rates of photosynthesis, assimilating large amounts of carbon dioxide and generating large quantities of dissolved oxygen (Lesser 2006). Maximum photosynthesis, and hence productivity, is dependent upon the efficiency of the light harvesting complexes (LHC) photosystem 1 (PSI) and photosystem 2 (PSII), in capturing and utilising light energy (Fig. 1.3). The two photosystems, present on the thylakoid membrane, pass light energy to the dark reactions where $\mathrm{CO}_{2}$ is fixed by the enzyme ribulose biphosphate carboxylase oxygenase (Rubisco). The amount of light energy flowing to the dark reactions is regulated by the inter-conversion of the two pigments diatoaxanthin and diadinoxanthin. Any active oxygen $\left(\mathrm{O}_{2}^{-}\right)$is quenched by the superoxide dismutase (SOD) and ascorbate peroxidise (APX) enzyme systems (Fig. $1.3)$.

As the light environment experienced by corals can be highly variable, the symbionts must be capable of adjusting to changes in light quality and quantity. The symbionts must dissipate excess excitation energy absorbed by the photosynthetic apparatus, when the light absorbed is in excess of that required for $\mathrm{CO}_{2}$ assimilation (Falkowski \& Raven 1997, Lesser \& Farrell 2004). Increasing light levels lead to the over-reduction of the light reactions and the production of potentially harmful products such as reactive oxygen species (ROS, Lesser 2006). Photoprotective measures are in place in corals and their symbionts to limit the effects of daily and seasonal stressors associated with high light intensities. These include ultraviolet radiation (UVR)-absorbing mycosporine-like amino acids (MAAs) (Shick \& Dunlap 2002), excess excitation energy dissipation in PSII via the xanthophyll cycle (i.e. 


\section{AMBIENT}

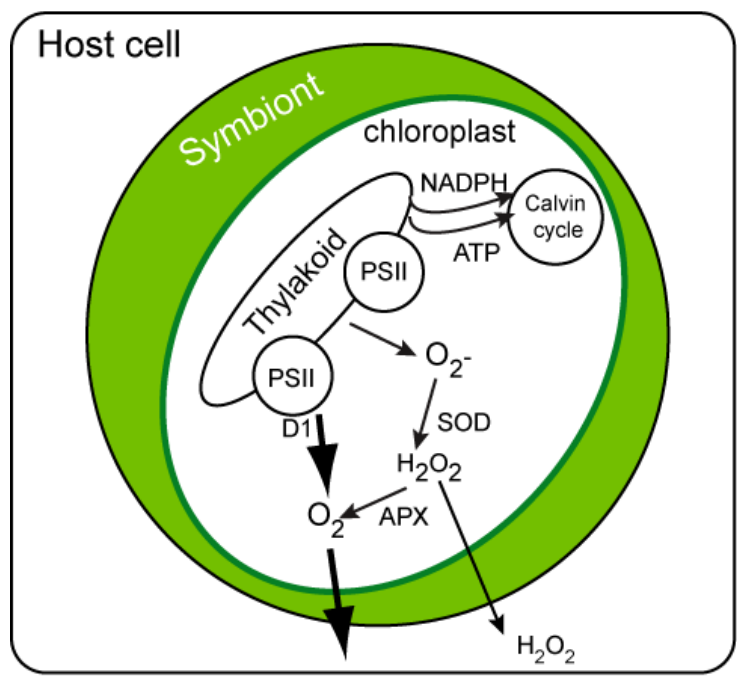

Excess heat

\& light

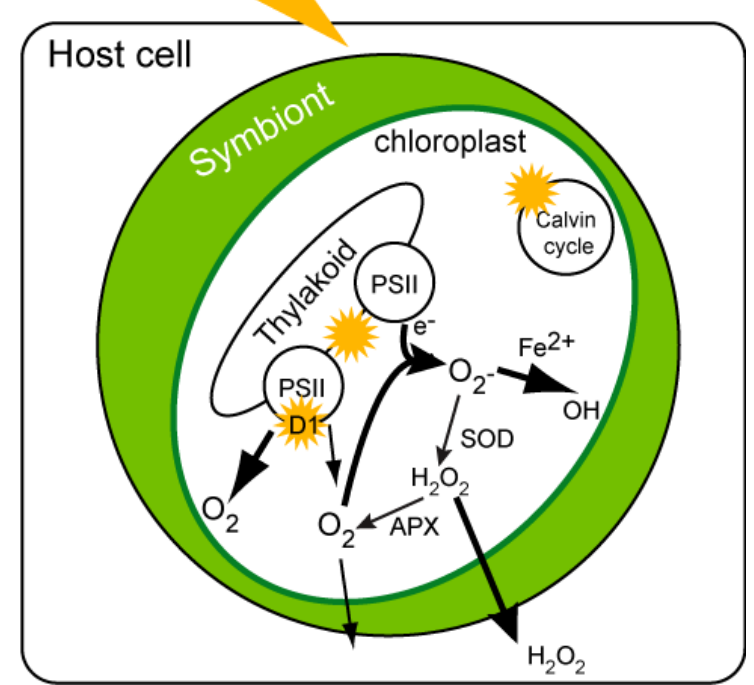

Figure 1.3 Schematic representation of photosynthesis under ambient conditions and elevated temperature and light conditions (stressed). Under ambient conditions, photosystems I (PSI) and II (PSII) on the thylakoid membrane operate normally, producing large amounts of oxygen which diffuse into the host. Any reactive oxygen species produced (ROS) are converted back to oxygen by superoxide dismutase (SOD) and ascorbate peroxidase (APX). Under stressed conditions, damage occurs to the photosystem in at least three places (depicted as yellow flashes): the D1 protein, the Calvin Cycle, and on the thylakoid membrane. This damage produces large amounts of ROS (in the form of ${ }^{-} \mathrm{O}_{2}$ and $\mathrm{O}_{2}^{-}$) that overwhelm the oxygen handling pathways. $\mathrm{O}^{-}$is converted to both the most highly reactive hydroxyl radical $(-\mathrm{OH})$ and the more stable and highly diffusible hydrogen peroxide $\left(\mathrm{H}_{2} \mathrm{O}_{2}\right)$, which can move into host tissues. Figure adapted from Weis (2008) and Venn et al. (2008).

non-photochemical quenching, NPQ, Demmig-Adams et al. 1990, Brown et al. 1999, Gorbunov et al. 2001), the expression of heat-shock proteins and other stress markers (Black et al. 1995, Downs et al. 2002, Lesser \& Farrell 2004), the upregulation of antioxidant enzymes (Lesser 1996, 2004, 2006), host energy reserve utilization (Porter et al. 1989, Grotolli et al. 2006), and heterotrophic plasticity (Grotolli et al. 2006). 
The primary cause of bleaching is thought to occur as a result of photosynthetic damage to Symbiodinium cells by thermal stress (either high or low) and high irradiance (Fitt \& Warner 1995, Warner \& Fitt 1999, Yakovleva \& Hidaka 2004), in at least three inter-related ways (Fig. 1.3). Firstly, damage to the D1 protein and its repair mechanism can occur, which results in a 'backup' of excitation energy and consequent dysfunction of PSII (Warner \& Fitt 1999). Secondly, energetic uncoupling in the thylakoid membranes can result, due to damage to the thylakoid membrane (Tchernov et al. 2004). Finally impairment of the Calvin-Benson Cycle can occur, with the site of damage suggested to be Rubisco, the enzyme responsible for primary carboxylation (Lesser 1996). This results in reduced consumption of adenosine triphosphate (ATP) and nicotinamide adenine dinucleotide phosphate (NADPH) coming from the light reactions (referred to as sink limitation) that in turn leads to the dysfunction of photosystem II via backup of excitation energy as described above (Jones et al. 1998, Venn et al. 2008a). In all cases, excess energy is passed to oxygen, causing a build-up of ROS that damage cellular components such as proteins and nucleic acids, and induce physiological malfunction. Furthermore, ROS may diffuse from the symbiont into the coral cytoplasm, where they cause further oxidative damage (Lesser 2006), and may trigger the coral to expel its algal symbionts (Downs et al. 2002, Tchernov et al. 2004, Weis 2008). As even moderate increases of $1-2^{\circ} \mathrm{C}$ can result in reef-wide bleaching events, especially when combined with seasonal high visible and/or UV radiation (Hoegh-Guldberg et al. 2007), understanding why some host-symbiont partnerships bleach whilst others can tolerate the stress is an area of great interest. 


\subsection{Corals in marginal environments}

Central to understanding how corals may cope in the future, with increasing SST and changing chemistry of the oceans, is knowledge of how corals persist in marginal environments, already subject to variable and stressful conditions. Coral reefs are most commonly associated with shallow, clear water environments at low-latitudes. In these locations, environmental conditions are commonly termed as 'optimal', with coral communities growing under favourable conditions and mild human impacts, and build well-defined reef structures. However, many reefs are associated with sub-optimal conditions and hence are termed as 'marginal'. Here, corals exist close to their survival thresholds of water temperature, light penetration and aragonite saturation (Kleypas et al. 1999, Table 1.2). These marginal coral communities generally occur outside the tropical belt or at its edge (Fig 1.4) and are commonly characterised by limited accretion, depth distribution and biological diversity (Harriott \& Banks 2002). Living under these highly variable and extreme conditions is likely facilitated by specific physiological adaptations and/or the presence of unique species of corals and dinoflagellate symbionts, but data on these patterns and processes are limited.

High latitude or temperate reefs, usually occurring above $25^{\circ} \mathrm{S}$ and $25^{\circ} \mathrm{N}$, represent marginal environments due to wide ranges in seasonal temperatures (widest in Arabian Gulf, $18-36^{\circ} \mathrm{C}$, Riegl 2003), low annual minimum temperatures (lowest $13.3^{\circ} \mathrm{C}$, Japan, Yamano et al. 2001) and relatively low irradiance levels (e.g. light penetration of $250 \mu \mathrm{mol}$ photons $\mathrm{m}^{-2} \mathrm{~s}^{-1}$ seasonally less than $10 \mathrm{~m}$, Japan, Kleypas et al. 1999). Examples of high latitude coral communities include the Persian Gulf, Bermuda, Japan 
Table 1.2 Characteristics of coral communities existing under optimal environmental settings (warm, clear water setting) and those associated with two distinct marginal environments. Symbiodinium types noted for typical optimal, turbid and high latitude sites.

\begin{tabular}{|c|c|c|c|}
\hline & $\begin{array}{c}\text { Warm, clear water } \\
\text { setting }\end{array}$ & Turbid setting & High latitude setting \\
\hline Environment & $\begin{array}{l}\text { Clear waters, optimal } \\
\text { temperatures, low } \\
\text { nutrient availability }\end{array}$ & $\begin{array}{l}\text { Reduced light penetration, } \\
\text { high nutrient load }\end{array}$ & $\begin{array}{c}\text { Cooler waters, reduced light } \\
\text { penetration }\end{array}$ \\
\hline $\begin{array}{l}\text { Coral } \\
\text { community }\end{array}$ & $\begin{array}{l}\text { High species diversity } \\
\text { High coral cover } \\
\text { extending to depths of } \\
60-70 \mathrm{~m}\end{array}$ & $\begin{array}{l}\text { Restricted species diversity } \\
\text { Coral growth spatially and } \\
\text { bathymetrically restricted } \\
\quad(\text { generally }<15 \mathrm{~m})\end{array}$ & $\begin{array}{l}\text { Reduced species diversity } \\
\text { and cover } \\
\text { Soft coral dominated } \\
\text { communities, } \\
\text { bathymetrically restricted to } \\
<30 \mathrm{~m}\end{array}$ \\
\hline $\begin{array}{c}\text { Coral } \\
\text { physiology }\end{array}$ & Optimal photosynthesis & $\begin{array}{l}\text { Depressed photosynthesis, } \\
\text { enhanced respiration and } \\
\text { mucus production }\end{array}$ & $\begin{array}{l}\text { Reduced rates of } \\
\text { photosynthesis }\end{array}$ \\
\hline Symbiodinium & $\begin{array}{l}\text { Clade C dominant in } \\
\text { Pacific, A, B and C in } \\
\text { Caribbean (Baker } \\
\text { 2004) }\end{array}$ & $\begin{array}{l}\text { Clade D (Toller et al. 2001) } \\
\text { and C (Garren et al. 2006) }\end{array}$ & $\begin{array}{l}\text { Clades A, B and/or F } \\
\text { (Rodriquez Lanetty et al. } \\
\text { 2002, Savage et al. 2002) }\end{array}$ \\
\hline Framework & $\begin{array}{l}\text { Thick }(5-10 \mathrm{~m}) \text { coral } \\
\text { dominated framework }\end{array}$ & $\begin{array}{c}\text { Detrital coral-rubble } \\
\text { framework set with mixed } \\
\text { carbonate:clastic sediments }\end{array}$ & $\begin{array}{l}\text { Non-framework coral } \\
\text { community common }\end{array}$ \\
\hline Examples & $\begin{array}{l}\text { Northern GBR (van } \\
\text { Woesik \& Done 1997) } \\
\text { Jamaica (Liddell \& } \\
\text { Ohlhurst 1981) }\end{array}$ & $\begin{array}{c}\text { Inhaca Is., Mozambique } \\
\text { (Perry 2003) } \\
\text { Inshore central GBR } \\
\text { (Smithers \& Larcombe 2003) }\end{array}$ & $\begin{array}{c}\text { Kermadec Islands (Schiel et } \\
\text { al. 1986) } \\
\text { S. Africa (Riegl 2003) } \\
\text { Lord Howe Island, Australia } \\
\text { (Veron \& Done 1979) }\end{array}$ \\
\hline
\end{tabular}



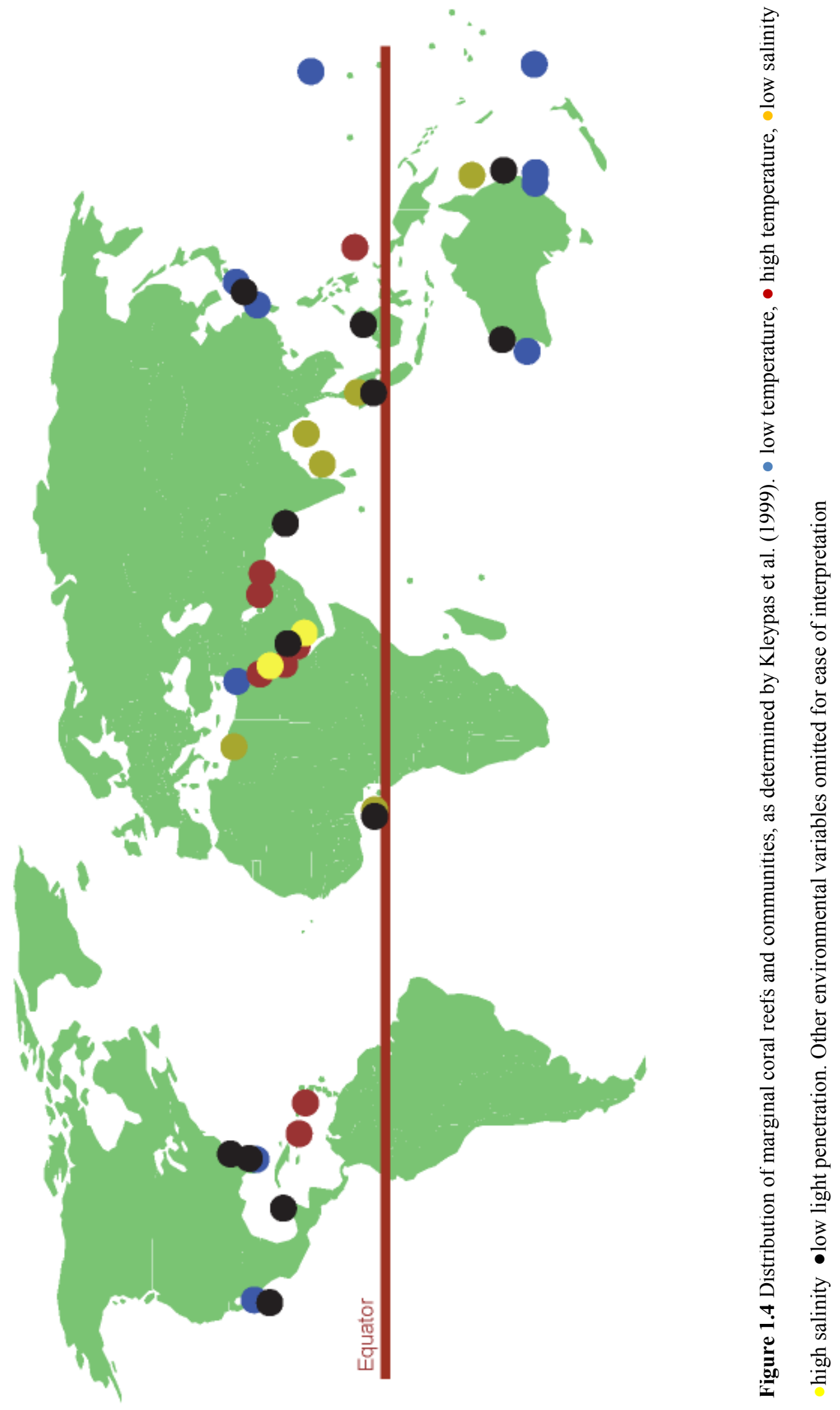
and Lord Howe Island, Australia. Under these challenging environmental conditions, coral diversity and cover are generally low and existing corals have reduced growth rates in comparison to their tropical counterparts (Crossland 1988, Veron 1995, Lough \& Barnes 2000). Total reef accretion is reduced in high latitude areas and in the extremes of hermatypic coral growth, corals form so-called non-reef building communities (van Woesik \& Done 1997, Perry \& Larcombe 2003).

Many reef-building species cannot grow and survive outside the tropics, and are replaced at high latitudes by subtropical non-reef building species, which are rare or absent on tropical reefs. For example, on the eastern Australian coast, massive Porites and staghorn Acropora species decline in abundance with increasing latitude, replaced by foliose and encrusting corals such as Turbinaria and Montipora species (van Woesik \& Done 1997). The absence of the dominant components of tropical reefs at high latitudes suggests that they are unable to establish and survive at these cooler temperatures and sub-optimal light levels. Lower temperatures and high nutrient concentrations, common to high latitude sites, favour the growth of macroalgae over corals at many subtropical reefs (Johannes et al. 2003, Harriott \& Banks 2002; Fig 1.5).

Marginal communities can also occur within the tropics, where localised conditions are 'sub-optimal', such as areas of high sedimentation or upwelling (Perry \& Larcombe 2003). For example, an increase in sediment load in the waters surrounding coral reefs can lead to reduced irradiance, compressed biotic zones, reduced species richness, and reduced coral cover, colony size and recruitment (Brown \& Howard 1985, Rogers 1990, Brown 1997a, Fabricius 2005). Marginal coral reefs and communities 

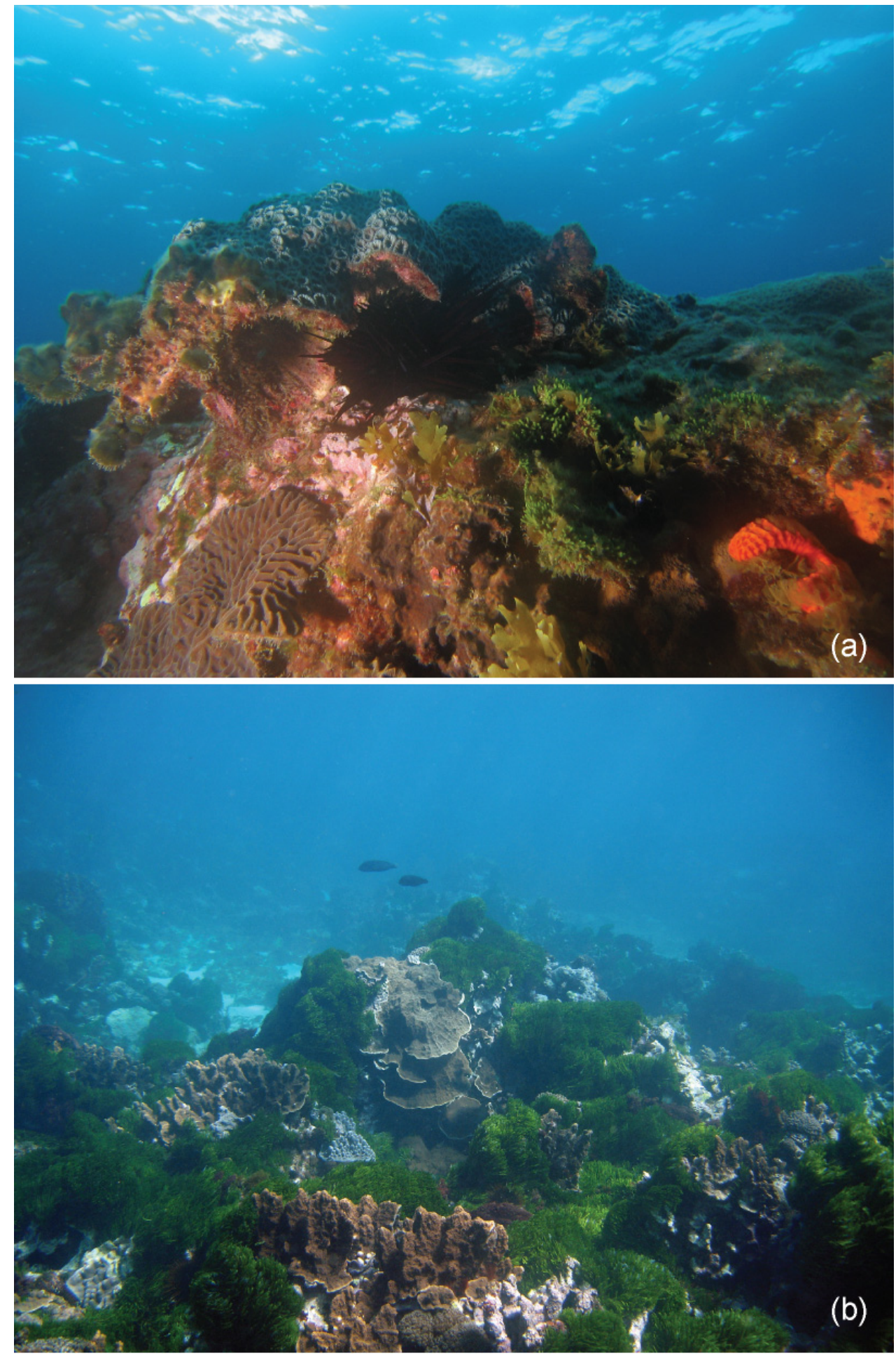

Figure 1.5 Landscape of typical high latitude coral reefs (a) Kermadec Islands, New

Zealand, and (b) Lord Howe Island, Australia. Kermadec photo courtesy of Jo Long. 
predisposed to environmental variability have been suggested as potential refuges for their resident populations or immigrant species in a future of warming seas and ocean acidification (Glynn 1996, Riegl 2003). If these communities will indeed act as coral refuges, then it is essential that we understand the dynamics of the coral and symbiont communities, and their physiological ability to survive under these variable conditions.

\subsection{Symbiodinium in marginal environments}

From the few studies conducted on marginal coral communities (both reefal and nonreefal), it has been shown that coral and Symbiodinium partnerships in these environments differ from their tropical counterparts. For example, marginal reefs in the Persian Gulf and marine lakes in Palau both experience extremes of temperatures and salinity, and are dominated by corals hosting clade D Symbiodinium (Baker et al. 2004, Fabricius et al. 2004, Mostafavi et al. 2007). Furthermore, whilst clade D is generally thought to be thermally tolerant, it is also found in high latitude colder regions (Chen et al. 2003, Lien et al. 2007) and limited light environments (Glynn et al. 2001, Toller et al. 2001b, Baker et al. 2004, Fabricius et al. 2004, Rowan 2004). Clades A, B, C and D have all been found in coral and/or anemone hosts at high latitudes and temperate regions, including Japan (Loh et al. 2001), Korea (Rodriguez-Lanetty et al. 2002), USA (LaJeunesse \& Trench 2000), and Europe (Savage et al. 2002). The discrepancy in cladal distributions highlights increasing evidence that physiological tolerance ranges overlap poorly at the cladal level, and that the wide variety of sub-cladal Symbiodinium 
types plays an important role in the distribution, ecology, and physiology of reef corals (Iglesias-Prieto \& Trench 1997a, Tchernov et al. 2004, Sampayo et al. 2007, Frade et al. 2008a, Macdonald et al. 2008, Sampayo et al. 2008).

While it is assumed that corals and their symbionts have inadequate phenotypic/genotypic capabilities for rapid adaptation in response to environmental change (Hughes et al. 2003, Hoegh-Guldberg et al. 2007, Edmunds \& Gates 2008), the presence of physiologically distinct symbionts and host-symbiont partnerships in marginal habitats may be measures whereby hosts have adapted to the variable and stressful conditions. Alternatively, they may be on the boundary limits of survival, and thus any change in environmental conditions may lead to local extinction. Given the importance of the symbiotic partner, comparing the symbiont communities of 'optimal' and 'marginal' reefs may be crucial to understanding how coral-Symbiodinium partnerships persist under marginal conditions.

\subsection{Objectives}

This study investigated the role that environmental parameters and stressors play in determining the distribution of corals and their dinoflagellate symbionts in marginal environments, as well as the role of the symbionts in facilitating survival under these conditions.

In this study, the marginal environments examined were the high latitude sites of Lord Howe Island, Australia, and the Kermadec Islands, New Zealand, and a site of varying sediment regimes, Palmyra Atoll, USA. The specific objectives of the study were to: 
1. Examine the genus and species diversity, and distribution patterns of corals in marginal environments. It is hypothesised that the diversity of corals in marginal environments will be reduced because of the stressful and/or variable environmental conditions.

2. Investigate the genetic diversity, distribution patterns and host specificity of dinoflagellate symbionts (Symbiodinium spp.) in marginal environments. It is hypothesised that symbiont diversity will be reduced, host-specificity will be high, and symbionts will be specific to those marginal sites, as a result of symbionts evolving to cope with the stressful and/or variable conditions.

3. Assess the influence of environmental variables on host and symbiont distribution in marginal environments, in comparison to 'optimal' environments. It is hypothesised that both coral and symbiont diversity will be reduced in areas of increased environmental stress.

4. Assess the photo-physiological responses of Symbiodinium spp. from a marginal location to thermal and light stress. It is hypothesised that the symbionts will be able to withstand variable/stressful conditions.

The four data chapters are divided into papers, which have either been submitted or are in the process of being submitted, each dealing with a different aspect of the specific objectives (hence there is a degree of repetition between chapters, especially in their introductions). 
Chapter 2 addresses the first and third objectives, by investigating the spatial patterns in coral community structure in the Kermadec Islands, with the aim of understanding the processes that control their growth and development. Additionally, the biogeographic affinities of marginal coral communities at high latitude sites and on a wider scale were identified, in order to better understand global patterns of coral biodiversity, the biogeographical limits of corals, and the factors that contribute to these patterns.

Chapter 3 outlines the diversity and host specificity of Symbiodinium types in corals at two high latitude locations, the Kermadec Islands and Lord Howe Island, focusing on the role that the symbiont community plays in regulating these high latitude coral reefs. This addresses the second and third objectives.

In chapter 4 the influence of sediment regimes on the diversity and distribution of both corals and their symbionts was investigated in reference to objectives $1-3$. This part of the study was conducted at Palmyra Atoll, USA, a variable reef ecosystem with a sediment regime gradient. This gradient enabled assessment of variability in community structure among 'marginal' and 'optimal' environments.

Chapter 5 outlines the photo-physiological responses to thermal and light stress of the distinct host-symbiont partnerships at Lord Howe Island, discovered in chapter 3. By elucidating the relationship between Symbiodinium photo-physiology and biogeography, this chapter aimed to further our understanding of the mechanisms involved in local adaptation to thermal and solar conditions. This chapter addresses the final objective.

Finally, chapter 6 provides an overview of the major findings, and considers the ecological significance and implications of the research, both in terms of contributing to 
our understanding of the structure and dynamics of coral ecosystems, and what the future will hold for 'marginal' sites. 


\title{
Chapter 2
}

\section{Spatial patterns and regional affinities of coral communities at the Kermadec Islands Marine Reserve (New Zealand), a marginal high- latitude site}

\begin{abstract}
The Kermadec Islands Marine Reserve $\left(29-31^{\circ} \mathrm{S}\right)$, New Zealand, harbours one of the world's highest latitude scleractinian coral communities, situated close to the lower thermal limits for coral survival. An understanding of how and why similarities and differences exist among so-called 'marginal' coral communities can provide insight into the physical and biological factors that influence coral distributions. In this study, a depth-stratified survey of benthic community structure and coral species assemblages was conducted at 9 sites around the Kermadec Islands. All coral species identified were subtropical non-reef building species. Scleractinian coral cover and diversity was low and variable among sites and depths (16 spp., $5.3 \pm$ $13.9 \%$ ) with macroalgae contributing between $36-95 \%$ of the benthic cover. Multivariate analyses revealed small-scale spatial variability among closely located sites, with no distinct latitudinal gradient in coral community structure. Resulting data on coral species diversity were compared to published data of coral communities from other 'marginal' locations. On a global scale, the Kermadec Islands community structure exhibits greatest affinity with south-eastern Australian sites. In comparison, there was a lack of affinities for other high latitude sites, both in
\end{abstract}


Australia and globally. Our analyses suggest that the low diversity, highly variable coral communities of the Kermadec Islands are likely shaped by their isolation and high wave energy, rather than the low annual temperatures experienced.

\subsection{INTRODUCTION}

Marginal coral reefs exist near or beyond the normal limits of reef distribution, close to the environmental thresholds for coral survival (Kleypas et al. 1999). These reefs frequently occur at high latitudes i.e. above $25^{\circ} \mathrm{S}$ and $25^{\circ} \mathrm{N}$, with well known examples being those of the Persian Gulf, Bermuda, Japan and Lord Howe Island, Australia. Structural development and coral species diversity of these high-latitude reefs, at both biogeographic and local scales, are largely regulated by low mean annual and seasonally variable temperatures and irradiances, and the low aragonite saturation state (Buddemeier 1997, Kleypas et al. 1999); other parameters with local importance include wave exposure (Harriott et al. 1994, Benzoni et al. 2003, Coles 2003).

At even higher latitudes, where minimum annual temperatures fall below $18^{\circ} \mathrm{C}$, reefs are replaced by coral communities that do not develop reef framework (Wells 1957, Johannes et al. 1983) due to the lack of significant accretion of calcium carbonate (Buddemeier \& Smith 1999). The corals in these communities attach to hard substrata, appearing as isolated colonies growing on exposed bedrock (e.g. Macintyre 2003). They can have similar species diversities to true coral reefs $(>100$ spp.; Sheppard \& Sheppard 1991, Harriott et al. 1999), though in most cases species diversities are much lower (less than 100 spp.; Dai 1988, DeVantier \& Pilcher 2000, Moyer et al. 2003). Macroalgae play a dominant role in many of these high latitude 
coral communities (Fig. 2.1), their rapid growth out-competing corals for space (Johannes et al. 1983). Furthermore, many high latitude coral communities are small and isolated (e.g. Babcock et al. 1986, Brook 1999, Hughes et al. 2002, Gardner et al. 2006), meaning that they are largely self-seeding in terms of larval supply (Ayre et al. 1997).

As most of the world's coral reefs will become marginalised as our climate rapidly changes (Hoegh-Guldberg et al. 2007), study of marginal coral communities may provide useful analogues for understanding the ecology of coral reefs subjected to deteriorating conditions (Perry \& Larcombe 2003). Moreover, it has been suggested that high latitude coral communities might be better adapted for survival in

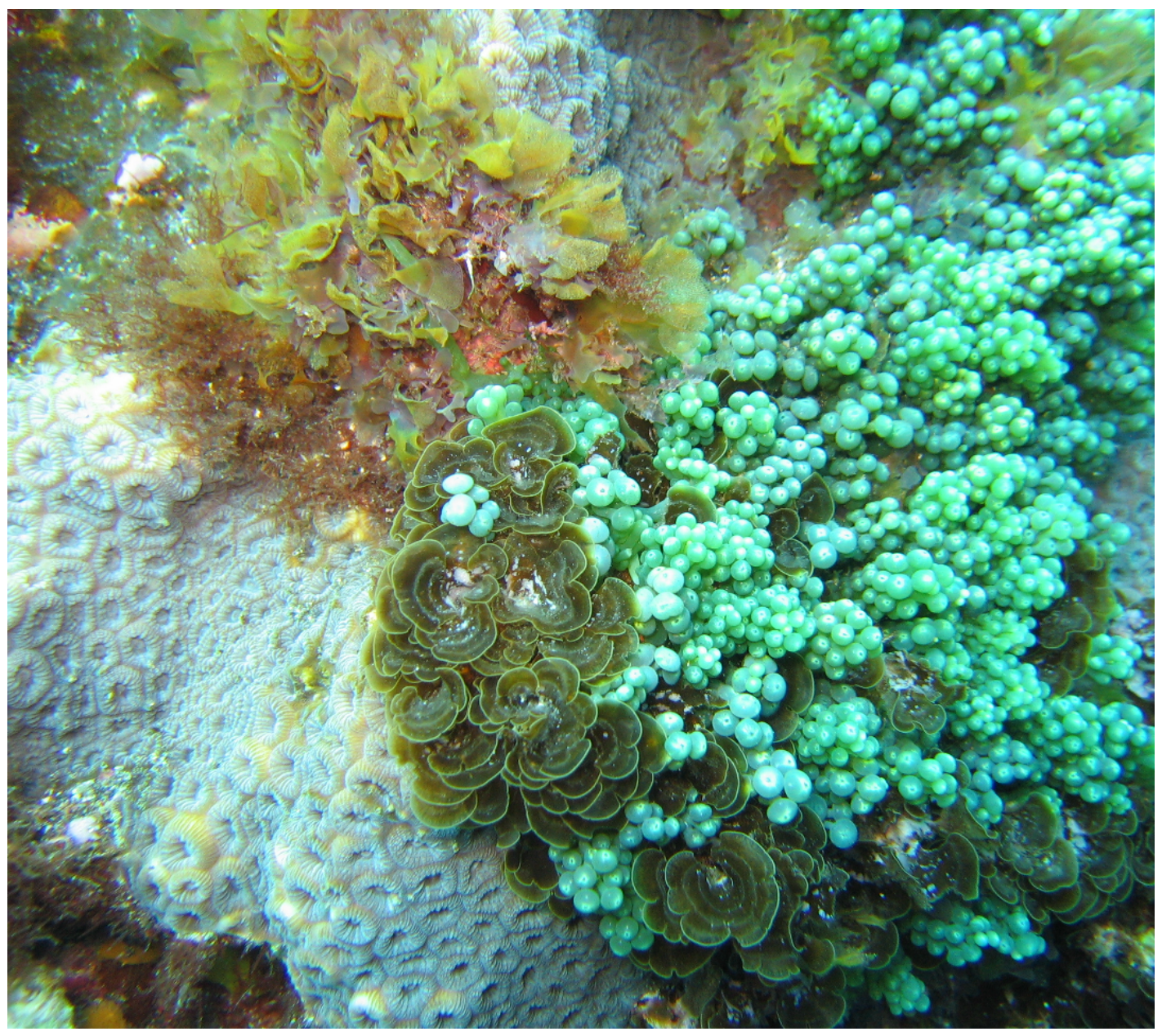

Figure 2.1 Algae competing for space with encrusting coral (Montastraea curta), Kermadec Islands, northern New Zealand (photo: J. Long). 
an environment modified by global climate change, as a result of their existence in already stressed conditions (Glynn 1996, Riegl \& Piller 2003). If these communities will indeed act as coral refuges, then it is essential that we understand the processes controlling their growth and development so that they can be appropriately managed and conserved for the future; it is also important that we have a more comprehensive knowledge of their relatedness to coral communities and reefs elsewhere.

To address this issue we focused on one of the South Pacific's highlatitude coral community sites, the Kermadec Islands Marine Reserve, $750 \mathrm{~km}$ off the northeast coast of New Zealand's North Island (Fig. 2.2) and approximately 3000 $\mathrm{km}$ east of the Great Barrier Reef (GBR). This study aimed to: (1) assess, in terms of cover and species diversity and richness, the spatial patterns of coral distribution at this high latitude location, (2) determine if different ecological communities exist among neighbouring sites at the Kermadec Islands and how these communities vary with latitude, and (3) identify similarities among coral diversity at the Kermadec Islands and other coral communities and reefs to assess the contribution of latitude in governing coral species distributions. The latter point is developed in analyses of published data of coral biodiversity at marginal and optimal sites throughout the world. It is hypothesised that coral diversity will be low at the Kermadec Islands, due to the high latitude nature of the site, and that environmental parameters will drive coral distribution patterns. Furthermore, coral diversities and community structure will be similar among sites of comparable annual temperature ranges.

Equidistant between temperate New Zealand and tropical Tonga, the Kermadec Islands are one of the few subtropical island groups in the western South Pacific Ocean, and form New Zealand's largest marine reserve (748,000 ha). The islands are volcanic in origin, with steeply sloping rock substrata dominant in the 
shallow sub-tidal zone down to $10 \mathrm{~m}$, and gently sloping reef areas of in situ rock and large boulders common to depths of $20-30 \mathrm{~m}$. The main oceanographic influence on the Kermadec Islands is poorly known (Gardner et al. 2006), but is suggested to be either from the East Australian Current (EAC), flowing from New South Wales (eastern Australia) to Norfolk Island and on to the Kermadec Islands (Marshall 1979, Schiel et al. 1986), or from the northwest route, passing by New Caledonia, Fiji and Tonga (Fig 2.2; Gardner et al. 2006). Little is known of localised oceanographic patterns.

Previous surveys of benthic species diversity at the Kermadec Islands have reported a marine biota that is a mix of tropical, subtropical and temperate species of Southwest Pacific origin (Schiel et al. 1986, Cole et al. 1992, Brook 1999, Gardner et al. 2006), with corals generally restricted to depths of $<30 \mathrm{~m}$ (Brook, 1999). The isolation of the Kermadec Islands, coupled with the lack of terrestrial inputs or a resident human population, means that they are free from many anthropogenic stressors to which other reefs are exposed, such as overfishing and terrestrial runoff. However, little is known of the biodiversity variability within the marine reserve (among islands, or among sites within islands), which spans a range of latitudes (29$31^{\circ} \mathrm{S}$ ) and sea surface temperatures (SST; $14-18^{\circ} \mathrm{C}$ annual minima, $23-26^{\circ} \mathrm{C}$ annual maxima; Francis et al. 1987). The lack of a comprehensive study of temporal and spatial variation in community structure of the benthic habitats (coral and noncoral benthic taxa) at the Kermadec Islands is due to their inaccessibility associated with their isolation, and problems of wave exposure once on site (Gardner et al. 2006). 


\subsection{MATERIALS AND METHODS}

\subsubsection{Study area}

The study was conducted at two locations at the Kermadec Islands, $120 \mathrm{~km}$ apart and situated between the latitudes of $29^{\circ}$ and $30^{\circ} \mathrm{S}$, in November 2004 . The 11 islands form three discrete groups (Fig. 2.2), the northern group around Raoul Island $\left(29^{\circ} 12^{\prime} \mathrm{S}, 177^{\circ} 55^{\prime} \mathrm{W}\right)$, the middle group around Macauley Island $\left(30^{\circ} 14^{\prime} \mathrm{S}\right.$, $\left.178^{\circ} 25^{\prime} \mathrm{W}\right)$, and the southern group of Curtis and Cheeseman Islands $\left(31^{\circ} 21^{\prime} \mathrm{S}\right.$, $\left.178^{\circ} 41^{\prime} \mathrm{W}\right)$. Although corals are present at the southern group, the area was not surveyed, because it was inaccessible at the time of study. Eight of the nine sites surveyed are situated in the northern group, and one site was located close to Macauley Island in the middle group. Sites were chosen on the basis of accessibility and repeatability.

\subsubsection{Sampling}

At each of the Kermadec sites, quantitative benthic surveys were carried out at four depth strata, $3-6 \mathrm{~m}, 6-9 \mathrm{~m}, 9-12 \mathrm{~m}$ and $12-15 \mathrm{~m}$, consistent with previous surveys (Schiel et al. 1986, Gardner et al. 2006). Sampling was conducted by photographing 16 haphazardly located quadrats of $50 \times 50 \mathrm{~cm}$ (total area sampled $=4$ $\mathrm{m}^{2}$ per stratum) using a Canon S60 camera. From the digital images, percent cover ( \pm SD) was estimated using random point counts (100 points) of nine benthic groups, including hard and soft corals. Corals present were identified to family and, where possible, to species; their percent cover was recorded. 


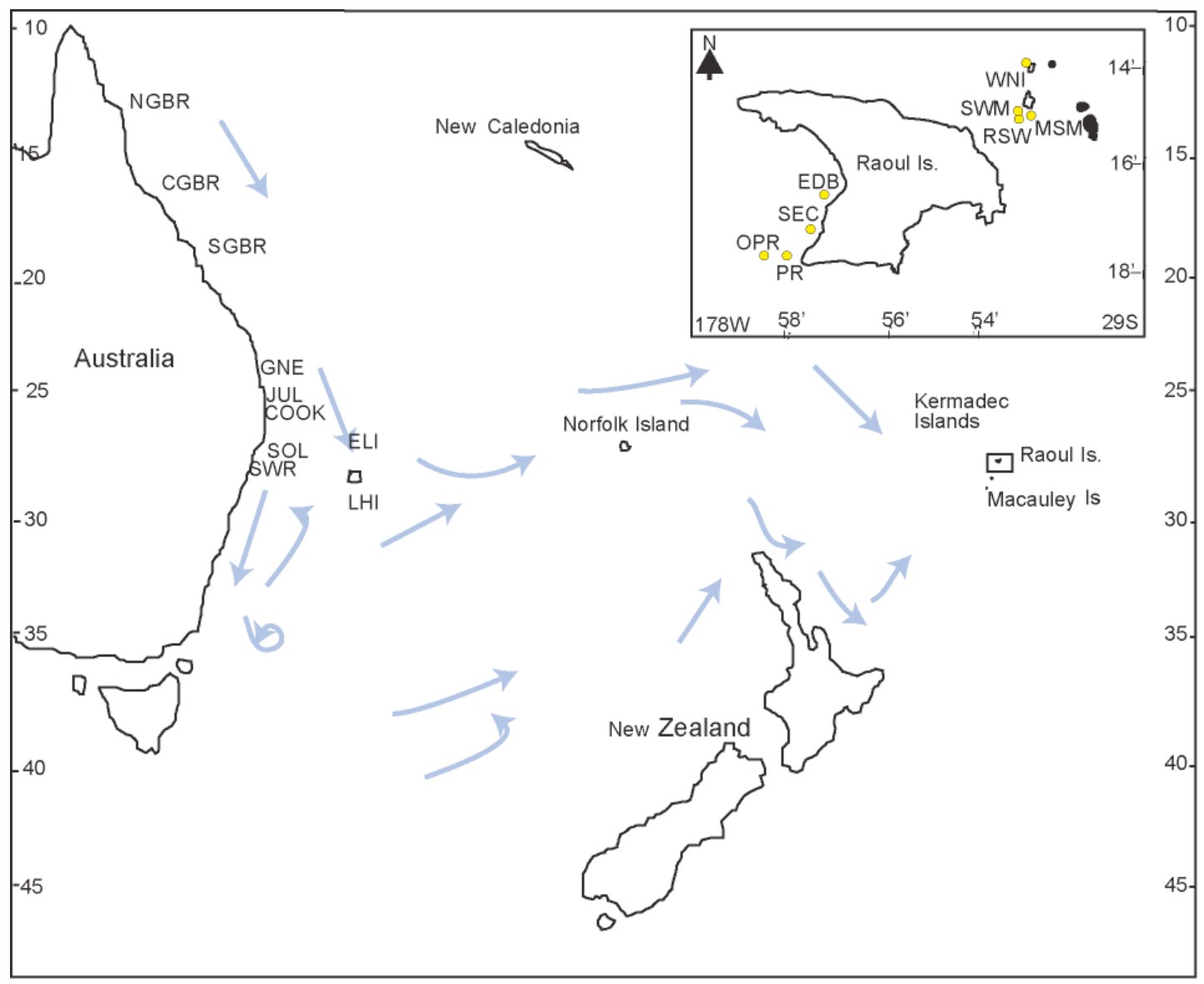

Figure 2.2 New Zealand and Australian sites. Geographic location of Kermadec Islands, northeastern New Zealand. Inset shows location of 8 sites within the Kermadec Islands Marine Reserve. Major oceanic currents indicated by arrows, from Schiel et al. (1986). Australian site abbreviations: GBR, Great Barrier Reef (N, North; C, Central; S, South); GNE, Gneering Shoals; JUL, Julian Rocks; COOK, Cook Island; SOL, Solitary Islands; SWR, Southwest Rocks; LHI, Lord Howe Island; ELI, Elizabeth Reef. Kermadec Islands site abbreviations: EDB, East Denham Bay; SEC, South-east Denham Bay; OPR, Outer Parsons Rock; PR, Parsons Rock; WNI, West Napier Island; SWM, Southwest Meyer; RSW, Rock South-west Mayer; MSM, Mid-south Meyer. 


\subsubsection{Regional affinities}

For multivariate analysis of coral community structure in relation to other geographic locations, data on coral species richness in the form of number of species per family was collated from 39 sites. Twelve Australian regions (Fig. 2.2; Ten published by Veron (1993a) cited in Harriott \& Banks (2002), others in Veron \& Marsh 1988, Oxley et al. 2004)); 19 Central and Eastern Pacific sites from French Polynesia in the east to Colombia in the west (Glynn et al. 2007) and 7 other marginal/isolated sites: Tsushima Is. and Iki Is. Japan (Sugihara \& Yamano 2004, Yamano et al. 2004 respectively), the Persian Gulf and the Red Sea (DeVantier \& Pilcher 2000), the Gulf of Aqaba (Sheppard \& Sheppard 1991), American Samoa (Lamberts 1983) and South Africa (Riegl 1996) were used in the study. For areas in the Central and Eastern Pacific, a biogeographic dataset of zooxanthellate corals was sourced from Glynn et al. (2007), which was combined with the present survey data and the aforementioned data sets (thus excluding azooxanthellate species) for further multivariate analysis. Coral species counts from the present study for the Kermadec Islands were supplemented with records from Brook (1999), who identified seven additional species. Where possible, percent coral cover (when recorded in aforementioned published records), survey depth, and average minimum and maximum annual temperatures for the sites were noted. Most temperature data were collated from ReefBase GIS information (http://reefgis.reefbase.org), with data from Japan from Yamano et al. (2001). 


\subsubsection{Data analysis}

Kermadec Islands

Mean ( $\pm 1 \mathrm{SD})$ of percent cover for each benthic category was estimated for the 16 replicate quadrats at each site. Percent cover of each coral species identified was estimated for each quadrat, and means calculated for each site/depth stratum. Indices used to assess diversity of corals per site were total number of species (S), Hill numbers $\mathrm{N} 1$ and $\mathrm{N} 2$ (to assess the influence of rare and dominant species on community diversity respectively), and the modified Hill's ratio (N21') (see Clarke \& Gorley 2006 for a summary of each index). The modified Hill's ratio was used as a measure of equitability (spread between taxa) as it has an advantage over traditional measures of evenness by its non-dependency on the number of species (Rogers et al. 1999). Significance of differences in coral cover (hard and soft combined) and species diversity among sites and depths were determined using either ANOVA (coral cover - normally distributed) or Kruskal-Wallis (species diversity - non-normal data) tests.

Multivariate analyses of similarities and differences among sites and depths were performed on percent cover of (a) all benthic categories and (b) coral species only. Data analysis was performed using the PRIMER package v6.0 with PERMANOVA (Multifactorial permutational analysis of variance) add-on (Plymouth Marine Lab.). All benthic group and coral species percent cover values were pre-treated with a dispersion weighting transformation in which the abundances of the different species were differentially weighted on the basis of their observed variability in replicate samples. This method compensates for the spatial clustering common to coral community studies (Clarke et al. 2006a). Similarities were 
calculated using the zero-adjusted Bray-Curtis similarity measure (Bray \& Curtis 1957) to account for samples with depauperate assemblages (see Clarke et al. 2006b). PERMANOVA with 9999 permutations was used to determine differences in community structure among sites and depths within sites. PERMANOVA is unconstrained by the assumptions of normality and homogeneity of variance that limit the use of traditional MANOVA, and relies on comparing the observed value of a test statistic (pseudo $F$-ratio) against a recalculated test statistic generated from random re-ordering (permutation) of the data (Anderson 2001). Patterns in the data were visualised using a canonical analysis of principal coordinates (CAP), and SIMPER analysis established the species causing the dissimilarities between most sites and outlying site/depth strata.

\section{Regional affinities}

To gain insight into the regional affinities of the coral species and diversity patterns seen at the Kermadec Islands, multivariate analyses of similarities and differences were conducted on the total number of species in each family present at each of the aforementioned Pacific, Australian and marginal locations, using the PRIMER software package. Analysis was conducted on untransformed and $4^{\text {th }}$ root transformed data, to identify the role of dominant and rare species respectively. Following calculation of similarities using the Bray-Curtis similarity measure, significant groupings in the multivariate space at the $95 \%$ level were identified using the similarity profile permutation test SIMPROF, with SIMPER analyses used to assess the contribution of each family to the similarities within clusters 


\subsection{RESULTS}

\subsubsection{Kermadec Islands}

Seventeen coral species were identified in this survey (Table 2.1): 16 hard (scleractinian) corals, and one soft coral (Sinularia sp.). The most common coral species observed were Montastraea curta, Hydnophora pilosa and an encrusting Montipora sp. Small spatial scale geographical divisions were observed for some coral species, with one species only found at the southern sites (Rhizopsammia sp), and three limited to the northeast region (H. pilosa, Tubastrea sp. and Dendrophyllia $\mathrm{sp}$ ). Coral colonies were generally small, ranging from $20 \mathrm{~mm}$ diameter (e.g. Cyphastrea serailia), to $1 \mathrm{~m}^{2}$ colonies of soft corals. Total number of species was greatest at the northernmost site of West Napier Island (10), and lowest at the southernmost site of Macauley Island (4).

Coral species diversity was significantly different among sites (Kruskal-Wallis; $\mathrm{H}=53.48, \mathrm{DF}=8, p<0.01)$ and depths within sites $(\mathrm{H}=14.59, \mathrm{DF}=3, p<0.01)$. Diversity of both rare and dominant species (N1, N2; Table 2.1) were greatest at West Napier Island $(\mathrm{N} 1=6.6, \mathrm{~N} 2=5.1)$, with a high diversity of rare species also observed at South West Meyer $(\mathrm{N} 1=5.4)$. Minimum species counts and diversity of both rare and dominant species were at the most southerly site of Macauley Island (4 spp., $\mathrm{N} 1=1.7, \mathrm{~N} 2=1.4) \mathrm{N} 1$ and $\mathrm{N} 2$ were also low at some sites in the northern group; Mid South Meyer and East Denham Bay $(\mathrm{N} 1=1.9, \mathrm{~N} 2=1.4$ at both sites). Evenness (N21') was variable among sites $(0.4-0.9)$, with the greatest value recorded at Outer Parsons Rock (0.9) and the minimum at East Denham Bay (0.4). 
Table 2.1 Mean percent cover \pm SD of the benthic categories and coral species at nine sites at the Kermadec Islands, New Zealand. Site codes are in brackets.

\begin{tabular}{|c|c|c|c|c|c|c|c|c|c|}
\hline & $\begin{array}{c}\text { W. Napier } \\
\text { Island (WNI) } \\
29^{\circ} 14^{\prime} \mathrm{S}\end{array}$ & $\begin{array}{c}\text { Mid S. Meyer } \\
\text { (MSM) } \\
29^{\circ} 14^{\prime} \mathrm{S}\end{array}$ & $\begin{array}{c}\text { Rock SW } \\
\text { Meyer (RSW) } \\
29^{\circ} 15^{\prime} \mathrm{S}\end{array}$ & $\begin{array}{l}\text { SW Meyer } \\
\text { (SWM) } \\
29^{\circ} 15^{\prime} \mathrm{S}\end{array}$ & $\begin{array}{c}\text { SE Denham Bay } \\
\text { (SEC) } \\
29^{\circ} 17^{\prime} \mathrm{S}\end{array}$ & $\begin{array}{c}\text { East Denham } \\
\text { (EDB) } \\
29^{\circ} 18^{\prime} \mathrm{S}\end{array}$ & $\begin{array}{c}\text { Outer Parsons } \\
\text { Rk (OPR) } \\
29^{\circ} 18^{\prime} \mathrm{S}\end{array}$ & $\begin{array}{c}\text { Parsons Rk } \\
\text { (PR) } \\
29^{\circ} 18^{\prime} \mathrm{S}\end{array}$ & $\begin{array}{c}\text { McCauley Is. } \\
\text { (MCI) } \\
30^{\circ} 17^{\prime} \mathrm{S}\end{array}$ \\
\hline RUBBLE/SAND & $3.4 \pm 4.0$ & $4.8 \pm 8.1$ & $14.1 \pm 22.6$ & $13.3 \pm 17.0$ & $10.4 \pm 13.8$ & $23.0 \pm 25.6$ & $5.2 \pm 3.9$ & $7.2 \pm 8.2$ & $2.7 \pm 5.6$ \\
\hline FILAMENTOUS ALGAE & $35.6 \pm 31.7$ & $57.9 \pm 21.9$ & $36.0 \pm 30.4$ & $48.1 \pm 22.5$ & $51.6 \pm 28.6$ & $66.1 \pm 25$ & $61.9 \pm 26.6$ & $75.6 \pm 26$ & $78.4 \pm 20.9$ \\
\hline ENC- RED- ALG & $49.7 \pm 34.6$ & $16.0 \pm 16.8$ & $20.8 \pm 22.5$ & $19.7 \pm 25.6$ & $18.1 \pm 24.9$ & $6.7 \pm 14.9$ & $17.8 \pm 21.7$ & $5.5 \pm 13.1$ & $15.8 \pm 17.8$ \\
\hline HARD CORAL & $3.2 \pm 11$ & $4.8 \pm 11.2$ & $10.2 \pm 17$ & $5.8 \pm 14.7$ & $18.0 \pm 26.0$ & $2.6 \pm 8.1$ & $1.2 \pm 6.9$ & $3.5 \pm 11$ & $0.2 \pm 0.9$ \\
\hline SOFT CORAL & $0.1 \pm 0.6$ & $10.5 \pm 18$ & $13.1 \pm 26.5$ & $0.4 \pm 2.1$ & $0.3 \pm 1.6$ & $0.1 \pm 0.3$ & $0.2 \pm 0.9$ & $0.6 \pm 2.3$ & $0.0 \pm 0.0$ \\
\hline BRYOZOAN & $0.0 \pm 0.0$ & $0.4 \pm 2.3$ & $<0.1 \pm 0.1$ & $0.0 \pm 0.0$ & $0.0 \pm 0.0$ & $0.0 \pm 0.0$ & $0.1 \pm 0.9$ & $0.0 \pm 0.0$ & $0.1 \pm 0.5$ \\
\hline SPONGE & $3.6 \pm 5.5$ & $3.0 \pm 3.7$ & $3.0 \pm 3.6$ & $6.6 \pm 11.2$ & $0.6 \pm 1.2$ & $0.3 \pm 0.8$ & $8.3 \pm 15.8$ & $3.6 \pm 7.4$ & $0.7 \pm 1.0$ \\
\hline ASCIDIAN & $0.4 \pm 1.2$ & $<0.1 \pm 0.2$ & $<0.1 \pm 0.2$ & $0.1 \pm 0.4$ & $0.0 \pm 0.0$ & $0.0 \pm 0.0$ & $0.5 \pm 1.5$ & $0.4 \pm 1.6$ & $0.1 \pm 0.5$ \\
\hline ANEMONES & $0.0 \pm 0.0$ & $0.0 \pm 0.0$ & $0.0 \pm 0.0$ & $0.0 \pm 0.0$ & $0.0 \pm 0.0$ & $0.0 \pm 0.0$ & $0.8 \pm 3.1$ & $0.0 \pm 0.0$ & $0.0 \pm 0.0$ \\
\hline CORAL & $3.3 \pm 11.0$ & $15.2 \pm 22.9$ & $23.3 \pm 29.7$ & $6.2 \pm 14.7$ & $18.3 \pm 25.9$ & $2.7 \pm 8.1$ & $1.4 \pm 6.9$ & $4.1 \pm 11.3$ & $0.2 \pm 1.0$ \\
\hline ALGAE & $85.4 \pm 14.9$ & $74.0 \pm 22.2$ & $56.8 \pm 30.3$ & $67.8 \pm 19.3$ & $69.7 \pm 23.9$ & $72.8 \pm 29.1$ & $79.7 \pm 20.1$ & $81.2 \pm 19.0$ & $94.2 \pm 14.4$ \\
\hline Acroporidae & & & & & & & & & \\
\hline Carophyllidae Montipora sp & $0.2 \pm 0.0$ & $0.4 \pm 2.9$ & $0.1 \pm 0.9$ & $0.2 \pm 1.2$ & $10.1 \pm 24.0$ & $0.0 \pm 0.0$ & $0.0 \pm 0.0$ & $0.4 \pm 3.0$ & $<0.1 \pm 0.1$ \\
\hline $\begin{array}{l}\text { Coenocyathus brooki } \\
\text { Pocilloporidae }\end{array}$ & $0.0 \pm 0.0$ & $0.0 \pm 0.0$ & $0.0 \pm 0.0$ & $0.0 \pm 0.0$ & $0.0 \pm 0.0$ & $0.0 \pm 0.0$ & $0.0 \pm 0.0$ & $<0.1 \pm 0.1$ & $0.0 \pm 0.0$ \\
\hline $\begin{array}{l}\text { Pocillopora damicornis } \\
\text { Dendrophyllidae }\end{array}$ & $0.1 \pm 0.5$ & $0.0 \pm 0.0$ & $0.9 \pm 3.3$ & $0.2 \pm 1.4$ & $0.0 \pm 0.0$ & $0.1 \pm 0.8$ & $0.0 \pm 0.0$ & $0.0 \pm 0.0$ & $0.0 \pm 0.0$ \\
\hline Dendrophyllia sp & $<0.1 \pm 0.1$ & $0.0 \pm 0.0$ & $0.0 \pm 0.0$ & $0.0 \pm 0.0$ & $0.0 \pm 0.0$ & $0.0 \pm 0.0$ & $0.0 \pm 0.0$ & $0.0 \pm 0.0$ & $0.0 \pm 0.0$ \\
\hline Tubastrea $\mathrm{sp}$ & $0.2 \pm 0.8$ & $0.0 \pm 0.0$ & $0.0 \pm 0.0$ & $<0.1 \pm 0.1$ & $0.0 \pm 0.0$ & $0.0 \pm 0.0$ & $0.0 \pm 0.0$ & $0.0 \pm 0.0$ & $0.0 \pm 0.0$ \\
\hline Turbinaria sp & $0.9 \pm 6.2$ & $0.9 \pm 6.7$ & $0.0 \pm 0.0$ & $0.0 \pm 0.0$ & $0.0 \pm 0.0$ & $0.0 \pm 0.0$ & $0.2 \pm 1.5$ & $0.0 \pm 0.0$ & $0.0 \pm 0.0$ \\
\hline Rhizopsammia sp & $0.0 \pm 0.0$ & $0.0 \pm 0.0$ & $0.0 \pm 0.0$ & $0.0 \pm 0.0$ & $0.0 \pm 0.0$ & $0.0 \pm 0.0$ & $0.0 \pm 0.0$ & $0.0 \pm 0.0$ & $<0.1 \pm 0.1$ \\
\hline Cyphastrea sp & $0.0 \pm 0.0$ & $<0.1 \pm 0.1$ & $0.0 \pm 0.0$ & $<0.1 \pm 0.1$ & $0.0 \pm 0.0$ & $0.0 \pm 0.0$ & $0.0 \pm 0.0$ & $<0.1 \pm 0.1$ & $0.0 \pm 0.0$ \\
\hline Goniastrea $\mathrm{sp}$ & $0.0 \pm 0.0$ & $0.0 \pm 0.0$ & $<0.1 \pm 0.2$ & $0.1 \pm 0.3$ & $3.2 \pm 7.8$ & $2.1 \pm 7.8$ & $<0.1 \pm 0.3$ & $0.1 \pm 0.4$ & $0.0 \pm 0.0$ \\
\hline Leptastrea $\mathrm{sp}$ & $0.0 \pm 0.0$ & $0.0 \pm 0.0$ & $0.0 \pm 0.0$ & $0.0 \pm 0.0$ & $0.0 \pm 0.0$ & $0.0 \pm 0.0$ & $0.8 \pm 6.4$ & $0.0 \pm 0.0$ & $0.0 \pm 0.0$ \\
\hline 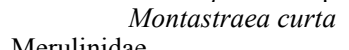 & $1.7 \pm 8.0$ & $0.1 \pm 0.3$ & $3.1 \pm 9.3$ & $2.0 \pm 9.2$ & $3.4 \pm 6.7$ & $0.2 \pm 1.6$ & $0.0 \pm 0.0$ & $3.0 \pm 10.8$ & $<0.1 \pm 0.4$ \\
\hline $\begin{array}{l}\text { Merulinidae } \\
\text { Hydnophora pilosa }\end{array}$ & $0.0 \pm 0.0$ & $3.1 \pm 8.9$ & $6.1 \pm 14.3$ & $3.2 \pm 10.9$ & $1.2 \pm 5.6$ & $0.1 \pm 0.8$ & $0.0 \pm 0.0$ & $0.0 \pm 0.0$ & $0.0 \pm 0.0$ \\
\hline $\begin{array}{l}\text { Poritidae } \\
\text { Alveopora spongiosa } \\
\text { Agariciidae }\end{array}$ & $0.0 \pm 0.0$ & $0.0 \pm 0.0$ & $0.0 \pm 0.0$ & $0.0 \pm 0.0$ & $0.1 \pm 0.5$ & $<0.1 \pm 0.1$ & $0.0 \pm 0.0$ & $0.0 \pm 0.0$ & $0.0 \pm 0.0$ \\
\hline Leptoseris $\mathrm{sp}$ & $0.0 \pm 0.0$ & $0.0 \pm 0.0$ & $<0.1 \pm 0.1$ & $0.0 \pm 0.0$ & $<0.1 \pm 0.1$ & $0.0 \pm 0.0$ & $0.0 \pm 0.0$ & $0.0 \pm 0.0$ & $0.0 \pm 0.0$ \\
\hline Pavona explanulata & $0.0 \pm 0.0$ & $<0.1 \pm 0.0$ & $0.0 \pm 0.0$ & $0.0 \pm 0.0$ & $0.0 \pm 0.0$ & $0.0 \pm 0.0$ & $0.0 \pm 0.0$ & $0.0 \pm 0.0$ & $0.0 \pm 0.0$ \\
\hline Soft Coral & $0.1 \pm 0.6$ & $10.8 \pm 18.4$ & $13.1 \pm 26.5$ & $0.4 \pm 2.1$ & $0.3 \pm 1.6$ & $0.1 \pm 0.4$ & $0.2 \pm 0.9$ & $0.6 \pm 2.3$ & $0.0 \pm 0.0$ \\
\hline Unidentified & $<0.1 \pm 0.1$ & $<0.1 \pm 0.1$ & $<0.1 \pm 0.2$ & $0.1 \pm 0.4$ & $0.1 \pm 0.4$ & $0.1 \pm 0.4$ & $0.2 \pm 0.8$ & $0.1 \pm 0.3$ & $0.2 \pm 0.8$ \\
\hline Total no spp. & 10 & 8 & 8 & 9 & 9 & 7 & 5 & 7 & 4 \\
\hline Shannon Weiner (H') & 1.5 & 0.9 & 0.6 & 0.7 & 0.7 & 0.6 & 2.1 & 0.6 & 1.0 \\
\hline Margalef's (d) & 7.5 & 2.6 & 2.2 & 4.4 & 2.8 & 6.1 & 11.2 & 4.2 & 0.2 \\
\hline
\end{tabular}


Both hard and soft coral cover were significantly different among sites and depths within sites (Hard: site $\mathrm{F}=9.7, p<0.01$, depth $\mathrm{F}=4.1, p<0.01$; Soft: site $\mathrm{F}$ $=13.9, p<0.01$, depth $\mathrm{F}=9.6, p<0.01)$. Soft corals were less abundant than hard corals, with an average $( \pm \mathrm{SD})$ of $2.9 \pm 11.9$ versus $5.2 \pm 13.9$ percent cover respectively, averaged over all depths at all sites. The highest total mean coral cover (i.e. both soft and hard) was recorded at the northern site of Rocks Southwest Meyer (23\%; Table 2.1$)$, whereas the lowest value $(0.2 \%)$ was recorded at the southernmost site of Macauley Island, where four hard coral species and no soft coral species were present. Southeast Denham Bay had the greatest cover of hard corals (18\%), and Rocks Southwest Meyer had the greatest soft coral cover (13\%). Coral cover among sites and depths was highly variable (Fig. 2.3). Overall, mean coral cover ( \pm SD) was lowest in the $12-15 \mathrm{~m}$ zone $(<8 \%$ of cover), although the two sites around Parsons Rock had their highest recorded coral covers in this depth zone $(\mathrm{PR}=5.3 \pm 14.1 \%$, OPR $=8.2 \pm 12.5 \%$ ). These deeper communities were dominated by Leptastrea $\mathrm{sp}$. and M. curta.

Coral cover was less than macroalgal cover in all sites surveyed $(\mathrm{DF}=130$, $p<0.001)$. Filamentous and encrusting macroalgae combined accounted for $57-94 \%$ of the benthic cover (Southwest Meyer and Macauley Is., respectively; Table 2.1). Filamentous macroalgal species observed included genera such as Caulerpa, Enteromorpha, Codium and Corallina, with encrusting species such as Lithothamnion sp., and Apophloea sp. also being common. Filamentous macroalgal cover declined with decreasing latitude, accounting for only $36 \%$ of the benthic cover west of Napier Island $\left(29^{\circ} \mathrm{S}\right)$, compared to $94 \%$ at Macauley Island $\left(30^{\circ} \mathrm{S}\right)$ though it was highly variable among neighbouring sites (e.g. 37 - 57\% filamentous macroalgal cover at the three sites south of Meyer Island). 
No. coral sp.

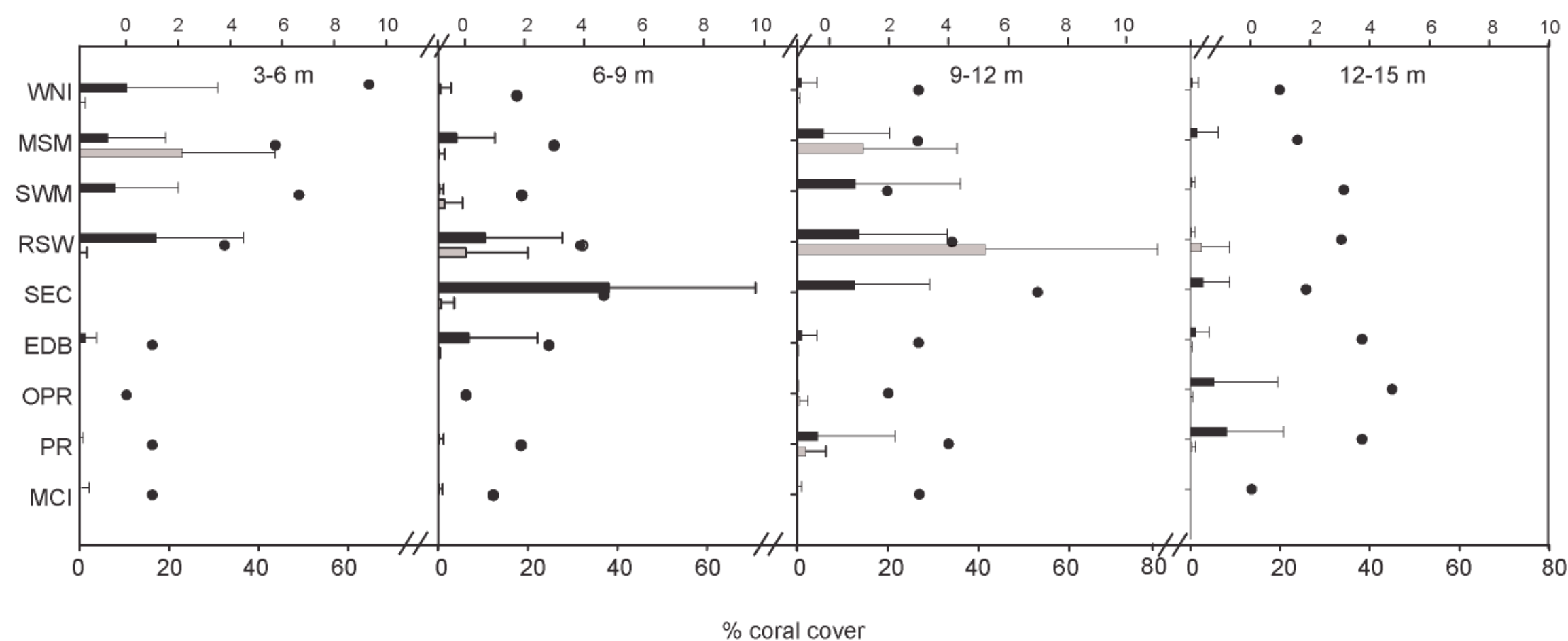

Figure 2.3 Mean percent coral cover \pm SD (bottom axis) of hard (dark bars) and soft corals (light bars), and number of species (dots - top axis) present at each of the nine sites (left axis) in the four depth strata surveyed at the Kermadec Islands (for site abbreviations see Table 2.1). Sites ordered from north to south (top to bottom). EDB, East Denham Bay; SEC, South-east Denham Bay; OPR, Outer Parsons Rock; PR, Parsons Rock; WNI, West Napier Island; SWM, South-west Meyer; RSW, Rock South-west Mayer; MSM, Mid-south Meyer 
Multivariate analysis of both benthic composition and coral community structure for the 9 sites (in 4 depth strata) around the Kermadec Islands revealed significant differences among sites and depths within sites (PERMANOVA: $p<0.01$ for both tests). However, only 13 of 32 and 8 of 32 possible site comparisons had significantly different benthic compositions and coral community structures, respectively. Canonical ordination supports this finding, with a clear overlap of most sites, due to their dominance by macroalgae and coral species scarcity. The few outliers identified by CAP were sites with high abundances of hard or soft coral (e.g. RSW 9-12 m had 41\% soft coral, Appendix 1).

The taxa that contributed most to the dissimilarity among the main grouping and the outliers were defined by SIMPER analysis. The site of Mid-South Meyer was significantly different to most other sites, due to its abundance of soft corals $(19 \%$ mean cover) in addition to the hard coral $H$. pilosa (3\% mean cover). The other outliers were characterised by their abundance of rare species (e.g. OPR 12-15 m had 4\% Leptastrea sp.), or the relatively high abundance of one species (e.g. RSW 3-6 m had $14 \%$ M. curta). Two site/depth combinations were significantly different to other site/depth strata in both benthic (including coral) and coral species community structure: Rock Southwest Meyer 9-12 m, which was dominated by soft coral (42\% cover), H. pilosa ( $13 \%$ cover) and filamentous macroalgae ( $23 \%$ cover $)$; and Southeast Denham Bay 6-9 m with 38\% hard coral cover (including 28\% Montipora sp.). The southern site of Macauley Island was not significantly different in community structure to 5 of the other 8 sites (PERMANOVA, $p=0.342$ ), despite its geographical isolation. The lack of clear groupings suggests a variable benthic community among sites and depths, rather than a clear latitudinal delineation. 


\subsubsection{Regional affinities}

Cluster analysis (Fig. 2.4) revealed the existence of pronounced divisions among the tropical, sub-tropical and high latitude sites. The exclusion of azooxanthellate species from the analysis did not change the groupings, suggesting that such species contribute little to community structure similarities. Analyses using both untransformed and transformed data gave the same clusters, at comparable similarity levels. The SIMPROF grouped sites based on the abundance of each coral family into 7 clusters at $p<0.05$, loosely defined as: A - Australasian high latitude, B Japan, C - Central Pacific (though also including the Gulf of Aqaba), D - Multiregional high latitude (including some eastern Australian sites), E - Houtman Abrolhos and American Samoa, F - GBR and Red Sea, G -Eastern Pacific, and Southwest Rocks (Australia) and Marquesas Islands (French Polynesia) were the two outliers.

The Kermadec Islands $\left(29-31^{\circ} \mathrm{S}, 178^{\circ} \mathrm{W}\right)$ fell into the Australasian high

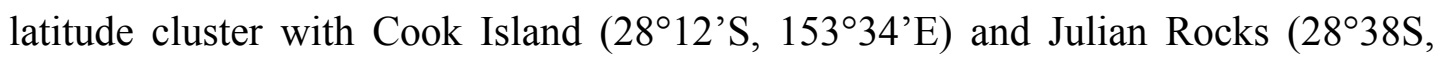
$\left.153^{\circ} 36^{\prime} \mathrm{E}\right)$, both in NSW, Australia. This cluster showed closest affinity with the cluster of high latitude sites of Japan (Iki Island $33^{\circ} 47^{\prime} \mathrm{N}, 129^{\circ} 43^{\prime} \mathrm{E}$ and Tsushima $\left.34^{\circ} 25^{\prime} \mathrm{N}, 129^{\circ} 20^{\prime} \mathrm{E}\right)$, at $p=0.055$. The two Australasian high latitude sites have similar coral cover to the Kermadec Islands (8\%) with $8 \%$ and $5 \%$, respectively, though their species counts are higher than at the Kermadec Islands ( 24 species) with 33 and 30 species, respectively. Notably, the other high latitude sites of Australia, including Lord Howe Island and the Solitary Islands, grouped with the South African and Persian Gulf Reefs, not the nearby Kermadec Islands or sites further south on the 


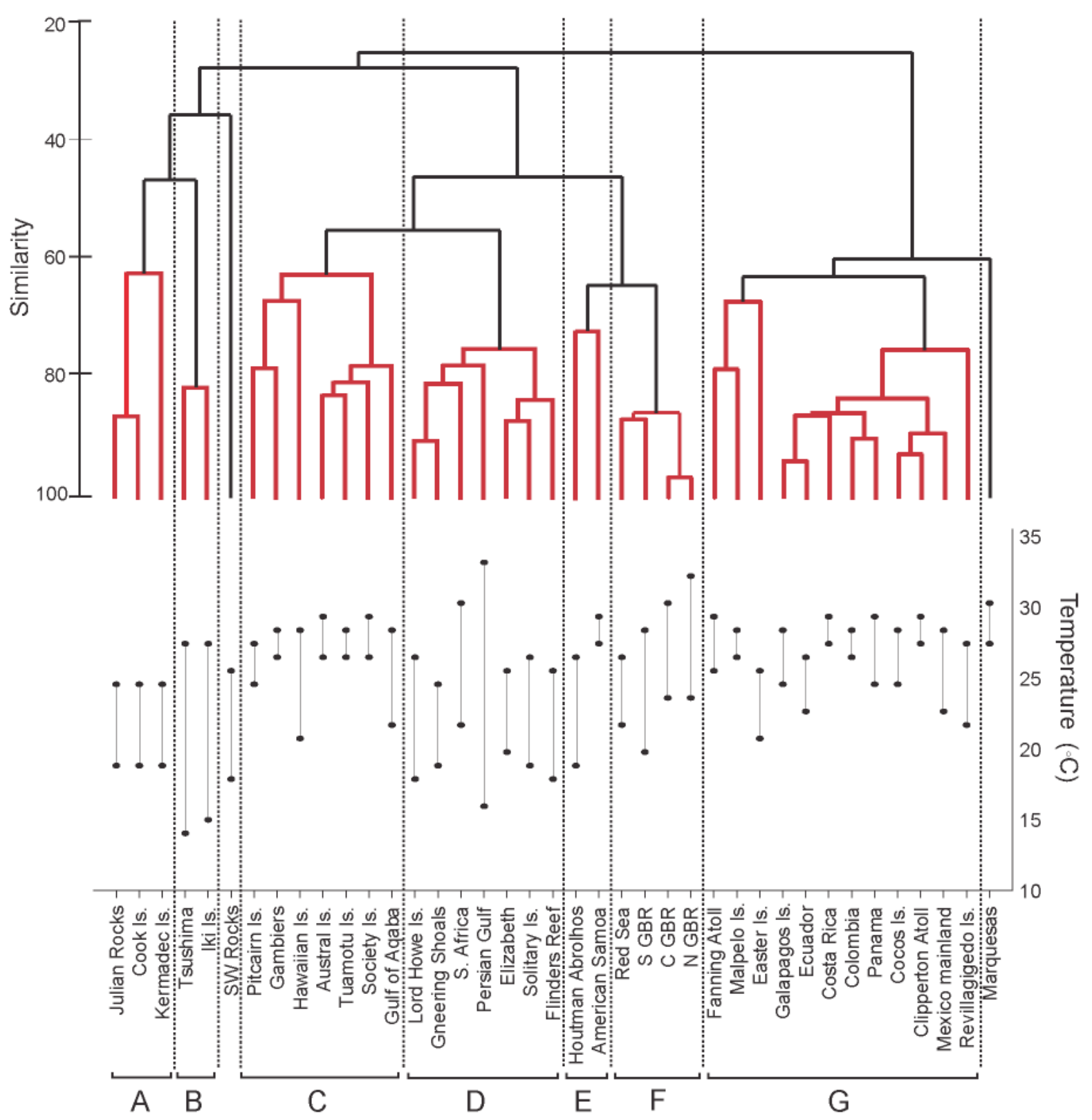

Figure 2.4 Cluster analysis of coral community structure patterns of the Kermadec Islands, locations in Australia, the Pacific and at marginal sites, with annual minimum and maximum temperatures. Temperatures of Hawaiian Islands, Red Sea and each specific GBR region are maximum and minimum over whole latitudinal range. GBR: Great Barrier Reef. Similarities calculated based on Bray-Curtis measure of square-root transformed coral species per family. 
Table 2.2 Coral genera contributing to SIMPROF groupings (Fig. 2.4) of similarities in coral assemblages at Australasian and marginal sites, calculated with BrayCurtis Similarity. Species are listed in order of \% contribution to within site similarity. Letters in brackets under site refer to groupings in text. Numbers in brackets aside families indicates average number of species per group in site assemblage. GBR: Great Barrier Reef

\begin{tabular}{|c|c|c|c|c|c|c|c|}
\hline Group & $\begin{array}{l}\text { Australasian high } \\
\text { latitude } \\
\text { (A) }\end{array}$ & $\begin{array}{l}\text { Japan } \\
\text { (B) }\end{array}$ & $\begin{array}{l}\text { Central Pacific } \\
\text { (and Gulf of } \\
\text { Aqaba) } \\
\text { (C) }\end{array}$ & $\begin{array}{l}\text { High latitude } \\
\text { (D) }\end{array}$ & $\begin{array}{l}\text { Houtman } \\
\text { Abrolhos/Am. } \\
\text { Samoa } \\
\text { (E) }\end{array}$ & $\begin{array}{l}\text { GBR/Red Sea } \\
\text { (F) }\end{array}$ & $\begin{array}{l}\text { Eastern Pacific } \\
(\mathrm{G})\end{array}$ \\
\hline $\begin{array}{l}\text { Within group } \\
\text { similarity }\end{array}$ & $79 \%$ & $80.70 \%$ & $67.96 \%$ & $77.70 \%$ & $71.66 \%$ & $87.60 \%$ & $72.36 \%$ \\
\hline $\begin{array}{l}\text { Species } \\
\text { contributing } \\
\text { (mean number } \\
\text { species) }\end{array}$ & $\begin{array}{l}\text { Faviidae (7) } \\
\text { Dendrophyllidae (6) } \\
\text { Acroporidae (5) } \\
\text { Siderstreidae (3) }\end{array}$ & $\begin{array}{l}\text { Faviidae (17) } \\
\text { Pectiniidae (4) } \\
\text { Acroporidae (2) } \\
\text { Poritidae (1) }\end{array}$ & $\begin{array}{l}\text { Acroporidae (32) } \\
\text { Pectiniidae (13) } \\
\text { Agariciidae (9) } \\
\text { Poritidae (7) }\end{array}$ & $\begin{array}{l}\text { Acroporidae (31) } \\
\text { Faviidae (22) } \\
\text { Poritidae (8) } \\
\text { Mussidae (5) }\end{array}$ & $\begin{array}{l}\text { Acroporidae (83) } \\
\text { Poritidae (20) } \\
\text { Merulinidae (11) } \\
\text { Sidersteidae (3) }\end{array}$ & $\begin{array}{l}\text { Acroporidae (89) } \\
\text { Faviidae (59) } \\
\text { Poritidae (31) } \\
\text { Fungiidae (27) }\end{array}$ & $\begin{array}{l}\text { Agariciidae (6) } \\
\text { Pocilloporidae (5) } \\
\text { Sidersteidae (3) } \\
\text { Poritidae (3) }\end{array}$ \\
\hline
\end{tabular}


Australian coast. Additionally, the most southern mainland site of Australia, Southwest Rocks $\left(30.90^{\circ} \mathrm{S} 153.04^{\circ} \mathrm{E}\right)$ was separate to all other groups (similarity of $30 \%$ ) due to the species-depauperate nature of the site; only 8 species were present. The coral community of the high latitude Australasian cluster was significantly different to all other tropical, subtropical and high latitude clusters $(p<0.05)$. Despite the surveys of all eastern Australian sites being conducted at $8-12 \mathrm{~m}$, as opposed to the $0-40 \mathrm{~m}$ at the Kermadec Islands, two of the Australian sites still show closer affinities to the Kermadec Islands rather than other Australian sites.

SIMPER analysis revealed that the families Faviidae (25\%), Dendrophyllidae (25\%) and Acroporidae (18\%) contributed most to the cluster similarities of the Kermadec Islands and two southern Australian sites (Table 2.2). The dissimilarity of the high latitude Australasian cluster to the Japanese sites was attributed to the abundance of species in the Faviidae at the latter (mean of 17 species compared to 7 species), and the high species counts in the Dendrophyllidae at the former (mean of 6 species compared to 1 species at the Japanese sites). The abundance of acroporids in the Central Pacific, Red Sea and GBR, and their absence at the Kermadec Islands, clearly explained the different coral community structures of the high latitude Australasian cluster versus the other clusters. Furthermore, the abundance of species in general, and specifically of acroporid and poritid species at the remaining high latitude sites (cluster D) caused the separation of this group from the Australasian high latitude sites. Whilst Acropora spp. dominate most sites in the Central and Western Pacific, including those at high latitudes, there is a lack of Acropora spp. in the far Eastern Pacific where species of the genera Agariciidae and Pocilloporidae dominate. Species counts overall are lowest in the Australasian high latitude sites and the Eastern/isolated Pacific sites. 
A clear pattern exists between the clustering of sites, and their annual temperature ranges. The high latitude cluster, which includes some Australian sites, South Africa and the Persian Gulf (D on Fig. 2.4) are all subject to substantial annual temperature ranges (Persian Gulf $15-33^{\circ} \mathrm{C}, \mathrm{S}$. Africa $21-30^{\circ} \mathrm{C}$ ), and these sites all host coral reefs. The cluster of the Kermadec Islands and the two southern Australian sites has annual average temperatures ranging from $18-24^{\circ} \mathrm{C}$, and all sites host coral communities as opposed to reefs. Their temperature ranges are comparable with many of the other high latitude Australian sites, yet they exhibit a lack of affinity in coral community composition. These three sites, however, have the lowest annual maxima of $24^{\circ} \mathrm{C}$. The Japanese sites, loosely clustering with the Kermadec Islands, are located at a higher latitude $\left(34^{\circ} \mathrm{N}\right)$ and subject to average annual temperatures of $13-27^{\circ} \mathrm{C}$. The Eastern Pacific sites (G on Fig. 2.4) are all characterised by low species diversity, ranging from 7 to 20 species, with high annual average temperature $\operatorname{maxima}\left(26.5-31{ }^{\circ} \mathrm{C}\right)$.

\subsection{DISCUSSION}

\subsubsection{Kermadec Islands}

The coral community of the Kermadec Islands is dominated by subtropical species and features low coral diversity and cover, as might be expected at such a high latitude location. Seventeen coral species were identified from a known 24, with considerable differences in community structure between closely located sites (3 $120 \mathrm{~km})$. Although located at a high latitude $\left(29-31^{\circ} \mathrm{S}\right)$, and subject to low annual SST $\left(18-24^{\circ} \mathrm{C}\right.$ annual range), the variability in coral diversity and cover at the 
Kermadec Islands suggests that local-scale variations in the environmental regime are important for controlling the structure of this marginal community. On a regional scale, the Kermadecs were most similar to two rocky subtropical sites of southeastern Australia (NSW); there was a lack of affinity with tropical sites, and a reduced affinity for other high latitude sites. A lack of congruence between depth of surveys and regional affinities suggests depth does not determine similarity in communities among sites in the present study. These different affinities are likely explained by local environmental factors such as wave energy, water quality and larval supply, rather than latitude and its associated influence on temperature.

The low coral diversity at the Kermadec Islands (24 spp.) is seemingly linked to the physiological tolerances of coral species to low temperatures. Many reefbuilding species cannot grow and survive outside the tropics (Harriott et al. 1994, Harriott et al. 1995) exemplified by the absence of some major reef-building taxa at the Kermadec Islands (e.g. staghorn Acropora and massive Porites), and at most subtropical Australian sites. However, coral communities with higher species diversity and cover have been observed in regions subject to lower annual SST minima than those seen at the Kermadec Islands. For example, along the coast of Japan, coral communities of up to 40 species and $20-30 \%$ cover have been recorded, usually subject to an annual average SST minimum of $17^{\circ} \mathrm{C}$ (compared with $18^{\circ} \mathrm{C}$ at the Kermadec Islands), and the most northerly of which are subject to a lowest annual SST of $13.3^{\circ} \mathrm{C}$ (Yamano et al. 2001). Additionally, as observed in the present study, coral communities on the east coast of Australia separated by $<50 \mathrm{~km}$, with similar annual temperature regimes have highly variable species diversity and cover. However, while low temperature goes some way towards explaining the low diversity and cover of corals at the Kermadec Islands, alone it cannot explain the lack 
of similarities in coral community structure among sites from similarly high latitudes. Other, more local factors must play a role.

The hydrodynamic conditions, in terms of exposure to high wave energy, at the Kermadec Islands create a challenging environment for habitation. The absence of shallow sheltered rocky reefs and lagoons limit the substrate available for coral settlement. Locally, the southern site of Macauley Island is exposed to unrefracted ocean swell and storm surges (Brook 1999) and the community present reflects this challenging environment: filamentous macroalgae dominate with no soft corals present and $<1 \%$ hard coral cover. The high wave energy experienced at the Kermadec Islands is also experienced at the rocky benthic communities of Julian Rocks and Cook Island (NSW, Australia), located $2 \mathrm{~km}$ and $600 \mathrm{~m}$ offshore respectively, with which it shows the closest affinities. Little is known of local hydrodynamic conditions at these 3 sites. Environments with high wave energy, such as these, favour compact growth forms of corals (Veron 1993b), with only those coral species that can withstand exposure to swell and storm surge able to establish there. Thus, the low abundance of branching species at the Kermadec Islands, Julian Rocks and Cook Island (e.g. acroporids, pocilloporids) may be due to the high degree of wave exposure. Comparatively, at Lord Howe Island, Australia, reef-building species are able to establish, but only in the lagoonal areas; they are uncommon on the seaward slopes where reef accretion capacity is very limited (Harriott et al. 1995). In addition to Lord Howe Island, the other high latitude sites considered here, all of which show greater species diversity than the Kermadec Islands, all feature sheltered areas, which potentially allow more fragile species to establish. Further, the decline in light penetration at these high latitude sites will prevent the development of corals at greater depths (Grigg 1982, Kleypas et al. 1999) where wave exposure 
would be minimized thus allowing settlement. The lack of sheltered areas at the Kermadec Islands means that even if temperatures are sufficient to allow colonization by reef building species, hydrodynamic conditions may prevent their long-term establishment.

The high wave energy at the Kermadec Islands also favours the dominance of communities of calcareous algae, which can establish in wave-exposed conditions and outcompete corals for space and light (Hustan 1985). At high latitudes, competition between corals and algae plays a significant role in regulating the coral communities (Birkleland 1977, Birkleland \& Randall 1981), because subtropical conditions (i.e. low SST) favour algae over coral. This is also linked to nutrient concentrations as, in general, inshore and higher latitude waters have greater nutrient concentrations than do offshore and lower latitude waters, which allows for the enhanced growth rates of macroalgae (Crossland 1983). The dominance by macroalgae, both filamentous and encrusting, at the Kermadec Islands, Julian Rocks and Cook Island (76\%, 45\%, and $67 \%$ respectively, compared to $25 \%$ on the GBR) suggests that algae are successfully out-competing corals for space at these sites, by overgrowth of the live coral tissue (Birkleland 1977). Additionally, any variation in nutrient availability among sites will affect community structure, as nutrients enhance growth and hence the competitive ability of macroalgae (Kojis \& Quinn 1984, Hughes 1989, Nugues \& Roberts 2003). Turbidity, a reflection of nutrient levels (Koenings \& Edmundson 1991) is indeed known to be variable among sites at the Kermadec Islands (0 - 3 FTU, J. Gardner, unpublished data), however long-term measurements of turbidity and/or nutrients are not available. Further study is needed to assess the role that nutrient levels play in shaping the coral community at this location. 
Larval supply to isolated sites is an additional factor that limits the species present. In a study of genetic connectivity between Lord Howe Island and the GBR (700 km apart), Ayre \& Hughes (2004) showed that expanses of open-ocean between isolated reefs are far more effective barriers to dispersal than are similar distances within continuous reef systems. This highlights the potential for limited recruitment of coral larvae at the Kermadec Islands, given that they lie at a minimum distance of $750 \mathrm{~km}$ from any landmass, and are approximately $3000 \mathrm{~km}$ from the GBR. Indeed, at the Kermadec Islands, there is evidence of limited connectivity between even closely located sites $(<1 \mathrm{~km})$, most likely associated with the hydrographic regime (Wood \& Gardner 2007). The low diversity of the Kermadec Islands may also reflect their geological history, with no evidence of a land bridge at any time (Brothers \& Searle 1970). Additionally, there appears to be a decline in coral recruitment with increasing latitude, linked to low water temperatures (Hughes et al. 2002, Nozawa et al. 2006), which at the Kermadec Islands likely compounds the problems associated with their remoteness. Finally, the mode of transmission of coral species will affect their likelihood of recruitment to the Kermadec Islands. Brooded larvae survive longer periods (greater than 1 month) in the water column (Richmond 1987, Harrison \& Wallace 1990), which confers an adaptive advantage at isolated sites. Approximately half of the species present at the Kermadec Islands are brooding species, whilst the remaining species are broadcast spawners with a lower larval competency period (Babcock et al. 1985).

It is important to note that small, isolated, and often peripheral islands in the Pacific Ocean are usually subject to high faunal turnover rates, which are a major factor contributing to differences in community structure in time and space at these locations (Pauley 1989, Harriott et al. 1994, Harriott et al. 1995). Temporally, little is 
known of the variability in community structure at the Kermadec Islands, as due to the Islands' isolation and inaccessibility, longer-term monitoring has not been possible. Previous short term studies have found large within-site variability (surveys 1991 - 1992 - Brook 1999; survey 2002 - Gardner et al. 2006), as well as variation between studies in depth-related patterns of coral distribution; however repeat sampling of the same sites has not been undertaken. Crucially, however, the present study identified the same coral species present at the Kermadec Islands as reported by Brook (1999), which suggests that although coral cover may be temporally variable, species presence is not. Hence, the analysis of regional species affinities remains valid.

\subsubsection{Wider implications}

In a time of global climate change and sea temperature warming, it is conceivable that 'marginal' coral communities may be more likely to survive than are 'optimal' communities, as they have an evolutionary history of persistence in stressful environments (Glynn 1996). On one hand, high latitude coral reefs or communities, at lower temperatures than their tropical counterparts, might be a refuge in the future as coral distributions change, and such sites become less marginal and more optimal (Riegl \& Piller 2003). However, as stressed here, latitude should not be considered in isolation from other local environmental factors, which have the potential to exert marked influence on community structure. For example, whilst the Kermadec Islands may be somewhat protected from future sea surface warming due to their high latitude and ocean situation, their potential to act as a refuge for many taxa found at other high latitude locations is diminished, due to the extreme wave energy and their isolation. Further, the potential for species living at the Kermadecs to 're-seed' reefs 
denuded of their coral fauna by global warming and other environmental stressors (Brown \& Suharsono 1990, Glynn 1996) is limited, again by the isolation of this oceanic site and the limited capacity for coral larvae to be transported across such large distances.

The Kermadec Islands will be affected in the near future by the combined effects of sea temperature rise and ocean acidification., as high latitude sites are likely to be among the first affected on a global scale (Hoegh-Guldberg et al. 2007). The decline in accretion by the corals at the KI will reduce their competitive ability against macroalgae, and potentially reduce in coral cover. Conversely, the increased temperatures will aid in faster growth rates, increasing their competitive ability. A change in species composition is likely; with only those remaining that can cope with the new environmental conditions.

Future research to assess coral species-specific responses to environmental factors will contribute to a better understanding of the distribution and evolution of coral reefs through time, and what the future holds for both marginal and optimal coral reefs and communities. As the Kermadec Islands are uninhabited, they offer a valuable example of a marginal coral community that is free from anthropogenic impact, and ongoing monitoring of the changes in coral community composition at this site will be of great value in assessing changes linked to future environmental disturbances, such as global warming, at other high latitude sites. 


\section{Chapter 3}

\section{Local endemicity and high diversity characterise high latitude coral- Symbiodinium partnerships}

\section{ABSTRACT}

Obligate symbiotic dinoflagellates (Symbiodinium) residing within the tissues of most reef invertebrates are important in determining the tolerance range of their host. Coral communities living at high latitudes experience wide fluctuations in environmental conditions and thus provide an ideal system to gain insights into the range within the symbiotic relationship can be sustained. Additionally, high latitude coral communities have the potential to act as refugia during periods of environmental change. Despite this, very little is known on the host and symbiont partnerships at high latitudes and thus Symbiodinium diversity and specificity of high latitude coral communities was explored using denaturing gradient gel electrophoresis (PCR-DGGE) analysis of the internal transcribed spacer regions (ITS1 and ITS2) of the ribosomal DNA at Lord Howe Island $\left(31^{\circ} \mathrm{S}\right.$; Australia), and the Kermadec Islands $\left(29^{\circ} \mathrm{S}\right.$; New Zealand). All but one hosts associated with clade C Symbiodinium, the exception being a soft coral (Capnella sp.) that contained Symbiodinium B1. Besides generalist Symbiodinium types C1 and C3, approximately $72 \%$ of the Symbiodinium identified were novel C-types, and zonation of symbionts in relation to environmental parameters such as depth and turbidity was evident in certain host species. The high latitude Symbiodinium communities showed little 
overlap and relatively high diversity compared with communities sampled on the tropical Great Barrier Reef. Although host specificity was maintained in certain species, others shared symbionts and this potential reduction of fidelity at high latitude locations may be the result of locally challenging and highly variable environmental conditions. The combination of a highly diverse Symbiodinium community with a tolerance to a broad range of environmental conditions may, however, be beneficial if high latitude coral communities are to act as refugia in the future.

\subsection{INTRODUCTION}

Much of the success of coral reefs lies in the symbiotic relationship between reef invertebrates and dinoflagellates of the genus Symbiodinium. Current knowledge on the evolution, biogeography and ecology of Symbiodinium stems from our ability to, with the aid of molecular techniques, distinguish members of this highly diverse group of microorganisms. Thus far, 8 clades (A-H) of Symbiodinium have been identified of which six (A-D, F and G) form stable symbiotic associations with scleractinian corals (reviewed in Rowan 1998; Baker 2003; Coffroth and Santos 2005). Within each clade numerous sub-cladal Symbiodinium types have been identified (LaJeunesse et al. 2003, 2004a). Whilst the ecology of reef corals as well as some of their physiological traits have been correlated to the presence of different clades of Symbiodinium present within the host tissues (for example, clade D is indicated as thermally tolerant and clade $\mathrm{C}$ as thermally sensitive; Rowan and Knowlton 1995; Rowan et al. 1997; Baker 2001; Baker et al. 2004; Ralph et al. 2005; Berkelmans and Van Oppen 2006), increasing evidence indicates that functional 
diversity of Symbiodinium may be better described at the sub-cladal level and distinct types exhibit host specificity, physiological differentiation as well as distinct ecological patterns (Iglesias-Prieto and Trench 1997; Warner and Fitt 1999; Tchernov et al. 2004; Sampayo et al. 2007, 2008, Frade et al. 2008a, 2008b).

Despite evidence that Symbiodinium plays an important role in driving tolerance ranges of the holobiont (host and symbiont) (Rowan and Knowlton 1995; Rowan et al. 1997; Iglesias-Prieto et al. 2004), little is known of the diversity of Symbiodinium in marginal environments where corals exist close to their survival thresholds (i.e., water temperature, light penetration and aragonite saturation; Kleypas et al. 1999). High latitude reefs represent marginal environments due to wide ranges in seasonal temperatures, low annual minimum temperatures and relatively low irradiance levels. In comparison to tropical reefs, high latitude coral communities generally sustain low species diversity, overall coral cover is low and existing corals experience reduced accretion rates (Crossland 1988; Veron 1995).

Living under highly variable or extreme conditions gives rise to unique coral communities that are adept to living under the specific environments governing higher latitude locations. Many common reef-building species do not occur outside the tropics (roughly $25^{\circ} \mathrm{S}$ and $25^{\circ} \mathrm{N}$ ) and high latitude coral communities differ in species composition from their tropical counterparts (Veron and Done 1979; Kleypas et al. 1999; Harriott and Banks 2002) with subtropical species that are rare or absent on tropical reefs becoming more abundant with increasing latitude. For example, along the coast of eastern Australia certain species of the coral genera Porites or Acropora decrease in abundance with increasing latitude and are replaced by species such as Acanthastrea lordhowensis, Hydnophora pilosa, and Favia speciosa which are relatively uncommon, rare or absent in the tropics (Veron 1986; Van Woesik and 
Done 1997). The absence of the dominant components of tropical reefs at high latitudes can result from limited dispersal (Harriott and Banks 2002) or a potential reduction in successful settlement. Although many factors are involved in successful recruitment and subsequent survival, the inherent physiological tolerance range of recruits and their resident symbionts are likely to be a major factor.

Although some data are available on the changes in community structure of reef corals as they extend into higher latitudes, similar information on the symbiont community is sparse. Symbiodinium of clades A, B, C and D have been found at high latitudes and thus distributional patterns appear inconsistent. A shift from clade $\mathrm{C}$ in tropical zones to clade A, B or D was recorded by studies on various invertebrate hosts from Japan, the northeastern Atlantic and Mediterranean Sea (Anthopleura elegantissima in LaJeunesse and Trench 2000; Acropora longicyathus in Loh et al. 2001; Plesiastrea versipora in Rodriguez-Lanetty et al. 2001; Porites porites in Savage et al. 2002). Interestingly, despite clade D Symbiodinium generally being indicated as thermally tolerant it was also found at high latitude reefs that experience low temperatures and limited light (Chen et al. 2003; Lien et al. 2007).

Members of clade C Symbiodinium largely dominate the tropical IndoPacific, and clear patterns of latitudinal zonation have been noted at the sub-cladal level (type) (Reimer et al. 2006; Macdonald et al. 2008). For example, distinct Symbiodinium types of clade C occur in Stylophora pistillata in relation to a latitudinal temperature gradient (Macdonald et al. 2008). Given that distinct Symbiodinium play an important role in driving the physiological tolerance range of their host (LaJeunesse et al. 2003; Iglesias-Prieto et al. 2004; Rowan 2004; Tchernov et al. 2004), understanding if and how symbiont communities associated with high 
latitude reef corals are different from their tropical counterparts will provide clues as to how corals can survive under marginal or changing conditions.

Symbiodinium diversity was examined in the most commonly found corals from two high latitude reefs, Lord Howe Island (LHI, Australia) and the subtropical Kermadec Islands (New Zealand). LHI (31"33'S, 159"05' E, Fig. 1) represents the southernmost coral reef in the world and is situated over $1000 \mathrm{~km}$ from the southern Great Barrier Reef (GBR). Corals are believed to have reached LHI under the influence of the warm East Australian Current (EAC; Wolanski 1994), which maintains annual sea-surface temperatures of between $18{ }^{\circ} \mathrm{C}$ and $26{ }^{\circ} \mathrm{C}$ at LHI (Wicks, pers. obs.). The presence of the EAC provides conditions amenable to coral growth that are quite exceptional for a location of such high latitude. Regardless of its geographical isolation (Veron and Done 1979), latitude and small size (11 km by $2.5 \mathrm{~km}$ ), and also thought to be a result from the connection with the EAC, LHI sustains high coral species diversity ( 83 species covering 33 genera) and coral cover comparable to tropical sites (Harriott et al. 1995).

The KI on the other hand, sustain only 24 scleractinian species that occur mainly in shallow waters less than $30 \mathrm{~m}$ deep (Brook 1999). The KI are $750 \mathrm{~km}$ off the northeast coast of New Zealand's North Island (Fig. 3.1), and approximately $3000 \mathrm{~km}$ from the GBR. Equidistant between temperate New Zealand and tropical Tonga, the KI are one of the few subtropical island groups in the western South Pacific Ocean, and form New Zealand's largest marine reserve (748,000 ha).

The two high latitude locations selected for surveys of Symbiodinium diversity are therefore fundamentally different. While LHI hosts a unique mix of tropical coral species at their southernmost limits as well as temperate coral species which are rare/absent on tropical reefs, the KI forms a non-reef building coral 
community that hosts only temperate coral species. Nonetheless, given the geographical position and extreme conditions of both locations, we hypothesize that, similar to a reduction of coral species diversity with latitude (Kleypas et al. 1999), Symbiodinium diversity will be low and local endemicity will be high in comparison to the tropical GBR.

\subsection{MATERIALS AND METHODS}

\subsubsection{Sampling and oceanographic parameters}

In January 2007, fragments of 12 coral species were collected by SCUBA at six sites (Fig 3.1) around LHI (1 - 3 samples per species and location, Table 1). Collection sites were situated in the shallow lagoon $(1-3 \mathrm{~m})$ and on the fore reef $(5 \mathrm{~m}$ and 15 m) on the eastern exposed side and the sheltered western side. At each of the locations it was ensured that collections were made of the three most common coral species, Acropora cuneata, Goniastrea favulus and Pocillopora damicornis in order to directly compare effects of the external habitat. Sampling at the KI was conducted at Raoul Island ( $29^{\circ} 14.75 \mathrm{~S}, 177^{\circ} 52.87 \mathrm{~W}$, Table 3.1, n=1 - 4) in November 2004. Of the 24 present species at this location, three of the most common hard corals and two soft corals were collected at $5-10 \mathrm{~m}$ (Table 3.1). All samples were collected more than 5 meters apart to avoid sampling of clone mates. Coral fragments were always removed from the top of colonies using a hammer and chisel, fixed in absolute ethanol and stored at $-20^{\circ} \mathrm{C}$ until further processing. Seawater temperature, turbidity and salinity were recorded at each of the sites and at each depth using a CTD Unit (Richard Brancker Research Ltd XR 420). Collections were conducted on cloudless days of similar environmental conditions 


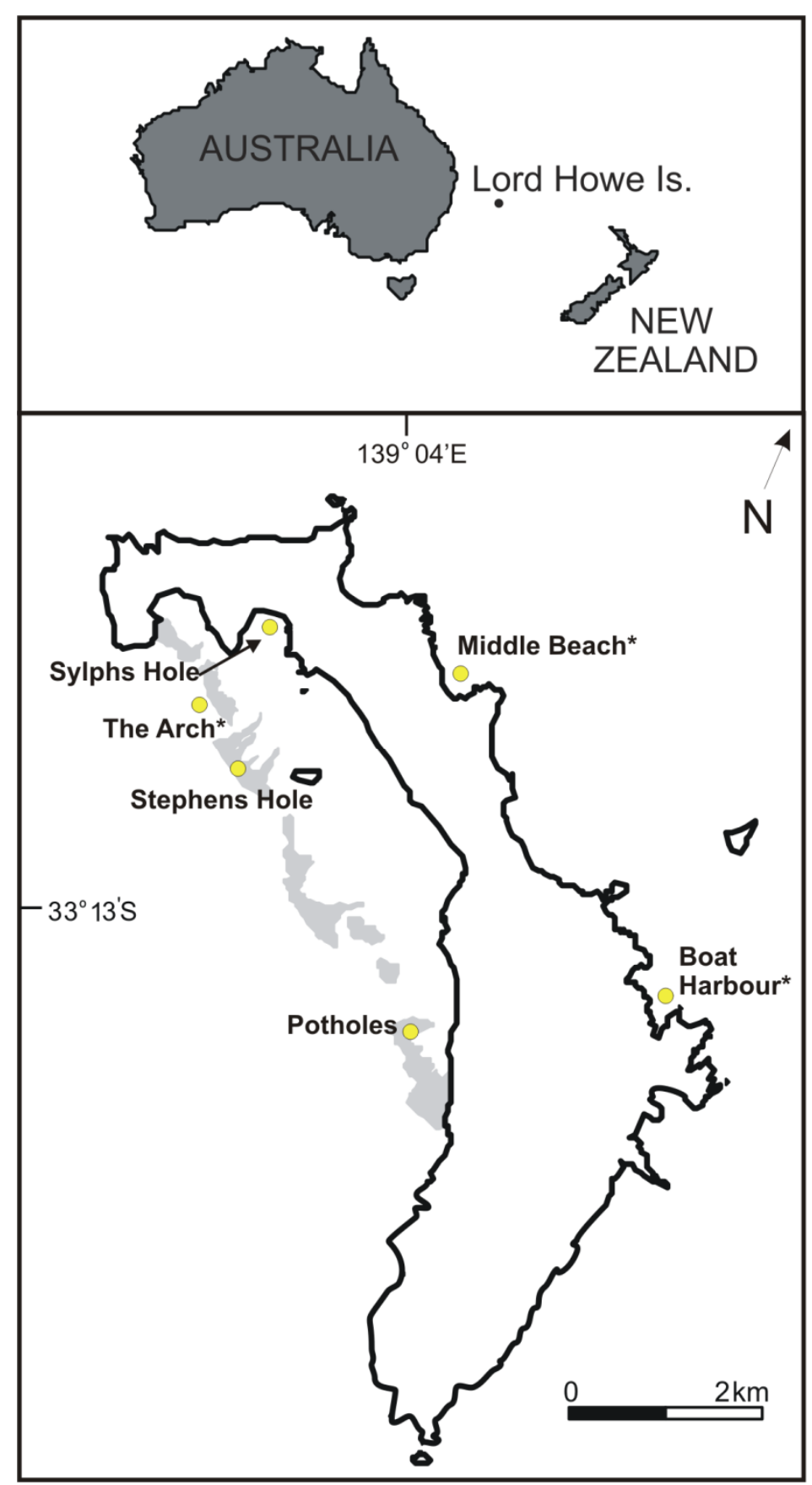

Figure 3.1 Location of (a) Lord Howe Island and the Kermadec Islands and (b) sampling sites around Lord Howe Island. Study sites are annotated by , asterisk marking sites sampled at 2 depths ( $5 \mathrm{~m}$ and $15 \mathrm{~m}$ ). For species sampled at each site see Table 3.1 . 


\subsubsection{DNA extraction and Symbiodinium identification}

Symbiodinium cells were isolated prior to DNA analyses by removing the coral tissue from the skeleton using an airgun connected to a scuba cylinder. The tissue was homogenized using a tissue grinder in extraction buffer (1.2 M filtered seawater and $5 \mathrm{mM}$ EDTA), the slurry was centrifuged at $1000 \mathrm{~g}$, the buffer discarded and the remaining pellet was re-homogenised in $0.01 \%$ Triton $\mathrm{X}-100$ extraction buffer, followed by a second centrifugation (1000 g) and homogenization step. DNA of the algal pellet was extracted using the DNeasy Plant Mini Kit following manufacturer's instructions (Qiagen).

Symbiodinium types were characterised using both the internal transcribed spacer 2 region (ITS2) and internal transcribed spacer 1 region (ITS1) of nuclear ribosomal DNA (cf. LaJeunesse 2001, 2002, LaJeunesse et al. 2008). The ITS2 region was PCR amplified using primers "ITS 2 clamp" ( $\underline{\text { CGCCCGCCGC }}$ GCCCCGCGCC CGTCCCGCCG CCCCCGCCC GGGATCCATA TGCTTAAGTT CAGCGGT-) and "ITSintfor 2", (GAATTGCAGA ACTCCGTG) (LaJeunesse and Trench 2000) under "touchdown" thermal cycle conditions specified in LaJeunesse (2002). The ITS1 region was amplified using primers "ITS1clamp" (CGCCCGCCGCGCCCCGCGCCCGTCCCGCCGCCCCCGCCCGGGATCCGTT

TCCGTAGGTGAACCTGC) and 'ITS1intrev2' (TTCACGGAGTTCTGCAAT) (LaJeunesse et al. 2008). ITS2 amplified PCR products were subsequently run on a Biorad DCode Denaturing Gradient Gel Electrophoresis (DGGE) system, using a $30 \%$ to $65 \%$ gel during a $100 \mathrm{~V}$ run for $14 \mathrm{~h}$. PCR amplifications of the ITS 1 region were run on a CBS Scientific DGGE system using an internal gradient of $50 \%$ to $90 \%$ denaturants and run at $115 \mathrm{~V}$ for $15 \mathrm{~h}$. All DGGE gels were stained using $1 \mathrm{X}$ SYBR Green for $30 \mathrm{~min}$ and visualized on a UV transilluminator. 
To identify distinct Symbiodinium type, prominent bands were excised from up to three representative samples of each characteristic ITS-DGGE fingerprint. Excised bands were eluted in $500 \mu \mathrm{dddH} 20$, kept at $4^{\circ} \mathrm{C}$ for $24 \mathrm{~h}$ and reamplified using GC-clamped primers (under conditions as above). Amplicons were re-run on the DGGE system to check band position and potential contamination with other bands during excision prior to sequencing. Clean bands running at the expected position in relation to the original sample were re-excised, eluted and reamplified with the non-GC clamped primer set (cf. LaJeunesse 2002; LaJeunesse et al. 2008). Amplifications were purified by ethanol precipitation and sequenced in both directions at the Australian Genome Research Facility (ABI BigDye Terminator v3.1; AB3730x1 sequencer). Chromatograms were checked using Seqman software (Lasergene) and aligned using Clustal-X (Thompson et al. 1997). The resulting consensus from each dominant or co-dominant band was identified by a BLAST search of previously recorded Symbiodinium types on GenBank (http://www.ncbi.nih.gov). Phylogenetic analyses of dominant rDNA ITS1 and ITS2 repeat sequences were performed in PAUP (version 4.0b10, Swofford 2000) under the maximum parsimony criterion treating gaps as a fifth character state and indels as a single evolutionary event with bootstrap values calculated based on 1,000 replicates.

\subsubsection{Data analysis}

Differences in measured environmental parameters (light, temperature, salinity and turbidity) among sites, depths and sampling location (lagoon, sheltered and exposed) were assessed using non-parametric Kruskal-Wallis and Dunn's posthoc tests (SPSS v16) because assumptions of normality and homogeneity of variances were not met. 
To test the effects of environmental parameters on Symbiodinium distributions across sites in the three coral species sampled at all sites (A. cuneata, G. favulus and $P$. damicornis) multivariate analyses were conducted in PRIMER v6 with PERMANOVA add-on (PRIMER-E, Plymouth, Clarke \& Gorley 2006), treating each coral colony as a replicate. The host was a significant factor in driving symbiont distributions (presence/absence data and Bray-Curtis similarity; ANOSIM, $p<0.01$ ) and, with little overlap of symbionts among hosts, all subsequent analyses were conducted separately for each of the three host species.

BIOENV was used as an exploratory tool to correlate the similarity matrix derived for the symbiont distributions with an equivalent for the suite of environmental measurements taken at each site. Results are expressed as a Spearman's correlation coefficient (r), and indicate the proportion of variance in the community data explained by these environmental variables (see Clarke \& Ainsworth 1993 for full details). Means of environmental parameters for each site (temperature, salinity, depth and turbidity) were $(\log +1)$ transformed, and normalized, and similarities calculated based on Euclidean distance. A distancebased redundancy analysis (dbRDA), which uses multiple regressions on any distance or similarity matrix, was performed to identify the proportion of total variation in the matrix (symbiont abundance) explained by predictor variables (environmental factors) (Legendre \& Anderson 1999, McArdle \& Anderson 2001).

Finally, community diversity of Symbiodinium at LHI and the KI was compared to published diversity surveys of the southern and central GBR (LaJeunesse et al. 2003, 2004a respectively). Due to differences in sampling intensity across studies, diversity estimates were generated as a normalization of species or 
genera of host sampled (number of symbionts divided by the number of hosts sampled).

\subsection{RESULTS}

\subsubsection{Symbiont community diversity and phylogenetic analysis}

In total 12 and 5 coral species were sampled at Lord Howe Island (LHI) and the Kermadec Islands (KI) respectively (Table 3.1), with 80 samples collected in total. Across these different hosts at both locations, 18 Symbiodinium types were identified, of which only one was a member of Symbiodinium clade B (type B1) and occurred in the soft coral Capnella. The remaining 17 were members of clade $\mathrm{C}$ (Table 3.1, Fig. 3.2). In total 15 and 5 different Symbiodinium types were identified at LHI and the KI respectively, of which Symbiodinium types C1, C3, C1c, C22a, and B1 were previously been recorded on the tropical GBR (Table 3.1). Thus, the majority of identified Symbiodinium identified at these high latitude locations represented novel types, and were assigned a name following current ITS2 nomenclature for Symbiodinium (cf. LaJeunesse et al. 2003, 2004a) as types C1z, C1bb, C3w, C3gg, C3n-hh, C41, C100, C102, C104, C108, C111, C117, and C118. Symbiodinium community diversity at LHI was relatively high with 1.56 type/genera compared to 0.58 (23 types in 40 genera) and 0.43 type/genera (32 types in 74 genera) on the southern and central GBR respectively.

Phylogenetic analyses of both the ITS1 and ITS2 regions of the ribosomal DNA indicated that the ITS1 region is more conserved. For example, the ITS1 region amplified for DGGE showed no difference between Symbiodinium types C1 and C3. 
Table 3.1 Sample list of host specimens and identified Symbiodinium type(s) from sites (and depths) around Lord Howe Island (LHI), Australia, and the Kermadec Islands (KI, NZ). Types hosted by same coral spp. or family on southern GBR (S GBR, LaJeunesse et al. 2003, Sampayo et al. 2007) and the central GBR (C GBR, LaJeunesse et al. 2004) noted († refers to type in closest coral spp.) Soft corals from Goulet et al. (2008). v: vertical transmission; h: horizontal transmission (Richmond + Hunter 1990).

\begin{tabular}{|c|c|c|c|c|c|c|c|}
\hline Family/Species & Site & $\begin{array}{c}\text { Depth } \\
\text { (m) }\end{array}$ & $\mathbf{n}$ & ITS1 & ITS2 & S GBR & N GBR \\
\hline \multicolumn{8}{|l|}{ Acroporidae } \\
\hline \multirow[t]{12}{*}{ Acropora cuneata (v) } & Stephens Hole (LHI) & $2-3 \mathrm{~m}$ & 3 & $\mathrm{C} 1 / \mathrm{C} 3$ & $\mathrm{C} 3$ & \multirow{12}{*}{$\mathrm{C} 3^{\dagger}$} & \multirow{12}{*}{$\begin{array}{c}\mathrm{C} 3 \mathrm{k}^{\dagger}, \mathrm{C} 1^{\dagger} \\
\mathrm{D} 2^{\dagger} \\
\mathrm{C} 3^{\dagger}, \mathrm{C} 3 \mathrm{i}^{\dagger}\end{array}$} \\
\hline & Potholes (LHI) & $2-3 \mathrm{~m}$ & 3 & $\mathrm{C} 1 / \mathrm{C} 3$ & $\mathrm{C} 3$ & & \\
\hline & The Arch (LHI) & $5 \mathrm{~m}$ & 3 & $\mathrm{C} 1 / \mathrm{C} 3$ & $\mathrm{C} 3$ & & \\
\hline & \multirow[t]{2}{*}{ Boat Harbour (LHI) } & $5 \mathrm{~m}$ & 2 & $\mathrm{C} 1 / \mathrm{C} 3$ & $\mathrm{C} 3$ & & \\
\hline & & $15 \mathrm{~m}$ & 3 & $\mathrm{C} 1 / \mathrm{C} 3$ & $\mathrm{C} 3$ & & \\
\hline & \multirow[t]{2}{*}{ Middle Beach (LHI) } & $5 \mathrm{~m}$ & 2 & $\mathrm{C} 1 / \mathrm{C} 3$ & $\mathrm{C} 3$ & & \\
\hline & & $15 \mathrm{~m}$ & 3 & $\mathrm{C} 1 / \mathrm{C} 3$ & $\mathrm{C} 3$ & & \\
\hline & Boat Harbour (LHI) & $5 \mathrm{~m}$ & 1 & $\mathrm{C} 100$ & $\mathrm{C} 100$ & & \\
\hline & Middle Beach (LHI) & $5 \mathrm{~m}$ & 1 & $\mathrm{C} 100$ & $\mathrm{C} 100$ & & \\
\hline & The Arch (LHI) & $15 \mathrm{~m}$ & 3 & $\mathrm{C} 102$ & $\mathrm{C} 102$ & & \\
\hline & Sylphs Hole (LHI) & $2-3 \mathrm{~m}$ & 2 & $\mathrm{C} 1 \mathrm{c}$ & $\mathrm{C} 1 \mathrm{c}$ & & \\
\hline & Sylphs Hole (LHI) & $2-3 \mathrm{~m}$ & 1 & $\mathrm{C} 1 / \mathrm{C} 3$ & $\mathrm{C} 3 \mathrm{w}$ & & \\
\hline A. abrotenoides (h) & Potholes (LHI) & $2-3 \mathrm{~m}$ & 3 & $\mathrm{C} 1 / \mathrm{C} 3$ & $\mathrm{C} 3$ & $\mathrm{C} 3^{\dagger}$ & As above \\
\hline \multirow[t]{2}{*}{ A. glauca $(\mathrm{h})$} & Stephens Hole (LHI) & $2-3 \mathrm{~m}$ & 2 & $\mathrm{C} 1 / \mathrm{C} 3$ & $\mathrm{C} 3$ & \multirow[t]{2}{*}{$\mathrm{C} 3^{\dagger}$} & \multirow[t]{2}{*}{ As above } \\
\hline & & & 1 & $\mathrm{C} 1 / \mathrm{C} 3$ & $\mathrm{C} 3$ & & \\
\hline A. latistella $(\mathrm{h})$ & Stephens Hole (LHI) & $2-3 \mathrm{~m}$ & 3 & $\mathrm{C} 1 / \mathrm{C} 3$ & $\mathrm{C} 3$ & $\mathrm{C} 3$ & As above \\
\hline \multicolumn{8}{|l|}{ Dendrophyllidae } \\
\hline \multirow[t]{2}{*}{ Turbinaria frondens } & \multirow[t]{2}{*}{$\mathrm{KI}$} & $5 \mathrm{~m}$ & 4 & $\mathrm{C} 1 / \mathrm{C} 3$ & $\mathrm{C} 1$ & \multirow[t]{2}{*}{$\mathrm{C} 22 \mathrm{a}^{\dagger}$} & \multirow{2}{*}{$\begin{array}{c}\mathrm{C} 40, \mathrm{C} 3 \mathrm{~h} \\
\mathrm{C} 1^{\dagger}\end{array}$} \\
\hline & & $15 \mathrm{~m}$ & 1 & $\mathrm{C} 22 \mathrm{a}$ & $\mathrm{C} 22 \mathrm{a}$ & & \\
\hline \multicolumn{8}{|l|}{ Faviidae } \\
\hline \multirow[t]{13}{*}{ Goniastrea favulus (h) } & Potholes (LHI) & $2-3 \mathrm{~m}$ & 3 & $\mathrm{C} 1 / \mathrm{C} 3$ & $\mathrm{C} 3 \mathrm{w}$ & \multirow{13}{*}{$\begin{array}{c}\mathrm{D} 1 \mathrm{a}, \mathrm{C} 3^{\dagger} \\
\mathrm{C} 1^{\dagger}\end{array}$} & \multirow{13}{*}{$\begin{array}{c}\mathrm{C} 1^{\dagger}, \mathrm{C} 3^{\dagger} \\
\mathrm{C} 3 \mathrm{~h}^{\dagger}\end{array}$} \\
\hline & The Arch (LHI) & $15 \mathrm{~m}$ & 2 & $\mathrm{C} 1 / \mathrm{C} 3$ & $\mathrm{C} 3 \mathrm{w}$ & & \\
\hline & Boat Harbour (LHI) & $15 \mathrm{~m}$ & 2 & $\mathrm{C} 1 / \mathrm{C} 3$ & $\mathrm{C} 3 \mathrm{w}$ & & \\
\hline & \multirow[t]{2}{*}{ Middle Beach (LHI) } & $5 \mathrm{~m}$ & 2 & $\mathrm{C} 1 / \mathrm{C} 3$ & $\mathrm{C} 3 \mathrm{w}$ & & \\
\hline & & $15 \mathrm{~m}$ & 2 & $\mathrm{C} 1 / \mathrm{C} 3$ & $\mathrm{C} 3 \mathrm{w}$ & & \\
\hline & Stephens Hole (LHI) & $2-3 \mathrm{~m}$ & 2 & $\mathrm{C} 1 \mathrm{c}$ & $\mathrm{C} 1 \mathrm{c}$ & & \\
\hline & \multirow[t]{2}{*}{ The Arch (LHI) } & $5 \mathrm{~m}$ & 1 & $\mathrm{C} 1 \mathrm{c}$ & $\mathrm{Clc}$ & & \\
\hline & & $15 \mathrm{~m}$ & 1 & $\mathrm{C} 1 \mathrm{c}$ & $\mathrm{Clc}$ & & \\
\hline & Boat Harbour (LHI) & $15 \mathrm{~m}$ & 1 & $\mathrm{C} 1 \mathrm{c}$ & $\mathrm{Clc}$ & & \\
\hline & Middle Beach (LHI) & $15 \mathrm{~m}$ & 1 & $\mathrm{C} 1 \mathrm{c}$ & $\mathrm{C} 1 \mathrm{c}$ & & \\
\hline & Stephens Hole (LHI) & $2-3 \mathrm{~m}$ & 1 & $\mathrm{C} 1 / \mathrm{C} 3$ & C108 & & \\
\hline & Middle Beach (LHI) & $5 \mathrm{~m}$ & 1 & $\mathrm{C} 1 / \mathrm{C} 3$ & $\mathrm{C} 108$ & & \\
\hline & The Arch (LHI & $5 \mathrm{~m}$ & 2 & $\mathrm{C} 1 / \mathrm{C} 3$ & C108 & & \\
\hline Favites abdita $(\mathrm{h})$ & The Arch (LHI) & $5 \mathrm{~m}$ & 3 & $\mathrm{C} 1 / \mathrm{C} 3$ & $\mathrm{C} 1$ & \multirow{3}{*}{$\begin{array}{c}\mathrm{C} 3, \mathrm{C} 21^{\dagger} \\
\mathrm{C} 3\end{array}$} & \multirow{3}{*}{$\begin{array}{l}\text { C3, C3h } \\
\text { C3, D1a }\end{array}$} \\
\hline \multirow[t]{2}{*}{ Montastrea curta (h) } & Boat Harbour (LHI) & $5 \mathrm{~m}$ & 3 & $\mathrm{C} 1 / \mathrm{C} 3$ & $\mathrm{C} 1$ & & \\
\hline & KI & $5 \mathrm{~m}$ & 3 & $\mathrm{C} 1 / \mathrm{C} 3$ & $\mathrm{C} 1$ & & \\
\hline Cyphastrea serailia $(\mathrm{h})$ & Boat Harbour (LHI) & $5 \mathrm{~m}$ & 1 & $\mathrm{C} 102$ & $\mathrm{C} 102$ & $\mathrm{C} 1, \mathrm{C} 1 \mathrm{i}$ & $\mathrm{C} 1, \mathrm{C} 3$ \\
\hline & & & 2 & n.a. & C104 & & \\
\hline Merulinidae & & & & & & & \\
\hline Hydnophora pilosa & KI & $5 \mathrm{~m}$ & 2 & $\mathrm{C} 1 / \mathrm{C} 3$ & $\mathrm{C} 3 \mathrm{w}$ & $\mathrm{C} 3^{\dagger}, \mathrm{D} 1 \mathrm{a}^{\dagger}$ & $\mathrm{C} 3^{\dagger}, \mathrm{C} 3 \mathrm{~h}^{\dagger}$ \\
\hline & & $10 \mathrm{~m}$ & 1 & $\mathrm{C} 1 / \mathrm{C} 3$ & $\mathrm{C} 3 \mathrm{w}$ & & \\
\hline & & $10 \mathrm{~m}$ & 3 & $\mathrm{C} 1 / \mathrm{C} 3$ & $\mathrm{C} 1 \mathrm{z}$ & & \\
\hline
\end{tabular}




\begin{tabular}{|c|c|c|c|c|c|c|c|}
\hline \multicolumn{8}{|l|}{ Pocilloporidae } \\
\hline \multirow{13}{*}{$\begin{array}{l}\text { Pocillopora damicornis } \\
(\mathrm{v} / \mathrm{h})\end{array}$} & Sylphs Hole (LHI) & $2-3 \mathrm{~m}$ & 3 & n.a. & $\mathrm{C} 41$ & \multirow{13}{*}{$\begin{array}{c}\mathrm{C} 1 \mathrm{c}, \mathrm{C} 42, \\
\mathrm{C} 42 \mathrm{a}, \\
\mathrm{C} 42 \mathrm{~b}, \\
\mathrm{C} 33, \mathrm{C} 33 \mathrm{a}\end{array}$} & \multirow[t]{13}{*}{$\mathrm{C} 1 \mathrm{j}, \mathrm{C} 1 \mathrm{c}^{\dagger}$} \\
\hline & The Arch (LHI) & $15 \mathrm{~m}$ & 1 & n.a. & $\mathrm{C} 41$ & & \\
\hline & Boat Harbour (LHI) & $15 \mathrm{~m}$ & 2 & n.a. & $\mathrm{C} 41$ & & \\
\hline & Middle Beach (LHI) & $15 \mathrm{~m}$ & 1 & n.a. & $\mathrm{C} 41$ & & \\
\hline & Stephens Hole (LHI) & $2-3 \mathrm{~m}$ & 3 & $\mathrm{C} 100$ & $\mathrm{C} 100$ & & \\
\hline & Potholes (LHI) & $2-3 \mathrm{~m}$ & 2 & $\mathrm{C} 100$ & $\mathrm{C} 100$ & & \\
\hline & \multirow{2}{*}{ The Arch (LHI) } & $5 \mathrm{~m}$ & 2 & C100 & $\mathrm{C} 100$ & & \\
\hline & & $15 \mathrm{~m}$ & 2 & $\mathrm{C} 100$ & $\mathrm{C} 100$ & & \\
\hline & \multirow{2}{*}{ Boat Harbour(LHI) } & $5 \mathrm{~m}$ & 3 & $\mathrm{C} 100$ & $\mathrm{C} 100$ & & \\
\hline & & $15 \mathrm{~m}$ & 1 & $\mathrm{C} 100$ & $\mathrm{C} 100$ & & \\
\hline & \multirow[t]{2}{*}{ Middle Beach (LHI) } & $5 \mathrm{~m}$ & 3 & $\mathrm{C} 100$ & $\mathrm{C} 100$ & & \\
\hline & & $15 \mathrm{~m}$ & 2 & $\mathrm{C} 100$ & $\mathrm{C} 100$ & & \\
\hline & Potholes (LHI) & $2-3 \mathrm{~m}$ & 1 & n.a. & $\mathrm{C} 118$ & & \\
\hline \multirow{2}{*}{ Stylophora pistillata (v) } & \multirow{2}{*}{ Boat Harbour (LHI) } & \multirow{2}{*}{$15 \mathrm{~m}$} & \multirow[t]{2}{*}{3} & $\mathrm{C} 1 / \mathrm{C} 3$ & $\mathrm{C} 1$ & \multirow{3}{*}{$\begin{array}{c}\mathrm{C} 1, \mathrm{C} 78, \\
\mathrm{C} 8 \mathrm{a}, \\
\mathrm{C} 35 \mathrm{a}, \mathrm{C} 79 \\
\mathrm{C} 3, \mathrm{C} 3 \mathrm{nt}\end{array}$} & \multirow{2}{*}{$\mathrm{C} 8$} \\
\hline & & & & $\mathrm{C} 1 / \mathrm{C} 3$ & C3gg & & \\
\hline Seriatopora hystrix (v) & Boat Harbour (LHI) & $15 \mathrm{~m}$ & 3 & $\mathrm{C} 1 / \mathrm{C} 3$ & C3n-hh & & $\mathrm{C} 3$ \\
\hline \multicolumn{8}{|l|}{ Poritidae } \\
\hline \multirow{3}{*}{$\begin{array}{l}\text { Porites cf. heronensis } \\
(v / h)\end{array}$} & Boat Harbour (LHI) & $5 \mathrm{~m}$ & 2 & $\mathrm{C} 117$ & $\mathrm{C} 117$ & \multirow{3}{*}{$\begin{array}{l}\mathrm{C} 15^{\dagger} \\
\mathrm{C} 28^{\dagger}\end{array}$} & \multirow[t]{3}{*}{$\mathrm{C} 15^{\dagger}, \mathrm{C} 60^{\dagger}$} \\
\hline & & & 1 & $\mathrm{C} 111$ & $\mathrm{C} 111$ & & \\
\hline & Sylphs Hole (LHI) & $2-3 \mathrm{~m}$ & 3 & $\mathrm{C} 1 / \mathrm{C} 3$ & $\mathrm{C} 3$ & & \\
\hline \multicolumn{8}{|l|}{ Alcyoniidae } \\
\hline \multirow[t]{2}{*}{ Sinularia sp. } & \multirow[t]{2}{*}{$\mathrm{KI}$} & $5 \mathrm{~m}$ & 3 & $\mathrm{C} 1 / \mathrm{C} 3$ & $\mathrm{C} 1 \mathrm{z}$ & \multirow[t]{3}{*}{$\mathrm{C} 3 \mathrm{j}$} & \multirow{3}{*}{$\begin{array}{c}\mathrm{C} 65, \mathrm{C} 1 \mathrm{c} \\
\mathrm{C} 1 \\
\mathrm{C}, \mathrm{A}\end{array}$} \\
\hline & & $10 \mathrm{~m}$ & 3 & $\mathrm{C} 1 / \mathrm{C} 3$ & $\mathrm{C} 1 \mathrm{z}$ & & \\
\hline Capnella sp. & $\mathrm{KI}$ & $5 \mathrm{~m}$ & 1 & B1 & B1 & & \\
\hline
\end{tabular}

Some ITS2 types characterized by the presence of co-dominant repeats of the ribosomal array occurring in conjunction with the $\mathrm{C} 1$ or $\mathrm{C} 3$ sequence, such as ITS2 type C1z, C3gg, C3n-hh are 'collapsed' to the C1-C3 core for the ITS1 region (compare Fig 3.3a, b). Nonetheless, highly divergent sequences representing the dominant sequence within each symbiont type were consistent between the two DNA regions (Fig. 3.3a, b; for example $\mathrm{C} 41, \mathrm{C} 102, \mathrm{C} 111, \mathrm{C} 117, \mathrm{C} 118$ ) and overall tree topology was similar.

Finally, symbiont types identified in the present study were compared to those found on the tropical GBR. Phylogenetic analyses (not shown) indicated that symbionts from high latitudes did not share a common ancestry with symbionts found in corals that usually associating with highly specific lineages across the IndoPacific, such as Porites with the C15/ C17 lineages (LaJeunesse 2005). Examples of such symbionts are those in association with Porites cf. heronensis (C111, C117), 
a) ITS2

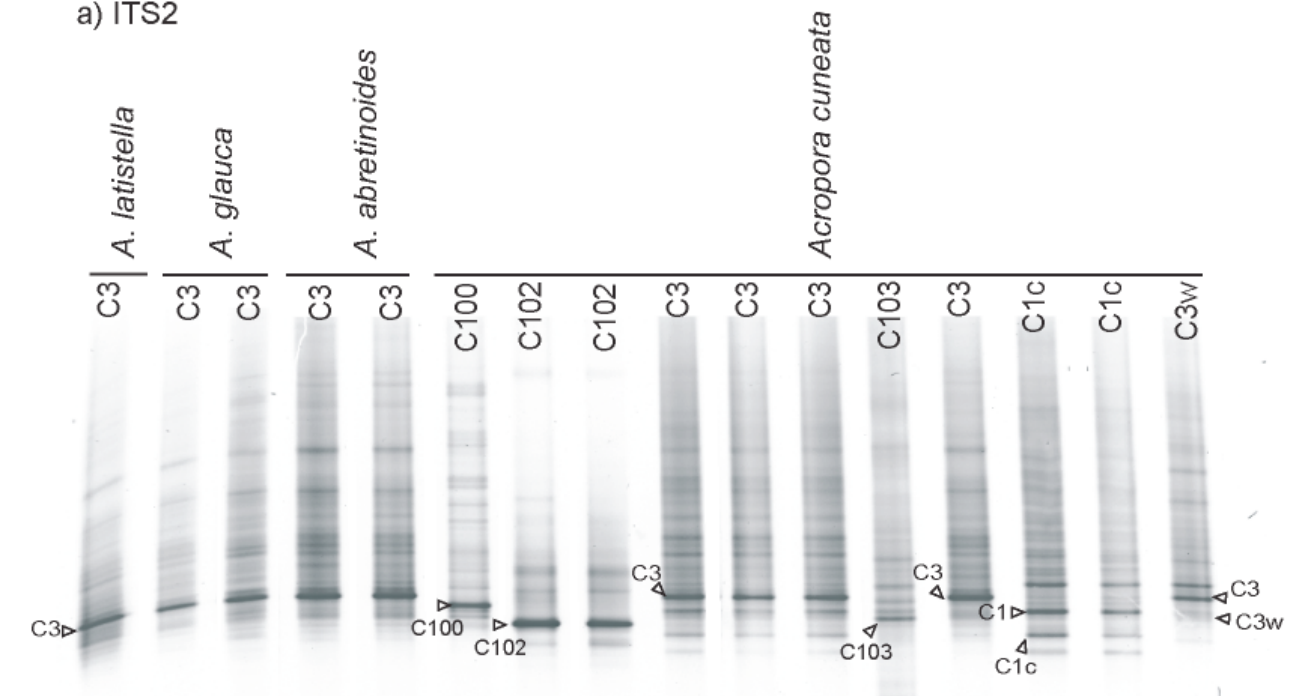

b) ITS2

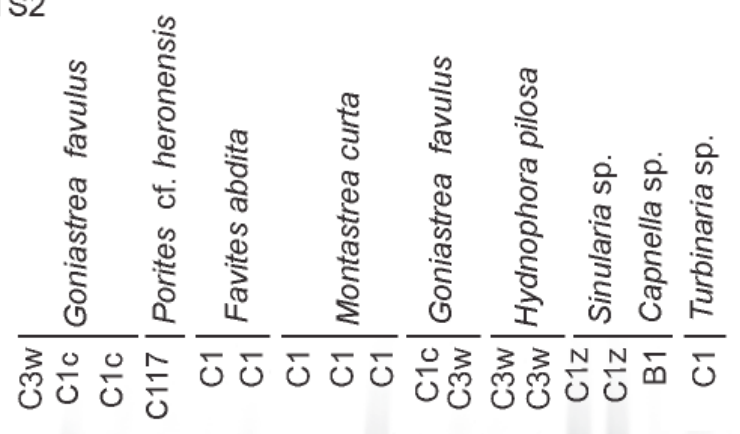

B1 $\triangleleft$

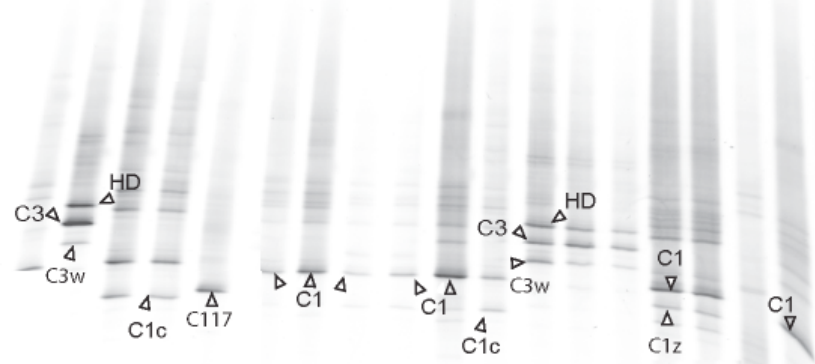

c) ITS1

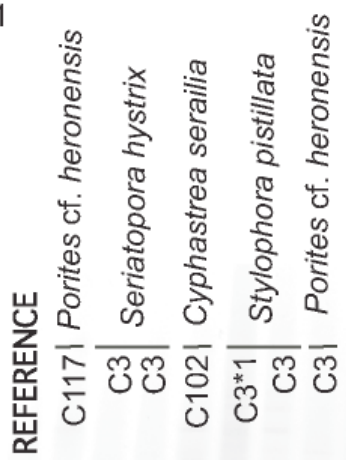

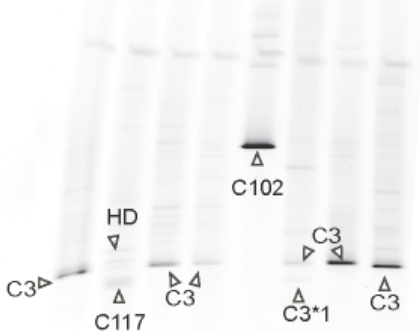

Figure 3.2 PCR-DGGE fingerprints of ITS2 (a, b) and ITS1 (c) Symbiodinium types identified in various coral species at Lord Howe Island (Australia) and the Kermadec Islands (New Zealand). Dominant and co-dominant bands in the ITS2-DGGE profile were excised (marked with arrows) to identify the resident Symbiodinium type (marked above each lane). For example, Symbiodinium type C1c represents a profile containing both the $\mathrm{C} 1$ and C1c sequence. HD: Heteroduplex. 
(a) ITS1

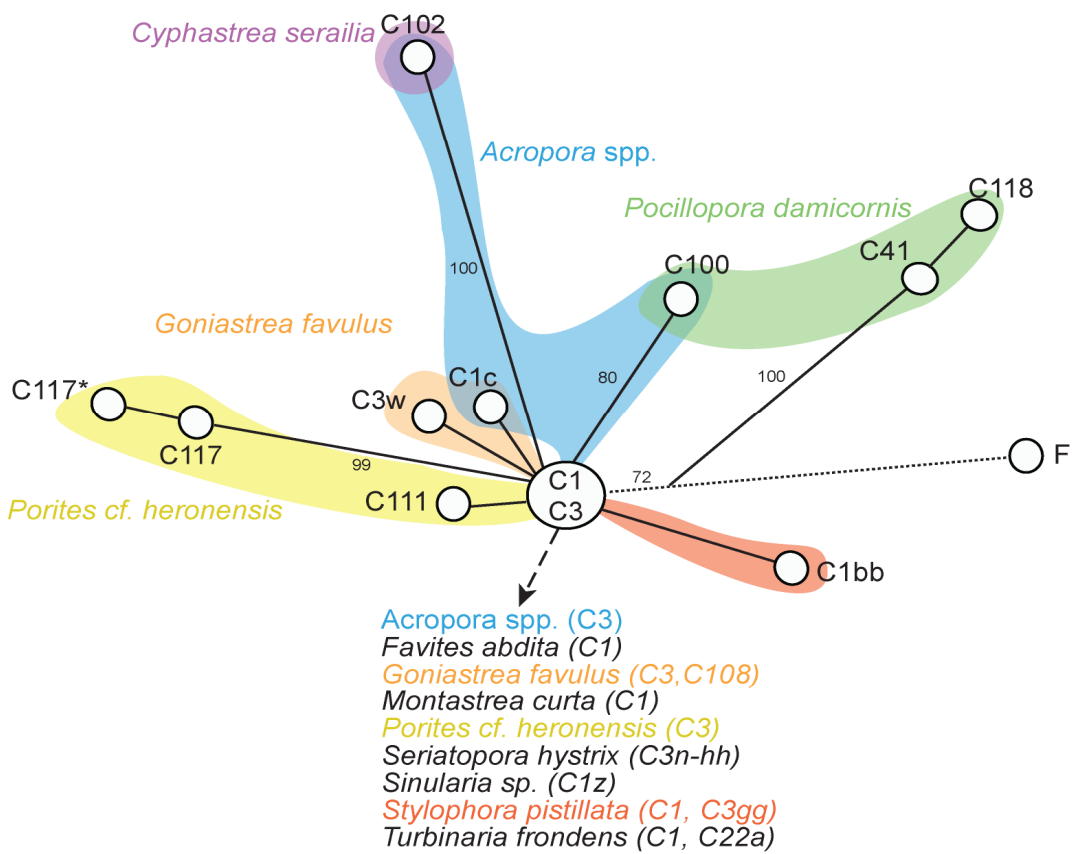

(b) ITS2

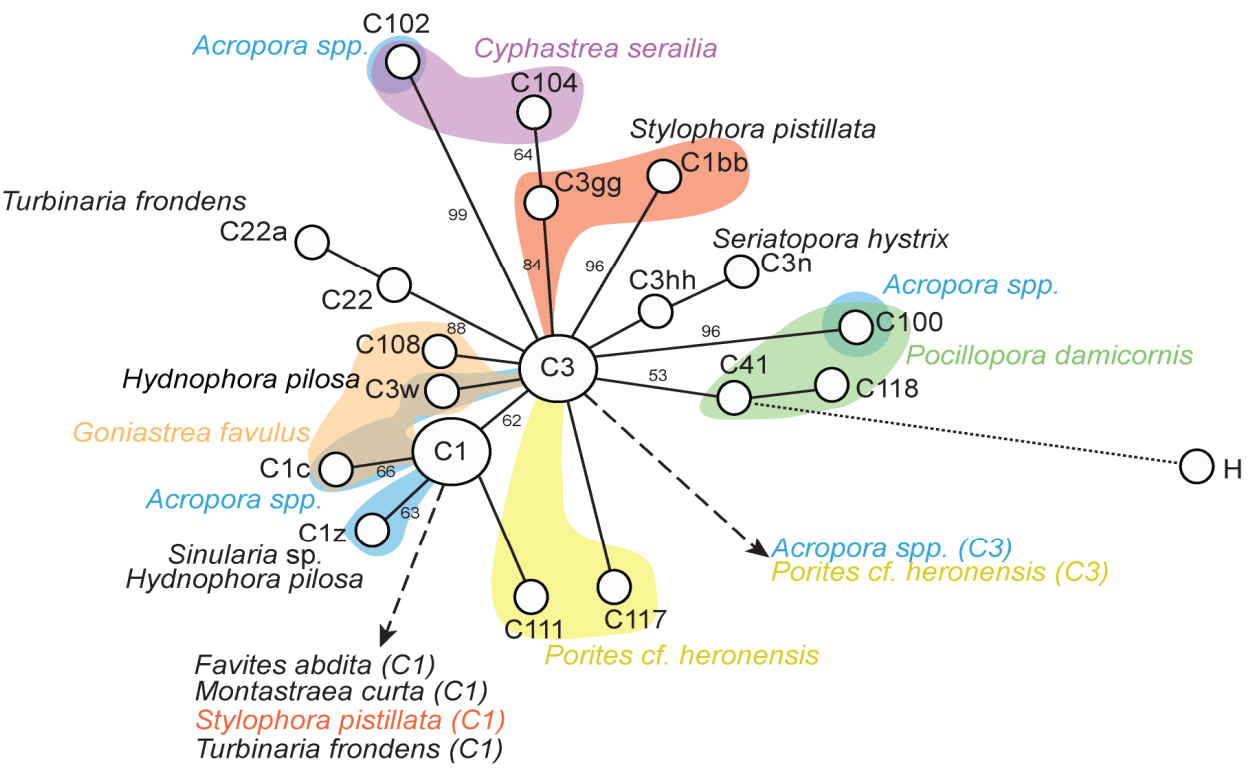

$1 \mathrm{bp}$

Figure 3.3 Most parsimonious un-rooted tree of the ITS rDNA of Symbiodinium isolated from various coral hosts repeats identified by (a) ITS1-DGGE and (b) ITS2-DGGE by direct sequencing of excised bands. Ancestral Symbiodinium types $\mathrm{C} 1$ and $\mathrm{C} 3$ are represented by larger circles compared to others but circle size is not representative of abundance. Branch length corresponds to the number of base changes between each sequence variant (number of changes shown next to each branch). Shaded areas of a single colour indicate that multiple symbionts were present; and colours indicate different hosts: Acropora cuneata (blue), Cyphastrea serailia (purple), Goniastrea favulus (orange). Pocillopora damicornis (green), Porites $\mathrm{cf}$. heronensis (yellow). 
Pocillopora damicornis (C41, C100, C118) and Stylophora pistillata (C1, C1bb, C3gg), all of which appear to have diverged from the $\mathrm{C} 1$ or $\mathrm{C} 3$ lineage as opposed to host specific radiations (LaJeunesse 2005). An exception is type C3n-hh found in Seriatopora hystrix, which is closely related to C3n-t commonly found on the southern GBR (Sampayo et al. 2007).

Host identity had a major influence on Symbiodinium distributions (ANOSIM, R = 0.404, $p<0.001$ ) and generalist as well as host specialist symbionts were found (Table 3.1). The pandemic host generalist Symbiodinium type C3 associated with 6 species at LHI: A. cuneata, Acropora abrotenoides, Acropora glauca, Acropora latistella, G. favulus, and P. cf. heronensis. Type $\mathrm{C} 1$, also a generalist, was found in Montastraea curta, Favites abdita and Stylophora pistillata at LHI and Turbinaria frondens. A number of Symbiodinium types other than the pandemic host generalists $\mathrm{C} 1$ and $\mathrm{C} 3$, also associated with multiple hosts (Table 3.1). For example, C1c was found in A. cuneata and G. favulus, $\mathrm{C} 1 \mathrm{z}$ in H. pilosa and Sinularia sp., $\mathrm{C} 3 \mathrm{w}$ in A. cuneata, G. favulus and H. pilosa, and type C102 in A. cuneata and C. serailia. Although it appeared that symbionts were mainly shared by host species that have a horizontal mode of symbiont transmission it is interesting to note that vertical transmitters (but see discussion) A. cuneata and $P$. damicornis shared type $\mathrm{C} 100(\mathrm{n}=2$ and $\mathrm{n}=8$ respectively; Table 3.1). Although symbionts appeared to be shared between hosts, such symbionts (except for $\mathrm{C} 1$ and $\mathrm{C} 3$ ) were usually dominant in one host and rare in the other. For example, $\mathrm{C} 3 \mathrm{w}$ was present in only $4 \%$ of $A$. cuneata samples but was found in $52 \%$ of $G$. favulus samples. Of the total 18 Symbiodinium types, ten were exclusively found in a single host and were type B1 in Capnella sp., C22a in T. frondens, C41 and C118 in P. damicornis, C104 in C. serailia, 
C108 in G. favulus, types $\mathrm{C} 111$ and $\mathrm{C} 117$ in P. cf. heronensis, C3n-hh in S. hystrix and $\mathrm{C} 3 \mathrm{gg}$ as well as $\mathrm{C} 1 \mathrm{bb}$ in S. pistillata

\subsubsection{Environmental variability and symbiont diversity}

At LHI, while turbidity was significantly higher at Sylphs Hole $(2.4 \pm 0.01$ FTU, mean \pm $\mathrm{SD} ; \mathrm{H}=1464, \mathrm{DF}=2, p<0.01)$, turbidity $(1.3-1.7 \pm 0.01 \mathrm{FTU}$, mean $\pm \mathrm{SD})$ was not significantly different between any of the other sites (Fig. 3.3b). Salinity (Fig 3a) was homogenous within the lagoon $(31.1 \pm 0.02$, mean \pm SD), excluding Sylphs Hole $(31.0 \pm$ 0.04 , mean $\pm \mathrm{SD})$, and was significantly lower than the shallow and fore reef sites $(31.2 \pm$ 0.01 and $31.4 \pm 0.02$ respectively, mean $\pm \mathrm{SD}$; Kruskal Wallis, $\mathrm{H}=7416, \mathrm{DF}=8, p<$ 0.001). Finally, at LHI the water temperature was significantly higher at the lagoon sites of Sylphs Hole, Potholes and Stephens Hole compared to the fore reef sites of The Arch, Middle Beach and Boat Harbour (Fig. 3c; Kruskal Wallis, $\mathrm{H}=1943, \mathrm{DF}=9, p<0.001$ ). On the western fore reef (The Arch), mean temperature $( \pm \mathrm{SD})$ was $0.1^{\circ} \mathrm{C}$ greater at $5 \mathrm{~m}$ $\left(22.7^{\circ} \mathrm{C} \pm 0.02\right)$ than $15 \mathrm{~m}\left(22.6^{\circ} \mathrm{C} \pm 0.02\right.$; Fig. 4). At the eastern side (Boat Harbour) the temperature was $0.3^{\circ} \mathrm{C}$ lower at $10 \mathrm{~m}\left(22.5^{\circ} \mathrm{C}\right)$ than at $5 \mathrm{~m}\left(22.8^{\circ} \mathrm{C}\right)$, but temperature at Middle Beach was homogenous with depth $\left(22.5^{\circ} \mathrm{C} \pm 0.02\right)$. At the $\mathrm{KI}$, mean water temperature $( \pm \mathrm{SD})$ at time of sampling was $20.3 \pm 0.01$ at $5 \mathrm{~m}$, decreasing by $0.2 \pm 0.01$ at $15 \mathrm{~m}$. Mean turbidity $( \pm \mathrm{SD})$ was $1.84 \pm 0.01 \mathrm{FTU}$ for all depths $5-15 \mathrm{~m}$.

The influence of the above measured environmental variables on the Symbiodinium community was assessed using the three coral species, A. cuneata, $P$. damicornis and $G$. favulus, collected at all 6 sites around LHI. A total of five, three and three Symbiodinium types were found in A. cuneata, P. damicornis and G. favulus respectively (Table 1). Assessing the influence of environmental variables on symbiont distributions at LHI using 


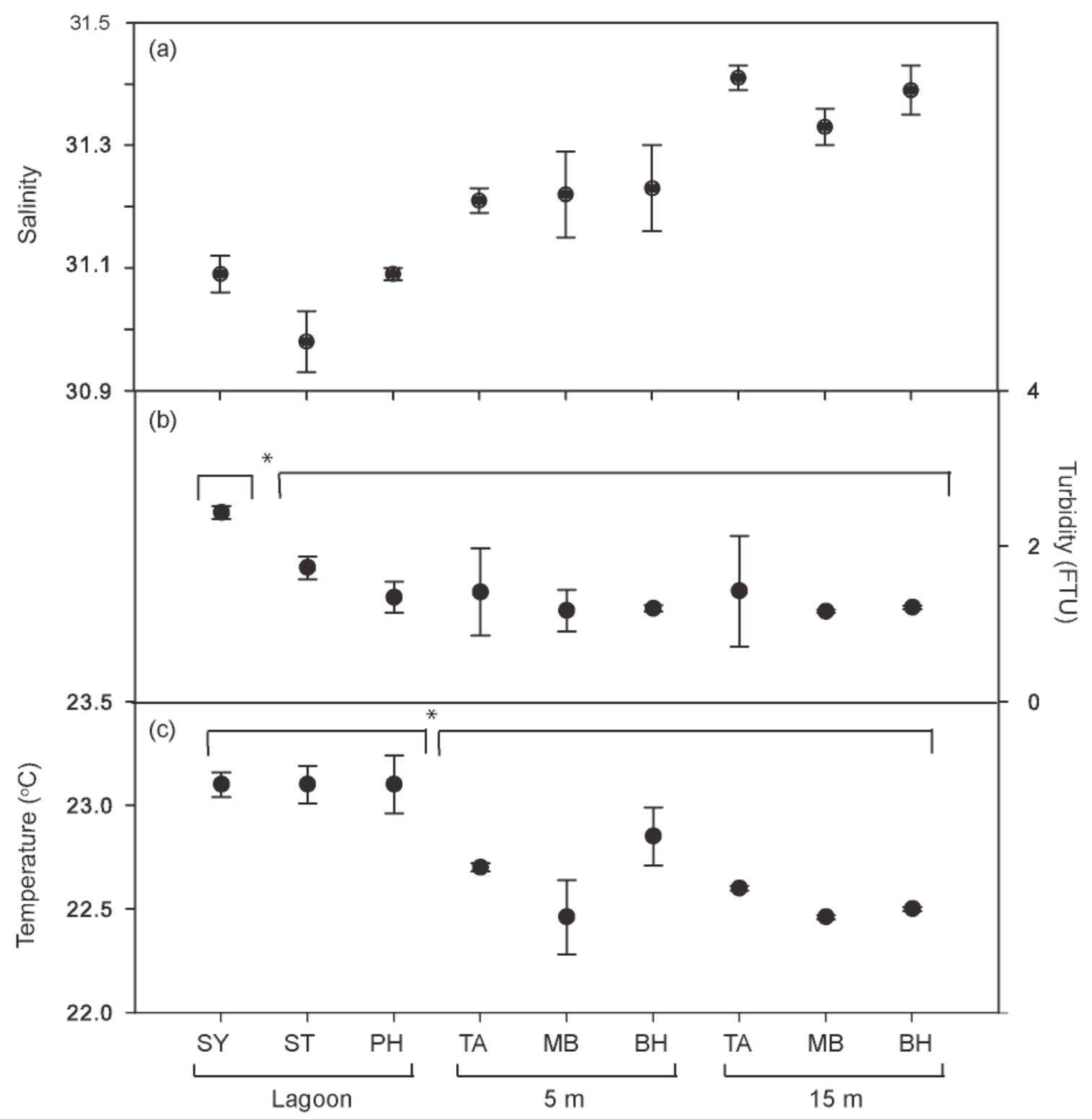

Figure 3.4 Mean $( \pm \mathrm{SD})$ of environmental parameters measured at sites around Lord Howe Island at time of sampling: (a) salinity, (b) turbidity (FTU), (c) temperature $\left({ }^{\circ} \mathrm{C}\right)$. SY: Sylphs Hole, ST: Stephens Hole, PH: Potholes, TA: The Arch, MB: Middle Beach, BH: Boat Harbour. Asterisk marks significant differences in environmental variable between groups of sites at $p<0.05$. 

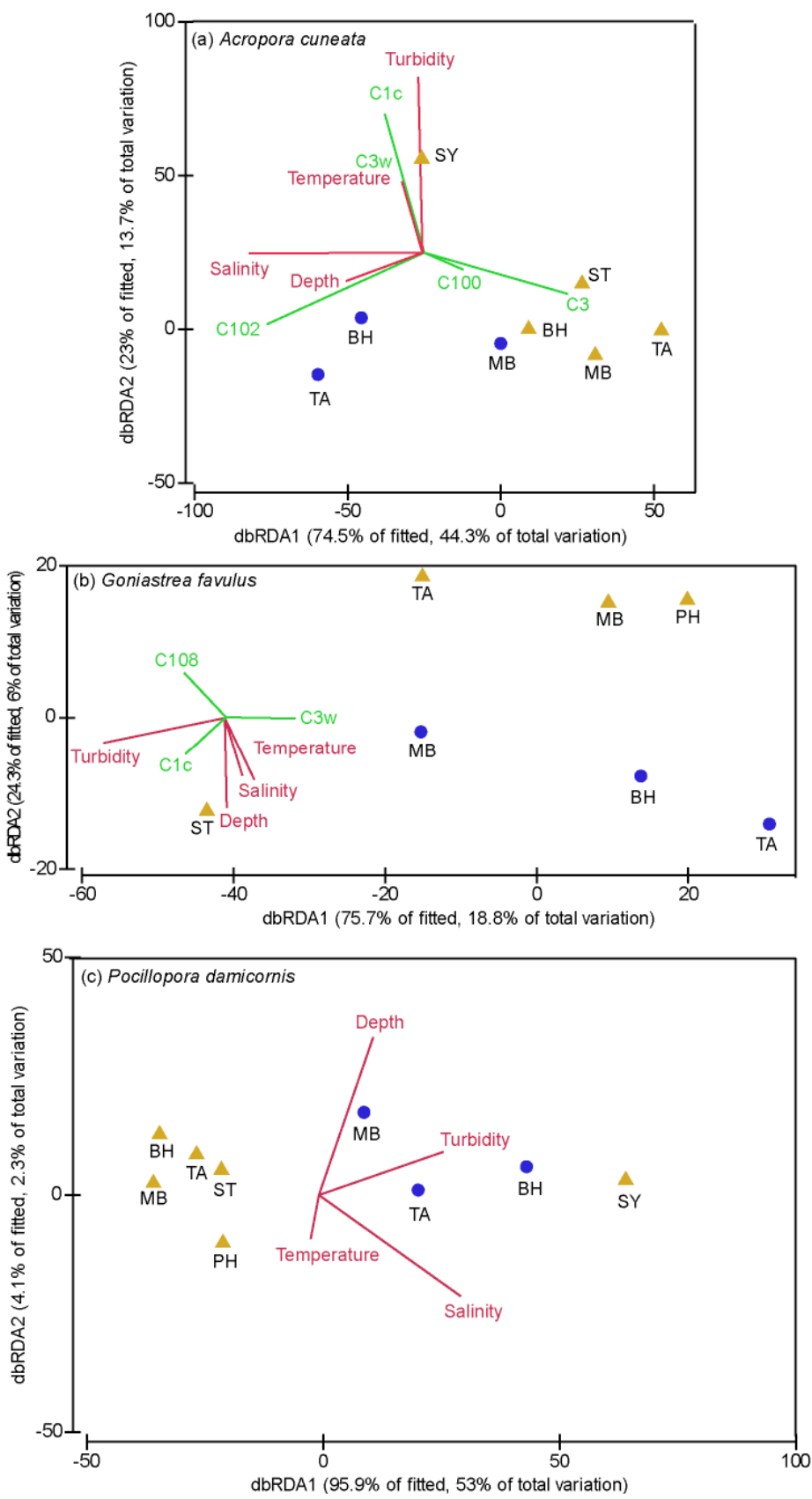

Figure 3.5 Distance based RDA ordination relating environmental variables to symbiont data, showing biplot projections for environmental data (in Figure 3.4) and symbiont types identified. Sites are labelled as abbreviations with symbols indicating depth (•deep $\Delta$ shallow). Analysis was performed on Bray-Curtis dissimilarities of symbiont presence/absence data. ' $\%$ of fitted' indicates the percentage of the variability in the original data explained by the axis and $\%$ of total variation indicates the percentage of the variation in the fitted matrix (i.e. the fitted relationship between $y$ and the explanatory variables) explained by the axis. Environmental variables $(\operatorname{Ln}+1)$ transformed and normalised. SY: Sylphs Hole, ST: Stephens Hole, PH: Potholes, TA: The Arch, MB: Middle Beach, BH: Boat Harbour. 
multivariate analyses revealed complex patterns that were highly variable between host species (Fig. 4). Turbidity was the primary predictive environmental parameter for all host species and although the parameters of depth, salinity and temperature had varying effects they were correlated with each other indicating that the effects of each parameter on symbiont distributions could not be distinguished.

The predominant symbionts identified in A. cuneata $(\mathrm{n}=27)$ were $\mathrm{C} 3$ and $\mathrm{C} 102$ (59\% and $22 \%$ of samples) with $\mathrm{C} 1 \mathrm{c}, \mathrm{C} 100$ and $\mathrm{C} 3 \mathrm{w}$ only occurring rarely $(7,7$ and $4 \%$ ). The main driving environmental variables explaining the observed distribution of symbionts in A. cuneata were turbidity and salinity ( $57 \%$ of the total variability; BIOENV $\mathrm{R}=0.566, p<0.01)$. The database redundancy analyses (dbRDA) depict the correlation of environmental variables to symbiont distributions in each of the three host species (Fig. 3.4), with the strongest effect of environmental predictors on symbiont distributions in $A$. cuneata (Fig. 3.4a). Turbidity is the main influential factor affecting symbiont distributions in A. cuneata, and is correlated with the presence of Symbiodinium C1c and C3w at the turbid site of Sylphs Hole. Depth dependence was observed for Symbiodinium type C100 and C102. C100 was found in colonies of $A$. cuneata from the western deep sites ( $>10 \mathrm{~m})$ and C102 was only present in samples from the shallow, eastern exposed sites.

Of the sampled $P$. damicornis colonies $(\mathrm{n}=24) 67 \%$ contained Symbiodinium type C100, 29\% had C41 and a single sample had C118 (at the site Potholes, Fig. 3.1). Turbidity was the environmental parameters best explaining the observed symbiont distributions in $P$. damicornis (Fig. 3.4b; 34\% of the variability; BIOENV $\mathrm{R}=0.335, p<0.05$ ). The distribution of $\mathrm{C} 41$ and $\mathrm{C} 100$ are strongly correlated to both depth and turbidity, with C41 only found in colonies from Sylphs hole and at depths greater than $10 \mathrm{~m}$, and C100 mainly present in colonies collected from shallow water or the lagoon. 
Finally, $57 \%$ of $G$. favulus colonies $(\mathrm{n}=21)$ associated with $\mathrm{C} 3 \mathrm{w}, 33 \%$ with $\mathrm{C} 1 \mathrm{c}$ and $9 \%$ with $\mathrm{C} 108$. In comparison to the other coral species, patterns of symbiont distributions of G. favulus were not significantly correlated to any of the measured environmental variables. Turbidity was the main factor identified, but explained the total variation in the symbiont community poorly (Fig 3.4c; 14\%) and was not significant $(\mathrm{BIOENV} \mathrm{R}=0.139, p=0.17)$. Symbiodinium $\mathrm{C} 3 \mathrm{w}$ contrary to its presence in A. cuneata, where it was rare and only found at Sylphs Hole, was abundant and widely distributed in $G$. favulus. Host-specific C108 associated exclusively with colonies of G. favulus in the lagoon and shallow regions of the forereef (Table 3.1).

\subsection{DISCUSSION}

A high degree of diversity and endemicity of Symbiodinium was identified in corals at the high latitude locations of Lord Howe Island (LHI) and the Kermadec Islands (KI). Clade C types dominate the coral species at LHI, with local patterns of distribution of sub-cladal types driven by environmental parameters such as depth and turbidity, as well as being host-dependent. Furthermore, host specificity is significantly reduced compared to tropical reefs, such as the GBR (LaJeunesse et al. 2003, 2004a).

\subsubsection{Biogeographic distribution patterns of Symbiodinium}

The dominance of Symbiodinium types belonging to clade C at LHI and the KI was expected because many invertebrates, including corals, anemones and zoanthids, associate 
with closely related clade C Symbiodinium in the Pacific (Baker and Rowan 1997; Loh et al. 2001; LaJeunesse et al. 2003,2004a, 2004b). At LHI and KI only B1 was identified in the soft coral Capnella, but all other Symbiodinium types identified were members of clade C (Table 1). Clade B Symbiodinium has been identified in the coral Plesiastrea versipora from high latitude regions, which harbours clade $\mathrm{C}$ in the tropics (Rodriguez-Lanetty et al. 2001). Studies of more temperate symbioses in the Atlantic region found a prevalence of both clades A and B Symbiodinium; clade A was present in Anemonia spp. in the Mediterranean and NE Atlantic (Savage et al. 2002), whilst Anthopleura elegantissima hosts clade B over a wide latitudinal range on the eastern North American coast (LaJeunesse and Trench 2000). High latitude corals on both sides of the Pacific, the Gulf of Cortez at $24^{\circ} \mathrm{N}$ (LaJeunesse et al. 2008), and Sesokojima, Japan at $27^{\circ} \mathrm{N}$ (Loh et al. 2001), however, also predominantly associated with clade C Symbiodinium. Furthermore, clade D symbionts, previously identified as 'heat tolerant' (Glynn et al. 2001; Baker et al. 2004), also occur in hosts at high latitudes (Lien et al. 2007), including P. damicornis (LaJeunesse et al. 2008), but was not found in the present study.

On a sub-cladal level, little is known of symbiont diversity at the high latitude limits of coral distribution. Most of the invertebrate hosts examined here at high latitudes associated with symbionts other than those found on the GBR (Table 1). For example, $F$. abdita and M. curta associate with C3 on the Southern GBR but are found with C1 at LHI, but both these symbionts are pandemic generalists. H. pilosa hosts Symbiodinium types $\mathrm{C} 3 \mathrm{w}$ and $\mathrm{C} 1 \mathrm{z}$ at the $\mathrm{KI}$ but other Hydnophora sp. associate with $\mathrm{C} 3$ throughout the whole range of the GBR (LaJeunesse et al. 2003). Only Acropora spp. hosting C3, and Turbinaria spp. with $\mathrm{C} 22 \mathrm{a}$ in the present study are the same partnerships as on the southern GBR (Table 1; LaJeunesse et al. 2003). 
Interestingly, whilst Symbiodinium C1c (and closely related symbionts C42a and $\mathrm{C} 1 \mathrm{~b}-\mathrm{c})$ is common to pocilloporid corals in locations ranging from Heron Island in the southern GBR to Lizard Island (north-central GBR; LaJeunesse et al. 2004b), Hawaii (LaJeunesse et al. 2004a), and the eastern Pacific (LaJeunesse et al. 2008), it is absent in Pocilloporid corals in the current study, where it hosts three novel symbiont types (C41, $\mathrm{C} 100$ and $\mathrm{C} 118)$. These three symbionts are from a novel lineage and thus are likely to have developed separately from the widespread Pacific symbiont species. Interestingly, C1c is present in other hosts at LHI, namely G. favulus and A. cuneata, and these partnerships have not previously identified at other locations, in fact $\mathrm{C} 1 \mathrm{c}$ was thought to be highly specific for P. damicornis in the western Pacific (Iglesias-Prieto et al. 2004). The absence of $\mathrm{C} 1 \mathrm{c}$ with $P$. damicornis may suggest that that holobiont is not the optimal partnership for the variable environment at LHI.

\subsubsection{Endemicity and diversity}

The diversity of symbionts at high latitudes, and the endemicity observed in the present study may be driven by (1) host-dependent habitat specificity, (2) host-specificity and the reproduction strategy of the host, and (3) the biogeographical isolation of the sites.

Habitat specificity is observed on a local scale in the present study, and it is likely that the variable environment around LHI underlies the diversification of host-symbiont partnerships. For example, both $A$. cuneata and $P$. damicornis exhibit depth and turbiditybased patterns in symbiont diversity. Symbiodinium C100, which is prevalent in $P$. damicornis in all environments sampled, is also found on the shallow forereef when hosted by $A$. cuneata. Similarly, $\mathrm{C} 1 \mathrm{c}$ and $\mathrm{C} 3 \mathrm{w}$ are common to $G$. favulus across multiple locations whilst at the turbid site of Sylphs Hole these symbionts are found in association with $A$. 
cuneata. The stratification of symbiont types linked to turbidity levels suggest that the symbiont types present at this site are specialized for the low light environment, but this pattern appears to be highly dependent on the host species in which the symbiont is found. Symbionts thus appear to have different environmental preferences according to the host they inhabit. Host-dependent thermal tolerance has been observed in symbionts associating with various Acropora spp. in the GBR; A. tenuis exhibited greater thermal tolerance whilst hosting $\mathrm{C} 1$ than D1, with the opposite responses observed in A. millepora (Abrego et al. 2008). The varying responses of host-symbiont partnerships was suggested to be due to (i) host factors, (ii) competitive ability of the symbionts in host cells, and (iii) the microenvironment of the host; possible explanations which require further exploration.

Interestingly, $P$. damicornis at the turbid site of Sylphs Hole was not found in association with any of the 'turbid' symbionts found in A. cuneata or G. favulus (C3w, C1c), but instead associated with Symbiodinium C41. The absence of C1c in P. damicornis suggests it is not a suitable symbiont under the current circumstances at LHI; these are a factor of the outside as well as the host species. C41 is likely to be shade adapted in combination with $P$. damicornis since it is also found at the deep sites.

These findings are consistent with light driven zonation patterns of Symbiodinium observed in many coral species. For example, the Caribbean coral Montastraea annularis is dominated by Symbiodinium clades A and B in shallow, well-illuminated sites, and by clade C in deep and poorly illuminated locations (Rowan and Knowlton 1995; Rowan et al. 1997). Depth based ecological stratification on a sub-cladal level has also been observed (LaJeunesse et al. 2003; Warner et al. 2006; Sampayo et al. 2007; Frade et al. 2008b), and for example in the coral genus Madracis functional differentiation between symbiont types is driven by light spectral niches (Frade et al. 2008a, 2008b). Whilst ecological zonation of 
symbiont types with depth has been linked to the physiological adaptations of different symbionts to light regimes, depth variable parameters other than light intensity, such as temperature (Rowan 2004; Tchernov et al. 2004) or nutrient availability (Fitt and Cook 2001), may also play a role.

The second factor involved in driving observed host symbiont associations is linked to host specificity and this has been related to the various reproductive strategies employed by corals. Symbioses in corals that acquire their symbionts directly from their parent egg or brooded larvae (vertical transmission) are thought to be more specific for their symbionts due to the faithful transmission of symbiont type from parent to offspring (Yamamura 1996; Loh et al. 2001) compared to hosts that acquire their symbionts from the water column (horizontal transmission) (Loh et al. 2001; LaJeunesse et al. 2008; Stat et al. 2009). At LHI and the KI, 70\% of the coral species sampled (with known transmission strategies) horizontally transmit their symbionts and thus have the opportunity to associate with a range of symbionts available from the water column. Most of the horizontal strategists either associate with the pandemic generalist types $\mathrm{C} 3$ or $\mathrm{C} 1$ but some contain locally endemic symbionts (i.e. C. serailia with C104, G. favulus with C108; Table 1).

Although host specificity in vertical strategists is usually high (Stat et al. 2009), 3 of the 4 known vertical transmitters in the present study harbour non-specific symbionts. Two of these hosts do additionally harbour host-specific symbionts $(P$. cf. heronensis with $\mathrm{C} 111$ and $\mathrm{C} 117$, and S. pistillata with $\mathrm{C} 3 \mathrm{gg}$ ). Interestingly, A. cuneata, a vertical strategist, harbours 5 non-specific symbiont types. Although one of these is a generalist (C3), the other types are all harboured by another host; C100 with $P$. damicornis, $\mathrm{C} 102$ with $C$. serailia, and $\mathrm{C} 3 \mathrm{w}$ and $\mathrm{C} 1 \mathrm{c}$ with $\mathrm{G}$. favulus. The fact that symbionts are shared between vertical and horizontal transmitters may be driven by long-term isolation under challenging 
environmental conditions, whereby perhaps normally host specific symbionts are acquired from the external environment rather than the generalist type. This scenario is rare, and has only been reported in Fungia scutaria with C1f in Hawaii (Weis et al. 2001; RodriguezLanetty et al. 2004). Interestingly, at LHI, the horizontal strategist G. favulus harbours $\mathrm{C} 108$ in low frequency, whereas the two dominant symbionts $(\mathrm{C} 3 \mathrm{w}$ and $\mathrm{C} 1 \mathrm{c})$ are present in multiple hosts. C108 may have evolved and be harboured by another vertical strategist not sampled in the present study. The ability of both horizontal and vertical strategists to associate with a range of symbiont types at these marginal locations may give them a greater flexibility to cope with the seasonally changing environmental conditions.

Where novel types are present, in many cases the host specific symbionts seem to have diverged independently from their Pacific radiations, which are widespread. For example $P$. damicornis harbours $\mathrm{C} 118$ and $\mathrm{C} 41$, which have the same lineage, separate to the $\mathrm{C} 42 \mathrm{a} / \mathrm{C} 1 \mathrm{c}$ lineage harboured in other locations. The reproductive strategy of $P$. damicornis is unknown but can be suggested to be vertical due to the high specificity observed. Furthermore Porites spp. generally associate with symbionts of the C15 lineage in the Pacific (LaJeunesse et al. 2004b; Apprill and Gates 2007), but at LHI P. cf. heronensis harbours c117 and C111 from a separate lineage. The independence of divergences suggests not only that these locations are very isolated but also hints to the need for novel adaptations to challenging conditions.

The biogeographical isolation of the high latitude sites is likely to have contributed to the high levels of endemicity observed as well as the presence of host-specific locally divergent lineages of Symbiodinium. Although LHI is linked to the GBR through the flow of the EAC, coral populations are genetically isolated indicating that influx of recruits occurs infrequently (Ayre and Hughes 2004). The KI are even more isolated, $3300 \mathrm{~km}$ from 
the GBR and $2200 \mathrm{~km}$ from LHI. Long distance dispersal of coral larvae from the GBR to both high latitude sites is rare, and low genetic diversity at LHI indicates that most populations are self-seeding, making them vulnerable to extinction (Ayre and Hughes 2004). In a study of Symbiodinium in a range of corals in the isolated Hawaiian Islands, high levels of endemicity were also observed (e.g., C75 hosted by Porites sp., LaJeunesse et al. 2004a). These findings are consistent with occurrence of biogeographical provinces across the Pacific (Udvardy 1975; Gaines and Lubchenco 1982), that have also been identified for Symbiodinium within the GBR (LaJeunesse et al. 2004a). Symbiont community composition differs between the northern, central and southern GBR, and based on our findings, the higher latitude reefs of LHI and KI would also represent a separate biogeographic province.

\subsubsection{Ecological implications}

The ecological patterns in symbiont distribution observed highlight the importance of subcladal identification. Despite the low numbers of coral colonies sampled in the present study high symbiont diversity was uncovered and increased sampling may be beneficial to uncover distinct patterns especially for corals hosting specialised symbionts (LaJeunesse et al. 2003, Sampayo et al. 2007).

The evolution of non-host specific partnerships between host and symbiont at high latitudes is no doubt linked to locally challenging environmental conditions. Whilst host specificity has previously been reported to be greatest in unstable and isolated environments (LaJeunesse et al. 2004a), the relaxation of host specificity at the high latitude isolated sites in the present study suggests the opposite. The presence of locally adapted symbionts likely indicates that, due to isolation and the hugely different 
environment, symbionts have evolved that are more suitable to these locations. The flexibility of host-symbiont relationships is of great importance in light of evidence of stress-tolerant symbionts, and their role in increasing thermal thresholds of their hosts (Buddemeier and Fautin 1993; Rowan et al. 1997; Glynn et al. 2001; Berkelmans and Van Oppen 2006). Further, this study demonstrates the importance of sub-cladal designation, with patterns in host and environment specificity identified which would not have been revealed using cladal designation techniques. Questions ensue as to how these coralsymbiont partnerships will fare with warming oceans, how these novel symbionts vary in the physiological functionality, and whether certain host-symbiont partnerships will become prevalent in a future of climate change. 


\title{
Chapter 4
}

\section{Effect of sedimentation on the community structure and resilience of corals and their symbionts}

\begin{abstract}
Susceptibility to environmental stress varies between both coral species and their symbionts of the physiologically diverse genus Symbiodinium, and thus influences the distribution of the holobiont (host and symbiont). This study aimed to assess the influence of the stressor, sedimentation, on symbiont distribution, and its consequences for coral distribution and diversity across the reef system of Palmyra Atoll, USA. A low diversity of symbiont types was discovered at the sites, with only ten Symbiodinium types identified in 34 coral species from 9 genera: 8 clade $\mathrm{C}$ types and 2 clade $\mathrm{D}$ types. Multivariate analysis revealed that field-based estimates of sedimentation explained $79 \%$ of the spatial variation of coral species among sites, however this environmental variation has not affected the holobiont distributions. The low symbiont diversity and lack of correlation between potential environmental stressors suggests that the symbionts are robust enough to cope with the environmental regime. Further, the similarity in coral-Symbiodinium to other locations and the dominance of generalist symbiont types suggest a high degree of connectivity may exist with other reef systems in the central Pacific. The data highlight (1) the importance of host tolerance to environmental stressors, which should be considered simultaneously with symbiont sensitivity when considering the impact of environmental degradation on coral
\end{abstract}


communities, and (2) the low diversity of potentially stress-tolerant symbionts which may, however, be vulnerable to further environmental change.

\subsection{INTRODUCTION}

Coral reefs owe much of their success to the mutualistic endosymbiosis between corals and dinoflagellates of the genus Symbiodinium. The host relies on the dinoflagellates for survival, with evidence that the latter release substantial amounts of photosynthate to the coral, and aid the recycling and conservation of essential nutrients (Muscatine 1990, Wang \& Douglas 1998). Within the genus Symbiodinium, high genetic and physiological diversity has been uncovered, with eight clades (A-H) and numerous sub-clades identified (Rowan \& Powers 1991, Baker 2003, Coffroth \& Santos 2005). The physiological diversity among symbiont types has ecological ramifications because the ability of corals to survive in a variety of habitats and environmental conditions has been attributed to their relationship with different Symbiodinium types (Iglesias-Prieto \& Trench 1994, 1997a, Robison \& Warner 2006, McCabe-Reynolds et al. 2008).

Few coral species can associate with a range of Symbiodinium types, specifically adapted to the local environment (Rowan \& Knowlton 1995, Rowan et al. 1997, Ulstrup \& van Oppen 2003, Mieog et al. 2007), with the host-symbiont combination driven by the specificity of a host for a specific symbiont type, or vice versa (Rowan et al. 1997, Baker 2003). Indeed, the physiological distinctions among symbiont types has wide-ranging significance, because they delineate host tolerance ranges and so influence host distribution on regional as well as wide latitudinal scales (Rowan \& Knowlton 1995, Loh et al. 2001, Iglesias-Prieto et al. 2004, Rodriguez-Lanetty et al. 2004, Rowan 2004, Berkelmans \& van 
Oppen 2006). For example, irradiance-specific symbionts have been shown to explain the distinctive vertical distribution patterns of two dominant coral species using genetic and physiological analyses (Iglesias-Prieto et al. 2004).

Although some corals have the ability to harbour multiple symbiont types, many corals only host a single symbiont type (Baker 2003, Goulet 2006, 2007). Occasionally, mixed populations of symbionts occur not only within a single species, but also within a single colony, their distribution often correlating with irradiance levels (Rowan et al. 1997, Frade et al. 2008b). This simultaneous harbouring of different symbiont types, presumably with differing physiologies, has led to the suggestion that some coral species may adapt to a particular environment by 'shuffling' their symbionts; that is, shifting the dominant Symbiodinium type towards one that is well suited to the abiotic regime (Buddemeier \& Fautin 1993, Fautin \& Buddemeier 2004, Berkelmans \& van Oppen 2006, Jones et al. 2008). Thus, the functional diversity of Symbiodinium types has implications for the host's ability to adapt/acclimate to environmental change, particularly if the host can shuffle its symbiont types, with the degree of host-symbiont specificity and flexibility also playing an important role.

On local and geographic scales, the structure and development of coral reefs is linked to a long list of environmental variables (Brown 1997ba), with those reefs occurring close to the thresholds for survival or in areas characterised by sub-optimal or widely fluctuating environmental conditions being termed as marginal (Kleypas et al. 1999). These variables include light, temperature, salinity, hydrodynamic factors and sedimentation (Achituv \& Dubinsky 1990, Kleypas et al. 1999). Species-specific responses to temperature (Cook et al. 1990, Coles \& Fadlallah 1991, reviewed in Baker et al. 2008), light (Done 1983, Cornell \& Karlson 2000), salinity (Coles \& Jokiel 1978) and turbidity (Rogers 1990, 
McClanahan \& Obura 1997, Fabricius 2005) have been well documented, and are reflected in the coral community established within an environment. For example, bleaching susceptibility varies among coral taxa (Hoegh-Guldberg \& Salvat 1995, Marshall \& Baird 2000), and thus following a bleaching event which results in selective mortality, communities will become dominated by 'hardy' coral species.

Sedimentation affects the distribution of coral species (Rogers 1990, Fabricius 2005), but little is known about how sediment regime affects the distribution of different Symbiodinium types specifically. Coral species exhibit differential responses to shading, abrasion and smothering which constitute the main mechanisms of sediment impact (Brown 1997ba). While some corals obtain nutritional benefits from ingestion of sediment particles (Anthony 1999) and have adapted to high sediment load habitats (Abdel-Salam et al. 1988, Stafford-Smith 1993, Riegl \& Branch 1995), for most corals the direct impact of sedimentation on the host is clear; increased sedimentation leads to reduced irradiance, reduced species richness, and reduced coral cover, size and recruitment (Brown \& Howard 1985, Rogers 1990, Brown 1997b, Fabricius 2005). With increasing sedimentation, coral growth rates decline, the corals lose their symbiotic dinoflagellates, and the coral tissue dies (Bak 1978, Rogers 1983, Peters \& Pilson 1985). In addition to the role that sediment regimes play in the distribution and survival of corals, these species are only able to survive in the stressful environment if they host a dinoflagellate symbiont that is adapted to the conditions (Iglesias-Prieto et al. 2004). However, what little is known about this subject is limited to two studies. Toller et al. (2001) and Garren et al. (2006) identified cladal-level symbiont distribution patterns in response to sedimentation, but made no mention of host distributions. Thus, the aim of the current study was to assess the influence of sedimentation on symbiont distribution and its consequences for coral distribution and 
diversity across a reef system. It was hypothesised that coral cover, coral diversity and symbiont diversity would all be lower in areas of high sedimentation than in areas of low sedimentation.

\subsection{METHOD}

\subsubsection{Study site}

The study was conducted between June and July 2007 at Palmyra Atoll $\left(05^{\circ} 52^{\prime} \mathrm{N}\right.$, $162^{\circ} 06^{\prime} \mathrm{W}$ ), an uninhabited atoll situated in the remote Central Pacific (Fig. 4.1), at the northwest end of the northern Line Islands. Palmyra has lacked an indigenous human population, but was extensively modified during WWII and abandoned shortly thereafter, with sparse human influence since (Collen et al. 2009). WWII construction disrupted the atoll's water-flow regime, leading to chronic sedimentation in some areas of the atoll, and catastrophic death of corals on the western side (Maragos et al. 2008a). In 2001, Palmyra became a National Wildlife Refuge, jointly managed by US Fish and Wildlife Service and The Nature Conservancy. The atoll is also part of the Pacific Remote Islands National Monument, established in 2009.

The atoll is $20 \mathrm{~km}$ long, made up of 50 islets and situated approximately 1,930 km south of the main Hawaiian Islands. Five sites were chosen from the backreef of the atoll, covering a range of sediment regimes (high, mid and low) at comparable depths (Fig. 4.1). The 6500 ha of shallow and deep reefs at Palmyra, and the marked spatial variability in sediment load, provide an ideal location for assessing the influence of sedimentation on coral and Symbiodinium distributions, and for examining the inter-relationship between these distributions. 


\subsubsection{Coral sampling and community surveys}

At each study site, quadrats $\left(1 \mathrm{~m}^{2}\right)$ were placed every $2 \mathrm{~m}$ along five $30-\mathrm{m}$ transects at a constant depth of $2-3 \mathrm{~m}$ at high tide ( $\mathrm{n}=75$ per site). Percentage cover of each coral species and other benthic categories (dead coral/rubble, sand, macroalgae, sponges) was estimated by eye in situ. In the case of Montipora spp., where species could not be accurately identified, corals were placed into 12 morphological groups (Appendix A4.1) as defined by Veron (2000). Coral species identifications were verified by a third party. Once the dominant and rare coral species at each site were ascertained, samples were taken for dinoflagellate symbiont identification. Samples $(n=3$ per species) were taken of five coral species that were present at every site surveyed. Additionally, coral species found at only one or two sites were sampled. To avoid sampling the same clone, colonies more than $5 \mathrm{~m}$ apart were selected at each site. Fragments of $1-2 \mathrm{~cm}^{3}$ were taken from the top of colonies using a hammer and chisel, fixed in absolute ethanol and stored at $-20^{\circ} \mathrm{C}$. Samples were transported in ethanol from Palmyra to New Zealand (NZ) for analysis.

\subsubsection{Symbiont identification}

At Victoria University of Wellington (NZ) Symbiodinium cells were isolated by removing the coral tissue from the skeleton. The tissue was rinsed, homogenised using a tissue grinder in extraction buffer (1.2 $\mathrm{M}$ filtered seawater and $5 \mathrm{mM}$ EDTA), and the Symbiodinium DNA extracted using the DNeasy Plant Mini Kit following manufacturer's instructions (Qiagen). Briefly, the internal transcribed spacer 2 region (ITS 2) of nuclear ribosomal DNA was used to identify distinct Symbiodinium types (cf. LaJeunesse 2001, 2002). The ITS 2 region was PCR amplified using primers "ITS 2 clamp" and "ITSintfor 


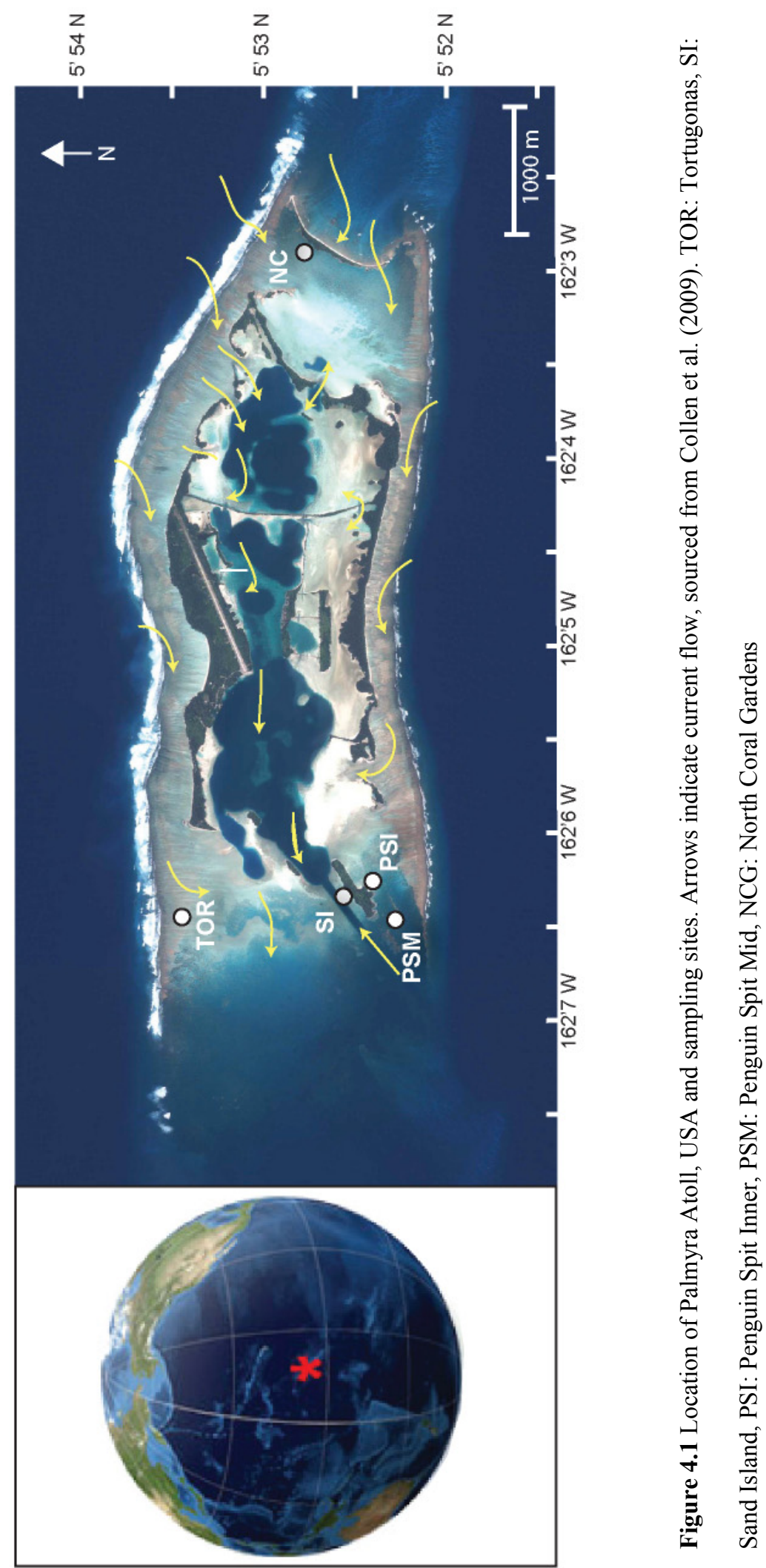


2" (LaJeunesse \& Trench 2000) under "touchdown" thermal cycle conditions specified in LaJeunesse (2002). ITS 2 amplified PCR products were subsequently run on a Biorad DCode Denaturing Gradient Gel Electrophoresis (DGGE) system, using a 30\% to $65 \%$ gel during a $100 \mathrm{~V}$ run for $14 \mathrm{~h}$. with dominant (brightest) bands excised, amplified and sequenced. All DGGE gels were stained using 1X SYBR Green for 30 min and visualized on a UV transilluminator.

To identify distinct Symbiodinium type, prominent bands were excised from up to three representative samples of each characteristic profile. Excised bands from the ITSDGGE fingerprint were eluted in $500 \mu \mathrm{ddH} 20$, kept at $4{ }^{\circ} \mathrm{C}$ for $24 \mathrm{~h}$ and reamplified using GC-clamped primers (under conditions as above). Amplicons were re-run on the DGGE system to check band position and potential contamination with other bands during excision prior to sequencing. Clean bands running at the expected position in relation to the original sample were re-excised, eluted and reamplified with the non-GC clamped primer set (cf. LaJeunesse 2002; LaJeunesse et al. 2008). Amplifications were purified by ethanol precipitation and sequenced in both directions at the Australian Genome Research Facility (ABI BigDye Terminator v3.1; AB3730x1 sequencer). Chromatograms were checked using Seqman software (Lasergene) and aligned using Clustal-X (Thompson et al. 1997). Identical DNA sequences recovered from each dominant or co-dominant band were identified by a BLAST search on GenBank (http://www.ncbi.nih.gov). Phylogenetic analyses of dominant rDNA ITS1 and ITS2 repeat sequences were performed in PAUP (version 4.0b10, Swofford 2000) under the maximum parsimony criterion treating gaps as a fifth character state and indels as a single evolutionary event with bootstrap values calculated based on 1,000 replicates. 


\subsubsection{Environmental variables}

At Palmyra Atoll, a range of environmental variables was recorded over a six-week period at the 5 sites to assess their influence on coral and symbiont distributions. Seawater temperature, fluorescence (as a proxy for chl- $a$ concentration) and salinity were recorded once every minute for 7-day periods at 1-2 m depth at each of the sites using a CTD unit (Richard Brancker Research Ltd XR 420). Temperature and light loggers (HOBO, Onset Ltd) were deployed for a five-week period at three of the sites (Penguin Spit Middle, Tortugonas and North Coral Gardens), recording once every 30 min. Temperature measures from the CTD and HOBOs were combined for sites where both recordings were taken.

Sedimentation rates at $2-4 \mathrm{~m}$ depth at each of the sites were measured using sediment traps connected vertically to the seabed. Traps were $5.1 \mathrm{~cm}$ internal diameter PVC cylinders with a height of $100 \mathrm{~cm}$. The mouth of each trap was located $\sim 1.1 \mathrm{~m}$ above the seabed. Traps were deployed at least twice at each of the sites during the study period for varying periods of time ( $\min 5$ days; $\max 72$ days). The trap contents were filtered onto $0.45-\mu \mathrm{m}$ Whatman $\mathrm{G} / \mathrm{FC}$ filter papers and dried at $60^{\circ} \mathrm{C}$ for $24 \mathrm{~h}$ to constant weight to determine total particulate matter (TPM $\left.-\mathrm{mg} \mathrm{m}^{-2} \mathrm{~d}^{-1}\right)$. To determine particulate organic matter (POM - $\mathrm{mg} \mathrm{m}^{-2} \mathrm{~d}^{-1}$ ) content the dry filter plus sediment was combusted at $500^{\circ} \mathrm{C}$ for $24 \mathrm{~h}$ in a furnace to determine its ash-free dry weight (the weight loss on ignition equals the organic matter content). Percent organic matter content (PCOM) was determined as POM / TPM * 100. To extend the precision of the analyses, sedimentation data collected over a 3year period (not just from the deployments in June and July 2007) were used in the analysis because preliminary testing revealed that no significant effect of time (date of deployment) was observed (ANOVA, $\mathrm{F}=2.34, p=0.111$ ) on sedimentation rates (TPM, POM and 
PCOM; ANOVA conducted on SPSS v16).

\subsubsection{Statistical analyses}

To determine the role that environmental variables play in controlling symbiont distribution, coral species distribution and their inter-correlation at Palmyra Atoll, a number of univariate and multivariate analyses were conducted. Indices used to assess diversity of corals per site were total number of species (S), Hill numbers N1 and N2 (to assess the influence of rare and dominant species on community diversity, respectively), and the modified Hill's ratio (N21') (see Clarke \& Gorley 2006 for a summary of each index). The modified Hill's ratio was used as a measure of equitability (spread among taxa) because it has an advantage over traditional measures of evenness by its non-dependency on the number of species (Rogers et al. 1999). All diversity indices were calculated using Primer v6.1.11 (Plymouth Marine Labs.) Percentage coral cover and environmental variables (temperature, salinity, chl- $a$ and the 3 sediment measures of TPM, POM and PCOM) were compared among sites using one-way analysis of variance (ANOVA, with Tukeys posthoc test), testing the null hypothesis that there was no significant difference in aforementioned variables among the five sites. Where assumptions of normality and/or homogeneity of variance were not met, data were transformed using the square root transformation, or nonparametric Kruskal-Wallis and Dunns post-hoc tests used. Quadrats were used as the replicates for each site in the biotic analysis.

Multivariate analyses were conducted to examine differences in coral and holobiont community structure at each site, and the relationship of community structure with environmental variables, using Primer v6 with PERMANOVA v1.0.1 add-on. Analysis was conducted on the percent cover of all benthic groups (including all coral species), coral 
species presence/absence and holobiont presence/absence. Presence of each holobiont type was restricted in all analyses to those present in five key coral genera: Acropora, Astreopora, Favia, Montipora and Pocillopora, with host colonies used as replicates, and analysis also conducted separately for each host species. Prior to the multivariate analysis, benthic percent cover data was subjected to a dispersion-weighted pre-treatment in which the abundances of the different species or groups were weighted differentially on the basis of their observed variability among replicate samples (1000 replications, Clarke et al. 2006a). This method compensates for the spatial clustering common to coral community studies (Clarke et al. 2006a). Similarities were calculated using the zero-adjusted BrayCurtis similarity measure (Bray \& Curtis 1957) to account for samples with denuded assemblages (see Clarke et al. 2006b). Non-adjusted Bray Curtis similarity was used for coral species and symbiont type presence/absence. Environmental variables were $(\log +1)$ transformed and normalised, with similarities then calculated using Euclidean distance.

Differences in benthic cover and coral species presence/absence among sites were assessed using the PERMANOVA routine with 999 permutations. PERMANOVA is a multi-factorial analysis of variance, unconstrained by the assumptions of normality and homogeneity of variance that limit the use of traditional MANOVA. It relies on comparing the observed value of a test statistic (pseudo $F$-ratio) against a recalculated test statistic generated from random reordering (permutation) of the data (Anderson 2001). Unconstrained multidimensional scaling (MDS) and constrained canonical analysis of principal components (CAP) were used to visualise the differences in benthic cover, coral species presence/absence, environmental parameters and holobiont presence/absence.

To assess the influence of environmental variables on distribution patterns, BIOENV was used as an exploratory tool to estimate correlations between the similarity 
matrix derived for the benthic cover, coral species presence, and holobiont presence and the matrix of environmental measurements taken at each site. The null hypothesis tested was that there was no correlation between environmental variables and coral/holobiont distribution patterns. Where possible, mean, maximum and minimum values of each environmental measure were used in the analysis. Results are expressed as a Spearman's correlation coefficient (r), ranked in the order of which a single variable or combination of variables best explains the observed community patterns (Clarke \& Ainsworth 1993). The results (correlation coefficient range of -1 to 1 ) indicate the proportion of variance in the community data explained by these environmental variables (see Clarke \& Ainsworth 1993 for full details). The environmental variables were screened for multi-collinearity prior to running the BIOENV routine and only a representative of any highly correlated water quality variables (i.e., those with Spearman's $\geq, 0.8$ ) was used. In a second step, only the environmental variables selected by BIOENV were included as explicative variables in the LINKTREE procedure (a non-parametric multivariate form of classification and regression trees; De'ath 2002). This non-parametric multivariate discrimination technique constructs a hierarchical tree through successive dichotomies of the set of observations. Each division is characterised by one or more variables, and ranges of their values, that appear to be responsible for discriminating each different assemblage grouping. LINKTREE is capable of demonstrating that an environmental variable is important for the internal assemblage structuring of one group of samples but not for another group (with similar value ranges). 


\subsection{RESULTS}

\subsubsection{Coral community structure}

Sixty-seven coral species from 10 genera were identified from the 5 sites around Palmyra Atoll (Appendix A4.1 lists all coral species identified at Palmyra Atoll). Species diversity was greatest at Penguin Spit Middle and Tortugonas (both 41 spp.) and least at Sand Island (only 8 spp., Table 4.1). Sand Island was conspicuous in terms of its low density of coral species $\left(2.64 \pm 0.1\right.$ species per $\mathrm{m}^{2}$, mean $\left.\pm \mathrm{SE}\right) . \mathrm{N} 1$, an index of the number of rare species at a site, was greatest at Penguin Spit sites (10.1 and 11.3), and lowest at Sand Island and Tortugonas (4.5 and 4.8 respectively). N2, an index of dominant species, was also greatest at Penguin Spit sites (6.6 and 6.8). Evenness (N21') of rare and dominant species was lowest at Tortugonas at 0.4 compared to the maximum of 0.7 at North Coral Gardens.

Mean coral cover $( \pm \mathrm{SE}$ ) varied significantly among 3 of the 5 sites, from a minimum of $3.61 \pm 0.33 \%$ at Sand Island, to a maximum of $66.73 \pm 2.2 \%$ at North Coral Garden $(\mathrm{p}<0.001, \mathrm{NCG}>\mathrm{PSM}$, PSI, TO $>$ SI, Figure 4.2). The most abundant genus at the depauperate site of Sand Island was Pocillopora, with 5 species recorded (P. eydouxi, P. damicornis, P. verrucosa, P. meandrina, P. brevicornis). Montipora spp. dominated at North Coral Gardens, accounting for a mean $( \pm \mathrm{SE})$ of $57 \pm 2.5 \%$ of the benthic cover. Montipora spp. were also the most abundant corals in terms of percent cover at Penguin Spit middle $(10.2 \pm 1.2 \%)$. Acropora spp. had the greatest abundance of all coral genera at both Tortugonas and Penguin Spit Inner, accounting for $25 \pm 3.4 \%$ and $20 \pm 2.6 \%$ of the benthic cover, respectively. Pocillopora spp., Montipora spp. and Faviid spp. were the only genera present at all 5 sites surveyed. Species of the family Siderasteridae and soft corals were notably absent at North Coral Gardens, but present at the western sites (excluding 
Sand Island, Table 4.1). No endemic coral species were identified.

\subsubsection{Symbiont identification}

Ten Symbiodinium types were identified in 34 coral species (172 samples) from 9 genera: 8 clade C types and 2 clade D types (Table 4.2, Figure 4.3). All Acropora spp. hosted type C3, as did both Favia spp. Astreopora gracilis hosted C1 solely, with $\mathrm{C} 1$ also present in Pavona spp., Gardinoseris planulata, Leptastrea purpurea, Psammacora nierstrazi and Fungia paumotensis. Two novel Symbiodinium clade C types were identified (yet to be named), $\mathrm{C}_{\mathrm{xx}}$ in $F$. paumotensis (present with $\mathrm{C} 1$ ) and $\mathrm{C} 3_{\mathrm{xx}}$ in Merulina ampliata; $\mathrm{C}_{\mathrm{xx}}$ was 2 basepairs divergent from ancestral $\mathrm{C} 1$, with $\mathrm{C} 3_{\mathrm{xx}} 2$ basepairs divergent from ancestral $\mathrm{C} 1$ (Fig. 4.3). ITS-DGGE fingerprints and sequences of novel types, yet to be named, were consistent and reproducible.

Porites lobata hosted Symbiodinium C15 and C15b, and C15 was also present in a range of Montipora spp. C1c and C42a were hosted by Pocillopora spp., with C1c also harboured by Pavona duerdeni. Finally, C1b was present in L. purpurea with C1. Of the D types identified, D1 and D1a were found in Montipora spp. and Echinophyllia sp., while D1a alone was present in Turbinaria reniformis.

There was no pattern of symbiont diversity among sites. The key genera/families identified (Acropora, Astreopora, Favia, Montipora, Pavona and Pocillopora) all associated with similar symbionts across the atoll (Table 4.2). Acropora, Astreopora and Favia consistently hosted one type across all sites samples at the atoll. Similarly, Montipora hosted C15 and D1a at all sites. Minor variation in symbiont distributions were seen in Pavona and Pocillopora spp. Pavona hosted C1 and C3 at all sites sampled (3 
Table 4.1 Coral community measures and environmental parameters recorded at 5 backreef sites around Palmyra Atoll, USA. Benthic categories and coral genera shown as percent cover \pm SE. Mean \pm SE of environmental variables shown. Temperatures recorded by HOBO over a 5-week period or CTD over a 7-day period in June/July 2007. CTD also recorded chlorophyll fluorescence $\left(\mu \mathrm{g}^{-1}\right)$ and salinity. Sedimentation, measured using sediment traps, given as total particulate matter (TPM), particulate organic matter (POM) and percent organic matter (PCOM).

\begin{tabular}{|c|c|c|c|c|c|}
\hline & Sand Island & $\begin{array}{l}\text { Penguin Spit } \\
\text { Inner }\end{array}$ & $\begin{array}{l}\text { Penguin Spit } \\
\text { Mid }\end{array}$ & Tortugonas & $\begin{array}{l}\text { North Coral } \\
\text { Gardens }\end{array}$ \\
\hline Dead/Rubble & $76.4 \pm 1.6$ & $62.2 \pm 3.1$ & $80.7 \pm 1.7$ & $69.1 \pm 3.3$ & $33.3 \pm 2.2$ \\
\hline Sand & $19.9 \pm 1.7$ & $13.8 \pm 2.7$ & $1.04 \pm 0.7$ & $0.0 \pm 0.0$ & $0.0 \pm 0.0$ \\
\hline Macroalgae & $<1 \pm 0.0$ & $0.0 \pm 0.0$ & $0.0 \pm 0.0$ & $0.0 \pm 0.0$ & $0.0 \pm 0.0$ \\
\hline Sponge & $<1 \pm 0.1$ & $<1 \pm 0.1$ & $<1 \pm 0.1$ & $<1 \pm 0.1$ & $<1 \pm 0.1$ \\
\hline Total coral cover & $3.6 \pm 0.3$ & $23.9 \pm 2.4$ & $18.5 \pm 1.5$ & $30.9 \pm 3.3$ & $66.7 \pm 2.2$ \\
\hline Fungiidae & $0.0 \pm 0.0$ & $0.2 \pm 0.1$ & $0.8 \pm 0.1$ & $0.2 \pm 0.1$ & $<0.1 \pm 0.0$ \\
\hline Pocilloporidae & $3.4 \pm 0.3$ & $1.4 \pm 0.3$ & $1.1 \pm 0.2$ & $0.7 \pm 0.2$ & $1.2 \pm 0.3$ \\
\hline Poritidae & $0.1 \pm 0.1$ & $0.0 \pm 0.0$ & $<0.1 \pm 0.0$ & $0.0 \pm 0.0$ & $0.2 \pm 0.2$ \\
\hline Siderasteridae & $0.0 \pm 0.0$ & $<0.1 \pm 0.0$ & $0.1 \pm 0.0$ & $0.1 \pm 0.1$ & $0.0 \pm 0.0$ \\
\hline Acropora spp. & $0.0 \pm 0.0$ & $9.9 \pm 2.6$ & $2.8 \pm 1.1$ & $25.1 \pm 3.4$ & $0.6 \pm 0.4$ \\
\hline Astreopora sp. & $0.0 \pm 0.0$ & $3.7 \pm 0.6$ & $0.3 \pm 0.2$ & $0.1 \pm 0.1$ & $3.1 \pm 0.7$ \\
\hline Montipora spp. & $0.3 \pm 0.1$ & $3.3 \pm 0.6$ & $10.2 \pm 1.2$ & $3.0 \pm 0.6$ & $57.4 \pm 2.5$ \\
\hline Dendrophyllidae & $0.0 \pm 0.0$ & $<0.1 \pm 0.0$ & $0.0 \pm 0.0$ & $0.0 \pm 0.0$ & $0.0 \pm 0.0$ \\
\hline Faviidae & $0.1 \pm 0.1$ & $2.4 \pm 0.6$ & $1.0 \pm 0.4$ & $0.6 \pm 0.2$ & $1.1 \pm 0.4$ \\
\hline Merulinidae & $0.0 \pm 0.0$ & $0.4 \pm 0.3$ & $0.1 \pm 0.1$ & $0.1 \pm 0.0$ & $2.4 \pm 1.1$ \\
\hline Agariciidae & $0.0 \pm 0.0$ & $1.0 \pm 0.3$ & $0.7 \pm 0.2$ & $1.1 \pm 0.3$ & $0.7 \pm 0.4$ \\
\hline Mussidae & $0.0 \pm 0.0$ & $0.2 \pm 0.2$ & $0.0 \pm 0.0$ & $0.0 \pm 0.0$ & $<0.1 \pm 0.0$ \\
\hline Soft corals & $0.0 \pm 0.0$ & $1.4 \pm 0.4$ & $1.5 \pm 0.4$ & $0.1 \pm 0.0$ & $0.0 \pm 0.0$ \\
\hline \multicolumn{6}{|l|}{ Diversity Indices } \\
\hline \multicolumn{6}{|l|}{ Coral } \\
\hline Total no. species & 8 & 39 & 41 & 41 & 34 \\
\hline N1 & 4.5 & 10.1 & 11.3 & 4.8 & 6.7 \\
\hline N2 & 2.9 & 6.6 & 6.8 & 2.3 & 5.0 \\
\hline $\mathrm{N} 21{ }^{\prime}$ & 0.5 & 0.6 & 0.6 & 0.4 & 0.7 \\
\hline \multicolumn{6}{|l|}{$\begin{array}{l}\text { Symbiodinium (in key } \\
\text { coral species) }\end{array}$} \\
\hline Total no. types & 3 & 6 & 5 & 6 & 6 \\
\hline \multicolumn{6}{|l|}{ Environmental } \\
\hline Mean temperature $\left({ }^{\circ} \mathrm{C}\right)$ & $28.7 \pm 0.8$ & $28.3 \pm 0.3$ & $28.2 \pm 0.3$ & $28.2 \pm 0.3$ & $28.4 \pm 0.5$ \\
\hline Max. temperature $\left({ }^{\circ} \mathrm{C}\right)$ & 31.1 & 29.5 & 31.3 & 31.1 & 34.8 \\
\hline Mean Chlorophyll $(\mu \mathrm{g} / \mathrm{l})$ & $3.4 \pm 3$ & $0.71 \pm 0.5$ & $0.4 \pm 0.2$ & $0.29 \pm 0.5$ & $0.86 \pm 2.1$ \\
\hline Mean TPM $\left(\mathrm{g} \mathrm{m}^{-2} \mathrm{~d}^{-1}\right)$ & $52.5 \pm 55$ & $9.3 \pm 12.3$ & $11.5 \pm 21.6$ & $7.9 \pm 20$ & $1.4 \pm 1.3$ \\
\hline Max. TPM $\left(\mathrm{g} \mathrm{m}^{-2} \mathrm{~d}^{-1}\right)$ & 129.8 & 43.8 & 75 & 74.4 & 3.81 \\
\hline Mean POM $\left(\mathrm{mg} \mathrm{m}^{-2} \mathrm{~d}^{-1}\right)$ & $1670 \pm 2077$ & $78 \pm 46$ & $64 \pm 46$ & $156 \pm 433$ & $23 \pm 18$ \\
\hline Max. POM $\left(\mathrm{mg} \mathrm{m}^{-2} \mathrm{~d}^{-1}\right)$ & 4730 & 201 & 131 & 1596 & 53 \\
\hline Mean PCOM $(\%)$ & $37.3 \pm 34$ & $10.9 \pm 6$ & $13.8 \pm 0.6$ & $12.6 \pm 6$ & $30.1 \pm 11$ \\
\hline Mean Salinity (PSU) & $34.1 \pm 0.3$ & $34.7 \pm 0.1$ & $34.6 \pm 0.1$ & $34.7 \pm 0.1$ & $34.5 \pm 0.3$ \\
\hline
\end{tabular}



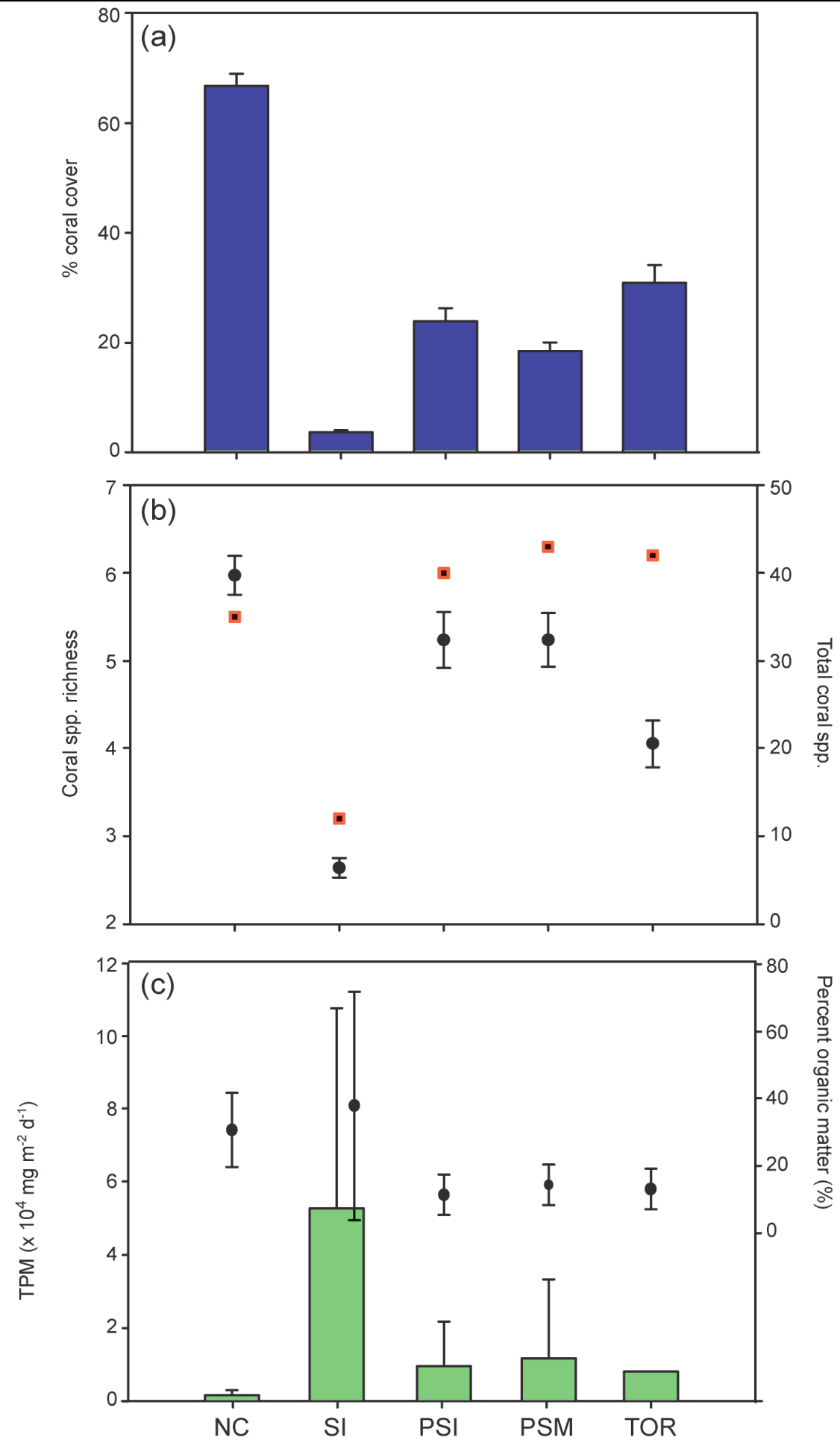

Figure 4.2 Variation in (a) coral \% cover (mean $\pm \mathrm{SE}$ ) (b) no. of coral spp. per $\mathrm{m}^{2}$ (mean $\pm \mathrm{SE}$, •, left axis) and per site (right axis $\square$ ), and (c) sedimentation measures (mean \pm SD) of total particulate matter ( $\square$, left axis) and percent organic matter $\left(\bullet\right.$ right axis, both $\left.\mathrm{mg} \mathrm{m}^{-2} \mathrm{~d}^{-1}\right)$ between five sites at Palmyra Atoll, USA. NC: North Coral Gardens, SI: Sand Island, PSI: Penguin Spit Inner, PSM: Penguin Spit Mid, TOR: Tortugonas. 
western sites) but C1c was also present at Penguin Spit Middle. Similarly, Pocillopora spp. associate with $\mathrm{C} 1 \mathrm{c}$ and $\mathrm{C} 42 \mathrm{a}$ at North Coral Gardens, Penguin Spit Inner and Tortugonas, but C1c alone is harboured by Pocillopora spp. at Penguin Spit Middle and Sand Island.

\subsubsection{Environmental variables}

Temperatures differed significantly among sites (Table 4.2, $p<0.001$ ) however on an ecological scale the variability was low, with means \pm SD ranging from $28.2 \pm 0.03^{\circ} \mathrm{C}$ to $28.7 \pm 0.8^{\circ} \mathrm{C}$. The maximum temperature recorded over the 5 -week period, $34.8^{\circ} \mathrm{C}$, was at North Coral Gardens, with the minimum temperature of $25.4^{\circ} \mathrm{C}$ recorded at Penguin Spit Middle. Salinity (PSU) ranged from $34.1 \pm 0.3$ to $34.7 \pm 0.1$, and was significantly different among 4 of the 5 sites $(\mathrm{p}<0.001$, Table 4.2). Chlorophyll- $a$ concentration (measured as fluorescence: FIC), was significantly different among all sites, with the largest mean value

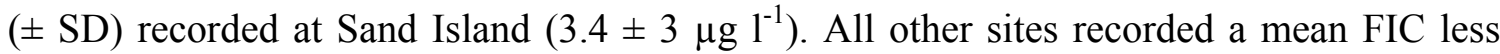

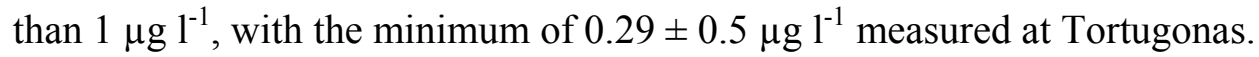

Levels of sedimentation were measured as total particulate matter (TPM), particulate organic matter (POM) and percent organic matter (PCOM) (Table 4.1, Fig. 4.2). TPM was significantly greater at Sand Island than North Coral Gardens $(p<0.05)$, but was not significantly different among any other site combinations. Sand Island exhibited the highest mean $( \pm \mathrm{SD})$ TPM of $52.5 \pm 55 \mathrm{~g} \mathrm{~m}^{-2} \mathrm{~d}^{-1}$, with TPM at North Coral Gardens being the lowest at $1.4 \pm 1.3 \mathrm{~g} \mathrm{~m}^{-2} \mathrm{~d}^{-1}$. Mean TPM at the three other sites ranged from $7.9-11.5 \mathrm{~g}$ $\mathrm{m}^{-2} \mathrm{~d}^{-1}$, although all measures were highly variable (Table 4.1). Mean POM $( \pm \mathrm{SD})$ ranged from $23 \pm 18 \mathrm{mg} \mathrm{m}^{-2} \mathrm{~d}^{-1}$ (North Coral Gardens) to $1670 \pm 2077 \mathrm{mg} \mathrm{m}^{-2} \mathrm{~d}^{-1}$ (Sand Island), again a highly variable measure. Significant greater POM was recorded at Sand 
Table 4.2 Symbiodinium types identified in coral species from 5 backreef sites at Palmyra Atoll,

USA, using ITS2-DGGE. NC: North Coral Gardens, SI: Sand Island, PSI: Penguin Spit Inner, PSM: Penguin Spit Mid, TOR: Tortugonas.

\begin{tabular}{|c|c|c|c|c|c|}
\hline Host species/genus & $\mathrm{NC}$ & PSI & PSM & SI & Tort \\
\hline \multicolumn{6}{|l|}{ Acroporidae } \\
\hline A. acuminata & & $\mathrm{C} 3$ & & & $\mathrm{C} 3$ \\
\hline A. cerealis & & $\mathrm{C} 3$ & & & \\
\hline A. cytherea & & & $\mathrm{C} 3$ & & \\
\hline A. danai & & $\mathrm{C} 3$ & & & \\
\hline A. elseyi & & $\mathrm{C} 3$ & & & \\
\hline A. formosa & & & & & $\mathrm{C} 3$ \\
\hline A. glauca & & & $\mathrm{C} 3$ & & \\
\hline A. nasuta & & & & & $\mathrm{C} 3$ \\
\hline A. valida & $\mathrm{C} 3$ & & & & $\mathrm{C} 3$ \\
\hline A. verweyi & & & & & $\mathrm{C} 3$ \\
\hline Astreopora gracilis & $\mathrm{C} 1$ & $\mathrm{C} 1$ & $\mathrm{C} 1$ & & $\mathrm{C} 1$ \\
\hline Montipora $\mathrm{Gp} 2$ & $\mathrm{D} 1 / \mathrm{a}$ & & & & \\
\hline Montipora $\mathrm{Gp} 3$ & $\mathrm{C} 15, \mathrm{D} 1 / \mathrm{a}$ & $\mathrm{D} 1 / \mathrm{a}$ & $\mathrm{C} 15$ & $\mathrm{C} 15, \mathrm{D} 1 / \mathrm{a}$ & \\
\hline Montipora Gp 4 & $\mathrm{C} 15$ & $\mathrm{D} 1 / \mathrm{a}$ & $\mathrm{D} 1 / \mathrm{a}$ & & $\mathrm{D} 1 / \mathrm{a}$ \\
\hline Montipora $\mathrm{Gp} 6$ & $\mathrm{C} 15$ & $\mathrm{C} 15$ & $\mathrm{C} 15$ & & \\
\hline Montipora $\mathrm{Gp} 7$ & C15 & & & & \\
\hline Montipora $\mathrm{Gp} 8$ & $\mathrm{C} 15$ & $\mathrm{C} 15$ & $\mathrm{C} 15$ & & $\mathrm{C} 15$ \\
\hline \multicolumn{6}{|l|}{ Pectiniidae } \\
\hline Echinophyllia sp. & & & $\mathrm{D} 1 / \mathrm{a}$ & & \\
\hline \multicolumn{6}{|l|}{ Faviidae } \\
\hline Favia matthai & & $\mathrm{C} 3$ & & & \\
\hline Favia stelligera & $\mathrm{C} 3$ & $\mathrm{C} 3$ & $\mathrm{C} 3$ & & $\mathrm{C} 3$ \\
\hline Leptastrea purpurea & & & & $\mathrm{C} 1 / \mathrm{b}$ & \\
\hline \multicolumn{6}{|l|}{ Fungiidae } \\
\hline Fungia paumotensis & & & $\mathrm{C} 1+\mathrm{C} 1_{\mathrm{xx}}$ & & \\
\hline \multicolumn{6}{|l|}{ Agariciidae } \\
\hline Gardinoseris planulata & & $\mathrm{C} 1$ & & & \\
\hline Pavona duerdeni & & $\mathrm{C} 1+\mathrm{C} 3$ & $\mathrm{C} 1 / \mathrm{c}, \mathrm{C} 3$ & & $\mathrm{C} 1+\mathrm{C} 3$ \\
\hline Pavona varians & & $\mathrm{C} 1$ & $\mathrm{C} 1$ & & \\
\hline \multicolumn{6}{|l|}{ Siderastreidae } \\
\hline Psammacora nierstrazi & & & $\mathrm{C} 1$ & & \\
\hline \multicolumn{6}{|l|}{ Merulinidae } \\
\hline Merulina ampliata & $\mathrm{C} 3_{\mathrm{xx}}$ & & & & \\
\hline \multicolumn{6}{|l|}{ Pocilloporidae } \\
\hline Pocillopora damicornis & $\mathrm{Clc}$ & $\mathrm{C} 1 \mathrm{c}+\mathrm{C} 42 \mathrm{a}$ & & $\mathrm{Clc}$ & \\
\hline Pocillopora eydouxi & $\mathrm{C} 1 \mathrm{c}+\mathrm{C} 42 \mathrm{a}$ & & & & $\mathrm{Clc}$ \\
\hline Pocillopora meandrina & $\mathrm{Clc}$ & $\mathrm{Clc}$ & $\mathrm{Clc}$ & $\mathrm{Clc}$ & \\
\hline Pocillopora verrucosa & & $\mathrm{C} 1 \mathrm{c}$ & & & $\mathrm{C} 1 \mathrm{c}+\mathrm{C} 42 \mathrm{a}$ \\
\hline Poritidae & & & & & \\
\hline Porites lobata & $\mathrm{C} 15 / \mathrm{b}$ & & & $\mathrm{C} 15 / \mathrm{b}$ & \\
\hline $\begin{array}{l}\text { Dendrophyllidae } \\
\text { Turbinaria reniformis }\end{array}$ & & D1a & & & \\
\hline
\end{tabular}




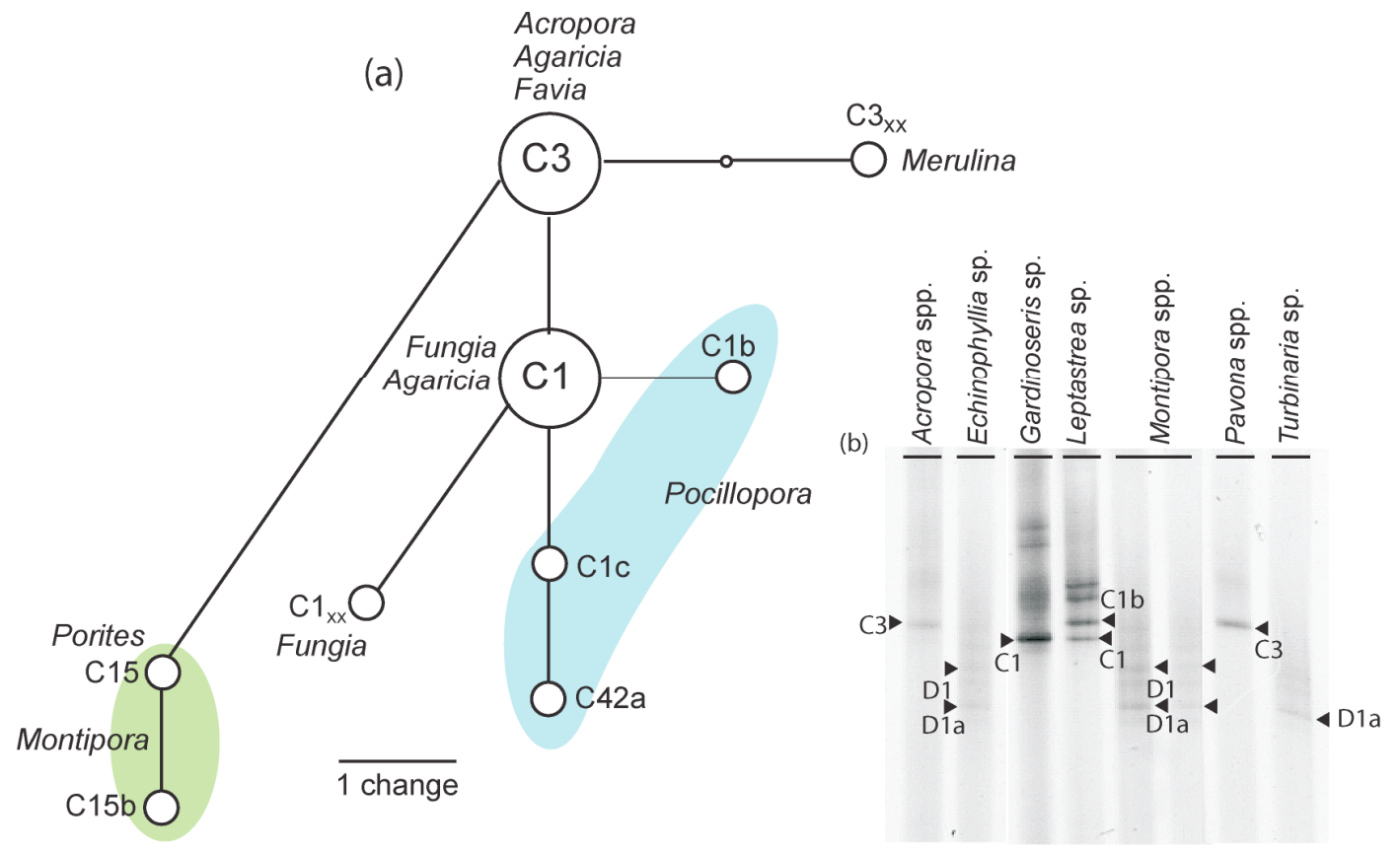

(c)
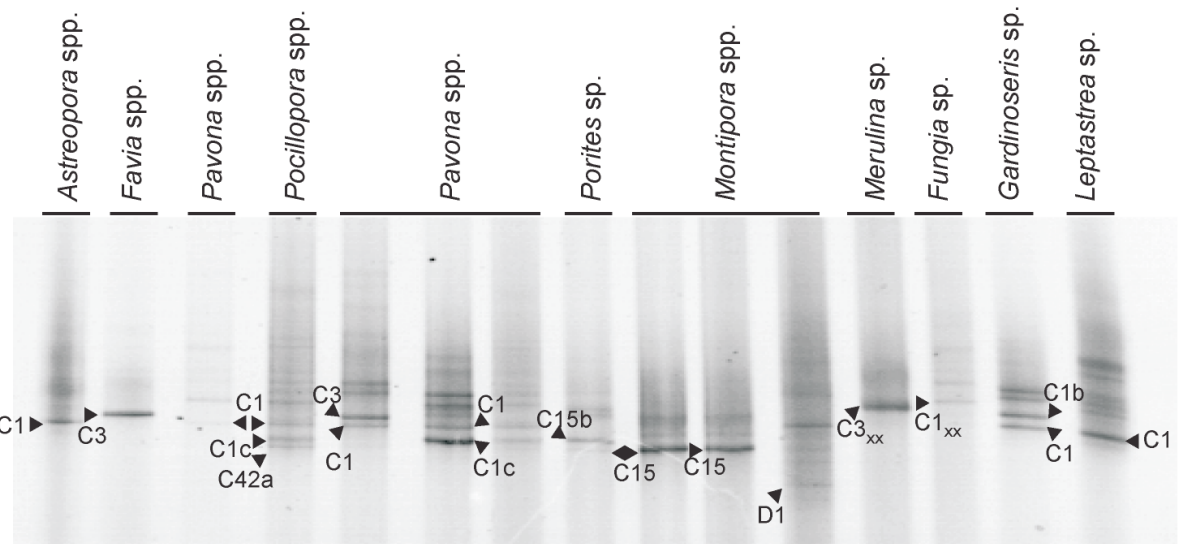

Figure 4.3. Symbiodinium types identified in corals at Palmyra Atoll, USA, based on ITS2 DGGE. (a) Unrooted phylogenetic sequence reconstruction showing the position of ITS2 types in relation to ancestral types $\mathrm{C} 1$ and $\mathrm{C} 3$, using maximum parsimony. Connections $90 \%$ connection support, and internodal branch lengths represent distance in terms of basepairs. Host genera from which symbionts identified noted. (b) and (c) ITS-DGGE gels showing symbiont profiles found in various host genera. Identified sequences are shown next to bands. $\mathrm{C} 3_{\mathrm{xx}}$ and $\mathrm{C} 1_{\mathrm{xx}}$ are novel types, yet to be named. 
Table 4.3 Summary of ANOVA/Kruskal-Wallis test of differences in environmental variables between sites at Palmyra Atoll, USA. F tests statistic refers to ANOVA test, H refers to KruskalWallis with Dunns post-hoc test.

\begin{tabular}{lclll}
\hline Factor & DF & Test statistic & $\boldsymbol{p}$ & Sites \\
\hline Temperature & 4 & $\mathrm{~F}=1364$ & $<0.001$ & SI $>$ NC $>$ PSM, TOR $>$ PSI \\
Salinity & 4 & $\mathrm{~F}=1350$ & $<0.001$ & SI $>$ NC $>$ PSM, TOR $>$ PSI \\
Chl- $a$ & 4 & $\mathrm{~F}=4947$ & $<0.001$ & SI $>$ NC $>$ PSI $>$ PSM $>$ TOR \\
TPM & 4 & $\mathrm{H}=17.6$ & $<0.001$ & SI $>$ PSM $>$ PSI, TOR $>$ NC \\
POM & 4 & $\mathrm{H}=13.7$ & $<0.001$ & SI $>$ TOR $>$ PSI,PSM,NC \\
PCOM & 4 & $\mathrm{H}=11.9$ & $<0.05$ & NCG, SI $>$ PSI \\
Coral cover & 4 & $\mathrm{~F}=117$ & $<0.001$ & NCG $>$ PSM, PSI, TO $>$ SI \\
\hline
\end{tabular}

Island than at all other sites $(p<0.05)$, with a maximum value of $4.7 \mathrm{~g} \mathrm{~m}^{-2} \mathrm{~d}^{-1}$ recorded at the site. PCOM also varied significantly among sites, with significantly greater values recorded at North Coral Gardens and Sand Island, than Penguin Spit Inner $(p<0.05)$. Maximum PCOM recorded was at Sand Island (89\%).

\subsubsection{Multivariate analyses of corals, symbionts and environmental variables}

Multivariate analysis revealed significant differences in coral species presence and benthic cover among all sites (PERMANOVA, $\mathrm{F}=63.77, p<0.001$, and $\mathrm{F}=42.81, p<0.001$, respectively), yet no difference in holobiont distribution among all sites was observed (PERMOANOVA, $\mathrm{F}=31.23, p=0.456$ ). All sites were grouped separately in terms of their biotic community, with North Coral Gardens a clear outlier when assessing similarities in benthic cover among sites. Differences in coral species presence separated the sites of Sand Island and Tortugonas from the three other sites (Fig. 4.4). Both 
constrained and unconstrained ordinations (CAP and MDS) revealed comparable patterns of similarities of benthic cover and coral species presence among sites (Appendix 4.2).

Significant correlations (Spearman's $\geq 0.08$ ) were recorded among maximum and mean temperature, minimum TPM and POM, chl- $a$ concentration and salinity, PCOM mean and maximum, mean and maximum TPM, and mean and maximum POM. These pairs of variables were treated as single variables in following analyses.

BIO-ENV analysis showed that the combination of environmental variables that best explained the spatial variation of coral species presence were the sedimentation measures of maximum and mean particulate organic matter $\left(\mathrm{POM}, \rho^{\mathrm{w}}=0.814\right)$. These variables explained $81 \%$ of the variation in coral species presence among sites $(\mathrm{R}=0.81, p$ $<0.01)$. In terms of benthic cover the variables minimum total particulate matter (TPM) and maximum TPM explained $80 \%$ of the spatial variation $(\mathrm{R}=0.8, p<0.01)$. TPM minimum was the best single environmental predictor, explaining $79 \%$ of the variability in benthic cover. Other important parameters explaining the spatial variation in both benthic cover and coral species presence, when considered alone, are percent organic matter ( $\rho=$ $0.19)$, chl- $a(\rho=0.27)$ and salinity $(\rho=0.19)$, but the latter two showed significant correlations with each other. BIOENV analysis on symbiont distribution revealed a lack of correlation between the presence of symbionts and environmental variables $(\rho=0.002, p=$ $0.85)$.

LINKTREE analysis showed that when linking the coral species presence and optimum environmental variables together, all sites grouped separately, with sediment measures primarily responsible for discriminating between coral species assemblages (Fig. 4.5). The first split in the assemblage data is between Sand Island and Tortugonas, and the 

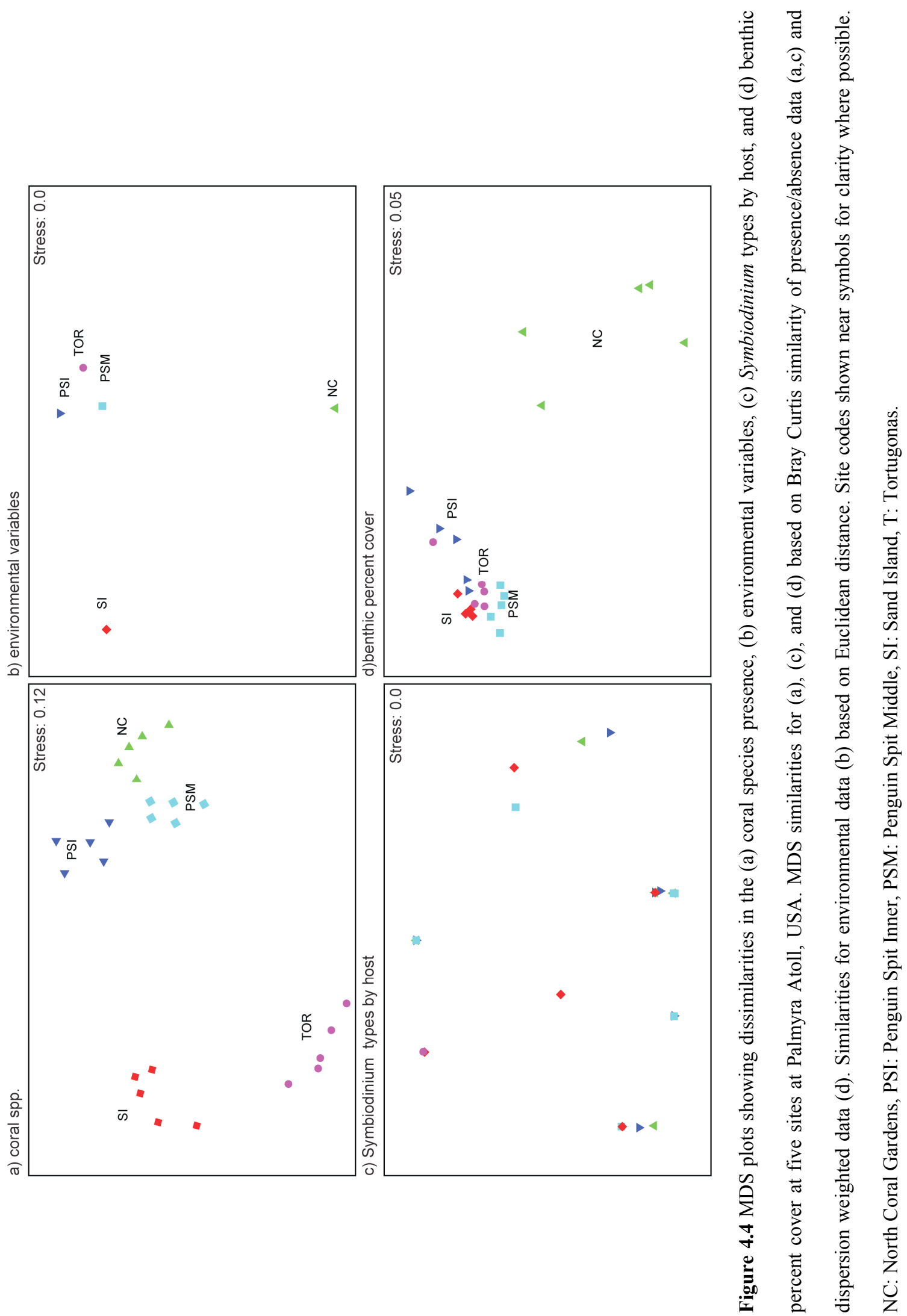
three other sites (ANOSIM $\mathrm{R}=0.83$, Linktree B $\%=96 \%$ ). The former two sites had the greatest mean and maximum POM $\left(>1596 \mathrm{mg} \mathrm{m}^{-2} \mathrm{~d}^{-1}\right.$ and $>156 \mathrm{mg} \mathrm{m}^{-2} \mathrm{~d}^{-1}$ respectively). The differences in coral species assemblages between Tortugonas and Sand Island were correlated with higher maximum PCOM, and mean TPM/POM at Sand Island (27\%, 7918 $\mathrm{mg} \mathrm{m}^{-2} \mathrm{~d}^{-1}$ and $156 \mathrm{mg} \mathrm{m}^{-2} \mathrm{~d}^{-1}$ respectively). The sites of Penguin Spit Mid and North Coral Gardens were aggregated together. These two sites were separated from Penguin Spit Inner $($ ANOSIM R $=0.61$, LINKTREE B $\%=43)$ because the minimum TPM $\left(2448 \mathrm{mg} \mathrm{m}^{-2} \mathrm{~d}^{-1}\right)$ and maximum POM (201 $\left.\mathrm{mg} \mathrm{m}^{-2} \mathrm{~d}^{-1}\right)$ were higher at the latter site. The final division between North Coral Gardens and Penguin Spit Mid was attributed to greater minimum POM (15.5 $\left.\mathrm{mg} \mathrm{m}^{-2} \mathrm{~d}^{-1}\right)$ and PCOM (3.4\%), and lower max TPM (3815 $\left.\mathrm{mg} \mathrm{m}^{-2} \mathrm{~d}^{-1}\right)$ at the former (ANOSIM R =0.88, LINKTREE B \% = 32). Linktree analysis on benthic cover produced similar results to those described for coral species cover (see Appendix A4.2).

\subsection{DISCUSSION}

The variation in environmental parameters, particularly sedimentation, around Palmyra Atoll has led to diversification of coral communities; however this environmental variation has not affected the symbiont communities. Symbiodinium diversity was low, with many coral species harbouring generalist symbionts. The potential cause of this low diversity and the diversification of coral and symbiont distributions at Palmyra will be discussed. 

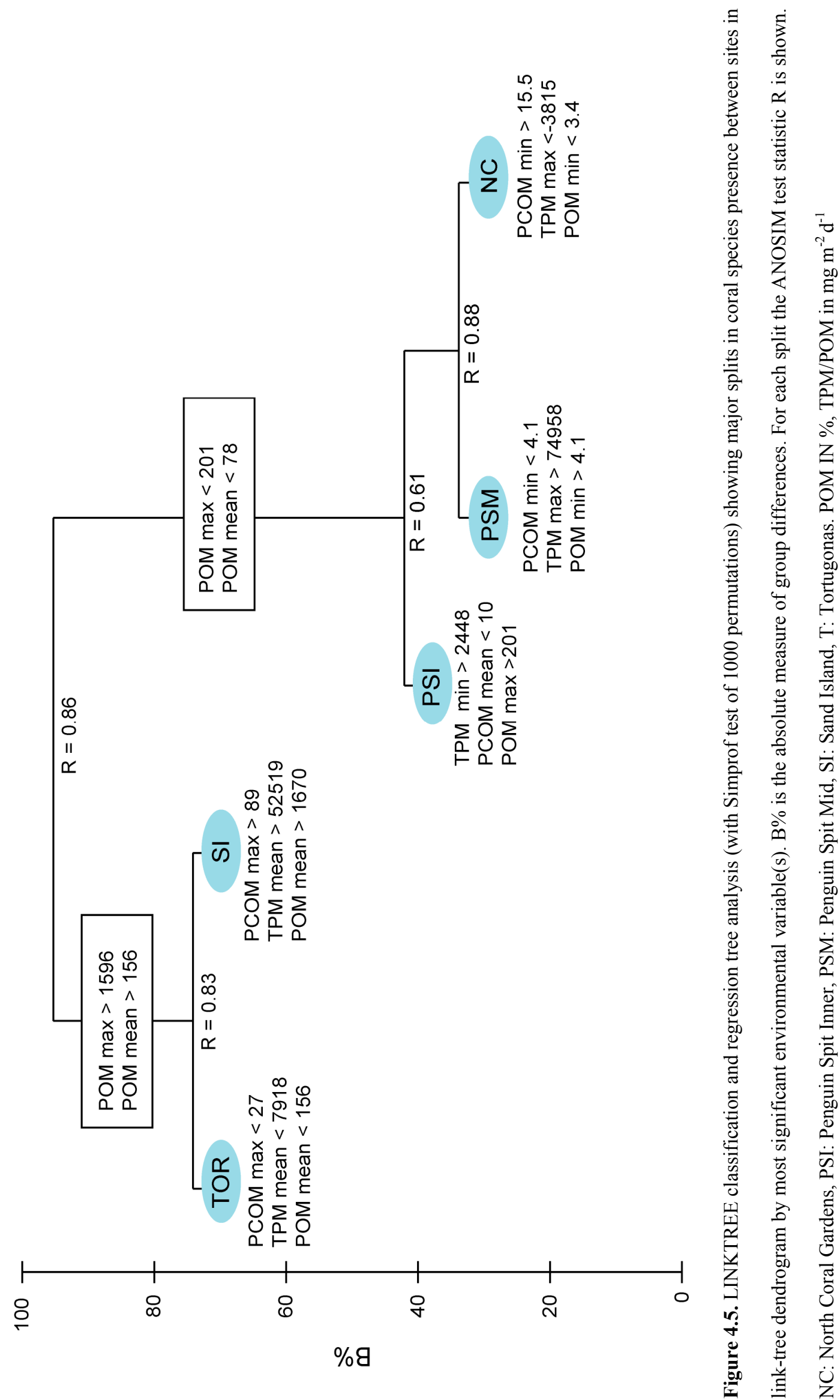


\subsubsection{Symbiodinium at Palmyra Atoll}

Diversity of Symbiodinium types at Palmyra Atoll was low, with only 10 types identified in 34 coral species (from 9 genera), compared to 16 in 24 hosts (in 12 genera) in Hawaii (LaJeunesse et al. 2004b), and 20 types in 37 hosts (in 8 genera) in the Caribbean (LaJeunesse 2002) Of the 10 Symbiodinium types identified, only two were novel types $\left(\mathrm{C} 1_{\mathrm{xx}}\right.$ and $\left.\mathrm{C} 3_{\mathrm{xx}}\right)$, with the generalist ancestral types $\mathrm{C} 1$ and $\mathrm{C} 3$ being dominant. Indeed, Clade $\mathrm{C}$ types overall were dominant at Palmyra, and represent the most frequent types found in scleractinian corals within the Pacific (Baker \& Rowan 1997, LaJeunesse et al. 2004a). At a sub-cladal level, many of the host-symbiont specificities correlate with those observed in the Hawaiian Islands and the Great Barrier Reef (GBR, LaJeunesse et al. 2003, LaJeunesse et al. 2004a). For example, Acropora spp. at Palmyra only harbour type C3 Symbiodinium, as do Acropora spp. on the GBR (van Oppen et al. 2001, LaJeunesse et al. 2004a, although see Chapter 3). Both Pocillopora spp. and Porites sp. sampled at Palmyra host the same symbionts as their counterparts in Hawaii $(\mathrm{C} 1 \mathrm{c}$ and $\mathrm{C} 15$, respectively; LaJeunesse et al. 2004b). At Palmyra, only 3 coral genera were seen to associate with more than one symbiont type: Pavona, Pocillopora and Montipora. The low diversity of Symbiodinium types found in scleractinian corals at Palmyra Atoll may reflect (1) the atoll's high degree of connectivity to other reef systems, (2) the lack of knowledge of symbionts in the Central Pacific, or (3) may be a result of previous environmental perturbation, leading to the dominance of a few stress-tolerant symbionts.

The similarity among the host-symbiont partnerships at Palmyra Atoll, the Hawaiian Islands and the GBR is surprising, given the location of the former in the Central Pacific. Situated $1930 \mathrm{~km}$ south of Hawaii, the high coral biodiversity (176 species) may be 
due to the location of the atoll in the Inter Tropical Convergence Zone, with the eastward flowing North Pacific Equatorial Countercurrent and the Pacific Equatorial current (Hamann et al. 2004), bringing larvae from multiple directions (Maragos et al. 2008b). The nearest reef, Kingman Reef, is 76 km north of Palmyra and hosts 162 coral species. The proximity of Kingman Reef, the rest of the Line Islands, and the Phoenix Islands could enable them to act as stepping stones in the transfer of coral larvae, as has been seen within a $1700 \mathrm{~km}$ length of the GBR (Ayre \& Hughes 2004). In addition to the high coral species diversity, the low diversity of symbiont types at Palmyra may be a factor of the high connectivity leading to a lack of co-evolution. Usually, geographic distinctness leads to genetic drift and the evolution of endemic/rare symbiont types, as observed at many remote locations (e.g. Gulf of California, LaJeunesse et al. 2008; Lord Howe Island, Chapter 3). Although some novel host-specific Symbiodinium types were identified $\left(\mathrm{C} 3_{\mathrm{xx}}\right.$ in $M$. ampliata, and $\mathrm{C}_{\mathrm{xx}}$ in $F$. paumotensis), the abundance of generalist symbionts and of similar host-symbiont partnerships to Hawaii suggests that co-evolution is rare at Palmyra Atoll, perhaps due to the connectivity with other reef systems. F. paumotensis in Hawaii hosted $\mathrm{C} 3 \mathrm{~h}$, whereas M. ampliata hosted $\mathrm{C} 3$ and $\mathrm{C} 1$, all types closely related to the novel ones identified at Palmyra.

The presence of the generalists $\mathrm{C} 1$ and $\mathrm{C} 3$, which have been found in a wide range of hosts and environments, and clade D types being harboured by Echinophyllia sp., Montipora spp. and Turbinaria sp., which all have the ability to associate with C types too (LaJeunesse 2005), suggests that they may have experienced stressful environmental conditions. Clade D Symbiodinium (particularly D1a) have been shown to be resistant to high sedimentation rates and elevated temperatures (Toller et al. 2001b), remaining in host tissue when other symbiont types are depleted (Baker 2001, Jones 2008). By hosting these 
potentially stress-tolerant symbionts, the corals may have survived the stressful conditions during the modification of the atoll, however hosting stress-tolerant symbiont may be at a cost to the host, in terms of their photosynthetic efficiency and growth (Rowan 2004, Little et al. 2004). Further testing of physiological tolerances of the host-symbiont partnerships at the atoll is needed, to determine whether a recent bleaching event is causing the low symbiont diversity observed.

\subsubsection{Environmental variability}

The effect of environmental variables such as temperature, light, wave exposure, salinity and sedimentation on coral communities is well known (Wells 1957, Connell 1978, Johannes et al. 1983, Smith \& Buddemeier 1992, Kleypas et al. 1999). Differences in coral community structure were best explained at Palmyra by the different sediment regimes around the atoll. Parameters such as total particulate matter showed a strong inverse relationship with coral cover, consistent with findings from other locations such as French Polynesia and Singapore (Adjeroud et al. 2000, Dikou \& van Woesik 2006). In a study of which specific aspect of sedimentation most affects coral communities, Dikou and van Woesik (2006) found that reduced light availability has the strongest negative effect. Measures of light were not taken in the present study, however it was clear that light levels were markedly lower at Sand Island, particularly during periods of strong tidal activity (L. Wicks, pers. obs), and this correlates with the lowest coral species diversity and percentage cover at the site. The measured levels of sedimentation were within normal ranges of coral reefs, as defined by Rogers (1990), of $10,000 \mathrm{mg} \mathrm{cm}^{-2}$ day $^{-1}$ or less, although Sand Island did experience some periods of greater sediment load. Heavy levels of sedimentation have been associated with depressed rates of photosynthesis and enhanced respiration and mucus 
production in corals (Riegl \& Branch 1995, Yentsch et al. 2002), in addition to a decline in growth rates, a loss of symbiotic algae and eventual tissue death (Bak 1978, Rogers 1983, Peters \& Pilson 1985). Sedimentation also negatively affects rates of survival and settlement of coral larvae (Babcock \& Davies 1991, Gilmour 1999), with low levels of coral cover, fewer coral species and lower general health of corals all associated with high sediment levels (Fabricius 2005).

The impact of sedimentation was further seen in the distribution of particular coral species, in addition to a decline in species diversity with increasing sediment load. Porites spp. are considered poor sediment rejectors (Stafford-Smith \& Ormond 1992): at Palmyra this is reflected in their highest abundance being at North Coral Gardens which was the site with lowest sedimentation. Porites spp. were, however, present as small isolated colonies at Sand Island and Penguin Spit, and this may be linked to their ability to tolerate sediment deposition through heavy mucus secretion, trapping and subsequent sloughing (Dikou \& van Woesik 2006). Solitary corals of the family Fungiidae possess morphological and physiological adaptations to highly turbid environments, such as broad septal edges and polyp inflation to allow sediment to slide off (Hubbard \& Pocock 1972, Schuhmacher 1977). Accordingly, Fungia spp. at Palmyra Atoll are more abundant on the western, more turbid side of the atoll. Many genera, such as Echinophyllia, Turbinaria and Hydnophora (L. Wicks, pers. obs.) are common in deep or turbid waters and are only found to the western side of the atoll. Pocillopora spp. have been cited as being characteristic of turbid waters in the Indo-Pacific (Rogers 1990): at Palmyra this is reflected in their dominance of the coral fauna at the highly turbid site Sand Island. Acropora spp. are poor sediment rejectors (Bak \& Elgershuizen 1976) and intolerant of low light (Roy \& Smith 1971, Sheppard 1980, Bouchon 1981): at Palmyra their dominance at Tortugonas may be linked 
to their ability to escape sedimentation due to their branching morphology, although their presence suggests that turbidity levels are low enough to allow sufficient light for photosynthesis.

The environmental variables influencing the diversity of coral communities at Palmyra have not affected the symbiont communities. Some coral species may harbour multiple physiologically-distinct symbiont types, sometimes simultaneously, with their presence or dominance being in response to the external environment (Rowan et al. 1997, van Oppen et al. 2001, Venn et al. 2008b). For example, Symbiodinium clades A, C and D were found evenly distributed in Montastrea spp. in areas of high sedimentation in Panama, with clade B dominant in the clearer waters of nearby Belize (Garren et al. 2006). At Palmyra, however, coral species tend to host single Symbiodinium types, commonly the generalist types C1 and C3 (LaJeunesse et al. 2003) which have the ability to associate with a range of hosts in various environments. The community structures of Symbiodinium types characterized from Palmyra's host assemblage is similar to those observed in Caribbean and western Pacific reefs where a greater percentage of host taxa share a common symbiont type (LaJeunesse 2002; LaJeunesse et al. 2003), attributed to increased extinction rates and the increased faunal turnover of scleractinian corals. Exceptions to this at Palmyra included Montipora spp., which hosted both C15 and 'stress tolerant' D1/a (Baker 2001, Thornhill et al. 2006a). However, both symbionts were present at all sites, excluding the turbid Sand Island at which Montipora spp. only hosted C15. It may be that both C15 and D1a are equally tolerant to potential stressors; indeed, Montipora digitata hosting C15 on the GBR was found to be less sensitive to thermal stress than were other Montipora-symbiont partnerships (LaJeunesse et al. 2003). This reduced host-specificity uncoupled with environmental conditions was observed in Pocillopora spp. at Palmyra, which had the 
ability to host $\mathrm{C} 1 \mathrm{c}$, either alone or with $\mathrm{C} 42 \mathrm{a}$, and Pavona spp. could host $\mathrm{C} 3, \mathrm{C} 1$ or $\mathrm{C} 1 / \mathrm{c}$. The homogeneity of coral-Symbiodinium partnerships across the atoll indicates that the partnerships are able to tolerate the wide range of environmental conditions.

The susceptibility of the host, rather than the symbiont, to sedimentation appears to drive coral distribution patterns at Palmyra Atoll. Host factors have been demonstrated to be critical to stress susceptibility (Fitt et al. 2009), however the nature of this susceptibility is less well recognised. For example, symbiont type $\mathrm{C} 3$ has been observed to be stresssusceptible in Acropora spp. but stress-tolerant in Favia and Goniastrea spp. (LaJeunesse et al. 2003). Differences in the capacity of host species to use mechanisms to combat sedimentation might therefore determine the host distributions in response to stressful environments. Much remains to be learnt of the physiological variability between symbionts and hosts, and the flexibility of the relationship between the two in response to changes in the environment.

\subsubsection{Future plans for Palmyra Atoll}

Although at present sedimentation levels at Palmyra are within normal levels of corals reefs, the proposed restoration of the atoll will change this, and may negatively impact the coral communities present. The man-made causeways are breaking down, with sediment being redistributed by physical processes (Collen et al. 2009), potentially affecting corals across the atoll. Restoration would involve the creation and widening of breaks in the causeways to re-establish flow to pre-WWII conditions, leading to short-term increases in sediment load, but long-term reduction in turbidity and water temperature in the shallow reef areas (Maragos et al. 2008a).The current host-symbiont partnerships tolerate a range of sediment regimes across the atoll, and thus may be able to withstand low levels of 
environmental perturbation. In the event of restoration going forward, host-symbiont communities should be monitored.

\subsubsection{Ecological implications}

Sedimentation is just one of many large-scale disturbances that can exert considerable impact on coral communities. Coral reefs face a rapid change in their environment from increasing sea surface temperature (SST), and questions exist as to how (if) they will adapt and whether their rates of adaptation will be rapid enough to match those of the changing environment. Palmyra is located to the north of equatorial upwelling, and so year round experiences temperatures greater than $28^{\circ} \mathrm{C}$ (Maragos et al. 2008b) comparable to temperatures on other Pacific reefs where bleaching commonly occurs (Oliver \& Palumbi 2009). In the shallow lagoon regions of the atoll where corals flourish, water temperature will increase beyond this $28^{\circ} \mathrm{C}$ on a diurnal basis. Further, El Niño conditions can increase annual SST at Palmyra, which in the past has led to bleaching events and the catastrophic death of staghorn and tabular corals on the southwest side of the atoll (Maragos et al. 2008a).

The lack of correlation between symbiont community and environmental attributes at Palmyra suggest that the symbionts are robust enough to cope with the environmental regime, which may be less severe than expected. However, if environmental conditions (i.e. increased SST, heavy sedimentation) do reach a level where stress-induced bleaching occurs, the low diversity of symbionts may put these corals at a greater risk of extinction, than reefs hosting diverse symbiont assemblages (LaJeunesse et al. 2003). The presence of 'stress-tolerant' clade D symbionts may allow resistance to bleaching by some coral species 
(Glynn et al. 2001, Baker et al. 2004, Rowan 2004, Berkelmans \& Van Oppen 2006), but only the coral species able to host tolerant symbiont types will have the capacity to survive. Despite the relatively high water temperatures experienced at Palmyra, and the high sedimentation regimes at some areas of the atoll, diverse coral communities still exist, and recovery from bleaching has been reported (Maragos et al. 2008b). Reefs experiencing no direct anthropogenic impact such as Palmyra have been reported to display a greater capacity than reefs experiencing anthropogenic impacts to survive or recover from bleaching episodes, due to the protection from added stressors of overfishing and pollution (Sandin et al. 2008). Further, the high degree of connectivity among Palmyra and other reef systems does mean that in the case of regional or global scale disturbances, a significant influx of larvae from multiple sources will help the community recover. 


\title{
Chapter 5
}

\section{Photophysiology of Symbiodinium in response to environmental stress at a}

\author{
high latitude, seasonally variable site
}

\begin{abstract}
Biogeographic variability in the partnerships of corals and their dinoflagellate symbionts (Symbiodinium spp.) is linked, in part, to the physiological difference between the symbionts. Pocillopora damicornis hosts genetically distinct and novel types of symbiont at the high latitude site of Lord Howe Island (LHI), yet why these novel types exist at LHI is unknown. In this study, I examined whether one of the novel holobiont partnership at LHI is physiologically adapted for this high latitude site and so help explain the success of this marginal coral reef. High and low thermal bleaching thresholds of the coral-symbiont partnerships were measured as $14^{\circ} \mathrm{C}$ and $30^{\circ} \mathrm{C}$. Photochemical sensitivity to temperature $\left(15^{\circ} \mathrm{C}\right.$ and $\left.29^{\circ} \mathrm{C}\right)$ and light treatments $(100 \%$ and $40 \%$ of sunlight $)$, measured as effective quantum yield and fast induction curves, were also determined over a $72 \mathrm{~h}$ period. A lesser impact on the photochemical processes of LHI symbionts was recorded in response to a $3^{\circ} \mathrm{C}$ temperature decrease from annual minima, than a $3^{\circ} \mathrm{C}$ temperature increase from annual maxima. Water temperatures at LHI annually range from $18-26^{\circ} \mathrm{C}$, but corals still did not bleach when temperature was reduced to $15^{\circ} \mathrm{C}$ for $72 \mathrm{~h}$, with minimal bleaching in the $14^{\circ} \mathrm{C}$ treatment. In contrast, after $72 \mathrm{~h}$, a $94 \%$ decline in photochemical efficiency were recorded in the $29^{\circ} \mathrm{C}$ treatment $\left(\Delta \mathrm{F} / \mathrm{F}_{\mathrm{m}}{ }^{\prime}<0.05\right)$, compared to $37 \%$ loss in the control.
\end{abstract}


Response to warm and cold temperature stress were both enhanced by high light levels. This study suggests that the types of Symbiodinium at LHI may be specialised for cooler and more variable temperatures, so contributing to the success of corals at this marginal location.

\subsection{INTRODUCTION}

The success of coral reefs results from the symbiotic relationship between scleractinian corals and dinoflagellates of the genus Symbiodinium. The coral relies on its dinoflagellate symbionts for survival, as they release substantial amounts of photosynthate to the host, and aid the recycling and conservation of nitrogen (Muscatine 1990, Wang \& Douglas 1998). In return, the host provides carbon dioxide for photosynthesis and nutrients (e.g. nitrogen and phosphorus) required for synthesis of cellular constituents, including the photosynthetic apparatus.

The photosynthetic efficiency of the dinoflagellates is a function of both their environment and the diversity within the genus Symbiodinium (Iglesias-Prieto \& Trench 1997b, Rowan 2004, Tchernov et al. 2004, Berkelmans \& Van Oppen 2006, Abrego et al. 2008). The genus is highly diverse, with 8 clades (A-H) and numerous sub-clades identified (reviewed in Rowan 1998, Baker 2003, Coffroth \& Santos 2005). As a reflection of the high genetic diversity within the genus Symbiodinium, considerable physiological diversity exists at both cladal and sub-cladal levels, including in terms of tolerance to irradiance and/or temperature (Iglesias-Prieto \& Trench 1997b, Iglesias-Prieto et al. 2004, Robison \& Warner 2006, McCabe-Reynolds et al. 2008, Takahashi et al. 2009). This physiological diversity is also evident in the distribution of these symbiotic dinoflagellates, at both global 
and local scales, and in bleaching patterns of host corals (Baker et al. 2004, Berkelmans \& Van Oppen 2006, Jones et al. 2008).

Despite evidence that these symbiotic dinoflagellates play an important role in determining the environmental tolerance of the holobiont (host and symbiont), and potentially its survival in response to environmental stress, little is known of the physiology of Symbiodinium types that live on so-called 'marginal' coral reefs. Marginal coral reefs are those living near or beyond the normal limits of reef distributions, close to the environmental thresholds for coral survival (Kleypas et al. 1999). Marginal reefs frequently occur at high latitudes i.e. above $25^{\circ} \mathrm{S}$ and $25^{\circ} \mathrm{N}$, with well known examples being those of the Persian Gulf, Bermuda, Japan and Lord Howe Island (LHI), Australia. High latitude or temperate reefs are generally subject to wide ranges in seasonal temperature (highest in Arabian Gulf; $18-36^{\circ} \mathrm{C}$, Riegl 2003), for example temperatures at LHI annually range from $18-26^{\circ} \mathrm{C}$ (L Wicks, personal observation) compared to the central Great Barrier Reef's (GBR) annual range of $23-30^{\circ} \mathrm{C}$ (Ulstrup et al. 2006). They also experience low annual minimum temperatures (lowest $13.3^{\circ} \mathrm{C}$, Japan, Veron 2000) and relatively low irradiance levels (Kleypas et al. 1999).

From the limited information available, it has been shown that the specific partnerships between corals and their dinoflagellate symbionts at high latitude reef sites differ from their tropical counterparts (see Chapter 3, LaJeunesse \& Trench 2000, Loh et al. 2001, Rodriguez-Lanetty et al. 2001, Savage et al. 2002, Loh et al. 2006). In a recent study at the high latitude site of LHI, many corals contain different types of clade C Symbiodinium to those found in the same coral species on the GBR (Chapter 3). LHI (31"33'S, 159"05' E, Fig. 5.1) is situated over $1000 \mathrm{~km}$ from the southern GBR, and is home to the southernmost coral reef in the world. Despite the high latitude conditions and 
isolation of the island, both symbiont and coral diversity are high (Chapter 3, Harriott et al. 1995), with flexible relationships identified in many coral species. Of particular note, Pocillopora damicornis hosts three novel C types (C41, C100, C118) at LHI, but is known only to associate with types $\mathrm{C} 1$, closely related types to $\mathrm{C} 1$, and $\mathrm{D} 1$ elsewhere in the IndoPacific (Ulstrup et al. 2006, Sampayo et al. 2007). These novel types at LHI are environmentally specialised, with one type only found in deeper and turbid waters, yet why these novel types exist at LHI, particularly in terms of their photo-physiological attributes, is unknown.

To assess physiological variability between Symbiodinium types, photosynthetic responses to thermal and irradiance stressors can be determined. Symbionts exposed to stress can undergo photosynthetic damage when temperature (either high or low) hinders photosynthetic $\mathrm{CO}_{2}$ assimilation by the symbiont, so causing light capture to exceed the rate of light utilization (Jones et al. 1998, Saxby et al. 2003, Smith et al. 2005). In response to increased temperature, excess energy leads to the production of reactive oxygen species (ROS), which can disrupt cellular components and induce physiological malfunction, and lead to expulsion of the symbiont from the host (Warner \& Fitt 1999, Tchernov et al. 2004, Weis 2008). Excessive irradiance or thermal stress can lead to permanent damage, including dysfunction of Photosystem II (PSII) and degradation of the associated D1 protein, energetic uncoupling in the thylakoid membranes, and impairment of the CalvinBenson Cycle (Jones et al. 1998, Warner \& Fitt 1999, Tchernov et al. 2004, Hill et al. 2006). Few studies have examined the impact of cold temperature stress on PSII; however, on the southern GBR, where temperatures annually average $17-25^{\circ} \mathrm{C}$, significant loss of photochemical efficiency was recorded after $12 \mathrm{~h}$ exposure to $12^{\circ} \mathrm{C}$ (Saxby et al. 2003) and bleaching at $13.3^{\circ} \mathrm{C}$ was observed in situ (Hoegh-Guldberg et al. 2005). 
To enable symbionts to cope with such stressors, several photo-protective pathways exist in Symbiodinium cells, to dissipate the excess excitation energy (Brown et al. 1999, Jones \& Hoegh-Guldberg 2001, Winters et al. 2003). These include down-regulation of PSII reaction centres and alternative electron transport pathways, such as the xanthophyll cycle (Brown et al. 1999, Jones \& Hoegh-Guldberg 2001, Winters et al. 2003, Warner \& Berry-Lowe 2006, McCabe-Reynolds et al. 2008). Down-regulation also occurs on a diurnal basis, where photosynthetic capacity declines following exposure to midday high light (Hill \& Ralph 2005). The efficiency of photo-protective mechanisms is thought to vary between Symbiodinium types, although the underlying mechanism is poorly understood (Takahashi et al. 2009).

This study aimed to determine if the novel holobionts at LHI are photophysiologically adapted for this high latitude site and so help explain the success of this marginal coral reef. The study focused on responses to temperature and light intensity, with the underlying hypothesis being that these high latitude Symbiodinium types are able to withstand a greater range of temperatures than are their tropical counterparts. Elucidation of the relationship between Symbiodinium photo-physiology and biogeography will further our understanding of the mechanisms involved in local adaptation to thermal and solar conditions, and the persistence of coral reefs at marginal sites. It is hypothesised that these high latitude Symbiodinium types would be able to withstand a greater range of temperatures, than their tropical counterparts on the GBR. By elucidating the relationship between Symbiodinium physiology and biogeography, this study aimed to further our understanding of the mechanisms involved in local adaptation to thermal and solar conditions, and the persistence of coral reefs at marginal sites. 


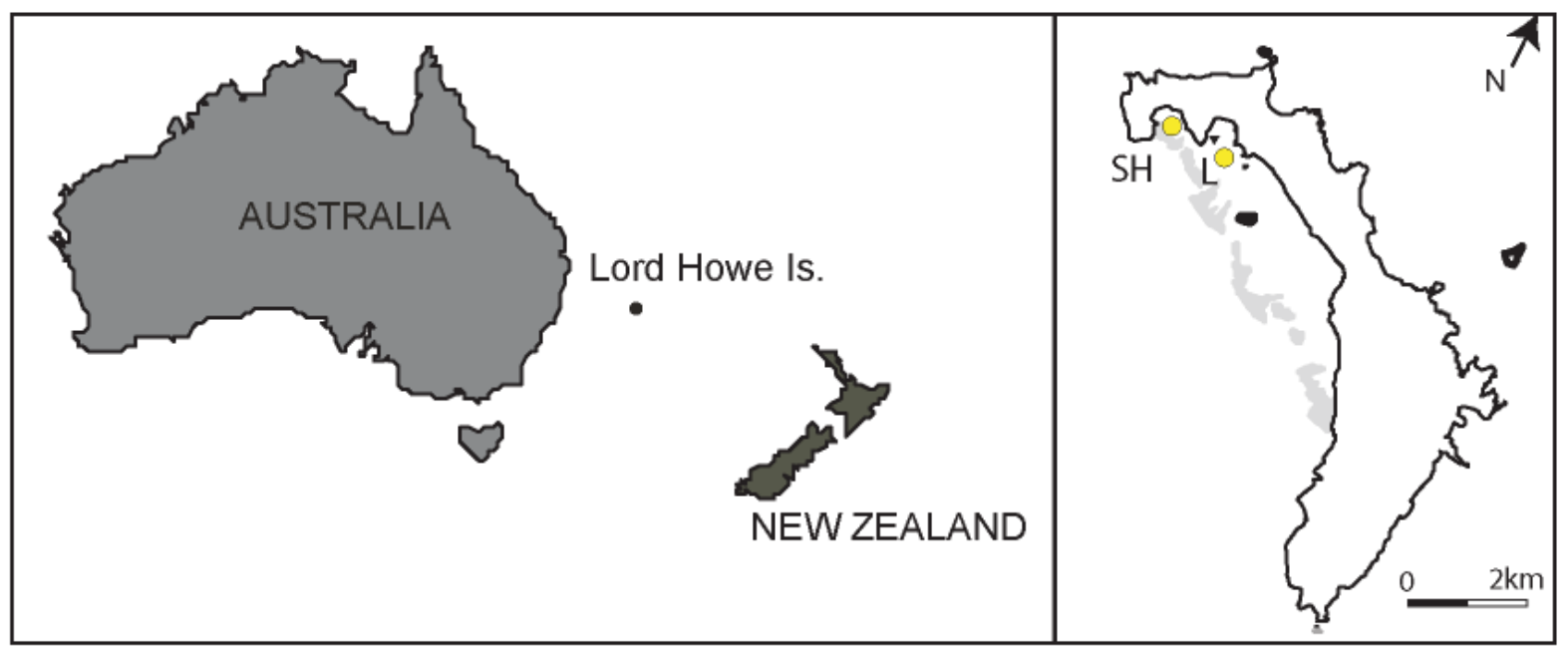

Figure 5.1. Lord Howe Island, Australia, with location of sample collection. SH: Sylphs Hole, L: Lagoon.

\subsection{MATERIALS AND METHODS}

\subsubsection{Sampling}

In September 2008, colonies of the scleractinian coral P. damicornis were collected from 2 - $3 \mathrm{~m}$ deep (during low tide) at two lagoon sites at LHI $\left(31^{\circ} 33^{\prime} \mathrm{S} 159^{\circ} 05^{\prime} \mathrm{E}\right)$ : the highly turbid site of Sylphs Hole and off Lagoon Beach in the central lagoon (Fig. 5.1). Colonies were collected from two sites to increase the chance of sampling multiple symbiont types. A previous study found that Symbiodinium C41 predominated in P. damicornis colonies at Sylphs Hole, whilst C100 was dominant at other lagoon sites (Chapter 3). Water temperatures at time of collection ranged between $19^{\circ} \mathrm{C}$ and $22^{\circ} \mathrm{C}$. Colonies were collected from the central lagoon and maintained in indoor tanks at ambient lagoon temperature (18 $19^{\circ} \mathrm{C}$ ) for 2 days. 


\subsubsection{Experimental procedure}

All experiments were set up in direct sunlight close to the shore at LHI, with 60-L tanks angled to all receive the same duration and intensity of sunlight, and fresh seawater used throughout. Portable air pumps aerated and circulated the water, and $50 \%$ of the water was changed every 2 hours to control for solar heating effects; this ensured that the water temperature did not deviate by more than $\pm 1^{\circ} \mathrm{C}$ from the experimental temperature.

To determine upper and lower bleaching thresholds of $P$. damicornis at LHI, corals were exposed to 5 different temperatures $\left(14^{\circ} \mathrm{C}, 15^{\circ} \mathrm{C}, 20^{\circ} \mathrm{C}, 29^{\circ} \mathrm{C}\right.$ and $\left.30^{\circ} \mathrm{C}\right)$ for a 62 -hour period, beginning at 6 am (dawn) $(n=6$ per treatment). All temperature treatments were run simultaneously, with one tank per treatment due to the logistical limitations of working at this remote site. Temperatures in the tanks were maintained using a chiller (Aqua Medic HL-260CA) for the $14^{\circ} \mathrm{C}$ and $15^{\circ} \mathrm{C}$ treatments, and 2 heating elements (Jager $150 \mathrm{~W}$, EHEIM) for the $29^{\circ} \mathrm{C}$ and $30^{\circ} \mathrm{C}$ treatments. In the control treatment $\left(20^{\circ} \mathrm{C}\right)$, temperatures were maintained by regular water changes with lagoon water. Temperatures were recorded each minute throughout the experiment using HOBO pendant loggers (Onset). Measurements of effective quantum yield $\left(\Delta \mathrm{F} / \mathrm{F}_{\mathrm{m}}{ }^{\prime}\right)$ (see Physiological measurements) were taken using a submersible Pulse Amplitude Modulated fluorometer (Diving-PAM, Walz) every two hours between 6 am and $8 \mathrm{pm}$ for the 62 -h period. Sunrise was at $\sim 6$ am, with sunset at $\sim 6 \mathrm{pm}$. The intensity of photosynthetically active radiation (PAR) was logged every minute by a submersible light meter (Odyssey). Bleaching thresholds were defined as the temperature at which $>50 \%$ of nubbins bleached (visible bleaching and $\Delta \mathrm{F} / \mathrm{F}_{\mathrm{m}}{ }^{\prime}<0.1$ ).

Once the upper and lower thermal thresholds had been established $\left(14^{\circ} \mathrm{C}\right.$ and $\left.30^{\circ} \mathrm{C}\right)$, 4 new colonies per site were divided into six nubbins and exposed to six different temperature/light combinations for $72 \mathrm{~h}: 15^{\circ} \mathrm{C}, 20^{\circ} \mathrm{C}$ (control) and $29^{\circ} \mathrm{C}$, each at both high 
irradiance (full light at $30 \mathrm{~cm}$ depth, peak irradiance $\sim 1900 \mu \mathrm{mol}$ quanta $\mathrm{m}^{-2} \mathrm{~s}^{-1}$ ) and low irradiance $\left(60 \%\right.$ neutral density filter, peak irradiance $\sim 1000 \mu \mathrm{mol}$ quanta $\left.\mathrm{m}^{-2} \mathrm{~s}^{-1}\right)$. These low and high temperatures were chosen as they were $\sim 1^{\circ} \mathrm{C}$ clear of the determined upper and lower bleaching thresholds. Coral nubbins were placed in the tanks at dawn on day 1 at ambient lagoon temperature $\left(18-19^{\circ} \mathrm{C}\right)$ and the temperature ramped upwards or downwards to reach the required temperature over 6 hours. It should be noted that the rate of ramping of the temperatures was relatively rapid due to experimental limitations, and thus the experiments act as a proxy for determining temperature stress reactions.

Fast induction curves (see Physiological measurements) were taken every 3 hours starting from dawn $(5.30 \mathrm{am})$ until after dark $(9 \mathrm{pm})$, on each of the three days of the experiment. Where samples appeared dead, as indicated by chlorophyll fluorescence signals and tissue loss, they were removed and preserved for genetic analysis of the dinoflagellate symbionts. In these cases ( $<5 \%$ of samples), physiological measures could not be taken.

\subsubsection{Physiological measurements}

Photosynthetic health of symbionts was measured with chlorophyll fluorescence techniques, namely the Diving-PAM and PEA (Plant Efficiency Analyser). Diving-PAM (settings: measuring intensity $=8$, saturation intensity $>4500 \mu \mathrm{mol}$ photons $\mathrm{m}^{-2} \mathrm{~s}^{-1}$, saturation width $=0.8$, gain $=12$ ) takes measures of the effective quantum yield of PSII $\left(\Phi_{\text {PSII }}\right)$ in a light-acclimated state. Dark-acclimated maximum quantum yield $\left(\mathrm{F}_{\mathrm{v}} / \mathrm{F}_{\mathrm{m}}\right)$ was recorded at dawn and after dark. In corals, a decline in $\Phi_{\mathrm{PSII}}$ precedes coral bleaching (Jones \& Hoegh-Guldberg 2001, Lesser \& Gorbunov 2001, Warner et al. 2002), and $\Phi_{\text {PSII }}$ varies both diurnally and seasonally (Jones and Hoegh-Guldberg 2001, Hill and Ralph 2005, Ulstrup et al. 2008). Evidence of down-regulation can be found from diel 
experiments where $F_{v} / F_{m}$ recovers by the evening or following morning; photodamage is implied when this recovery takes longer to occur (several days). To better characterize the physiological performance of the symbionts, we calculated the maximum excitation pressure over PSII $\left(\mathrm{Q}_{\mathrm{m}}\right)$ as described in Iglesias-Prieto et al. (2004):

$$
\mathrm{Q}_{\mathrm{m}}=1-\left[\left(\Phi_{\mathrm{PSII}}\right) /\left(\mathrm{F}_{\mathrm{v}} / \mathrm{F}_{\mathrm{m}}\right)\right]
$$

where $\Phi_{\mathrm{PSII}}$ is the effective quantum yield of fluorescence recorded at noon, and $\mathrm{F}_{\mathrm{v}} / \mathrm{F}_{\mathrm{m}}$ is the maximum quantum yield after dark.

The PEA measures polyphasic fluorescence-induction kinetics, to obtain detailed information about the photochemical state of PSII, as well as the plastoquinone (PQ) pool (Govindjee 1995, Strasser et al. 1995, Hill et al. 2004a). Fast induction curves (FIC) have been employed to assess the impact of bleaching conditions on symbiont photosynthesis in terms of the condition of PSII and the redox state of the primary $\left(\mathrm{Q}_{\mathrm{A}}\right)$ and secondary $\left(\mathrm{Q}_{\mathrm{B}}\right)$ electron acceptors (Hill et al. 2004a, Hill \& Ralph 2006), as well as changes in these mechanisms both diurnally and seasonally (Hill \& Ralph 2005). Prior to each PEA measurement, dark adaptation was conducted for 5 min to allow substantial re-oxidation of the primary electron acceptor $\left(\mathrm{Q}_{\mathrm{A}}\right.$, Schreiber 2004). The measuring head of the PEA was attached to a dark adaptation chamber (Hill et al. 2004b) before each measurement, and a pre-amplifier (x 10) was used. Illumination was provided by an array of six red LEDs (peak wavelength $650 \mathrm{~nm}$ ) focused on an area of $4-\mathrm{mm}$ diameter, resulting in a maximum excitation irradiance of $3200 \mu \mathrm{mol}$ photons $\mathrm{m}^{-2} \mathrm{~s}^{-1}$. For the first $2 \mathrm{~ms}$ of saturation the fluorescence signal was measured every $10 \mu \mathrm{s}$, followed by $1 \mathrm{~ms}$ sampling up to $1 \mathrm{~s}$, and then $100 \mathrm{~ms}$ sampling up to $5 \mathrm{~s}$. All curves were normalized to the fluorescence yield at $0.05 \mathrm{~ms}\left(\mathrm{~F}_{\mathrm{o}}\right)$ to eliminate any changes linked to a possible reduction in chlorophyll concentration (or symbiont density) due to stress (Iglesias-Prieto 1995, Jones et al. 2000). 
When plotted on a $\log _{10}$ time scale, the fast induction curves followed the O-J-I-P steps of the 'Kautsky' curve. The ' $\mathrm{O}$ ' step ( $\mathrm{F}_{\mathrm{o}}$, the origin) occurred at $0.05 \mathrm{~ms}$, the $\mathrm{J}$ step (intermediate) at $1 \mathrm{~ms}$, the I step (second intermediate) at $100 \mathrm{~ms}$, and the $\mathrm{P}$ step $\left(\mathrm{F}_{\mathrm{m}}\right.$, maximum) at $2 \mathrm{~s}$ (Hill et al. 2004a).

Both prior to and following the treatments, coral tissue was removed from each nubbin with an airbrush. The tissue slurry was diluted in $5 \mathrm{ml}$ of filtered seawater (FSW; 1 $\mu \mathrm{m}$ ), and centrifuged at $6,000 \times g$ for $5 \mathrm{~min}$. The remaining algal pellet was resuspended in $5 \mathrm{ml} \mathrm{FSW}$ and homogenized by vigorous shaking; $0.5 \mathrm{ml}$ was removed for symbiont cell counts, and $0.5 \mathrm{ml}$ preserved at $-20^{\circ} \mathrm{C}$ in darkness for determination of chlorophyll concentrations. The remaining sample was centrifuged for $5 \mathrm{~min}$ at $8,000 \times g$, the supernatant discarded, and the pellet preserved in $20 \%$ DMSO buffer and stored at $-20^{\circ} \mathrm{C}$ for symbiont identification. Symbiont densities were estimated by using a haemocytometer (Neubauer) with 10 replicates of each sample, and expressed per unit surface area of the coral, obtained by the wax weight method (Stimson \& Kinzie 1991). Chlorophyll extractions were undertaken in darkness, using $100 \%$ acetone at $4{ }^{\circ} \mathrm{C}$ overnight, and concentrations determined with a spectrophotometer as described by Jeffrey \& Humphrey (1975). Chlorophyll concentrations were determined per cell and per $\mathrm{cm}^{2}$ of coral surface area.

\subsubsection{Genetic data}

The preservation buffer was removed using a 3-fold DNAB washing step and the DNA extracted using a DNeasy plant kit (Qiagen) according to the manufacturer's instructions. The ITS2 region of the ribosomal DNA was amplified with the primers ITSintfor and ITS2clamp (LaJeunesse \& Trench 2000). Amplified ITS2 fragments were separated by 
using 30-60\% DGGE gels (DCode system, Bio-Rad) during a 14-h run at 100V, after which gels were stained with SYBR green (Invitrogen). Symbiont profiles were compared with those previously identified in P. damicornis from Lord Howe Island (Chapter 3).

\subsubsection{Data analysis}

Repeated measures ANOVA (rmANOVA) was used to determine if the fluorescence parameters $\left(\mathrm{F}_{\mathrm{v}} / \mathrm{F}_{\mathrm{m}}, \Phi_{\mathrm{PSII}}, \mathrm{Q}_{\mathrm{m}}\right.$, and $\mathrm{O}, \mathrm{J}, \mathrm{I}$ and $\mathrm{P}$ steps $)$ differed significantly $(\alpha=0.05)$ between temperature and light treatments in the 3 day period (19 time points). rmANOVA also tested for significant differences in $\Phi_{\mathrm{PSII}}$ between temperature treatments in the bleaching threshold test. Due to the similarity of photo-physiological responses between the two collection sites, inter-site comparisons are not considered further here, except in relation to symbiont density and chlorophyll concentrations where differences existed. Oneway ANOVA assessed significant differences in chl- $a$ concentration and symbiont density between treatments, and pre- versus post-treatment. Assumptions of normality and of homogeneity of variances were tested using Kolmogorov-Smirvov's and Levene's tests, respectively. If these assumptions were not met, transformations were performed (Arcsine for $\mathrm{F}_{\mathrm{v}} / \mathrm{F}_{\mathrm{m}}, \Phi_{\mathrm{PSII}}$, and $\mathrm{Q}_{\mathrm{m}}$; square root for chl- $a$ concentration, symbiont density, and $\mathrm{O}, \mathrm{J}, \mathrm{I}$ and P). Where rmANOVA determined a significant difference, Box's test of equality of covariance matrices was used to test the homogeneity of variances between treatments. The assumption of sphericity was tested, and where assumptions were not met, the GreenhouseGeisser adjustment was performed. Tukey's multiple comparisons were used to identify significant differences between individual temperature treatments. Each physiological parameter was analysed separately, with temperature and light as between-subject factors. 
Time was analysed as a within-subject factor, as photochemical measures were repeated on the same colony. All analyses were performed using SPSS software v16.0.0.

\subsection{RESULTS}

\subsubsection{Symbiont identification}

All coral colonies $(n=10)$ collected from the lagoon harboured Symbiodinium type C100, while three of four colonies collected from the more turbid site of Sylphs Hole also harboured this type; the fourth colony from Sylphs Hole contained type C41.

\subsubsection{Bleaching thresholds}

In the bleaching threshold experiment, all P. damicornis samples contained $\mathrm{C} 100$. The effective quantum yield of PSII ( $\left.\Phi_{\mathrm{PSII}}\right)$ declined from 6 am to $12 \mathrm{pm}$ in all temperature treatments, with significantly higher $\Phi_{\mathrm{PSII}}$ recorded for the control nubbins than the nubbins subject to high $\left(29\right.$ and $\left.30^{\circ} \mathrm{C}\right)$ or low $\left(14\right.$ and $\left.15^{\circ} \mathrm{C}\right)$ temperatures $(p<0.001$ Fig. 5.2). Furthermore, the $29^{\circ} \mathrm{C}$ and $15^{\circ} \mathrm{C}$ treatments exhibited significantly higher $\Phi_{\text {PSII }}$ than did the $30^{\circ} \mathrm{C}$ and $14^{\circ} \mathrm{C}$ treatments, throughout the experiment ( $p<0.001$ Fig. 5.2).

Bleaching was only observed in the $14^{\circ} \mathrm{C}(50 \%$ of nubbins $), 29^{\circ} \mathrm{C}(17 \%$ of nubbins $)$ and $30^{\circ} \mathrm{C}$ treatments. Indeed, after 6 am on day 2 (i.e. $24 \mathrm{~h}$ after the start of the treatments), all nubbins $(n=6)$ exposed to $30^{\circ} \mathrm{C}$ had completely bleached or died. Mean $\mathrm{F}_{\mathrm{v}} / \mathrm{F}_{\mathrm{m}}( \pm \mathrm{SE})$ of nubbins exposed to $29^{\circ} \mathrm{C}$ was $0.2 \pm 0.01$ at $72 \mathrm{~h}$, less than half the $\mathrm{F}_{\mathrm{v}} / \mathrm{F}_{\mathrm{m}}$ of the control $(0.44$ \pm 0.03 ). Three of the six nubbins exposed to $14^{\circ} \mathrm{C}$ had $\mathrm{F}_{\mathrm{v}} / \mathrm{F}_{\mathrm{m}}<0.1$ at 24 and $48 \mathrm{~h}$, with $\mathrm{F}_{\mathrm{v}} / \mathrm{F}_{\mathrm{m}}$ of the three remaining nubbins being $\sim 0.25$ at these same time points. Considerable 
changes in $\Phi_{\mathrm{PSII}}$ occurred over the first $24 \mathrm{~h}$ of the experiment. At $24 \mathrm{~h}$, mean $\Phi_{\mathrm{PSII}}( \pm \mathrm{SE})$ in the control treatment was $0.46( \pm 0.02)$, which was significantly higher than in the $29^{\circ} \mathrm{C}$ and $15^{\circ} \mathrm{C}$ treatments $\left(\Delta \mathrm{F} / \mathrm{F}_{\mathrm{m}}{ }^{\prime}=0.31 \pm 0.04\right.$ and $0.22 \pm 0.03$ respectively $)$, and four-times the mean $\Phi_{\mathrm{PSII}}( \pm \mathrm{SE})$ in the $14^{\circ} \mathrm{C}$ treatment $\left(0.12 \pm 0.02\right.$; all nubbins at $30^{\circ} \mathrm{C}$ were dead $)$ at this time-point.

\subsubsection{Photochemical efficiency}

Once the bleaching thresholds of 14 and $30^{\circ} \mathrm{C}$ were established, an experiment on the responses of photochemical efficiency to extreme temperature and light treatments was performed. Maximum $\left(\mathrm{F}_{\mathrm{v}} / \mathrm{F}_{\mathrm{m}}\right)$ and effective quantum yield $\left(\Phi_{\mathrm{PSII}}\right)$, and fast induction curves (FICs) were measured every 3 hours from dawn to dusk in nubbins exposed to three temperature treatments $\left(29^{\circ} \mathrm{C}, 20^{\circ} \mathrm{C}, 15^{\circ} \mathrm{C}\right)$, each at two light levels $(100 \%$ and $40 \%$ full irradiance, referred to as high and low light) over $72 \mathrm{~h}$. Significant differences in each of the parameters measured between temperature and light treatments are displayed in Table 5.1.

The well-known inverse relationship of photosynthetic quantum yield with irradiance (Brown et al. 1999, Hoegh-Guldberg \& Jones 1999, Hill \& Ralph 2005) was observed for all P. damicornis nubbins in all treatments (Fig. 5.3). Maximum $\mathrm{F}_{\mathrm{v}} / \mathrm{F}_{\mathrm{m}}$ was recorded at 6 am, with $\Phi_{\mathrm{PSII}}$ then decreasing diurnally from 9 am, reaching a minimum at $\sim 3 \mathrm{pm}$ following the $12 \mathrm{pm}$ peak in natural sunlight intensity. In the afternoon, $\Delta \mathrm{F} / \mathrm{F}_{\mathrm{m}}$ ' recovered as natural sunlight intensity decreased, with $\mathrm{F}_{\mathrm{v}} / \mathrm{F}_{\mathrm{m}}$ reaching a maximum 


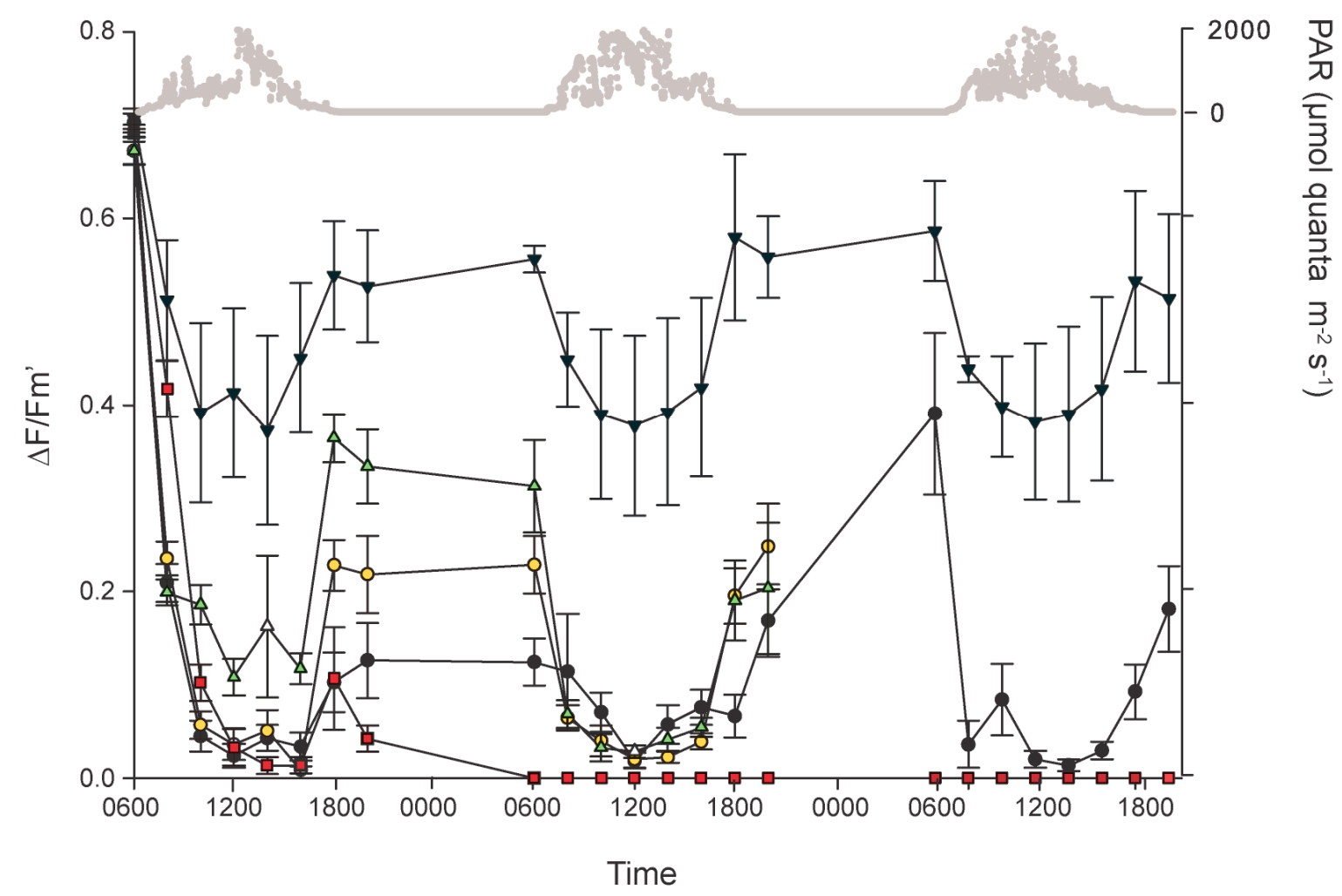

Figure 5.2 $\Phi_{\mathrm{PSII}}$ in Pocillopora damicornis nubbins over 62 hour treatment period at 5 temperature

treatments: $\bullet 14^{\circ} \mathrm{C} \bullet 15^{\circ} \mathrm{C} \vee 20^{\circ} \mathrm{C} \Delta 29^{\circ} \mathrm{C} \backsim 30^{\circ} \mathrm{C}$. Photosynthetically active radiation ( $\mu$ mol quanta m-2 s-1) on right axis $\left({ }^{\circ}\right)$.

at $\sim 9 \mathrm{pm}$. Overnight, $\mathrm{F}_{\mathrm{v}} / \mathrm{F}_{\mathrm{m}}$ did not increase or decline significantly (ANOVA, $p<0.01$ ). Significant differences in $\Phi_{\text {PSII }}$ were recorded between both light and temperature treatments, in addition to the additive effect of both factors (rmANOVA, $p<0.001$ Refer to Table). $\Phi_{\text {PSII }}$ was significantly higher over the $72 \mathrm{~h}$ period in low light than in high light for all treatments (rmANOVA, $p<0.001$ Table 5.1). After $72 \mathrm{~h}$ at low light, $\Delta \mathrm{F} / \mathrm{F}_{\mathrm{m}}$ ' maintained $88 \%, 63 \%$ and $45 \%$ of initial readings at $20^{\circ} \mathrm{C}, 15^{\circ} \mathrm{C}$ and $29^{\circ} \mathrm{C}$, respectively, 
compared to $63 \%, 14 \%$ and $9 \%$ in the high light treatment. Under both low and high irradiance, coral nubbins in the $20^{\circ} \mathrm{C}$ temperature treatment maintained the highest $\Delta \mathrm{F} / \mathrm{Fm}$ ' over the $72 \mathrm{~h}$ period, which was significantly greater than in the $29^{\circ} \mathrm{C}$ and $15^{\circ} \mathrm{C}$ treatments (rmANOVA, $p<0.001$ Table 5.1). $\Phi_{\mathrm{PSII}}$ varied among temperature treatments over time at both light levels; the $20^{\circ} \mathrm{C} /$ low light treatment $(0.58 \pm 0.03)$, was greatest, closely followed by $20^{\circ} \mathrm{C} /$ high light and $15^{\circ} \mathrm{C} /$ low light $(0.43 \pm 0.03$ and $0.42 \pm 0.04$ respectively $)$. The lowest mean $\Phi_{\mathrm{PSII}}$ overall was recorded in the $29^{\circ} \mathrm{C} /$ high light treatment, which remained at $<0.05$ for the final $21 \mathrm{~h}$ of the experiment.

PSII excitation pressure $\left(\mathrm{Q}_{\mathrm{m}}\right)$ was significantly higher in nubbins exposed to high light than low light on days 1 and 3 of the experiment (rmANOVA, $p<0.001$ ), however this varied among temperature treatments (Fig. 5.4, Table 4.1). Assessed alone, neither temperature nor light significantly affected $\mathrm{Q}_{\mathrm{m}}$ over time $(p=0.722$ and $p=0.784$, respectively). In high light, nubbins exposed to $29^{\circ} \mathrm{C}$ had significantly higher $\mathrm{Q}_{\mathrm{m}}$ than corals in the control or $15^{\circ} \mathrm{C}$ treatments (rmANOVA, $p<0.01$ ). In contrast, in low light, no significant difference in $\mathrm{Q}_{\mathrm{m}}$ was observed among temperature treatments (rmANOVA, $p=$ 0.342). In high light, $\mathrm{Q}_{\mathrm{m}}$ either declined or was stable from day 1 to 2 , depending upon treatment. The greatest decline in mean $\mathrm{Q}_{\mathrm{m}}( \pm \mathrm{SE})$ from day 1 to 2 in high light was in the $20^{\circ} \mathrm{C}$ treatment $(0.83 \pm 0.02$ to $0.61 \pm 0.11) . \mathrm{Q}_{\mathrm{m}}$ in the $29^{\circ} \mathrm{C}$ and $15^{\circ} \mathrm{C} /$ low light treatments remained stable over the 3 days (range $0.8-0.88$ ). For the low light treatment, mean $\mathrm{Q}_{\mathrm{m}}$ rose from day 1 to 2 for all temperature treatments (from $0.52 \pm 0.02$ to $0.66 \pm 0.11$ at $29^{\circ} \mathrm{C}, 0.32 \pm 0.04$ to $0.74 \pm 0.02$ at $20^{\circ} \mathrm{C}$, and $0.62 \pm 0.05$ to $0.85 \pm 0.03$ at $15^{\circ} \mathrm{C}$ ), with the day $2 \mathrm{Q}_{\mathrm{m}}$ being sustained to day 3 in the $15^{\circ} \mathrm{C}$ treatment $(0.84 \pm 0.02)$. In the $20^{\circ} \mathrm{C}$ treatment, however, mean $\mathrm{Q}_{\mathrm{m}}$ declined on day 3 to $0.61( \pm 0.06)$, while in the $29^{\circ} \mathrm{C}$ 
Table 5.1 $p$ values of the rmANOVA analyses which tested for changes in the maximum $\left(\mathrm{F}_{\mathrm{v}} / \mathrm{F}_{\mathrm{m}}\right)$ and effective $\left(\Delta \mathrm{F} / \mathrm{F}_{\mathrm{m}}{ }^{\prime}\right)$ quantum yields, $\mathrm{O}$, J,

I and P steps and PSII excitation pressure $\left(\mathrm{Q}_{\mathrm{m}}\right)$ over the $72 \mathrm{~h}$ experiment for three temperature treatments $\left(29^{\circ} \mathrm{C}, 20^{\circ} \mathrm{C}\right.$ and $\left.15^{\circ} \mathrm{C}\right)$ at two light levels (high and low) of Pocillopora damicornis from Lord Howe Island.

\begin{tabular}{|c|c|c|c|c|c|c|c|}
\hline & $\Delta \mathrm{F} / \mathrm{F}_{\mathrm{m}}$ & $\mathrm{F}_{\mathrm{v}} / \mathrm{F}_{\mathrm{m}}$ & $\mathrm{O}$ & $\mathrm{J}$ & I & $\mathrm{P}$ & $\mathrm{Q}_{\mathrm{m}}$ \\
\hline \multicolumn{8}{|l|}{ Within subjects } \\
\hline Time & $<0.001 *$ & $<0.001 *$ & $<0.001 *$ & $<0.01$ & $<0.001$ & $<0.001$ & $<0.001$ \\
\hline Time $\mathrm{x}$ Temp & $<0.001 *$ & $<0.01 *$ & $<0.001 *$ & 0.09 & 0.058 & 0.062 & 0.722 \\
\hline Time $\mathrm{x}$ light & $<0.001^{*}$ & $<0.001 *$ & $<0.01^{*}$ & $<0.05$ & $<0.05$ & $<0.05$ & $<0.001$ \\
\hline Time $\mathrm{x}$ temp $\mathrm{x}$ light & 0.339 & 0.458 & 0.292 & 0.384 & 0.391 & 0.924 & 0.171 \\
\hline \multicolumn{8}{|l|}{ Between subjects } \\
\hline Temp & $<0.001 *$ & $<0.001 *$ & 0.229 & $<0.01 *$ & $<0.001 *$ & $<0.001 *$ & $<0.01 *$ \\
\hline Light & $<0.001^{*}$ & $<0.001^{*}$ & $<0.05^{*}$ & $<0.001^{*}$ & $<0.001^{*}$ & $<0.01 *$ & $<0.001 *$ \\
\hline \multirow[t]{2}{*}{ Temp x light } & 0.517 & 0.938 & 0.735 & 0.326 & 0.51 & 0.561 & 0.157 \\
\hline & $15,19>28$ & $19>28>15$ & $\sim$ & $15,19>28$ & $15,19>28$ & $15,19>28$ & $15,19>28$ \\
\hline
\end{tabular}




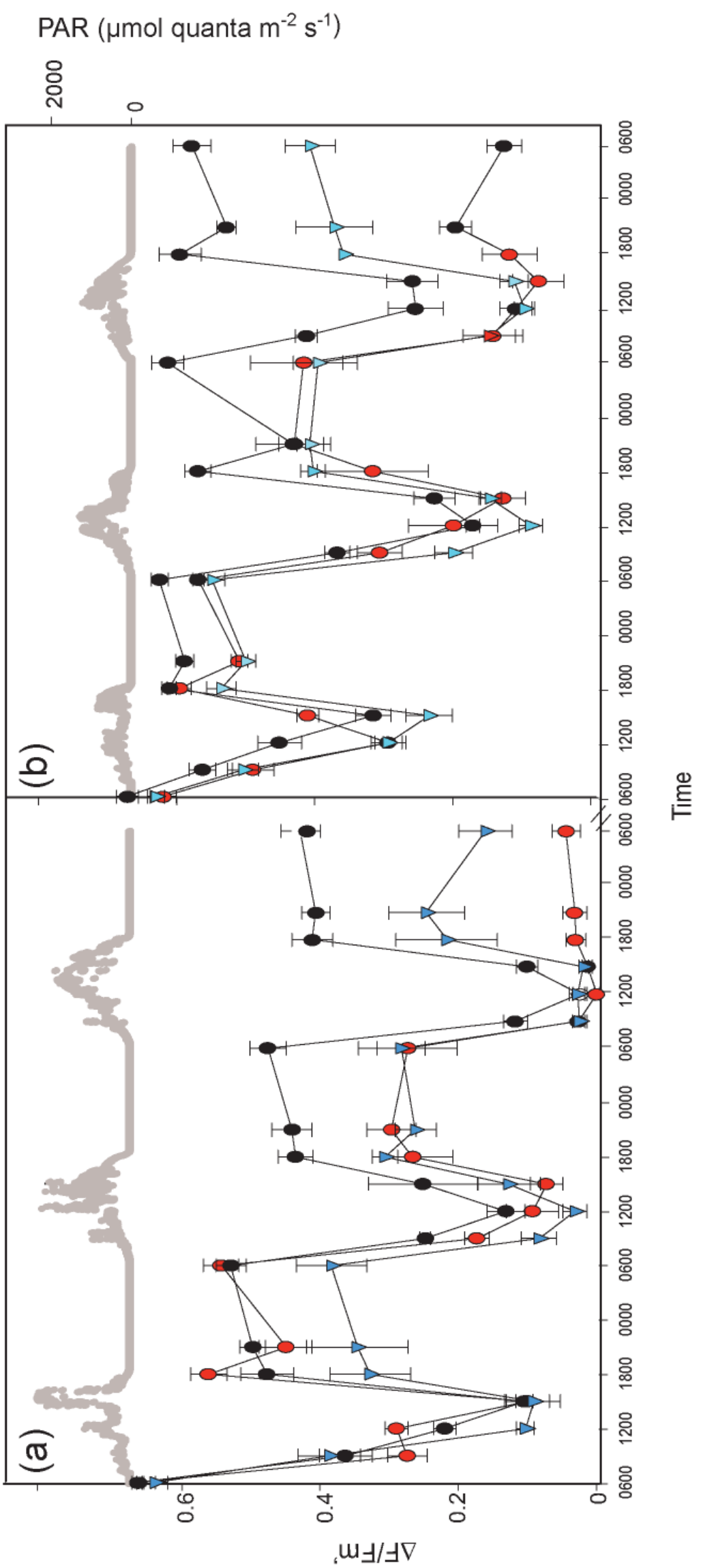

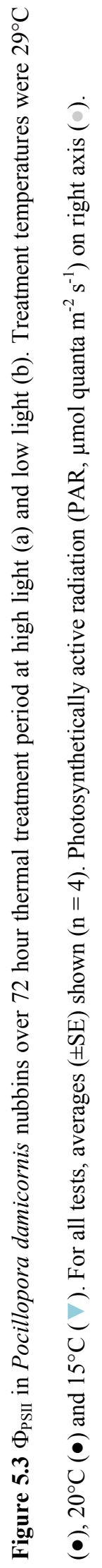




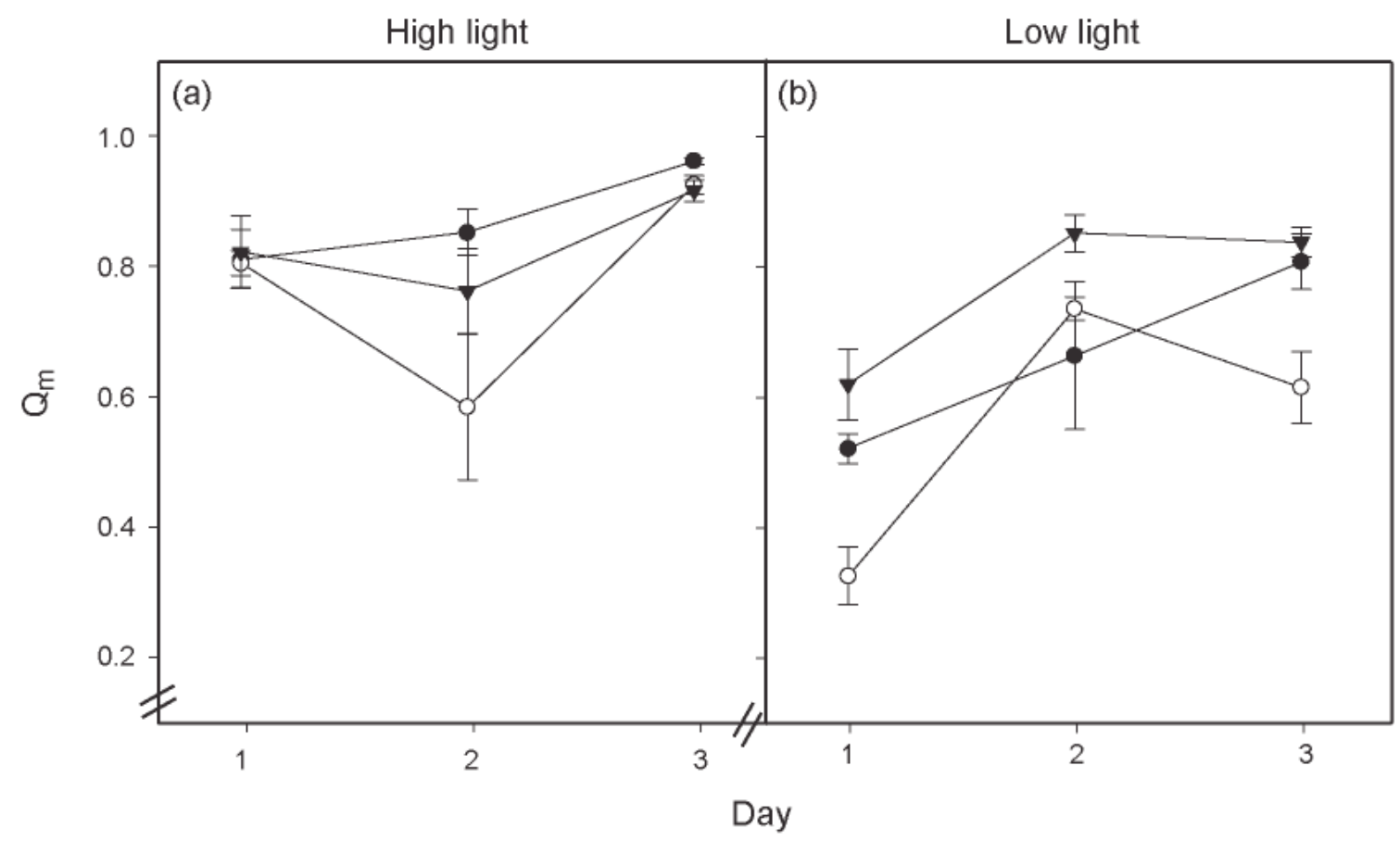

Figure 5.4 PSII excitation pressure $\left(\mathrm{Q}_{\mathrm{m}}\right)$ in Pocillopora damicornis nubbins over 3 day thermal treatment period at high light (a) and low light (b). Treatment temperatures were $29^{\circ} \mathrm{C}(\bullet), 20^{\circ} \mathrm{C}\left({ }^{\circ}\right)$ and $15^{\circ} \mathrm{C}(\boldsymbol{\nabla})$. For all tests, averages $( \pm \mathrm{SE})$ shown $(\mathrm{n}=8)$.

treatment it increased further to $0.81( \pm 0.04)$. However, no significant difference in $\mathrm{Q}_{\mathrm{m}}$ was observed among temperature treatments in low light (rmANOVA, $p=0.342$ ). In high light, nubbins exposed to $29^{\circ} \mathrm{C}$ had significantly higher $\mathrm{Q}_{\mathrm{m}}$ than corals in the control or $15^{\circ} \mathrm{C}$ treatments (rmANOVA, $\left.p<0.01\right)$.

\subsubsection{Fast induction kinetics}

Figure $5.5 \mathrm{a}-\mathrm{f}$ shows the fast induction curves (FICs) of $P$. damicornis for a series of thermal treatments at two light levels $(100 \%$ and $40 \%$ of natural daylight, high and low light respectively). For each treatment, a selection of FICs normalized to $F_{o}$ is shown from the 72 -h period $(\mathrm{T}=0,9,24,33,48,72 \mathrm{~h})$. At each timepoint in all temperature treatments, 
the FIC amplitude of nubbins subjected to high light was lower than that of nubbins subjected to low light. In the low light treatment at all temperatures, the $\mathrm{P}$ step remained

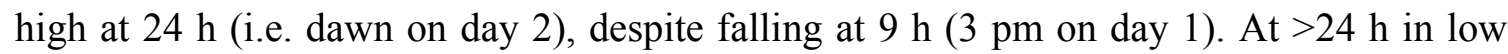
light, the $\mathrm{P}$ step declined in the $29^{\circ} \mathrm{C}$ and $15^{\circ} \mathrm{C}$, however in the $20^{\circ} \mathrm{C}$ treatment it remained high. In the high light treatment, the $\mathrm{P}$ step declined over time in all temperature treatments. Least variability among FICs over time was recorded in the $20^{\circ} \mathrm{C}$ and $29^{\circ} \mathrm{C} /$ low light treatments, with greatest variability in the $29^{\circ} \mathrm{C} /$ high light treatment.

The mean amplitudes of the O, J, I and P steps over the 72-h period are shown in Figures 5.6a-f. In all treatments, the amplitude of steps varied diurnally, declining from a maximum at 6 am to a minimum at $3 \mathrm{pm}$ (following maximum PAR at $12 \mathrm{pm}$ ) followed by an increase in the afternoon. For all steps, the amplitudes were significantly lower at high light than low light, in all temperature treatments over the $72 \mathrm{~h}$ (rmANOVA $p<0.01$, Table 5.1). Magnitude of the $\mathrm{J}, \mathrm{I}$ and $\mathrm{P}$ steps was significantly higher in the $20^{\circ} \mathrm{C}$ treatment than in the $29^{\circ} \mathrm{C}$ or $15^{\circ} \mathrm{C}$ treatments (rmANOVA, $p<0.05$ ), with $\mathrm{O}$ significantly variable among temperature treatments over time. No significant synergistic effect of temperature and light was observed for any of the steps (rmANOVA, $p>0.3$, Table 5.1).

Diurnal changes in the $\mathrm{O}, \mathrm{J}, \mathrm{I}$ and $\mathrm{P}$ steps varied among temperature treatments at both light levels. In the $20^{\circ} \mathrm{C} /$ low and high light treatments, each step had increased in amplitude by $6 \mathrm{pm}$, and returned to pre-dawn measurements by $9 \mathrm{pm}$. Similarly, in the $15^{\circ} \mathrm{C} /$ low and high light treatments, amplitudes of each step at dusk were comparable to pre-dawn measures, after the decline associated with the high natural irradiance from 12 - 3 pm. However, at $29^{\circ} \mathrm{C}$ in both light levels, amplitudes of each peak did not return to their 


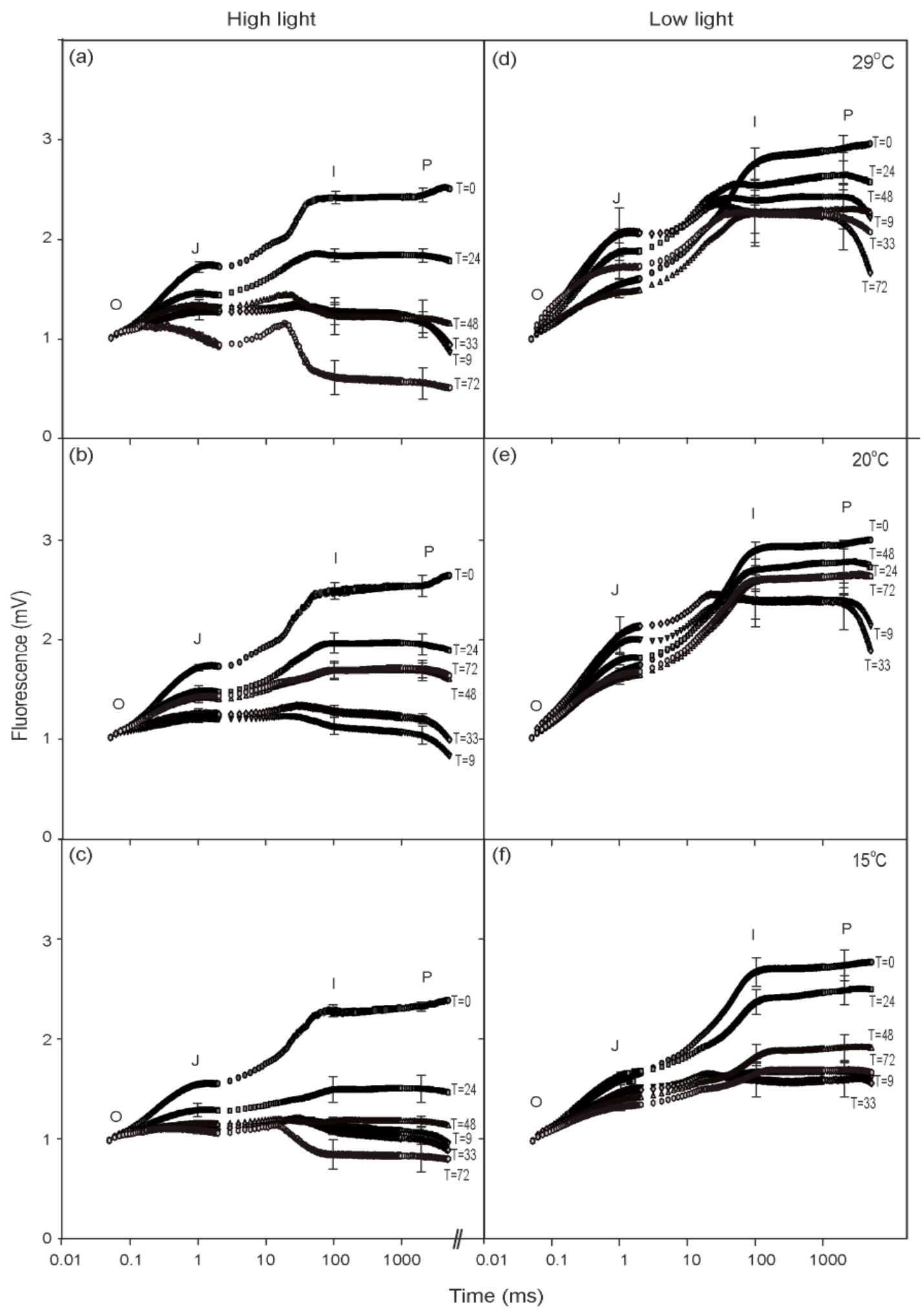

Figure 5.5 Fast kinetic induction curves (FICs) of thermal treatments of Pocillopora damicornis at 7 timepoints over a 72-hour period at high light $(\mathrm{a}-\mathrm{c})$ and low light $(\mathrm{d}-\mathrm{f})$. Treatment temperatures were $29^{\circ} \mathrm{C}$ (a, d), $20^{\circ} \mathrm{C}(\mathrm{b}, \mathrm{e})$ and $15^{\circ} \mathrm{C}(\mathrm{c}, \mathrm{f})$. Curves are normalised to $\mathrm{F}_{0}$ and are plotted on a $\log 10$ time scale. Average curves are shown ( $n=6-8)$, with SE given at the J, I and P steps (labelled). 


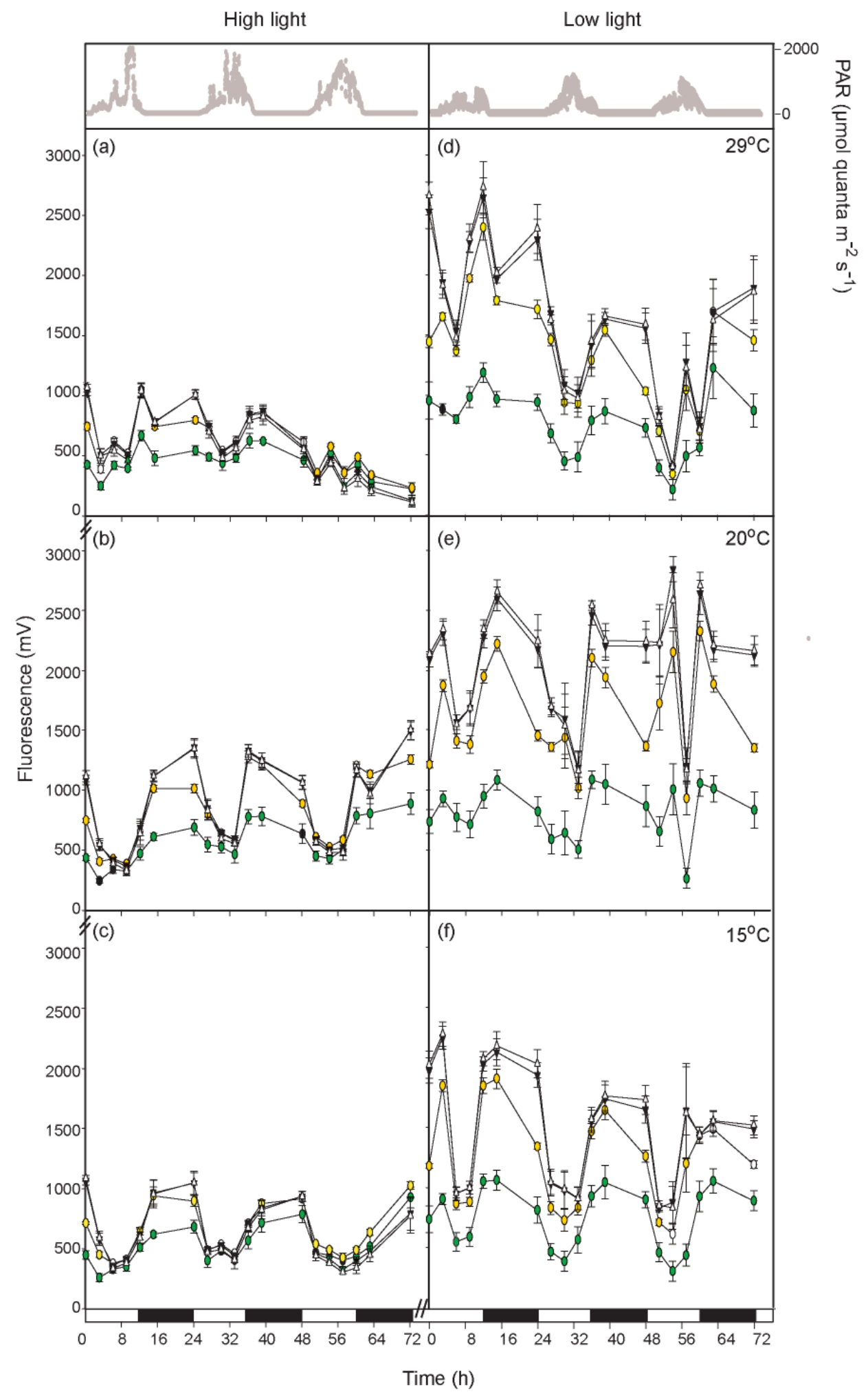

Figure 5.6 Amplitude of the $\mathrm{O}, \mathrm{J}, \mathrm{I}$ and $\mathrm{P}$ steps ( $\bullet \triangle$ respectively) along fast induction curves (FICs) in $P$.

damicornis over a 72-hour period at high light (a-c) and low light $(\mathrm{d}-\mathrm{f})$. Treatment temperatures were $29^{\circ} \mathrm{C}$ $(\mathrm{a}, \mathrm{d}), 20^{\circ} \mathrm{C}(\mathrm{b}, \mathrm{e})$ and $15^{\circ} \mathrm{C}(\mathrm{c}, \mathrm{f})$. Average values $(\mathrm{n}=7)$ from all nubbins and $\mathrm{SE}$ shown. Photosynthetically active radiation $\left(\mathrm{PAR}, \mu \mathrm{mol}\right.$ quanta $\left.\mathrm{m}^{-2} \mathrm{~s}^{-1}\right)$ on right axis $\left({ }^{\circ}\right)$. 
pre-dawn maxima, and were significantly lower at $72 \mathrm{~h}$ than at $0 \mathrm{~h}$.

At $72 \mathrm{~h}$, differences among the magnitude of each of the steps in response to light levels and temperatures were apparent, with values significantly lower in nubbins subject to high light than low light (one way ANOVA, $p<0.05$ ). In low light, the O step was not significantly different from initial readings at $72 \mathrm{~h}$ in any temperature treatment. However, over the $72 \mathrm{~h}$ in high light, the $\mathrm{O}$ step had increased significantly in the $20^{\circ} \mathrm{C}$ and $15^{\circ} \mathrm{C}$ treatments (by $101 \%$ and $100 \%$, respectively), but declined in the $29^{\circ} \mathrm{C}$ treatment by $55 \%$ (rmANOVA, $p<0.001$ ). Over $72 \mathrm{~h}$ at low light, percent change in $\mathrm{J}$ (normalized to $\mathrm{F}_{\mathrm{o}}$ ) in the $29^{\circ} \mathrm{C}$ treatment was not significantly different to that of $\mathrm{J}$ in the $15^{\circ} \mathrm{C}$ treatment ( $1 \%$ increase in both treatments), however in high light, percent change in the $29^{\circ} \mathrm{C}$ treatment was significantly greater than in the $20^{\circ} \mathrm{C}$ and $15^{\circ} \mathrm{C}$ treatments $(67 \%$ decline $v s$. $67 \%$ and $42 \%$ increase, respectively; $p<0.001$ ). For the I and P steps, magnitude and variability were greater in low light than in high light, but similar responses to temperature existed for both light treatments over the course of the experiment. In the $29^{\circ} \mathrm{C}$ treatment at both light levels, I and P declined over 72 h (low light: 26\% and 3\% declines, respectively; high light: $86 \%$ and $88 \%$ declines, respectively). At $15^{\circ} \mathrm{C}$ however, the decline was significantly less in both I and P than the $29^{\circ} \mathrm{C}(p<0.01$; low light: $25 \%$ decline for both steps; high light: 24 and $28 \%$ declines, respectively). However, in the $20^{\circ} \mathrm{C}$ treatment, I and $\mathrm{P}$ actually increased after $72 \mathrm{~h}$ in high light (by $37 \%$ and $34 \%$, respectively), but declined in the low light (by $2 \%$ and $1 \%$, respectively). 


\subsubsection{Symbiont density and chlorophyll concentrations}

P. damicornis colonies from the lagoon had significantly higher mean $( \pm \mathrm{SE})$ densities of symbionts than those from Sylphs Hole $\left(8.08 \pm 0.97 \times 10^{6} \mathrm{~cm}^{-2} v s .4 .87 \pm 0.66 \times 10^{6}\right.$ cells $\mathrm{cm}^{-2}$, respectively; Table 5.2, $\left.p<0.05\right)$. Change in symbiont density over the $72 \mathrm{~h}$ was variable among treatments (Fig. 5.7), with symbiont loss significantly greater in the $29^{\circ} \mathrm{C}$ treatment than in the $20^{\circ} \mathrm{C}$ and $15^{\circ} \mathrm{C}$ treatments (Table 5.2, ANOVA, $p<0.001$ ). No significant effect of light or collection site on percent change in symbiont density was recorded (one way ANOVA, $p=0.274$ and $p=0.774$, respectively).

Chlorophyll concentration per symbiont cell at the start of the experiment did not differ significantly with site (ANOVA, $p=0.342$, Table 5.3 ), however did vary per $\mathrm{cm}^{2}$ coral (ANOVA, $\mathrm{p}<0.01$ ). Following treatment, chlorophyll concentration per symbiont cell did not differ significantly with temperature $\left(15^{\circ} \mathrm{C}, 20^{\circ} \mathrm{C}\right.$ and $\left.29^{\circ} \mathrm{C}\right)$ or collection site, but was highly variable among nubbins $(p=0.225, p=0.984$, respectively, Fig. 5.8). However, light did significantly affect chl- $a$ loss (one way ANOVA, $p<0.01$ ); in the low light treatment, all cells gained chl- $a$ per cell (means $12-29 \%$ over $72 \mathrm{~h}$ for three temperature treatments); however in high light most cells lost chl- $a$ (mean of $11-23 \%$ loss).

Chlorophyll- $a \mathrm{~cm}^{-2}$ declined in all nubbins under all treatments. Neither light level nor collection site had a significant effect on the loss of chl- $a \mathrm{~cm}^{-2}(p=0.226$ and $p=$ 0.758 , respectively). However, decline in chl- $a \mathrm{~cm}^{-2}$ was significantly greater in the $29^{\circ} \mathrm{C}$ treatment than the $15^{\circ} \mathrm{C}$ and $20^{\circ} \mathrm{C}$ treatments at both light levels (mean $\pm \mathrm{SE}$ : low light $85 \pm$ $6 \%$ vs. $43 \pm 13 \%$ and $23 \pm 21 \%$ respectively, high light: $83 \pm 7 \%$ vs. $65 \pm 9 \%$ and $33 \pm$ 17\%, ANOVA $p<0.05$, Table 5.3). 
Table 5.2 Symbiont density (per $\mathrm{cm}^{2} \times 10^{-6}$ ), and chl- $a$ concentration (per symbiont cell and per $\mathrm{cm}^{2}$ ) in Pocillopora damicornis from Lord Howe Island. Measurements were taken pre-experiment and at $72 \mathrm{~h}$, at each temperature/light treatment $\left(29^{\circ} \mathrm{C}, 20^{\circ} \mathrm{C}\right.$ and $15^{\circ} \mathrm{C}$, high and low light $)$. Mean $\pm \mathrm{SE}(\mathrm{n}=8)$.

\begin{tabular}{cccccc}
\hline Site & $\begin{array}{c}\text { Light } \\
\text { level }\end{array}$ & Treatment & $\begin{array}{c}\text { Zoox. density } \\
\left(\mathrm{cm}^{-2} \times 10^{6}\right)\end{array}$ & $\begin{array}{c}\text { Chl } a \text { cell } \\
(\mathrm{pg})\end{array}$ & $\begin{array}{c}\text { Chl } a \\
\left(\mu \mathrm{g} \mathrm{cm}^{-2}\right)\end{array}$ \\
\hline Lagoon & & pre-treatment & $8.08 \pm 0.97$ & $3.99 \pm 0.83$ & $16.34 \pm 3.64$ \\
& High & 28 & $0.45 \pm 0.26$ & $4.88 \pm 1.56$ & $0.89 \pm 0.38$ \\
& & 19 & $7.39 \pm 0.63$ & $3.52 \pm 0.2$ & $12.89 \pm 0.86$ \\
& & 15 & $2.25 \pm 0.52$ & $7.33 \pm 3.46$ & $4.37 \pm 10.4$ \\
& Low & 28 & $1.04 \pm 0.4$ & $3.31 \pm 0.39$ & $1.82 \pm 0.71$ \\
& & 19 & $4.37 \pm 0.19$ & $5.82 \pm 0.85$ & $12.52 \pm 1.41$ \\
Sylphs & & 15 & $2.95 \pm 0.26$ & $6.81 \pm 0.31$ & $10.03 \pm 1.04$ \\
& \multirow{3}{*}{ High } & 28 & $4.87 \pm 0.66$ & $6.46 \pm 0.82$ & $16.33 \pm 2.81$ \\
& & 19 & $2.99 \pm 0.39$ & $2.06 \pm 0.21$ & $1.46 \pm 0.05$ \\
& & 15 & $3.97 \pm 0.52$ & $4.67 \pm 0.56$ & $5.67 \pm 1.52$ \\
& Low & 28 & $0.56 \pm 0.22$ & $2.56 \pm 0.37$ & $5.28 \pm 1.45$ \\
& & 19 & $2.05 \pm 0.19$ & $7.96 \pm 2.55$ & $5.51 \pm 0.8$ \\
& & 15 & $2.61 \pm 0.21$ & $5.92 \pm 1.13$ & $7.51 \pm 1.23$ \\
\hline
\end{tabular}




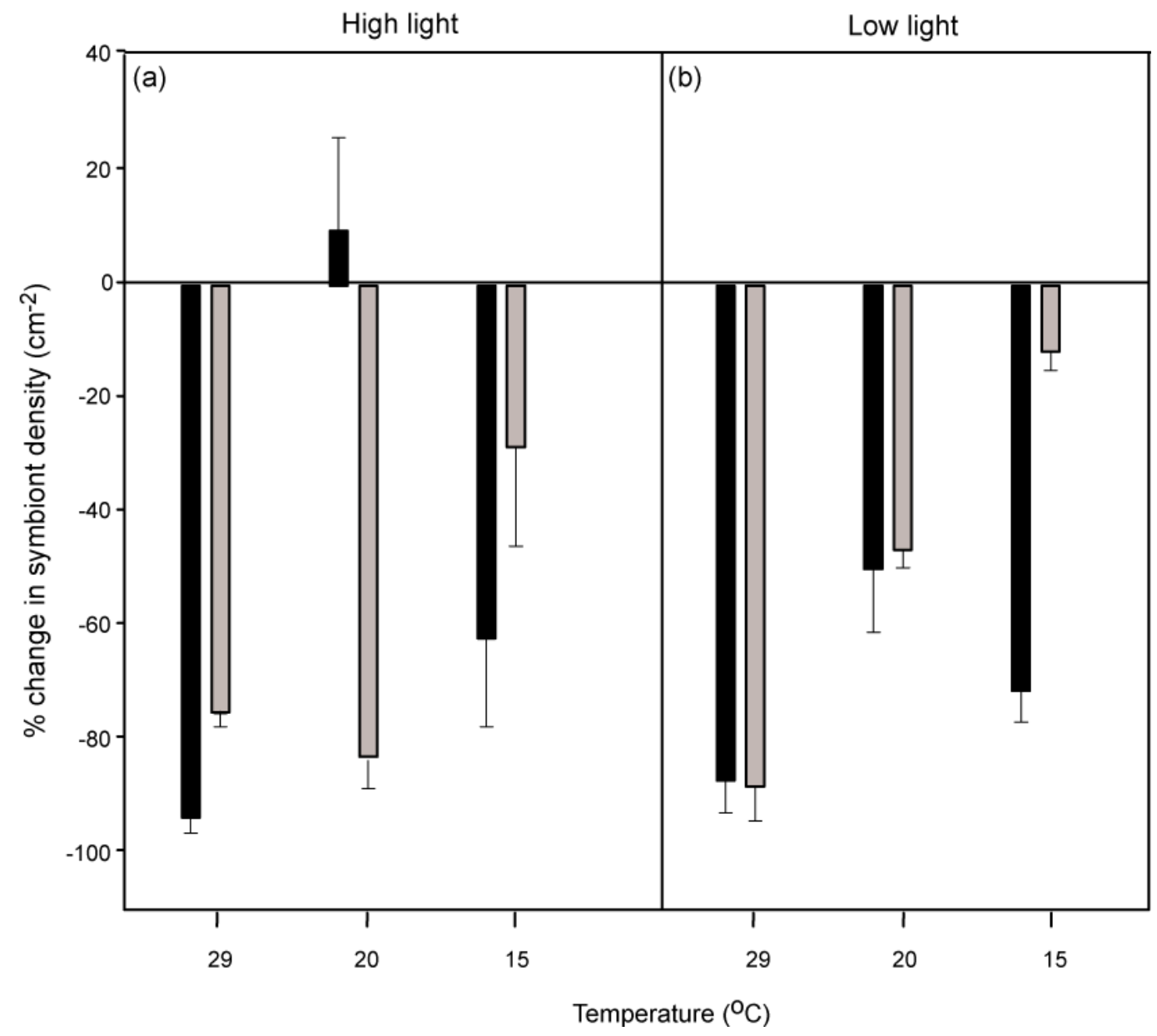

Figure 5.7. Relative change (\%) of symbiont density $\left(\times 10^{6} \mathrm{~cm}^{-2}\right)$ following $72 \mathrm{~h}$ exposure to temperature treatments $\left(29^{\circ} \mathrm{C}, 20^{\circ} \mathrm{C}\right.$ and $\left.15^{\circ} \mathrm{C}\right)$ in $P$. damicornis nubbins at a) high light and b) low light, from the lagoon (black bars), and from Sylphs Hole (grey bars)). Mean \pm SE $(n=4)$. 


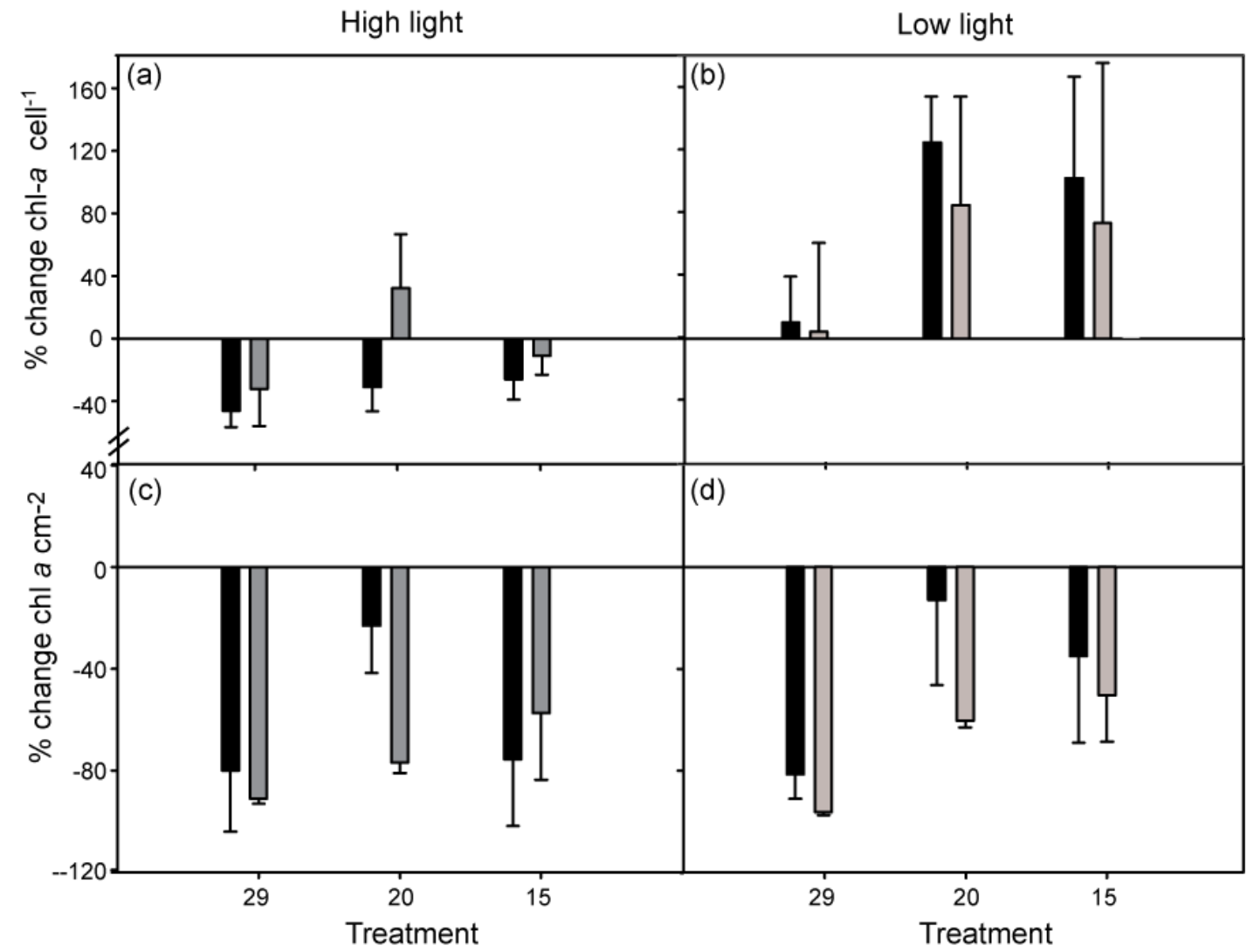

Figure 5.8 Relative change (\%) in chl-a of Pocillopora damicornis nubbins after $72 \mathrm{~h}$ of exposure to elevated or lowered temperatures $\left(29^{\circ} \mathrm{C}, 20^{\circ} \mathrm{C}\right.$ and $\left.15^{\circ} \mathrm{C}\right)$ at $(\mathrm{a}, \mathrm{c})$ high light and $(\mathrm{b}, \mathrm{d})$ low light. $(\mathrm{a}, \mathrm{b})$ Chlorophyll concentration per symbiont $\left(\mathrm{pg} \mathrm{cell}^{-1}\right) .(\mathrm{c}, \mathrm{d})$ Chlorophyll concentration per unit surface area (pg $\mathrm{cm}^{-2}$ ). Nubbins from the lagoon shown as (black bars, and nubbins from Sylphs shown as grey bars. Mean \pm SE $(n=4)$. 
Table 5.3 $p$ values of one-way ANOVA which tested for changes in symbiont density, and chlorophyll $a$ concentration in Pocillopora damicornis nubbins over a $72 \mathrm{~h}$ experiment for three temperature treatments $\left(29^{\circ} \mathrm{C}, 20^{\circ} \mathrm{C}\right.$ and $\left.15^{\circ} \mathrm{C}\right)$ at two light levels (high and low), from two locations.

\begin{tabular}{lccc}
\hline \multicolumn{3}{c}{ Percent change } \\
\hline Factor & $\begin{array}{c}\text { Symbiont } \\
\text { density } \\
\left(\mathrm{cm}^{-2} \times 10^{6}\right)\end{array}$ & $\begin{array}{c}\text { Chl } a \mathrm{zx}^{-1} \\
(\mathrm{pg})\end{array}$ & $\begin{array}{c}\text { Chl } a \\
\left.(\mu \mathrm{g} \mathrm{cm})^{-2}\right)\end{array}$ \\
\hline Temp & $<0.001$ & 0.225 & $<0.01$ \\
Light & 0.274 & $<0.05$ & 0.335 \\
Site & 0.774 & 0.984 & 0.124 \\
Temp x light & 0.419 & 0.759 & 0.718 \\
Temp x site & $<0.01$ & 0.909 & 0.186 \\
Light x site & 0.211 & 0.295 & 0.223 \\
Temp x light x site & 0.225 & 0.674 & 0.602 \\
& $29>15,20$ & & $29>15,20$ \\
\hline
\end{tabular}

\subsection{DISCUSSION}

The results of this study demonstrate a greater tolerance of the dinoflagellate symbionts of P. damicornis at LHI to a $3^{\circ} \mathrm{C}$ temperature decrease than a $3^{\circ} \mathrm{C}$ temperature increase from the annual temperature range $\left(18-26^{\circ} \mathrm{C}\right)$. Both temperature extremes were $1^{\circ} \mathrm{C}$ clear of their thermal thresholds. An additive effect of light and cold temperature stress was demonstrated, with high light and high temperature having the greatest impact on PSII photochemical efficiency, maximum excitation pressure, symbiont density and chl- $a$ concentration per cell. The results suggest that the presence of novel types of clade $\mathrm{C}$ Symbiodinium at LHI may be due to photo-physiological differences between the LHI symbionts and those found at lower latitudes, such as clade $\mathrm{C} 1$ in $P$. damicornis on the GBR. Essentially, this study suggests that the types of Symbiodinium at LHI may be specialised for cool and variable temperatures, so contributing to the success of corals at this marginal location 


\subsubsection{Photo-physiology of Lord Howe Island Symbiodinium}

P. damicornis at LHI has been observed to host three novel symbiont types, C41, C100 and C118, with the local scale distribution of these three types relating to environmental conditions (Chapter 3). In terms of the physiological parameters of P. damicornis from LHI, symbiont density was 6 times that of $P$. damicornis from the southern GBR $\left(23.3^{\circ} \mathrm{S}\right.$, $151.5^{\circ}$ E, Jones \& Hoegh-Guldberg 2001, Ulstrup et al. 2006, 2008), when both were sampled during the winter-spring. The high density of symbionts in P. damicornis colonies at LHI is probably linked to decreased irradiance at this high-latitude site, which is similarly known to cause increased symbiont density when linked with depth (Falkowski \& Dubinsky 1981, Stimson 1997). Further, the high density corroborates the findings of Ulstrup et al. (2006) of an increase in symbiont density with increasing latitude (and thus decreasing irradiance) across the range of the GBR $\left(14.4^{\circ} \mathrm{S}-23.3^{\circ} \mathrm{S}\right)$.

On a local scale, symbiont density was nearly $50 \%$ higher in corals sampled from the lagoon, compared to corals from Sylphs Hole. The latter site is characterised by high turbidity and low irradiance (2.4 FTU at Sylphs Hole compared to 1.7 FTU in the lagoon, Chapter 3), and thus the lower density at Sylphs Hole is unexpected, as reduced irradiance usually equates to increased symbiont density (Falkowski \& Dubinsky 1981, Stimson 1997). However, the low symbiont density in P. damicornis at Sylphs Hole may be attributable to the increase in nutrients at this site, whereby the corals may be making greater use of the heterotrophic carbon from particulate matter (Grotolli et al. 2006), and thus have less need for a high density of symbionts. A freshwater spring has been reported at Sylphs Hole (LHI MPA Manager, pers. comm.), but further study is needed to confirm these observations of high nutrient loads. Interestingly, chl- $a$ concentration per cell was 
greater in Sylphs Hole than the lagoon, which may compensate for the lower symbiont density, allowing photosynthetic output to remain high despite low cell densities (Falkowski \& Owens 1980, Kinzie et al. 1984).

\subsubsection{Photochemical responses to low temperature}

Symbiotic dinoflagellates in corals at LHI are seasonally exposed to extremes of temperature, with annual averages ranging from $18-26^{\circ} \mathrm{C}$ (Chapter 3 ). Cold temperature stress in the present study caused a decline in effective photosynthetic yield, particularly evident in the first $32 \mathrm{~h}$ of the experiment. It is well documented that decreased temperatures intensify photoinhibition in higher plants (Smilie et al. 1988, Aro et al. 1990, Greer 1990) due to a reduction in the rate at which the quenching of PSII occurs (Krause 1992). However, few studies have documented the effect of cold temperature stress on corals (Saxby et al. 2003, Hoegh-Guldberg et al. 2005), despite knowledge of increased temperatures causing a breakdown of the symbiotic relationship (Lesser 1996, Brown 1997a, Thornhill et al. 2006b).

Early evidence showed that, while some corals are adapted for cooler conditions (Roberts et al. 1982), others are killed by severe declines in temperature (Saxby et al. 2003, Hoegh-Guldberg et al. 2005). Cold temperature stress causing light-dependent photoinhibition of Symbiodinium cells has been documented in the coral Montipora digitata, following short-term cold exposure (Saxby et al. 2003). Following exposure to $12^{\circ} \mathrm{C}$ and $14^{\circ} \mathrm{C}$, in symbionts usually subject to temperatures from $23-26^{\circ} \mathrm{C}$, irreversible photodamage was reported, evident in chronically-depressed photochemical efficiency several hours after temperatures were returned to their original state. These findings parallel 
the present study, with photochemical efficiency depressed following cold temperature exposure, however the LHI symbionts were still able to photosynthesize at $63 \%$ of original capacity after $72 \mathrm{~h}$ in low light, suggesting a degree of tolerance to cold stress. Symbionttype specific responses to cold stress have been observed in cultured Symbiodinium cells, with clade B2 from the temperate western Atlantic found to be physiologically cold tolerant and able to rapidly recover from prolonged exposure to low temperatures $\left(10^{\circ} \mathrm{C}\right)$, unlike Symbiodinium types from tropical environments (A3, B1 and C2, Thornhill et al. 2008). The cold-tolerance of B2 was suggested to contribute to its distribution in temperate habitats (Thornhill et al. 2008); a pattern which may be emulated by the symbionts present at LHI. Although no attempt was made to assess the potential for recovery in the present study, the reduced impact of cold temperature after $32 \mathrm{~h}$ suggests that the symbionts can tolerate cold conditions, and thus may explain why these novel types are present in corals at LHI.

While the effect of cold stress on the symbiotic relationship in corals has received some attention, little is known of the impact on the photosynthetic apparatus of Symbiodinium cells. The present study used a plant efficiency analyzer (PEA) to determine the impact of temperature stress on the condition of PSII and the redox state of the primary $\left(\mathrm{Q}_{\mathrm{A}}\right)$ and secondary $\left(\mathrm{Q}_{\mathrm{B}}\right)$ electron acceptors in symbionts; a method previously used to show the site of impact of high temperature stress on symbionts (Hill et al. 2004a, Ulstrup et al. 2008; Hill and Ralph 2006). Our results suggest that cold temperatures impact a similar site to that impacted by warm temperatures, with a decrease in the $\mathrm{J}$ step along fast induction curves (FICs) indicating a decline in the rate of $\mathrm{Q}_{\mathrm{A}}$ reduction and the reduced capacity for $\mathrm{Q}_{\mathrm{A}}$ to transport electrons through the electron transport chain to $\mathrm{Q}_{\mathrm{B}}$, due to 
photoinhibition (Chylla \& Whitmarsh 1989, 1990, Hill \& Ralph 2006). A primary cause for this response could be an increase in the proportion of inactive PSII centres, whereby $Q_{B}$ cannot oxidize $\mathrm{Q}_{\mathrm{A}}{ }^{-}$, and as a consequence the photochemical capacity of PSII declines (Hill \& Ralph 2006). The cold-induced reduction in photochemical efficiency, specifically the capacity to transport electrons, may also be linked to the impact of cold temperatures on rates of reactions, via the effect on the kinetic energy of enzymes and substrates (HoeghGuldberg \& Pearse 1995, Saxby et al. 2003), including those of the Calvin-Benson cycle (Nobel 1991, Saxby 2003). Finally, Takahashi et al. (2009) reported that acceleration of photoinhibition by moderate heat stress is attributed primarily to inhibition of the repair of photodamaged PSII, and that the photoinhibition sensitivity of Symbiodinium to heat stress is determined by the thermal sensitivity of the PSII repair processes. The same mechanisms may play a part in cold temperature stress; however further study is required to determine if this is the case.

While the responses to cold temperature stress reported here are similar to those reported for increased thermal stress, both in the present study and in multiple comparable studies (Iglesias-Prieto et al. 1992, Warner et al. 1996, Warner \& Fitt 1999, Robison \& Warner 2006), the effect of a $3^{\circ} \mathrm{C}$ temperature decrease from annual minima on the photochemical efficiency, maximum excitation pressure $\left(\mathrm{Q}_{\mathrm{m}}\right)$ and the FIC steps of symbionts appears to be less than a $3^{\circ} \mathrm{C}$ increase in temperature from annual maxima. Additional evidence for limited cold stress is seen in the higher symbiont density and chlorophyll concentration per cell in the cold treatment compared to the warm one. Cold shock $\left(3-11^{\circ} \mathrm{C}\right.$ below ambient) has been shown to trigger the loss of dinoflagellate symbionts from some sea anemones and corals (Shinn 1966, Coles \& Jokiel 1977, Steen \& 
Muscatine 1987, Saxby et al. 2003, Hoegh-Guldberg et al. 2005), particularly observed at lower latitudes (Shinn 1966, Coles \& Jokiel 1977, Hoegh-Guldberg et al. 2005) where symbionts would have been less adapted to cooler and variable conditions than those present at LHI. For example, Hoegh-Guldberg et al. (2005) reported winter bleaching in corals at Heron Island $\left(23^{\circ} 26^{\prime} \mathrm{S}\right)$, when corals were subject to a 2-day period of $14-15^{\circ} \mathrm{C}$, when annual average temperatures usually range from $17-25^{\circ} \mathrm{C}$. Based on the findings of the present study, it is clear that photosynthetic damage can ensue from cold temperature stress, however the continued photosynthetic activity of symbionts at LHI suggests they may be adapted to these cool and variable conditions.

\subsubsection{Additive effect of low temperature and high irradiance}

Most bleaching observed in the field is caused by elevated temperatures combined with solar radiation, with excessive light causing the impairment of PSII by a loss of functional PSII centres (Fitt \& Cook 2001, Lesser \& Farrell 2004). The present study found an additive effect of both increased and lowered temperatures with heightened irradiance, causing a decline in photochemical efficiency, and increased maximum excitation pressure over PSII $\left(\mathrm{Q}_{\mathrm{m}}\right)$. An additive effect of low temperature and high irradiance was demonstrated by Saxby et al. (2003), whereby exposure of corals to $14^{\circ} \mathrm{C}$ in low light had little effect on photochemical efficiency while corals exposed to $14^{\circ} \mathrm{C}$ and full sunlight were heavily impacted. Variation in the photochemical responses to light intensities and temperatures are also evident from the FICs in the present study. A greater decline in the $\mathbf{J}$ step is evident in high light treatments compared to low light, which equates to a decrease in the rate in $\mathrm{Q}_{\mathrm{A}}$ reduction, and an increase in non-photochemical quenching (Hill \& Ralph 
2005). Diurnal patterns in the FIC in the present study are similar to those observed by Hill and Ralph (2005), however the daily recovery reported in that study was not observed in the high and low temperature treatments in the present study, particular in high light, suggesting that photodamage has occurred (Demmig-Adams et al. 1989). The lack of a morning rise in the $\mathrm{P}$ step in all the high-light treatments, irrespective of temperature, provides further evidence of permanent damage to PSII; in optimal conditions nighttime reduction in the PQ pool occurs and is followed by a morning rise in the P step when there is a greater capacity for the electron transport chain to oxidize the PQ pool (Hill \& Ralph 2008). Although corals in the experiment were at a similar water depth to that they would experience at low tide, the high light treatments used may have been too intense, and thus may have confounded results. However, the additive effect of light and temperature stress was consistant among temperatures, and therefore the results remain valid.

\subsubsection{Ecological implications}

While many high latitude corals can withstand seasonal variations in sea temperature of more than $12^{\circ} \mathrm{C}$ (Kleypas et al. 1999), small excursions above and below geographically associated maxima or thresholds lead to stress in both tropical and high latitude corals (Hoegh-Guldberg 1999, Hoegh-Guldberg \& Fine 2004, Hoegh-Guldberg et al. 2005). The flexibility of $P$. damicornis to associate multiple symbiont types as opposed to the previously reported fidelity to $\mathrm{C} 1$ in the Indo-Pacific, and its ability to cope with low temperatures by hosting apparently thermally-resilient symbionts, helps to explain the success of this coral at the marginal location of LHI. However, the detrimental effect of a

$3^{\circ} \mathrm{C}$ increase above the summer maximum suggests that $P$. damicornis may be on the 
boundary limits of its survival, and that future warming may lead to coral bleaching events. Further, Ulstrup et al. (2006) found P. damicornis hosting C1 on the GBR to be highly sensitive to elevated temperatures $\left(<2^{\circ} \mathrm{C}\right)$, and therefore, even if $P$. damicornis colonies at LHI did associate with $\mathrm{C} 1$ (present in other host species), this may not confer a greater thermal tolerance. As $P$. damicornis is a dominant species at Lord Howe Island (Harriott et al. 1995), its loss would have a considerable effect on the community. Questions remain as to whether these novel high latitude coral-Symbiodinium associations will have the ability to acclimate to rapidly increasing temperatures, despite their ability to cope with cooler temperatures. Furthermore, despite predictions that high latitude reefs could act as refuges in a future of warming seas (Glynn 1996), the proximity of these high latitude corals to their upper thermal threshold suggests this is unlikely, unless they prove to have the ability to rapidly adjust their thresholds. 


\section{Chapter 6}

\section{General Discussion}

Collectively, the chapters in this thesis examine the persistence of corals in marginal environments, and highlight the roles that the symbiotic dinoflagellates and the environment play in shaping these communities. Contrary to the expectation that symbiont diversity would be low at high latitude sites because of the challenging conditions faced, major findings include high diversity and reduced host specificity of symbionts in corals at the high latitude site of Lord Howe Island (LHI), Australia. Physiological assessment of novel LHI symbionts (Symbiodinium spp.) led to the suggestion that they may be specialised for cooler and more variable temperatures, so contributing to the success of corals at this marginal location. In contrast, a low diversity of generalist symbionts was uncovered at the equatorial site of Palmyra Atoll.

Local environmental conditions, primarily sediment regimes, were found to affect the distribution of coral species at Palmyra Atoll, with no discernible effect on symbiont distribution (in terms of the holobiont). On a wider scale, local environment conditions (specifically wave exposure) were shown to influence coral community structure at the Kermadec Islands (KI), New Zealand, as opposed to the low and variable temperatures associated with high latitude sites. By assessing the diversity and physiological tolerances of symbionts in marginal environments, and their associated control of host distribution, this study was able to gain a better understanding of how corals survive in marginal 
environments, which will provide greater insight into how corals may respond to climate change.

Three major questions arose from the results of this study, and these will be considered in detail here. First, how and why do symbiont communities differ at marginal sites compared to 'optimal' sites? Second, why is there such a difference in the diversity of corals and symbionts, and the degree of host-specificity of symbiont communities between marginal sites? The potential causes of this variability will be discussed. Finally, the susceptibility of these marginal reefs to future climate change will be assessed, and their potential to act as refuges for corals in a future of warming seas.

\subsection{Marginal vs. optimal sites}

Marginal reefs or communities are defined as those that occur where conditions are close to the environmental thresholds for coral survival (Kleypas et al. 1999, Harriott \& Banks, 2002). These thresholds include high or low temperatures, salinities or nutrient levels, or low light penetration or aragonite saturation state (Kleypas et al 1999). Marginal communities also occur within the tropical belt where environmental conditions are suboptimal for reef development, such as in areas influenced by upwelling, heavy runoff, or river deltas (Perry \& Larcombe 2003). It is traditionally viewed that optimal environmental conditions lead to high coral diversity (Guinotte et al. 2003), evident in the decline of coral diversity and cover with increasing latitude and the associated decline in temperature (Harriott \& Banks 2002). Assessing differences in coral community structure between optimal and marginal sites in the present study, clear differences exist, with reduced 
diversity and cover at high latitude LHI and marginal regions of Palmyra Atoll, compared to optimal sites/regions.

However, of interest to the present study is the contrasting high diversity of symbionts at high latitudes (19 types in 13 genera at LHI, and 10 types in 9 genera at the KI) to those on the optimal sites such as the Great Barrier Reef (GBR, see Chapter 3, LaJeunesse et al. 2003, LaJeunesse et al. 2004a). The high symbiont diversities at high latitudes may be (1) a potential adaptation of the host to the seasonally variable conditions of high latitude sites, and (2) linked to the isolation of the high latitude sites.

High latitude sites exhibit wide ranges in their annual temperatures, for example Lord Howe Island annually varies between $18-26^{\circ} \mathrm{C}$ (chapter 3 ), whereas areas of the Central GBR only fluctuate approximately $2^{\circ} \mathrm{C}$ annually (Lough \& Barnes 2000). To persist under these variable conditions, hosts at LHI and the KI may have evolved the ability to harbour a range of symbiont types, with varying physiologies to cope with temperature fluctuations. For example, Acropora cuneata hosted 5 different symbiont types at LHI, but across the range of the GBR $\left(15^{\circ}\right)$ the greatest number of types found in an Acropora sp. is only four (LaJeunesse et al. 2004a). The local scale niche diversification of symbionts at LHI contributes to the high diversity of symbionts, and has been observed in many other cnidarian hosts at multiple locations (Rowan \& Knowlton 1995, Rowan et al 1997, Baker 2001, Iglesias-Prieto et al 2004, Sampayo et al. 2007, Venn et al 2008b). By hosting multiple types, varying with local environmental conditions, these corals persist and indeed thrive in these 'stressful' marginal environments, with potentially little cost to the host. Further information is required on the physiological diversity of these novel symbionts, in order to assess the benefits derived from hosting them. 
The presence of multiple novel types at LHI and the KI may also be attributable to their biogeographic isolation. LHI is extremely isolated, located over $1000 \mathrm{~km}$ from the GBR, which is proposed as its the source of larvae (Wolanski 1994). Long distance dispersal to LHI has been found to be rare and populations are genetically isolated (Ayre \& Hughes 2004), with a lack of migratory 'stepping-stones' acting as a barrier to genetic exchange between symbionts. It is suggested that isolation can lead to the co-evolution of regionally distinctive host-symbiont combinations (LaJeunesse 2005), such as the multiple regionally endemic types of Symbiodinium at LHI. Comparatively, the GBR exhibits high gene flow between reefs (Ayre \& Hughes 2004), thus negating the need or capacity for the evolution of endemic types. Interestingly, LHI and the KI do share some novel, potentially high-latitude specific symbiont types, despite being located 2,200 km apart. Furthermore, symbiont type $\mathrm{C} 3 \mathrm{w}$ is present in hosts at LHI, the KI and Thailand (LaJeunesse, in prep). Separate evolutionary events may have occurred in these symbiont types, however further examination of the evolutionary events leading to Symbiodinium diversification is required to fully understand current distribution patterns.

Of note, some divergent symbionts were present in horizontal strategists at LHI, a scenario that is rare and has only been reported in Fungia scutaria that contains C1f in Hawaii (Weis et al. 2001, Rodriguez-Lanetty et al. 2004). The presence of novel symbionts that have not co-evolved in vertically transmitting species may be attributable to their evolution under long-term isolation in stressful environmental conditions, whereby a particular symbiont is selected over a generalist type from the external environment. 


\subsection{Marginality - a variable term}

Considerable variability existed in the community structure of the three marginal communities examined in the present study, both in terms of corals and symbionts. LHI and the KI both exist on the thresholds for coral growth, with low mean annual and seasonal temperatures, and a low aragonite saturation state (Buddemeier 1997; Kleypas et al. 1999). Yet, when assessing the variability in coral community structure among these sites and other high latitude sites, distinct differences were established based on local scale conditions (i.e. wave exposure), rather than latitude. Furthermore, the gradient of marginality at Palmyra Atoll, associated with the variation in local scale sediment regime, led to variation in the coral community structure, with reduced diversity and cover in highly sedimented areas, and thus marginal sites. The considerable variability in coral diversities and distributions among marginal sites (whether marginal due to extremes of temperatures, or any other wide scale variable) suggest that local scale factors should also be considered when assessing the parameters controlling the structure of the communities.

Looking more closely at symbiont diversity, and distributions among and within marginal sites, scale becomes an important factor in assessing the degree of marginality. The scale of marginality at LHI and the KI would be deemed large-scale, whereas Palmyra is subject to local scale marginality, and a vast difference in symbiont diversity is seen between the two sites. Within the localised, marginal, regions of Palmyra, and across the atoll as a whole, symbiont diversity was low and unaffected by the extent of sedimentation. Conversely, LHI, the epitome of marginality due to its high latitude location, exhibits a high diversity of symbionts, despite the variable and extreme conditions experienced, and 
perhaps as a factor of this variability. At Palmyra Atoll, the lack of correlation between symbiont distribution and potential environmental stressors suggests that the symbionts present are robust enough to cope with the current environmental regime.

It is clear from the vast sub-cladal diversity discovered in the present study, that sub-cladal distinctions of Symbiodinium need to be the standard in studies of distributions and physiology of symbionts, as physiological differences at a sub-cladal level have now been established (Tchernov et al. 2004, Sampayo et al. 2007, Sampayo et al. 2008). Further, it is estimated that $25 \%$ of scleractinian coral species can host more than one clade of Symbiodinium (Goulet 2007), but this may greatly underestimate the flexibility of the host, because the relevant question is: how many species can host more than one sub-clade (type)? A greater understanding of the mechanisms underlying these differences is required, assessing the full genetic and physiological diversity within the genus Symbiodinium, particularly in marginal environments.

\subsection{Future of 'marginal' reefs and communities}

Predictions on the rate of global change at their most conservative expect a rise of $2^{\circ} \mathrm{C}$ by $2050-2010$, in addition to atmospheric carbon increasing to twice pre-industrial measures (Hoegh-Guldberg et al. 2007). It has been proposed that marginal reefs/communities, predisposed to broad environmental variability and/or on the boundary limits of survival, may in the future act as refuges in an environment modified by global climate change (Glynn 1996, Riegl \& Piller 2003). Furthermore, it is suggested that reefs under 'optimal' conditions may become more marginal through shifts in environmental variables (Kleypas et al. 1999, Guinotte et al. 2003, Perry \& Larcombe 2003). However, a wide range of 
environmental and physiological requirements need to be satisfied in order for these communities to act as refuges (Fig. 6.1). Additionally, the fact that the rate of change from 'optimal' to 'marginal' conditions is likely to exceed the rate of acclimation/adaptation (Hoegh-Guldberg et al. 2007, Edmunds \& Gates 2008) causes further concern for the future of coral reefs.

A key point when assessing the appropriateness of high latitude sites as refuges is the dissimilarity of the coral species compositions at high latitude sites compared to 'optimal' sites, and the cause(s) of these dissimilarities. Many important coral species on tropical reefs are absent or rare at high latitudes, for example massive Porites and branching Acropora spp. (Veron \& Done 1979). Their dearth at high latitudes is correlated with the absence of reef accretion capacity caused by the reduced temperatures (Glynn \& Stewart 1973, Crossland 1988). If the water temperatures increase, as they are predicted to, perhaps accretion would occur at the high latitude sites which at present lack a reef framework, such as the KI, however many factors argue against the establishment of tropical species in subtropical locations. For example, for low latitude coral species to successfully colonise at high latitudes, they must first get there. However, many high latitude islands are isolated, with rare larval input as a result of most corals having short dispersal distances (Hughes et al. 2002, Ayre \& Hughes 2004). Furthermore, vast variability in the physical setting of these sites exists. For instance, the KI are exposed to high wave energy, which deems them challenging for settlement and growth. Most reefbuilding species are absent there, due to the low temperatures, the lack of larval supply, and the difficulty associated with growth and establishment in high wave-energy environments (Menge \& Olsen 1990, Harriott \& Banks 2002). Add to this the impacts of thermal stress 
which reduce reproductive output and gamete production (Szmant \& Gassman 1990, Lasker \& Coffroth 1999, Baird \& Marshall 2002), and the associated decrease in carbonate ion concentrations at higher latitudes as atmospheric carbon dioxide levels spiral upwards (Caldeira \& Wickett 2003, Hoegh-Guldberg 2005, Hoegh-Guldberg et al. 2007), and the chance that these remote high-latitude sites will act as refuges becomes highly unlikely. The complexities of these potential refuges would need to be assessed on a site-by-site basis, to allow such predictions to be made.

In recent times, many studies have concentrated on the ability of corals to acclimate or adapt to changes in their environment by varying the identities and/or composition of their algal symbionts (Buddemeier \& Fautin 1993, Fautin \& Buddemeier 2004, Berkelmans \& van Oppen 2006). Physiological distinctiveness of community symbiont types (Tchernov et al. 2004, Frade et al. 2008a, Takahashi et al. 2009), and adaptive shifts in symbiont communities have been demonstrated in a number of studies, both under experimental conditions (Berkelmans \& van Oppen 2006, Sampayo et al. 2008) and in situ (Suwa et al. 2008, Venn et al. 2008b). Corals present at marginal locations, such as LHI, may be predisposed to broad environmental variability, perhaps through their flexibility to associate with a range of thermally-tolerant symbiont types. However, these types probably evolved over long periods, with slowly changing environmental conditions. The likelihood of these symbionts being available at optimal sites as they become more marginal is low; future rises in temperature are, at their most conservative, $2^{\circ} \mathrm{C}$ by 2050 , much greater than the absolute change at any one location over the last $20 \mathrm{yr}$ of $<0.5^{\circ} \mathrm{C}$ (Hoegh-Guldberg 1999, IPCC 2007). Thus, as the climate rapidly changes, natural selection of corals and 
their symbionts is likely to occur, leading to changes in the composition of reefs, and favouring tolerant holobionts over stress-susceptible ones.

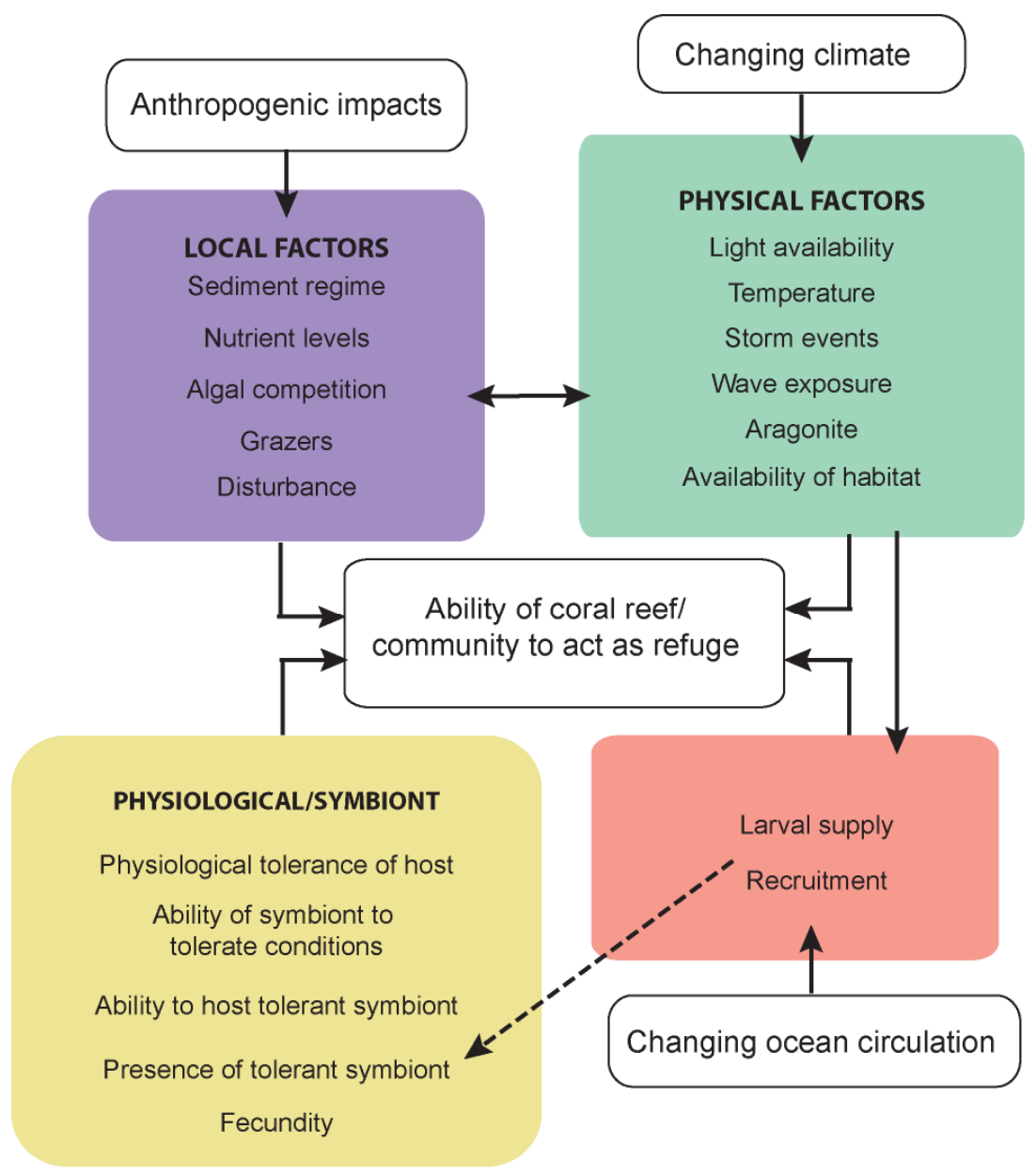

Figure 6.1 Environmental and physiological factors and processes that will influence the ability of a marginal reef/community to act as a refuge. Factors are grouped on the basis of similarity. Potential impacts on these processes are indicated in the outer white boxes. Arrows between boxes indicate where factors/processes interact. Dotted line indicates a single factor is affected. 
Crucially, at sites that are already marginal, tolerant symbionts may be favoured in the future as conditions change, but only corals that have the ability to associate with thermally-tolerant symbiont types will theoretically be able to survive. Additionally, corals that can harbour tolerant symbionts may do so as a trade-off to other attributes that favour them less in the future, such as increased susceptibility to disease (Stat et al. 2008, Correa et al. 2009), and low growth rates (Little et al. 2004). Furthermore, contrary to the original definition of the 'adaptive bleaching hypothesis' (Buddemeier \& Fautin 1993), the flexibility of a coral to associate with multiple Symbiodinium types does not mean that it has the ability to switch its symbionts for completely new ones. Indeed, long-term fidelity to certain symbiont types has been demonstrated in colonies of various species of coral analyzed over many years (Goulet \& Coffroth 2003, LaJeunesse et al. 2004a, Thornhill et al. 2006a, Thornhill et al. 2006b), and it is suggested that permanent changes in the symbiont composition are more likely to occur over generations than within the life-cycle of an individual host (Thornhill et al. 2006b, Baird et al. 2007, Sampayo et al. 2008). Although the flexibility of corals to harbour multiple symbiont types is important for their future, physiological differences in these symbionts should be assessed, as should the longterm effect on the host of harbouring these different symbiont types.

Assessing the susceptibility of the sites studied here to future abiotic changes, tentative predictions can be made. Palmyra Atoll may be most at risk. Potentially if the clade D symbionts already present in some hosts at this site are 'stress-tolerant' clade D symbionts (Baker et al. 2004, Mostafavi et al. 2007), and if conditions change to the extent that current symbionts cannot cope, only hosts able to harbour either this 'tolerant' clade D or other tolerant types will survive. At both LHI and the KI, the considerable symbiont diversity and 
the flexibility of many hosts to associate with multiple, potentially physiologically distinct, symbiont types may aid these communities in their survival. Further, physiological testing indicated an ability for the symbionts to tolerate a range of conditions, and their presence in thermally-variable environments stands them in good stead for dealing with future environmental changes. However, predictions like this will depend on the rate of change of the global conditions, as well as the physiological tolerance range of both symbiont types and coral species.

In conclusion, much remains to be learnt of the ability of corals and their dinoflagellate symbionts to adapt to changing environmental conditions, and the role that marginal communities may play as refuges. Questions remain as to whether the symbionts present in marginal environments are indeed physiologically distinct, the physiological cost of harbouring tolerant symbionts on the host, and most importantly, whether corals and their symbionts do indeed have the capacity to adapt or acclimate to new environmental conditions, and whether these changes can occur quickly enough to prevent the future degradation of coral reefs and communities on a global scale. 


\section{References}

Abdel-Salam H, Porter JW, Hatcher BG (1988) Physiological effects of sediment rejection on photosynthesis and respiration in three Caribbean reef corals. Proc 6th Int. Coral Reef Symp, Townsville, Australia, 1: 285-292

Abrego D, Ulstrup KE, Willis BL, van Oppen MJH (2008) Species-specific interactions between algal endosymbionts and coral hosts define their bleaching response to heat and light stress. Proc R Soc Lond B 275:2273-2282

Achituv Y, Dubinsky Z (1990) Evolution and zoogeography of coral reefs. In: Dubinsky Z (ed) Ecosystems of the World 25: Coral Reefs. Elsevier, Amsterdam, pp 1-9

Adjeroud M, Andrefouet S, Payri C, Orempuller J (2000) Physical factors of differentiation in macrobenthic communities between atoll lagoons in the Central Tuamotu Archipelago (French Polynesia). Mar Ecol Prog Ser 196:25-38

Anderson M (2001) Permutation tests for univariate or multivariate analysis of variance and regression. Can J Fish Aquat Sci 58:626-640

Anthony KRN (1999) Coral suspension feeding on fine particulate matter. J Exp Mar Biol Ecol 232:85-106

Apprill AM, Gates RD (2007) Recognizing diversity in coral symbiotic dinoflagellate communities. Mol Ecol 16:1127-1134

Aro EM, Hundal T, Carlberg I, Anderson B (1990) In vitro studies on light-induced inhibition of photosystem II and D-1 protein degradation at low temperatures. Biochim Biophys Acta 1019:269-275 
Ayre DJ, Hughes TP (2004) Climate change, genotypic diversity and gene flow in reefbuilding corals. Ecol Lett 7:273-278

Ayre DJ, Hughes TP, Standish RS (1997) Genetic differentiation, reproductive mode, and gene flow in the brooding coral Pocillopora damicornis along the Great Barrier Reef, Australia. Mar Ecol Prog Ser 159:175-187

Babcock RC, Davies P (1991) Effects of sedimentation on settlement of Acropora millepora. Coral Reefs 9:205-208

Babcock RC, Heyward AJ (1985) Larval development of certain gamete-spawning scleractinian corals. Coral Reefs 5:111-116

Babcock RC, Bull GD, Harrison PL, Heyward AJ, Oliver JK, Wallace CC, Willis BL (1986) Synchronous spawnings of 105 scleractinian coral species on the Great Barrier Reef. Mar Biol 90:379-394

Baghdasarian G, Muscatine L (2000) Preferential expulsion of dividing algal cells as a mechanism for regulating algal-cnidarian symbiosis. Biol Bull 199: 278-286.

Baillie BK, Belda-Baillie CA, Maruyama T (2000) Conspecificity and Indo-Pacific distribution of Symbiodinium genotypes (Dinophyceae) from Giant clams. J Phycol $36: 1153-1161$

Baird AH, Cumbo VR, Leggat W, Rodriguez-Lanetty M (2007) Fidelity and flexibility in coral symbioses. Mar Ecol Prog Ser 347: 307-309

Bak RPM (1978) Lethal and sublethal effects of dredging on reef corals. Mar Poll Bull 9:14-16 
Bak RPM, Elgershuizen JHBW (1976) Patterns of oil-sediment rejection in corals. Mar Biol 37:105-113

Baker AC (1999) The symbiosis ecology of reef building corals. PhD thesis. Univ Miami $120 \mathrm{pp}$

Baker AC (2001) Reef Corals Bleach to Survive Change. Nature 411:765-766

Baker AC (2003) Flexibility and Specificity in coral-algal symbiosis: Diversity, Ecology, and Biogeography of Symbiodinium. Annu Rev Ecol Evol Syst 34:661-669

Baker AC, Rowan R (1997) Diversity of symbiotic dinoflagellates (zooxanthellae) in scleractinian corals of the Caribbean and Eastern Pacific. Proc 8th Int Coral Reef Symp, Panama, 2:1301-1306

Baker AC, Romanski AM (2007) Multiple symbiotic partnerships are common in scleractinian corals, but not in octocorals: Comment on Goulet (2006). Mar Ecol Prog Ser 335:237-242

Baker AC, Glynn PW, Riegl B (2008) Climate change and coral reef bleaching: An ecological assessment of long-term impacts, recovery trends and future outlook. Estuarine Coastal Shelf Sci 80:435-471

Baker AC, Rowan R, Knowlton N (1997) Symbiosis ecology of two Caribbean acroporid corals. Proc 8th Int Coral Reef Symp 2:1295-1300

Baker AC, Starger CJ, R. MT, Glynn PW (2004) Corals' adaptive responses to climate change. Nature 430:741 
Banaszak AT, Iglesias-Prieto R, Trench RK (1993) Scrippsiella velellae sp. nov. (Peridiniales) and Gloeodinium viscum sp. nov. (Phytodiniales), dinoflagellate symbionts of two hydrozoans (Cnidaria). J Phycol 29:517-528

Barneah O, Weis VM, Perez ST, Benayahu Y (2004) Diversity of dinoflagellate symbionts in Red Sea soft corals: mode of symbiont acquisition matters. Mar Ecol Prog Ser 275:89-95

Benzoni F, Bianchi CN, Morri C (2003) Coral communities of the northwestern Gulf of Aden (Yemen): variation in framework building related to environmental factors and biotic conditions. Coral Reefs 22:475-484

Berkelmans R, van Oppen M (2006) The role of zooxanthellae in the thermal tolerance of corals: a "nugget of hope" for coral reefs in an era of climate change. Proc R Soc Lond B 273:2305-2312

Birkleland C (1977) The importance of rate of biomass accumulation in early successional stages of benthic communities to the survival of coral recruits. Proc 3rd Int Coral Reef Symp, University of Miami, Florida, 15-21

Birkleland C, Randall RH (1981) Facilitation of coral recruitment by Echinoid excavations. Proc 4th Int Coral Reef Symp, Manila, 1:695-698

Black NA, Voellmy R, Szmant AM (1995) Heat shock protein induction in Montastraea faveolata and Aiptasia pallida to elevated temperatures. Biol Bull 188:234-240

Bouchon C (1981) Quantitative Study of the Scleractinian Coral Communities of a Fringing Reef of Reunion Island (Indian Ocean). Mar Ecol Prog Ser 4:273-288 
Bray JR, Curtis JT (1957) An ordination of the upland forest communities of Southern Wisconsin. Ecol Mono 27:325-349

Brook FJ (1999) The coastal scleractinian corals of the Kermadec Islands, southwestern Pacific Ocean. J R Soc NZ Zool 29:435-460

Brothers RN, Searle EJ (1970) The geology of Raoul Island, Kermadec Group, southwest Pacific. Bull volcanologique 34:7-37

Brown BE (1997a) Disturbances to reefs in recent times (Chapter 15). In: Birkeland C (ed) Life and Death of Coral Reefs. Chapman and Hall, New York, p 354-379

Brown BE (1997b) Coral bleaching: causes and consequences. Coral Reefs 16:S129-S138

Brown BE, Howard LS (1985) Assessing the effects of "Stress" on reef corals. Adv Mar Biol 22:1-63

Brown BE, Suharsono (1990) Damage and recovery of coral reefs affected by El Nino related seawater warming in the Thousand Islands, Indonesia. Coral Reefs 8:163170

Brown BE, Ambarsari I, Warner ME, Fitt WK, Dunne RP, Gibb SW, Cummings D (1999) Diurnal changes in photochemical efficiency and xanthophyll concentrations in shallow water reef corals: evidence for photoinhibition and photoprotection. Coral Reefs 18:99-105

Brown BE, Dunne RP, Goodson MS, Douglas AE (2002) Experience shapes the susceptibility of a reef coral to bleaching. Coral Reefs 21:119-126

Buddemeier RW (1997) Making light work of adaptation. Nature 338:229-230 
Buddemeier RW, Fautin DG (1993) Coral bleaching as an adaptive mechanism: A testable hypothesis. Bioscience 43:320-326

Buddemeier RW, Smith SV (1999) Coral adaptation and acclimatization: a most ingenious paradox. Am Zool 39:1-9

Caldeira K, Wickett ME (2003) Oceanography: Anthropogenic carbon and ocean pH. Nature 425: 365

Carlos AA, Baillie BK, Maruyama T (2000) Diversity of dinoflagellate symbionts (zooxanthellae) in a host individual. Mar Ecol Prog Ser 195:93-100

Celliers L, Schleyer MH (2007) Coral community structure and risk assessment of high latitude coral communities at Sodwana Bay, South Africa. Biodiv Conserv 17:30973117

Chang SS, Prezelin BB, Trench RK (1983) Mechanisms of photoadaptation in three strains of the symbiotic dinoflagellate Symbiodinium microadriaticum. Mar Biol 76:219229

Chen CA, Lam KK, Nakano Y, Tsai WS (2003) A Stable Association of the StressTolerant Zooxanthellae, Symbiodinium Clade D, with the Low-TemperatureTolerant Coral, Oulastrea crispata (Scleractinia:Faviidae) in Subtropical NonReefal Coral Communities. Zool Stud 42:540-550

Chylla RA, Whitmarsh J (1989) Inactive Photosystem II complexes in leaves. Plant Physiol $90: 765-772$ 
Chylla RA, Whitmarsh J (1990) Light saturation response of inactive Photosystem II reaction centers in spinach. Photosynth Res 25:39-48

Clarke KR, Ainsworth M (1993) A method of linking multivariate community structure to environmental variables. Mar Ecol Prog Ser 92:205-219

Clarke KR, Gorley RN (2006) PRIMER v6: User Manual/Tutorial, Plymouth, UK

Clarke KR, Chapman MG, Somerfield PJ, Needham HR (2006a) Dispersion-based weighting of species counts in assemblage analyses. Mar Ecol Prog Ser 320:11-27

Clarke KR, Somerfield PJ, Chapman MG (2006b) On resemblance measures for ecological studies, including taxonomic dissimilarities and a zero-adjusted Bray-Curtis coefficient for denuded assemblages. J Exp Mar Biol Ecol 330:55-80

Coffroth MA, Santos SR (2005) Genetic Diversity of Symbiotic Dinoflagellates in the Genus Symbiodinium. Protist 156:19-34

Cole RG, Creese RG, Grace RV, Irving P, Jackson BR (1992) Abundance patterns of subtidal benthic invertebrates and fishes at the Kermadec Islands. Mar Ecol Prog Ser 82:207-218

Coles SL (2003) Coral species diversity and environmental factors in the Arabian Gulf and the Gulf of Oman: A comparison to the Indo-Pacific region. Atoll Res Bull 507

Coles SL, Fadlallah YH (1991) Reef coral survival and mortality at low temperatures in the Arabian Gulf: new species-specific lower temperature limits. Coral Reefs 9:231-237

Coles SL, Jokiel PL (1977) Effects of temperature on photosynthesis and respiration in hermatypic corals. Mar Biol 43:209-216 
Coles SL, Jokiel PL (1978) Synergistic effects of temperature, salinity and light on the hermatypic coral Montipora verrucosa. Mar Biol 49:187-195

Collen J, Garton DW, Gardner JPA (2009) Shoreline Changes and Sediment Redistribution at Palmyra Atoll (Equatorial Pacific Ocean): 1874-Present. J Coastal Res 25:711722

Colley NJ, Trench RK (1983) Selectivity in phagocytosis and persistence of symbiotic algae by the scyphistoma stage of the jellyfish Cassiopeia xamachana. Proc R Soc Lond B 219:61-82

Connell JH (1978) Diversity in tropical rainforests and coral reefs. Science 199:1302-1310

Cook CB, Logan A, Ward J, Luckhurst B, Berg CJ (1990) Elevated temperatures and bleaching on a high latitude coral reef: the 1988 Bermuda event. Coral Reefs 9:4549

Cornell HV, Karlson RH (2000) Coral species richness: ecological versus biogeographical influences. Coral Reefs 19:37-49

Correa A, Baker A (2009) Understanding diversity in coral-algal symbiosis: a cluster-based approach to interpreting fine-scale genetic variation in the genus Symbiodinium. Coral Reefs 28:81-93

Correa A, Brandt ME, Smith TB, Thornhill DJ, Baker AC (2009) Symbiodinium associations with diseased and healthy scleractinian corals. Coral Reefs 28 (2): 437448 
Crossland CJ (1981) Seasonal growth of Acropora cf. formosa and Pocillopora damicornis on a high latitude reef (Houtman Abrolhos, Western Australia). 4th Int Coral Reef Symp, Manila, 663-667

Crossland CJ (1983) Dissolved nutrients in coral reef waters. In: Barnes DJ (ed) Perspectives on coral reefs, Manuka, pp 56-68

Crossland CJ (1988) Latitudinal comparisons of coral reef structure and function. Proc 6th Int Coral Reef Symp, Townsville, Australia 1:221-226

Dai C (1988) Coral Communities of Southern Taiwan. Proc 6th Int Coral Reef Symp, Townsville, Australia 2:647-652

Davy SK, Turner JR (2003) Early development and acquisition of zooxanthellae in the temperate symbiotic sea anemone Anthopleura balliii (Cocks). Biol Bull 205:66-72.

De'ath G (2002) Multivariate regression trees: a new technique for modelling species environment relationships. Ecology 83:1105-1117

Demmig-Adams B, Adams WW, Heber U, Neimanis S, Winter K, Kruger A, Czygan F-C, Bilger W, Bjorkman O (1990) Inhibition of Zeaxanthin Formation and of Rapid Changes in Radiationless Energy Dissipation by Dithiothreitol in Spinach Leaves and Chloroplasts. Plant Physiol 92:293-301

DeVantier L, Pilcher N (2000) The Status of Coral Reefs in Saudi Arabia. Global Coral Reef Monitoring Network 
Diekmann OE, Bak RPM, Tonk L, Stam WT, Olsen JL (2002) No habitat correlation of zooxanthellae in the coral genus Madracis on a Curaçao reef. Mar Ecol Prog Ser $227: 221-232$

Diekmann OE, Olsen JL, Stam WT, Bak RPM (2003) Genetic variation within Symbiodinium clade B from the coral genus Madracis in the Caribbean (Netherlands Antilles). Coral Reefs 22:29-33

Dikou A, van Woesik R (2006) Survival under chronic stress from sediment load: Spatial patterns of hard coral communities in the southern islands of Singapore. Mar Poll Bull 52:7-21

Done TJ (1983) Patterns in the distribution of coral communities across the central Great Barrier Reef. Coral Reefs 1:95-147

Donner SD, Skirving WJ, Little CM, Oppenheimer M, Hoegh-Guldberg O (2005) Global assessment of coral bleaching and required rates of adaptation under climate change. Glob Change Biol 11:2251-2265

Douglas AE (1998) Host benefit and the evolution of specialisation in symbiosis. Heredity $81: 599-603$

Downs CA, Fautin JE, Halas JC, Dustan P, Berniss J, Woodley CM (2002) Oxidative stress and seasonal coral bleaching. Free Radical Bio Med 33:533-543

Dunn SR, Weis VM (2009) Apoptosis as a post-phagocytic winnowing mechanism in a coral-dinoflagellate mutualism. Env Microbiol 11:268-276. 
Dunn SR, Bythell JC, Le Tissier MDA, Burnett WJ, Thomason JC (2002) Programmed cell death and cell necrosis activity during hyperthermic stress-induced bleaching of the symbiotic sea anemone Aiptasia sp, J Exp Mar Biol Ecol 272: 29-53

Edmunds PJ (1994) Evidence that reef-wide patterns of coral bleaching may be the result of the distribution of bleaching susceptible clones. Mar Biol 121:137-142

Edmunds PJ, Gates R (2008) Acclimatization in tropical reefs corals. Mar Ecol Prog Ser $361: 307-310$

Fabricius KE (2005) Effects of terrestrial runoff on the ecology of corals and coral reefs: review and synthesis. Mar Poll Bull 50:125-146

Fabricius KE, Mieog JC, Colin PL, Idip D, van Oppen MJH (2004) Identity and diversity of coral endosymbionts (zooxanthellae) from three Palauan reefs with contrasting bleaching, temperature and shading histories. Mol Ecol 13:2445-2458

Fagoonee I, Wilson HB, Hassel MP, Turner JF (1999) The dynamics of zooxanthellae populations: a long-term study in the field. Science 283:843-845

Falkowski PG, Dubinsky Z (1981) Light-shade adaptation of Stylophora pistillata, a hermatypic coral from the Gulf of Eilat. Nature 289:172-174

Falkowski PG, LaRoche J (1991) Acclimation to spectral irradiance in algae. J Phycol $27: 8-14$

Falkowski PG, Owens TG (1980) Light-shade adaptation: two strategies in marine phytoplankton. Plant Physiol 66:592-595 
Falkowski PG, Raven JA (1997) Aquatic photosynthesis. Blackwell Scientific Publishers, Oxford, UK.

Falkowski PG, Dubinsky Z, Muscatine L, McCloskey L (1993) Population control in symbiotic corals. Bioscience 43:606-611

Farmer MA, Fitt WK, Trench RK (2001) Morphology of the symbiosis between Corculum cardissa (Mollusca:Bivalvia) and Symbiodinium corculorum (Dinophyceae). Biol Bull 200:336-343

Fautin DG, Buddemeier RW (2004) Adaptive bleaching: a general phenomenon. Hydrobiol $530-31: 459-467$

Fay SA, Weber MX, Lipps JH (2009) The distribution of Symbiodinium diversity within individual host foraminifera. Coral Reefs DOI: 10.1007/s00338-009-0511

Fitt W, Cook C (2001) The effects of feeding or addition of dissolved inorganic nutrients in maintaining the symbiosis between dinoflagellates and a tropical marine cnidarian. Mar Biol 139:507-517

Fitt WK, McFarland FK, Warner ME, Chilcoat GC (2000) Seasonal patterns of tissue biomass and densities of symbiotic dinoflagellates in reef corals and relation to coral bleaching. Limnol Oceanogr 45:677-685

Fitt WK, Warner ME (1995) Bleaching patterns of four species of Caribbean Corals. Biol Bull 189:298-307

Fitt WK, Gates R, Hoegh-Guldberg O, Bythell J, Jatkar A, Grottoli AG, Gomez M, Fisher P, LaJeunesse T, Pantos O, Iglesias-Prieto R, Franklin DJ, Rodrigues LJ, Torregiani 
JM, van Woesik R, Lesser M (2009) Response of two species of Indo-Pacific corals, Porites cylindrica and Stylophora pistillata, to short-term thermal stress: The host does matter in determining the tolerance of corals to bleaching. J Exp Mar Biol Ecol $373: 102-110$

Frade PR, Englebert N, Faria J, Visser P, Bak R (2008a) Distribution and photobiology of Symbiodinium types in different light environments for three colour morphs of the coral Madracis pharensisis there more to it than total irradiance? Coral Reefs 27:913-925

Frade PR, De Jongh F, Vermeulen F, Van Bleijswijk J, Bak RPM (2008b) Variation in symbiont distribution between closely related coral species over large depth ranges. Mol Ecol 17:691-703

Francis MP, Grace RV, Paulin CD (1987) Coastal fishes of the Kermadec Islands. N Z J Mar Freshw Res 21:1-13

Freudenthal HD (1962) Symbiodinium gen. nov. and Symbiodinium microadriactum sp. nov., a Zooxanthella: Taxonomy, life cycle and morphology. Journal of Protozoology 9:45-52

Gardner JPA, Curwen MJ, Long J, Williamson RJ, Wood AR (2006) Benthic community structure and water column characteristics at two sites in the Kermadec Islands Marine Reserve, New Zealand. N Z J Mar Freshw Res 40:179-194

Garren M, Walsh SM, Caccone A, Knowlton N (2006) Patterns of association between Symbiodinium and members of the Montastraea annularis species complex on 
spatial scales ranging from within colonies to between geographic regions. Coral Reefs 25:503-512

Gates RD, Baghdasarian G, Muscatine L (1992) Temperature stress causes host cell detachment in symbiotic cnidarians: implications for coral bleaching. Biol Bull 182: 324-332.

Gilmour JP (1999) Experimental investigation into the effects of suspended sediment on fertilisation, larval survival and settlement in a scleractinian coral. Mar Biol $135: 451-462$

Glynn PW (1996) Coral reef bleaching: facts, hypotheses and implications. Glob Change Biol 2:495-509

Glynn PW, Stewart RH (1973) Distribution of coral reefs in the Pearl Islands (Gulf of Panama) in relation to thermal conditions. Limnol Oceanogr 18:367-379

Glynn PW, Mat, LJ, Baker AC, Calderon MO (2001) Coral bleaching and mortality in Panama and Ecuador during the 19971998 El Nino Southern Oscillation Event: spatial/temporal patterns and comparisons with the 19821983 event. Bull Mar Sci 69:79-109

Glynn PW, Wellington GM, Riegl B, Olson DB, Borneman E, Wieters EA (2007) Diversity and biogeography of the Scleractinian Coral fauna of Easter Island (Rapa Nui). Pac Sci 61:67-90

Gorbunov MY, Kolber ZS, Lesser MP, Falkowski PG (2001) Photosynthesis and photoprotection in symbiotic corals. Limnol Oceanogr 46:75-85 
Goulet TL (2006) Most corals may not change their symbionts. Mar Ecol Prog Ser 321:721

Goulet TL (2007) Most scleractinian corals and octocorals host a single symbiotic zooxanthella clade. Mar Ecol Prog Ser 335:243-248

Goulet TL, Coffroth MA (2003) Genetic composition of zooxanthellae between and within colonies of the octocoral Plexaura kuna, based on small subunit rDNA and multilocus DNA fingerprinting. Mar Biol 142: 233-239.

Goulet TL, LaJeunesse TC, Fabricius KE (2008). Symbiont specificity and bleaching susceptibility among soft corals in the 1998 Great Barrier Reef mass coral bleaching event. Mar Biol 154:795-804

Govindjee (1995) Sixty-three years since Kautsky: chlorophyll a fluorescence. Aust J Plant Physiol 22:131-160

Greer DH (1990) The combined effects of chilling and light stress on photoinhibition of photosynthesis and its subsequent recovery. Plant Physiol Biochem 28:447-455

Grigg RW (1982) Coral reef development at high latitudes in Hawaii. Proc 4th Int Coral Reef Symp, Manila, 1:687-693

Grotolli AG, Rodriguez LJ, Palardy JE (2006) Heterotrophic plasticity and resilience in bleached corals. Nature 440:1186-1189

Guinotte JM, Buddemeier RW, Kleypas JA (2003) Future coral reef habitat marginality: temporal and spatial effects of climate change in the Pacific basin. Coral Reefs $22: 551-558$ 
Hamann IM, Boehlert GW, Wilson CD (2004) Effects of steep topography on the flow and stratification near Palmyra Atoll. Ocean Dyn 54:460-473

Harriott VJ, Banks SA (2002) Latitudinal variation in coral communities in eastern Australia: a qualitative biophysical model of factors regulating coral reefs. Coral Reefs 21:83-94

Harriott VJ, Banks SA, Mau RL, Richardson D, Roberts LG (1999) Ecological and conservation significance of the subtidal rocky reef communities of northern New South Wales, Australia. Mar Freshw Res 50:299-306

Harriott VJ, Harrison PL, Banks SA (1995) The coral communities of Lord Howe Island. Mar Freshw Res 46:457-465

Harriott VJ, Smith SDA, Harrison PL (1994) Patterns of coral community structure of subtropical reefs in the Solitary Islands Marine Reserve, Eastern Australia. Mar Ecol Prog Ser 109:67-76

Harrison PL, Wallace CC (1990) Reproduction, Dispersal and Recruitment of Scleractinian Corals. In: Dubinsky Z (ed) Ecosystems of the world, Vol 25, Coral Reef Ecosystems. Elsevier, Amsterdam, pp 133-207

Harrison PL, Babcock RC, Bull GD, Oliver JK, Wallace CC, Willis BL (1984) Mass spawning in tropical reef corals. Science 223:1186-1189

Hill R, Ralph PJ (2005) Diel and seasonal changes in fluorescence rise kinetics of three scleractinian corals. Funct Plant Biol 32:549-559 
Hill R, Ralph PJ (2006) Photosystern II heterogeneity of in hospite zooxanthellae in scleractinian corals exposed to bleaching conditions. Photochem Photobiol 82:15771585

Hill R, Ralph PJ (2008) Impact of bleaching stress on the function of the oxygen evolving complex of zooxanthellae from scleractinian corals. J Phycol 46:45-56

Hill R, Larkum A, Frankart C, Kuhl M, Ralph P (2004a) Loss of functional Photosystem II reaction centres in zooxanthellae of corals exposed to bleaching conditions using fluorescence rise kinetics. Photosynth Res 82:59-72

Hill R, Schreiber U, Gademann R, Larkum AWD, Kuhl M, Ralph PJ (2004b) Spatial heterogeneity of photosynthesis and the effect of temperature-induced bleaching conditions in three species of corals. Mar Biol 144:633-640

Hoegh-Guldberg O (1995) Temperature, Food Availability, and the Development of Marine Invertebrate Larvae. Am Zool 35:415-425

Hoegh-Guldberg O (1999) Climate change, coral bleaching and the future of the world's coral reefs. Mar Freshw Res 50:839-866

Hoegh-Guldberg O (2004) Coral reefs in a century of rapid environmental change. Symbiosis $37: 1-31$

Hoegh-Guldberg O (2005) Low coral cover in a high- $\mathrm{CO}_{2}$ world. J Geophys Res 110:C09S06

Hoegh-Guldberg O, Fine M (2004) Low temperatures cause coral bleaching. Coral Reefs $23: 444-444$ 
Hoegh-Guldberg O, Jones RJ (1999) Photoinhibition and Photoprotection in symbiotic dinoflagellates from reef-building corals. Mar Ecol Prog Ser 183:73-86

Hoegh-Guldberg O, Salvat B (1995) Periodic mass-bleaching and elevated sea temperatures:bleaching of outer reef slope communities in Moorea, French Polynesia. Mar Ecol Prog Ser 121:181-190

Hoegh-Guldberg O, Fine M, Skirving W, Johnstone R, Dove S, Strong A (2005) Coral bleaching following wintry weather. Limnol Oceanogr 50:265-271

Hoegh-Guldberg O, Mumby PJ, Hooten AJ, Steneck RS, Greenfield P, Gomez E, Harvell CD, Sale PF, Edwards AJ, Caldeira K, Knowlton N, Eakin CM, Iglesias-Prieto R, Muthiga N, Bradbury RH, Dubi A, Hatziolos ME (2007) Coral reefs under rapid climate change and ocean acidification. Science 318:1737-1742

Hubbard JH, Pocock YP (1972) Sediment rejection by recent scleractinian corals: a key to palaeo-environmental reconstruction. Geol Rundsch 61:598-626

Hughes TP (1989) Community structure and diversity of coral reefs: the role of history. Ecology 70:275-279

Hughes TP, Baird AH, Bellwood DR, Card M, Connolly SR, Folke C, Grosberg R, HoeghGuldberg O, Jackson JBC, Kleypas J, Lough JM, Marshall P, Nyström M, Palumbi SR, Pandolfi JM, Rosen B, Roughgarden J (2003) Climate Change, Human Impacts, and the Resilience of Coral Reefs. Science 301:929-933

Hughes TP, Bellwood DR, Connolly SR (2002) Biodiversity hotspots, centers of endemicity, and the conservation of coral reefs. Ecol Lett 5:775-784 
Hunter CL, Morden CW, Smith CM (1997) The utility of ITS sequences in assessing relationships among zooxanthellae and corals. Proc 8th Int. Coral Reef Symp 2:1599-1602.

Hustan MA (1985) Patterns of species diversity on coral reefs. Annu Rev Ecol System $16: 149-177$

Iglesias-Prieto R (1995) The effects of elevated temperature on the photosynthetic responses of symbiotic dinoflagellates. In: Mathis P (ed) Photosynthesis: from Light to Biosphere, Vol IV. Kluwer Academic Publishers, Dordrecht, The Netherlands, pp 793-796

Iglesias-Prieto R, Trench RK (1994) Adaptation and acclimation to irradiance in symbiotic dinoflagellates I. Response of the photosynthetic unit to changes in photon flux density. Mar Ecol Prog Ser 113:163-175

Iglesias-Prieto R, Trench RK (1997a) Acclimation and adaptation to irradiance in symbiotic dinoflagellates. II. Response of chlorophyll-protein complexes to different photonflux densities. Mar Biol 130:23-33

Iglesias-Prieto R, Trench RK (1997b) Photoadaptation, photoacclimation and niche diversification in invertebrate-dinoflagellate symbioses. Proc. 8th Int Coral Reef Symp, Panama, 2:1319-1324

Iglesias-Prieto R, Beltran VH, LaJeunesse TC, Reyes-Bonilla H, Thome PE (2004) Different algal symbionts explain the vertical distribution of dominant reef corals in the eastern Pacific. Proc R Soc Lond B 271:1757-1763 
Iglesias-Prieto R, Matta JL, Robins WA, Trench RK (1992) Photosynthetic response to elevated temperature in the symbiotic dinoflagellate Symbiodinium microadriaticum in culture. PNAS 89:10302-10305

IPCC (2007) Climate Change 2007: The Physical Science Basis. Contribution of Working Group I to the Fourth Assessment Report of the Intergovernmental Panel on Climate Change, S. Solomon et al. (Eds). Cambridge Univ. Press, Cambridge, UK, and New York.

Jeffrey SW, Humphrey GF (1975) New spectrophotometric equations for determining chlorophylls a, b, c1 and c2 in higher plants, algae and natural phytoplankton. Biochem Physiol Pfl 167:191-194

Johannes RE, Wiebe WJ, Crossland CJ, Rimmer DW, Smith SV (1983) Latitudinal limits of reef growth. Mar Ecol Prog Ser 11:105-111

Jones AM, Berkelmans R, van Oppen MJH, Mieog JC, Sinclair W (2008) A community change in the algal endosymbionts of a scleractinian coral following a natural bleaching event: field evidence of acclimatization. Proc R Soc Lond B 275:13591365

Jones RJ (2008) Coral bleaching, bleaching-induced mortality, and the adaptive significance of the bleaching response. Mar Biol 154:65-80

Jones RJ, Hoegh-Guldberg O (2001) Diurnal changes in the photochemical efficiency of the symbiotic dinoflagellates (Dinophyceae) of corals: photoprotection, photoinactivation and the relationship to coral bleaching. Plant Cell Env 24:89-99 
Jones RJ, Hoegh-Guldberg O, Larkum AWD, Schreiber U (1998) Temperature-induced bleaching of corals begins with impairment of the $\mathrm{CO}_{2}$ fixation mechanism in zooxanthellae. Plant Cell Env 21:1219-1230

Jones RJ, Ward S, Amri AY, Hoegh-Guldberg O (2000) Changes in quantum efficiency of Photosystem II of symbiotic dinoflagellates of corals after heat stress, and of bleached corals sampled after the 1998 Great Barrier Reef mass bleaching event. Mar Freshw Res 51:63-71

Kinzie RA, Jokiel PL, York R (1984) Effects of light of altered spectral composition on coral zooxanthellae associations and on zooxanthellae in vitro. Mar Biol 78:239-248

Kleypas JA, McManus JW, Menez LAB (1999) Environmental limits to coral reef development:Where do we draw the line? Am Zool 39:146-159

Koenings JP, Edmundson JA (1991) Secchi disk and photometer estimates of light regimes in Alaskan lakes: Effects of yellow color and turbidity. Limnol Oceanogr 36:91-105

Kojis BL, Quinn NJ (1984) Seasonal and depth variation in fecundity of Acropora palifera at two reefs in Papua New Guinea. Coral Reefs 3:165-172

Krause GH (1992) Effects of temperature on energy-dependant fluorescence quenching in chloroplasts. Photosynthetica 27:249-252

LaJeunesse TC (2001) Investigating the biodiversity, ecology and phylogeny of endosymbiotic dinoflagellates in the genus Symbiodinium using the ITS region: In search of a 'species' level marker. J Phycol 37:866-880 
LaJeunesse TC (2002) Diversity and community structure of symbiotic dinoflagellates from Caribbean coral reefs. Mar Biol 141:387-400

LaJeunesse TC (2005) "Species" Radiations of Symbiotic Dinoflagellates in the Atlantic and Indo-Pacific Since the Miocene-Pliocene Transition. Mol Biol Evol 22:348-359

LaJeunesse TC, Trench RK (2000) Biogeography of Two Species of Symbiodinium (Freudenthal) Inhabiting the Intertidal Sea Anemone Anthopleura elegantissima (Brandt). Biol Bull 199:126-134

LaJeunesse TC, Pinzon JH (2007) Screening intragenomic rDNA for dominant variants can provide a consistent retrieval of evolutionarily persistent ITS (rDNA) sequences. Mol Phylogenet Evol 45:417-422

LaJeunesse TC, Bhagooli R, Hidaka M, DeVantier L, Done TJ, Schmidt GW, Fitt WK, Hoegh-Guldberg O (2004a) Closely related Symbiodinium spp. differ in relative dominance in coral reef host communities across environmental, latitudinal and biogeographic gradients. Mar Ecol Prog Ser 284:147-161

LaJeunesse TC, Loh W, van Woesik R, Hoegh-Guldberg O, Schmidt GW, Fitt WK (2003) Low symbiont diversity in southern Great Barrier Reef corals, relative to those of the Caribbean. Limnol Oceanogr 48:2046-5054

LaJeunesse TC, Reyes-Bonilla H, Warner ME, Wills M, Schmidt GW, Fitt WK (2008) Specificity and stability in high latitude eastern Pacific coral-algal symbioses. Limnol Oceanogr 53:719-727 
LaJeunesse TC, Thornhill DJ, Cox EF, Stanton FG, Fitt WK, Schmidt GW (2004b) High diversity and host specificity observed among symbiotic dinoflagellates in reef coral communities from Hawaii. Coral Reefs 23:296-603

Lamberts AE (1983) An annotated checklist of the corals of American Samoa. Atoll Res Bull 264:1-20

Lasker HR, Coffroth MA (1999) Responses of clonal reef taxa to environmental change. Am Zool 39:92-103

Legendre P, Anderson MJ (1999) Distance-based redundancy analysis: testing multispecies responses in multifactorial ecological experiments. Ecol Mono 69:1-24

Lesser MP (1996) Elevated temperatures and ultraviolet radiation cause oxidative stress and inhibit photosynthesis in symbiotic dinoflagellates. Limnol Oceanogr 41:271283

Lesser MP (2004) Experimental biology of coral reef ecosystems. J Exp Mar Biol Ecol $300: 217-252$

Lesser MP (2006) Oxidative stress in marine environments: biochemistry and physiological ecology. Annu Rev Physiol 68:253-278

Lesser MP, Farrell JH (2004) Exposure to solar radiation increases damage to both host tissues and algal symbionts of corals during thermal stress. Coral Reefs 23:367-377

Lesser MP, Gorbunov MY (2001) Diurnal and bathymetric changes in chlorophyll fluorescence yields of reef corals measured in situ with a fast repetition rate fluorometer. Mar Ecol Prog Ser 212:69-77. 
Lewin RA, Chang L (1989) Prochloron: A Microbial Enigma. Chapman and Hall, New York

Lin KL, Wang JT, Fang LS (2000) Participation of glycoproteins on zooxanthellal cell walls in the establishment of a symbiotic relationship with the sea anemone, Aiptasia pulchella. Zool Stud 39: 172-178

Little AF, van Oppen MJH, Willis BL (2004) Flexibility in algal endosymbiosis shapes growth in reef corals. Science 304: 1492-1494

Liddell WD, Ohlhurst SL (1981) Geomorphology and community composition of two adjacent reef areas, Discovery Bay, Jamaica. J Mar Res 39:791-804

Lien Y-T, Nakano Y, Plathong S, Fukami H, Wang J-T, Chen C (2007) Occurrence of the putatively heat-tolerant Symbiodinium phylotype D in high-latitudinal outlying coral communities. Coral Reefs 26:35-44

Loh W, Carter D, Hoegh-Guldberg O (2001) Genetic variability of the symbiotic dinoflagellates from the wide ranging coral species Seriatopora hystrix and Acropora longicyathus in the Indo-West Pacific. Mar Ecol Prog Ser 222:97-107

Loh WKW, Cowlishaw M, Wilson NG (2006) Diversity of Symbiodinium dinoflagellate symbionts from the Indo-Pacific sea slug Pteraeolidia ianthina (Gastropoda: Mollusca). Mar Ecol Prog Ser 320:177-184

Lough JM, Barnes DJ (2000) Environmental controls on growth of the massive coral Porites. J Exp Mar Biol Ecol 245: 225-243 
Macdonald AHH, Sampayo EM, Ridgway T, Schleyer MH (2008) Latitudinal symbiont zonation in Stylophora pistillata from southeast Africa. Mar Biol 154:209-217

Macintyre IG (2003) A classic marginal coral environment: tropical coral patches off North Carolina, USA. Coral Reefs 22:474

Maragos JE, Friedlander S, Godwin S, Musburge C, Tsuda R, Flint E, Pantos O, Ayotte P, Sala E, Sandin SA, McTee S, Siciliano D, Obura D (2008a) U.S. coral reefs in the Line and Phoenix Islands, Central Pacific Ocean: Status, Threats and Significance. In: Riegl B, Dodge R (eds) Coral Reefs of the USA. Springer, pp 643-654

Maragos JE, Miller J, Gove J, Demartini E, Friedlander A, Godwin S (2008b) U.S. coral reefs in the Line and Phoenix Islands, Central Pacific Ocean:History, Geology, Oceanography, and Biology. In: Riegl B, Dodge RE (eds) Coral Reefs of the USA. Springer, pp 595-642

Markell DA, Trench RK (1993) Macromolecules exuded by symbiotic dinoflagellates in culture: amino acid and sugar composition. J Phycol 29:64-68

Markell DA, Trench RK, Iglesias-Prieto R (1992) Macromolecules associated with the cellwalls of symbiotic dinoflagellates. Symbiosis 12:19-31

Marshall BA (1979) The Trochidae and Turbinidae of the Kermadec Ridge (Mollusca Gastropoda). N Z J Zool 6:521-522

Marshall PA, Baird AH (2000) Bleaching of corals on the Great Barrier Reef: differential susceptibilities among taxa. Coral Reefs 19:155-163 
McArdle BH, Anderson MJ (2001) Fitting multivariate models to community data: a comment on distance-based redundancy analysis. Ecology 82:290-297

McCabe-Reynolds J, Bruns BU, Fitt WK, Schmidt GW (2008) Enhanced photoprotection pathways in symbiotic dinoflagellates of shallow-water corals and other cnidarians. PNAS 105:13674-13678

McClanahan TR, Obura D (1997) Sedimentation effects on shallow coral communities in Kenya. J Exp Mar Biol Ecol 209:103-122

Menge BA, Olson AM (1990) Role of scale and environmental factors in regulation of community structure. Trends Ecol Evol 5:52-57

Mieog JC, van Oppen MJH, Cantin NE, Stam WT, Olsen JL (2007) Real-time PCR reveals a high incidence of Symbiodinium clade D at low levels in four scleractinian corals across the Great Barrier Reef: implications for symbiont shuffling. Coral Reefs $26: 449-457$

Mostafavi PG, Fatemi SMR, Shahhosseiny MH, Hoegh-Guldberg O, Loh WKW (2007) Predominance of clade D Symbiodinium in shallow-water reef-building corals off Kish and Larak Islands (Persian Gulf, Iran). Mar Biol 153:25-34

Moyer RP, Riegl B, Banks K, Dodge RE (2003) Spatial patterns and ecology of benthic communities on a high-latitude South Florida (Broward County, USA) reef system. Coral Reefs 22:447-464

Muscatine 1 (1990) The role of symbiotic algae in carbon and energy flux in reef corals. In: Dubinsky Z (ed) Ecosystems of the World, 25, Coral Reefs. Elsevier, Amsterdam, pp 75-87 
Muscatine L, Kaplan IR (1994) Resource partitioning by reef corals as determined from stable isotope composition II $\delta^{15} \mathrm{~N}$ of zooxanthellae and animal tissue versus depth. Pac Sci 48:304-312

Muscatine L, Porter JW (1977) Reef Corals: Mutualistic Symbioses Adapted to NutrientPoor Environments. Bioscience 27:454-460

Muyzer G, De Waal E, Uitterlinden AG (1993) Profiling of complex microbial populations by denaturing gradient gel electrophoresis analysis of polymerase chain reactionamplified genes coding for 16S rRNA. Appl Environ Microbiol 59:695-700

Myers RM, Fischer SG, Lerman LS, Maniatis T (1985) Nearly all single base substitutions in DNA fragments joined to a GC-clamp can be detected by gradient gel electrophoresis. Nucleic Acids Res 13:3131-3145

Nobel PS (1991) Physiochemical and environmental plant physiology. Academic Press, San Diego, CA.

Nozawa Y, Tokeshi M, Nojima S (2006) Reproduction and recruitment of scleractinian corals in a high-latitude coral community, Amakusa, southwestern Japan. Mar Biol 149:1047-1058

Nugues MM, Roberts CM (2003) Coral mortality and interaction with algae in relation to sedimentation. Coral Reefs 22:507-516

Oliver TA, Palumbi SR (2009) Distributions of stress-resistant coral symbionts match environmental patterns at local but not regional scales. Mar Ecol Prog Ser 378:93103 
Oxley WG, Ayling AM, Cheal AJ, Osborne K (2004) Marine Surveys undertaken in the Elizabeth and Middleton Reefs Marine National Nature Reserve, December 2003, Department of the Environment and Heritage, NSW, Australia.

Pauley G (1989) Marine invertebrates of the Pitcairn Islands, species composition and biogeography of corals, molluscs, and echinoderms. Atoll Res Bull 326

Pawlowski J, Holzmann M, Fahrni JF, Pochon X, Lee JJ (2001) Molecular Identification of Algal Endosymbionts in Large Miliolid Foraminifera: 2 Dinoflagellates. J Eukaryot Microbiol 48:368-373

Pearse VB, Muscatine L (1971) Role of symbiotic algae (zooxanthellae) in coral calcification. Biol Bull 141:350-363

Perry CT (2003) Reef development at Inhaca Island, Mozambique: coral communities and impacts of the 1999/2000 southern African floods. Ambio. 32: 133-139

Perry CT, Larcombe P (2003) Marginal and non-reef-building coral environments. Coral Reefs 22:427-432

Peters EC, Pilson MEQ (1985) A comparative study of the effects of sedimentation on symbiotic and asymbiotic colonies of the coral Astrangia danae Milne Edwards and Haime 1849. J Exp Mar Biol Ecol 92:215-230

Pettay DL, LaJeunesse T (2007) Microsatellites from clade B Symbiodinium spp. specialized for Caribbean corals in the genus Madracis. Mol Ecol Notes 7:12711274 
Pochon X, LaJeunesse T, Pawlowski J (2004) Biogeographic partitioning and host specialization among foraminiferan dinoflagellate symbionts (Symbiodinium; Dinophyta). Mar Biol 146:17-27

Porter JW, Fitt WK, Spero HJ, Rogers CS, White MW (1989) Bleaching in reef corals: Physiological and stable isotopic responses. PNAS 86:9342-9346

Ralph P, Schreiber U, Gademann R, Kuhl M, Larkum AWD (2005) Coral photobiology studied with a new imaging pulse amplitude modulated fluorometer. J Phycol $41: 335-342$

Reimer PJ, Baillie MGL, Bard E, Beck JW, Blackwell G, Buck CE, Burr GS, Edwards RL, Friedrich M, Guilderson TP, Hogg AG, Hughen KA, Kromer B, McCormac G, Manning S, Reimer RW, Southon JR, Stuiver M, van der Plicht J, Weyhenmeyer CE (2006) Comment on "radiocarbon calibration curve spanning 0 to 50,000 years B. P. based on paired ${ }^{230} \mathrm{Th} /{ }^{234} \mathrm{U} /{ }^{238} \mathrm{U}$ and ${ }^{14} \mathrm{C}$ dates on pristine corals. Quaternary Science Rev 25:855-862

Richmond RH (1987) Energetics, competency, and long-distance dispersal of planula larvae of the coral Pocillopora damicornis. Mar Biol 93:527-533

Richmond RH, Hunter CL (1990) Reproduction and recruitment of corals: Comparisons among the Caribbean, the tropical Pacific, and the Red Sea. Mar Ecol Prog Ser 60:185-203.

Riegl B (1996) Hermatypic Coral Fauna of Subtropical Southeast Africa: A Checklist. Pac Sci 50:404-414 
Riegl B (2003) Climate change and coral reefs: different effects in two high-latitude areas (Arabian Gulf, South Africa). Coral Reefs 22:433-446

Riegl B, Branch GM (1995) Effects of sedimentation on the energy budgets of four scleractinian and five alcyonacean corals. J Exp Mar Biol Ecol 186:259-275

Riegl B, Piller WE (2003) Possible refugia for reefs in times of environmental stress. Int J Earth Sci 92:520-531

Roberts HH, Rouse LJJ, Walker ND, Hudson JH (1982) Coldwater stress in Florida Bay and Northern Bahamas: a product of winter cold-air outbreaks. J Sed Res 52 (1): $145-155$

Robison JD, Warner ME (2006) Differential impacts of photoacclimation and thermal stress on the photobiology of four different phylotypes of Symbiodinium (Pyrrhophyta). J Phycol 42:568-579

Rodriguez-Lanetty M, Krupp DA, Weis VM (2004) Distinct ITS types of Symbiodinium in Clade C correlate with cnidarian/dinoflagellate specificity during onset of symbiosis. Mar Ecol Prog Ser 275:97-102

Rodriguez-Lanetty M, Loh W, Carter D, Hoegh-Guldberg O (2001) Latitudinal variability in symbiont specificity within the widespread scleractinian coral Plesiastrea versipora. Mar Biol 138:1175-1181

Rogers CS (1983) Sublethal and lethal effects of sediments applied to common Caribbean reef corals in the field. Mar Poll Bull 14:378-382 
Rogers CS (1990) Responses of coral reefs and reef organisms to sedimentation. Mar Ecol Prog Ser 62:185-202

Rogers SI, Clarke KR, Reynolds JD (1999) The taxonomic distinctness of coastal bottomdwelling fish communities of the North-east Atlantic. J Anim Ecol 68:769-782

Rohwer F, Seguritan V, Azam F, Knowlton N (2002) Diversity and distribution of coralassociated bacteria. Mar Ecol Prog Ser 243: 1-10

Rowan R (1998) Review - Diversity and Ecology of Zooxanthellae on Coral Reefs. J Phycol 34:407-417

Rowan R (2004) Thermal adaptation in reef coral symbionts. Nature 430:742

Rowan R, Knowlton N (1995) Intraspecific diversity and ecological zonation in coral-algal symbiosis. PNAS 92:2850-2853

Rowan R, Powers DA (1991) A Molecular Genetic Classification of Zooxanthellae and the Evolution of Animal-Algal symbiosis. Science 251:1348-1351

Rowan R, Knowlton N, Baker AC, Jara J (1997) Landscape ecology of algal symbionts creates variation in episodes of coral bleaching. Nature 388:265-269

Roy KJ, Smith SV (1971) Sedimentation and coral reef development in turbid water: Fanning Lagoon. Pac Sci 25:234-248

Sachs JL, Wilcox TP (2006) A shift to parasitism in the jellyfish symbiont Symbiodinium microadriaticum. Proc R Soc Lond B 273:425-429

Salih A, Hoegh-Guldberg O, Cox G (1998) Photoprotection of symbiotic dinoflagellates by fluorescent pigments in reef corals. In: Greenwood JG, Hall NJ (eds) Australian 
Coral Reef Society 75th Anniversary Conference, The University of Queensland, pp $217-230$

Salih A, Larkum A, Cox G, Kuhl M, Hoegh-Guldberg O (2000) Fluorescent pigments in corals are photoprotective. Nature 408:850-853

Sampayo EM, Dove S, LaJeunesse T (2009) Cohesive molecular genetic data delineate species diversity in the dinoflagellate genus Symbiodinium. Mol Ecol 18:500-519

Sampayo ES, Franceschinis L, Hoegh-Guldberg O, Dove S (2007) Niche partitioning of closely related symbiotic dinoflagellates. Mol Ecol 16:3721-3733

Sampayo EM, Ridgway T, Bongaerts P, Hoegh-Guldberg O (2008) Bleaching susceptibility and mortality of corals are determined by fine-scale differences in symbiont type. PNAS 105:10444-10449

Sandin SA, Smith JE, DeMartini EE, Dinsdale EA, Donner SD, Friedlander A, Konotchick T, Malay M, Maragos JE, Obura D, Pantos O, Paulay G, Richie M, Rowher F, Schroeder RE, Walsh S (2008) Baselines and degradation of coral reefs in the northern Line Islands. PLoS ONE 3 (2):e1548

Santos SR, Gutiérrez-Rodríguez C, Lasker HR, Coffroth MA (2003) Symbiodinium sp. associations in the gorgonian Pseudopterogorgia elisabethae in the Bahamas: high levels of genetic variability and population structure in symbiotic dinoflagellates. Mar Biol 143:111-120

Santos SR, Taylor DJ, Coffroth MA (2001) Genetic comparisons of freshly isolated versus cultured symbiotic dinoflagellates: implications for extrapolating to the intact symbiosis. J Phycol 37:900-912 
Santos SR, Taylor DJ, Kinzie RA, Hidaka M, Sakai K, Coffroth MA (2002) Molecular phylogeny of symbiotic dinoflagellates inferred from partial chloroplast large subunit (23S)-rDNA sequences. Mol Phylogenet Evol 23:97-111

Savage AM, Goodson MS, Visram S, Trapido-Rosenthal H, Wiedenmann J, Douglas AE (2002) Molecular diversity of symbiotic algae at the latitudinal margins of their distribution: dinoflagellates of the genus Symbiodinium in corals and sea anemones. Mar Ecol Prog Ser 244:17-26

Saxby T, Dennison WC, Hoegh-Guldberg O (2003) Photosynthetic responses of the coral Montipora digitata to cold temperature stress. Mar Ecol Prog Ser 248:85-97

Schiel DR, Kingsford MJ, Choat JH (1986) Depth distribution and abundance of benthic organisms and fishes at the subtropical Kermadec Islands. N Z J Mar Freshw Res 20:521-535

Schoenberg DA, Trench RK (1980a) Genetic variation in Symbiodinium (=Gymnodinium) microadriaticum Freudenthal, and specificity in its symbiosis with marine invertebrates. I. Isoenzyme and soluble protein patterns of axenic cultures of $S$. microadriaticum. Proc R Soc Lond B 207:405-427

Schoenberg DA, Trench RK (1980b) Genetic variation in Symbiodinium (=Gymnodinium) microadriaticum Freudenthal, and specificity in its symbiosis with marine invertebrates. II. Morphological variation in S. microadriaticum. Proc R Soc Lond B 207:429-444

Schoenberg DA, Trench RK (1980c) Genetic variation in Symbiodinium (=Gymnodinium) microadriaticum Freudenthal, and specificity in its symbiosis with marine 
invertebrates. III. Specificity and infectivity of S. microadriaticum. Proc R Soc Lond B 207:445-460

Schreiber U (2004) Pulse-amplitude-modulation (PAM) fluorometry and saturation pulse method: An overview. In: Papageorgiou GC, Govindjee (eds) Chlorophyll fluorescence:A signature of photosynthesis. Kluwer Academic, Dordrecht, The Netherlands, pp 279-319

Schuhmacher H (1977) Ability in fungiid corals to overcome sedimentation. Proc 3rd Int Coral Reef Symp, University of Miami, Florida, 1:503-509

Schwarz JA, Weis V, Potts DC (2002) Feeding behaviour and acquisition of zooxanthellae by the planulae larvae of the sea anemone Anthopleura elegantissima. Mar Biol $140: 471-478$

Sheppard CRC (1980) Coral fauna of Diego Garcia lagoon, following harbor construction. Mar Poll Bull 11:227-230

Sheppard CRC, Sheppard ALS (1991) Corals and Coral Communities of Arabia. Fauna of Saudi Arabia 12:1-170

Shick JM, Dunlap WC (2002) Mycosporine-like amino acids and related gadusols: biosynthesis, accumulation, and UV-protective functions in aquatic organisms. Annu Rev Physiol 64:223-262

Shinn EA (1966) Coral Growth-Rate, an Environmental Indicator. J Paleontol 40:233-240

Smilie RG, Hetherington SE, He J, Nott R (1988) Photoinhibition at chilling temperatures. Aust J Plant Physiol 15:207-222 
Smith DJ, Suggett DJ, Baker NR (2005) Is photoinhibition of zooxanthellae photosynthesis the primary cause of thermal bleaching in corals? Glob Change Biol 11:1-11

Smith SDA, Buddemeier RW (1992) Global change and coral reef ecosystems. Annu Rev Ecol Evol System 23:89-118

Smithers S, Larcombe P (2003) Late Holocene initiation and growth of a nearshore turbidzone coral reef: Paluma Shoals, central Great Barrier Reef, Australia. Coral Reefs 22:499-505

Stafford-Smith MG (1993) Sediment-rejection efficiency of 22 species of Australian scleractinian corals. Mar Biol 115:229-243

Stafford-Smith MG, Ormond RFG (1992) Sediment-rejection mechanisms of 42 species of Australian scleractinian corals. Aust J Mar Freshw Res 43:683-705

Stat M, Carter D, Hoegh-Guldberg M (2006) The evolutionary history of Symbiodinium and scleractinian hosts - Symbiosis, diversity, and the effect of climate change. Perspect Plant Ecol Evol Syst 8:23-43

Stat M, Loh W, Hoegh-Guldberg O, Carter DA (2009) Symbiont acquisition strategy drives host-symbiont associations in the southern Great Barrier Reef. Coral Reefs 27(4):763-772

Steen RG, Muscatine L (1987) Low temperature evokes rapid exocytosis of symbiotic algae by a sea anemone. Biol Bull 172:246-263

Stimson J (1997) The annual cycle of density of zooxanthellae in the tissues of field and laboratory-held Pocillopora damicornis (Linnaeus). J Exp Mar Biol Ecol 214:35-48 
Stimson J, Kinzie RA (1991) The temporal pattern and rate of release of zooxanthellae from the reef coral Pocillopora damicornis (Linnaeus) under nitrogen-enrichment and control conditions. J Exp Mar Biol Ecol 153:63-74

Strasser RJ, Srivastava A, Govindjee (1995) Polyphasic chlorophyll a fluorescence transient in plants and cyanobacteria. Photochem Photobiol 61:32-42

Sugihara K, Yamano H (2004) Coral Reefs of Japan. Ministry of the Environment and Japanese Coral Reef Society (eds.). Tokyo, pp 245-247

Suwa R, Hirose M, Hidaka M (2008) Seasonal fluctuation in zooxanthella composition and photo-physiology in the corals Pavona divaricata and P. decussata in Okinawa. Mar Ecol Prog Ser 361: 129-137

Swofford DL (2000) PAUP*: Phylogenetic Analysis Using Parsimony (*and Other Methods). Version 4.0b2. Sinauer Associates, Sunderland MA

Szmant AM, Gassman NJ (1990) The effect of prolonged "bleaching" on the tissue biomass and reproduction of the reef coral Montastrea annularis. Coral Reefs 8:217-224

Takabayashi M, Santos SR, Cook CB (2004) Mitochondrial DNA phylogeny of the symbiotic dinoflagellates (Symbiodinium, Dinophyta). J Phycol 40:160-164

Takahashi S, Whitney SM, Badger MR (2009) Different thermal sensitivity of the repair of photodamaged photosynthetic machinery in cultured Symbiodinium species. PNAS $106: 3237-3242$ 
Tchernov D, Gorbunov MY, de Vargas C, Yadav SW, Milligan AJ, Haggblom M, Falkowski PG (2004) Membrane lipids of symbiotic algae are diagnostic of sensitivity to thermal bleaching in corals. PNAS 101:13531-13535

Thompson JD, Gibson TJ, Plewniak F, Jeanmougin F, Higgins DG (1997). The CLUSTAL_X windows interface: flexible strategies for multiple sequence alignment aided by quality analysis tools. Nucleic Acids Res 25:48764882

Thornhill DJ, Fitt WK, Schmidt GW (2006b) Highly stable symbioses among western Atlantic brooding corals. Coral Reefs 25:515-519

Thornhill DJ, LaJeunesse TC, Kemp DW, Fitt WK, Schmidt GW (2006a) Multi-year, seasonal genotypic surveys of coral-algal symbioses reveal prevalent stability or post-bleaching reversion. Mar Biol 148:711-722

Thornhill DJ, Kemp DW, Bruns BU, Fitt WK, Schmidt GW (2008) Correspondence between cold tolerance and temperate biogeography in a Western Atlantic Symbiodinium (Dinophyta) lineage. J Phycol 44:1126-1135

Thornhill DJ, LaJeunesse TC, Santos SR (2007) Measuring rDNA diversity in eukaryotic microbial systems: how intragenomic variation, pseudogenes, and PCR artifacts confound biodiversity estimates. Mol Ecol 16:5326-5340

Toller WW, Rowan R, Knowlton N (2001a) Zooxanthellae of the Montastraea annularis Species Complex: Patterns of Distribution of Four Taxa of Symbiodinium on Different Reefs and Across Depths. Biol Bull 201:348-359 
Toller WW, Rowan R, Knowlton N (2001b) Repopulation of zooxanthellae in the Caribbean corals Montastraea annularis and M. faveolata following experimental and disease-associated bleaching. Biol Bull 201:360-373

Trench RK (1979) The cell biology of plant-animal symbiosis. Annu Rev Plant Physiol $30: 485-531$

Trench RK (1987) Dinoflagellates in non-parasitic symbioses. Blackwell Scientific Publications, London

Trench RK (1993) Microalgal-Invertebrate Symbioses - a Review. Endocytobiosis Cell Res 9:135-175

Trench RK, Blank RJ (1987) Symbiodinium microadriaticum Freudenthal, S. goreauii sp. nov., S. kawagutii sp. nov. and S. pilosum sp. nov.:gymnodinioid dinoflagellate symbionts of marine invertebrates. J Phycol 23:469-481

Tytler EM, Trench RK (1986) Activities of enzymes in B-carboxylation reactions and of catalase in cell-free preparations from the symbiotic dinoflagellates Symbiodinium sp. from a coral, a clam, a zoanthid and two sea anemones. Proc R Soc Lond B 228:483-492

Ulstrup KE, Berklemans R, Ralph PJ, van Oppen MJH (2006) Variation in bleaching sensitivity of two coral species across a latitudinal gradient on the Great Barrier Reef: the role of zooxanthellae. Mar Ecol Prog Ser 314:135-148

Ulstrup KE, Hill R, van Oppen M, Larkum AWD, Ralph P (2008) Seasonal variation in the photo-physiology of homogeneous and heterogeneous Symbiodinium consortia in two scleractinian corals. Mar Ecol Prog Ser 361:139-150 
Ulstrup KE, van Oppen MJH (2003) Geographic and habitat partitioning of genetically distinct zooxanthellae (Symbiodinium) in Acropora corals on the Great Barrier Reef. Mol Ecol 12:3477-3484

van Oppen MJH (2004) Mode of zooxanthella transmission does not affect zooxanthella diversity in acroporid corals. Mar Biol 144:1-7

van Oppen MJH, Palstra FP, Piquet AMT, Miller DJ (2001) Patterns of coral-dinoflagellate associations in Acropora: significance of local availability and physiology of Symbiodinium strains and host-symbiont selectivity. Proc R Soc Lond B 268:17591767

van Woesik R, Done TJ (1997) Coral communities and reef growth in the southern Great Barrier Reef. Coral Reefs 16:103-115

Venn AA, Loram JE, Douglas AE (2008a) Photosynthetic symbioses in animals. J Exp Bot 59:1069-1080

Venn AA, Loram JE, Trapido-Rosenthal HG, Joyce DA, Douglas AE (2008b) Importance of Time and Place: Patterns in Abundance of Symbiodinium Clades A and B in the Tropical Sea Anemone Condylactis gigantea. Biol Bull 215:243-252

Veron JEN (1993a) A biogeographic database of hermatypic corals. Australian Institute of Marine Sciences Monograph Series 1

Veron JEN (1993b) Corals of Australia and the Indo-Pacific, University of Hawaii Press edition 
Veron JEN (1995) Corals in Space and Time: The Biogeography \& Evolution of the Scleractinia., UNSW PRESS

Veron JEN (1986) Corals of Australia and the Indo-Pacific. Angus \& Robertson Publishers, London

Veron JEN (2000) Corals of the World. Australian Institute of Marine Science, Townsville, Australia

Veron JEN, Done TJ (1979) Corals and Coral Communities of Lord Howe Island. Aust J Mar Freshw Res 30:203-236

Veron JEN, Marsh LM (1988) Hermatypic corals of Western Australia. Records and annotated species list. Records of the Western Australian Museum Supplement $29: 1-136$

Wang J-T, Douglas AE (1998) Nitrogen recycling or nitrogen conservation in an algainvertebrate symbiosis? J Exp Mar Biol Ecol 201:2445-2453

Warner ME, Berry-Lowe S (2006) Differential xanthophyll cycling and photochemical activity in symbiotic dinoflagellates in multiple locations of three species of Caribbean coral. J Exp Mar Biol Ecol 339:86-95

Warner ME, Fitt WK (1999) Damage to photosystem II in symbiotic dinoflagellates: A determinant of coral bleaching. PNAS 96:8007-8012

Warner WE, Chicoat GC, McFarland FK, Fitt KW (2002) Seasonal fluctuations in the photosynthetic capacity of photosystem II in symbiotic dinoflagellates in the Caribbean reef-building coral Montastrea. Mar Biol 141:31-38 
Warner ME, Fitt WK, Schmidt GW (1996) The effects of elevated temperature on the photosynthetic efficiency of zooxanthellae in hospite from four different species of reef coral: A novel approach. Plant Cell Env 19:291-299

Weis VM (2008) Cellular mechanisms of Cnidarian bleaching: stress causes the collapse of symbiosis. J Exp Biol 211:3059-3066

Weis VM, Reynolds WS, deBoer MD, Krupp DA (2001) Host-symbiont specificity during onset of symbiosis between the dinoflagellates Symbiodinium spp. and planula larvae of the scleractinian coral Fungia scutaria. Coral Reefs 20:301-308

Wells JW (1957) Coral Reefs. In: Hedspeth JW (ed) Treatise on marine ecology and paleoecology. Geological Society America, Memoir 67, pp 609-632

Williams GJ, Maragos JE, Davy SK (2008) Characterization of the coral communities at Palmyra Atoll in the remote Central Pacific. Atoll Res Bull 557: 1-30

Winters G, Loya Y, Rottgers R, Beer S (2003) Photoinhibition in shallow water colonies of the coral Stylophora pistillata as measured in situ. Limnol Oceanogr 48:1388-1393

Wolanski E (1994) Physical Oceanographic Processes of the Great Barrier Reef. CRC Press, Boca Raton, Florida, 194pp

Wood AR, Gardner JPA (2007) Small spatial scale population genetic structure in two limpet species endemic to the Kermadec Islands, New Zealand. Mar Ecol Prog Ser 349:159-170 
Yakovleva I, Hidaka M (2004) Differential recovery of PSII function and electron transport rate in symbiotic dinoflagellates as a possible determinant of bleaching susceptibility of corals. Mar Ecol Prog Ser 268:43-53

Yamamura N (1996) Evolution of mutualistic symbiosis: A differential equation model. Pop Ecol 38:211-218

Yamano H, Hori K, Yamauchi M, Yamagawa O, Ohmura A (2001) Highest latitude coral reef at Iki Island, Japan. Coral Reefs 20:9-12

Yamano H, Sugihara K, Nakai T, Yamagawa O (2004) Iki Islands.In: Ministry of the Environment and Japanese Coral Reef Society (eds) Coral Reefs of Japan. Ministry of the Environment, Tokyo, pp 242-244

Yentsch CS, Yentsch CM, Cullen JJ, Lapointe B, Phinney DA, Yentsch SW (2002) Sunlight and water transparency: cornerstones in coral research. J Exp Mar Biol Ecol 268:171-183 
Appendices 


\section{Appendix 1}

\section{Kermadec Islands coral community analysis}

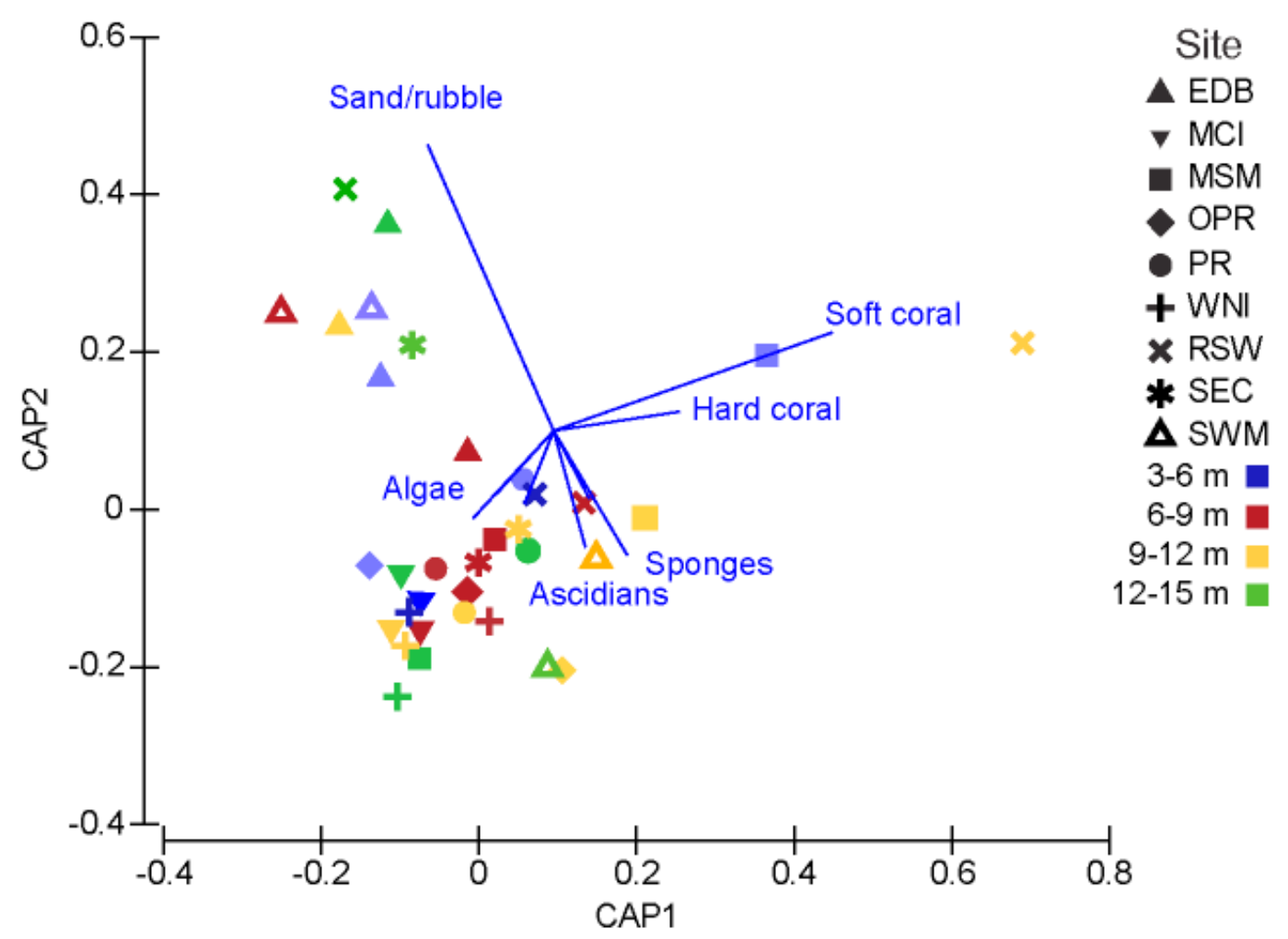

Figure A1.1 Canonical analysis of principal components examining differences in benthic community cover at 9 sites at the Kermadec Islands. Shapes represent sites, colours represent depths. Benthic groups driving the separation of sites shown as vectors. Similarities calculated using dispersion weighted zero-adjusted BrayCurtis resemblance measure. 


\section{Appendix 2}

\section{Physiological capacity of Symbiodinium to facilitate survival of scleractinian corals at environmentally marginal sites}

\section{A2.1 INTRODUCTION}

Reef-building corals contain symbiotic, unicellular dinoflagellate microalgae of the genus Symbiodinium, which play a significant role in host nourishment and physiology. As a reflection of the high genetic diversity of the genus ( 8 clades and numerous sub-clades), considerable physiologically diversity of Symbiodinium has been observed at both a cladal and subcladal level, in terms of tolerance to irradiance and/or temperature (Rowan \& Knowlton 1995, Baker \& Rowan 1997, Iglesias-Prieto \& Trench 1997b, Rowan et al. 1997, Baker et al. 2004, Rowan 2004). In many cases, external environmental conditions promote certain pairings between partners, including combinations with regard to depth, irradiance or temperature gradients, latitude and longitude, and host ontogeny (Rowan et al. 1997, LaJeunesse et al. 2003, Coffroth \& Santos 2005, Frade et al. 2008b). The physiological variation in Symbiodinium types has been suggested as a basis for coral tolerance of bleaching stressors, including elevated temperature. Specifically, corals are proposed to enhance their bleaching resistance by associating with thermally tolerant Symbiodinium genotypes, either by uptake from the external environment or by increasing their population of cryptic symbionts (Buddemeier \& Fautin 1993, Fautin \& Buddemeier 2004). The 
capacity of corals to shift or "shuffle" symbiont populations towards different hostsymbiont combinations has been observed in response to coral bleaching (Baker et al. 2004), transplantation to a different light habitat (Baker 2001, Toller et al. 2001b), living in marginal habitats (Toller et al. 2001b,Venn et al. 2008b), or variability within a species on regional scales (van Oppen et al. 2001). It has been suggested that flexibility in hostsymbiont partnerships and physiological responses to changing environmental conditions are likely to be most evident at high latitudes, where the coral-symbiont partnerships are subject to far more variable environmental conditions than at tropical locations. Considering the more conservative temperature increases of $1-2^{\circ} \mathrm{C}$ by 2030 (HoeghGuldberg 1999), understanding the potential for adaptive responses of Symbiodinium to changing environmental conditions, and thus to future climate change is of critical importance. Thus, the aim of the present study was to assess the capacity for shuffling of corals living in a marginal environment. Specifically, we aimed to address the following questions:

(1) Do corals at high latitude host symbionts specifically adapted to their extreme and variable environment?

(2) Are corals from high latitudes specifically adapted to modify their dominantly expressed symbiont type (achieved by either external acquisition or from internal shuffling)?

(3) Following transplantation can the holobiont survive in the long term and maintaining growth rates equivalent to the holobiont optimal for that specific environment? 
(4) Are there any changes in symbiont density or photosynthetic performance after transplantation into the new environment in comparison to the control individuals?

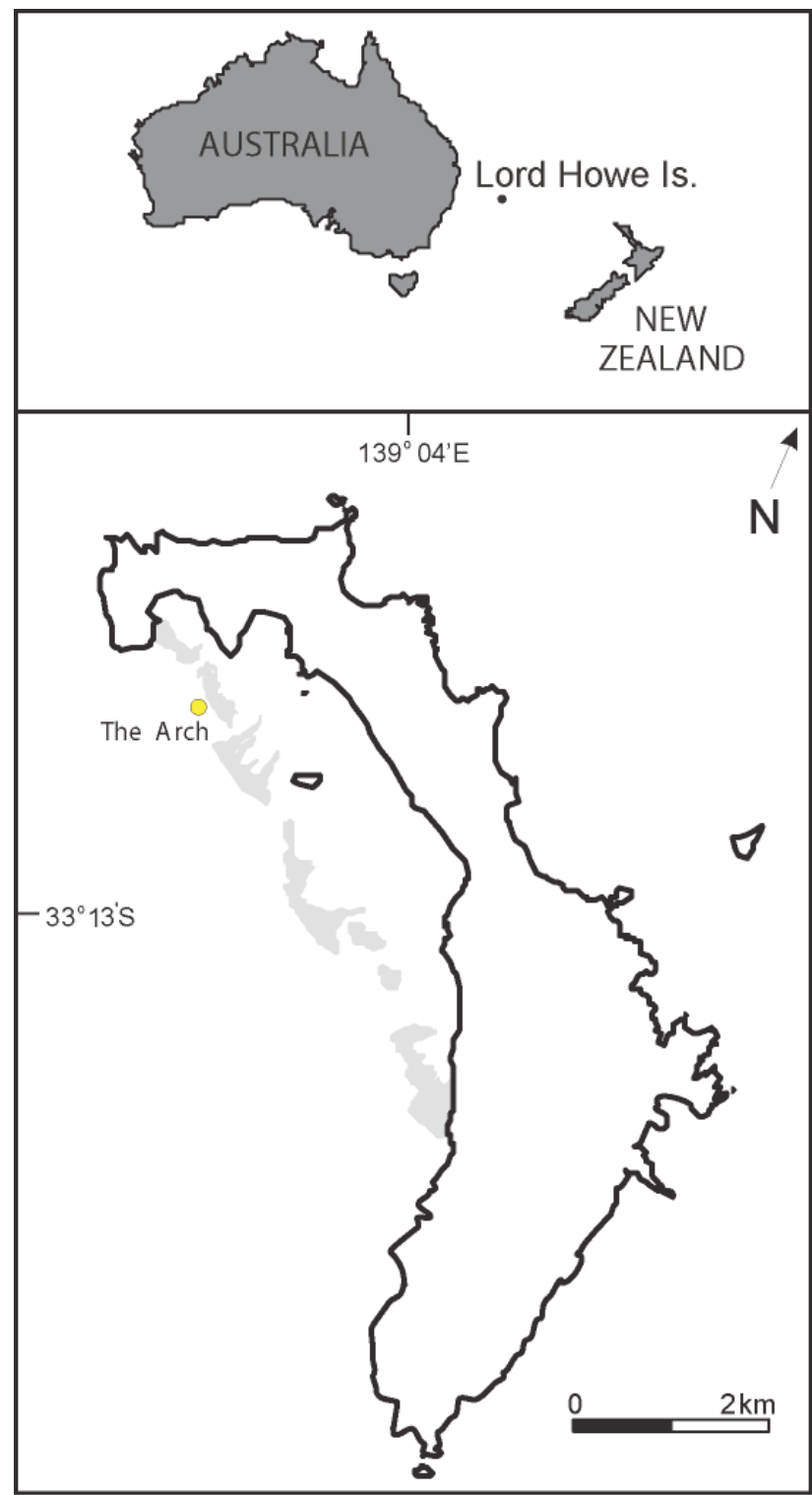

Figure A2.1 Location of Lord Howe Island, Australia, and backreef site, The Arch, at which coral transplants were conducted. 


\section{A2.2 METHODS}

\section{A2.2.1 Study site and experimental setup}

Situated over $1000 \mathrm{~km}$ from the southern Great Barrier Reef (GBR), Lord Howe Island (LHI; 31"33'S, 159"05' E, Fig. A2.1) is home to the southernmost coral reef in the world. Coral reefs occur at Lord Howe Island due to the influence of the warm-water East Australian Current (EAC). The boundary between the EAC and the southern temperate Tasman Current varies from $30^{\circ} \mathrm{S}$ in winter to $34^{\circ} \mathrm{S}$ in summer and runs close to LHI (Martinez 1994). The EAC maintains relatively high mean annual sea-surface temperatures at the island of between $18^{\circ} \mathrm{C}$ and $26^{\circ} \mathrm{C}$ (Veron \& Done 1979 , Chapter 4), the average low temperature similar to that of the southern GBR and subtropical coastal coral communities of south-eastern Australia. Considering its geographical isolation, latitude and small size (11 $\mathrm{km}$ by $2.5 \mathrm{~km}$ ), LHI sustains surprisingly high coral species diversity with 83 hermatypic coral species (from 33 genera) and coral cover comparable to tropical sites.

Samples of two common corals at Lord Howe Island, Acropora cuneata (15 colonies) and Pocillopora damicornis (10 - 15 colonies), were collected at two depths: 5 - 7 $\mathrm{m}$ and $12-15 \mathrm{~m}$ at The Arch, on the western backreef of the island (Fig. A2.1). Two nubbins (4 - $5 \mathrm{~cm}$ diameter of base) were removed from each individual colony, and placed into seedling trays and fixed in place with fast-drying underwater cement (Mapei Granirapid), and left cure in aquaria overnight. During this period the nubbins were stained with Alizarin red $\left(100 \mathrm{mg} \mathrm{l}^{-1}\right)$ to allow for determination of growth over the transplant period. The seedling trays containing the coral fragments were fixed securely 
underwater to the existing reef using cable ties, and placed at both collection depths (Fig. A2.2). Following deployment, photographs were taken of each tray in situ to allow additional determination of growth rates at the end of the experimental period. The experimental setup entailed half of the fragments ( 8 fragments) from each colony being placed in seedling trays and returned to their collection depth (i.e. controls), and the other eight fragments were placed in seedlings trays and returned to the opposite depth (i.e. treatment - shallow to deep, or deep to shallow). The A. cuneata transplants were set up in August 2007, and the P. damicornis transplants in January 2008, both to be retrieved in September 2008.
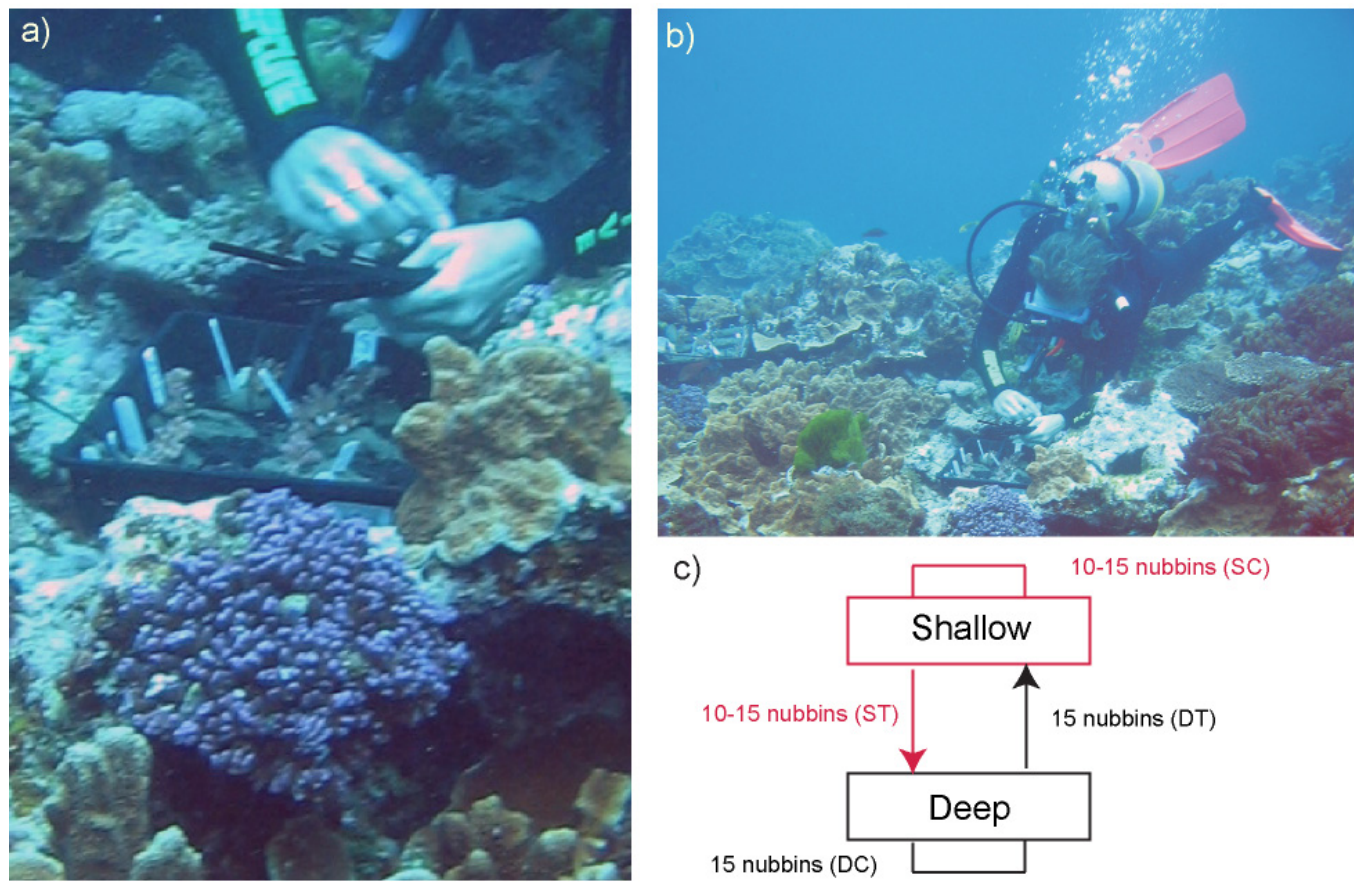

c)

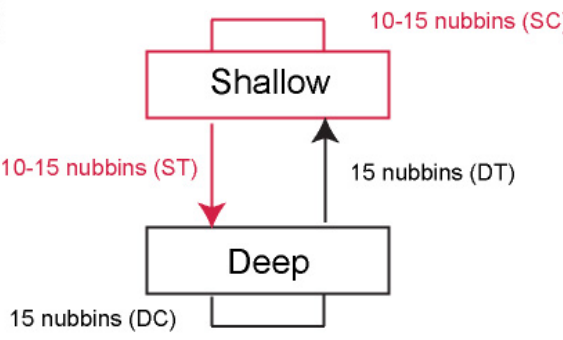

Figure A2.2 Overview of the transplantation experiment, showing setup (a, b) and sampling design (c). SC = shallow controls, $\mathrm{DC}=$ deep controls, $\mathrm{DT}=$ nubbins transplanted from the deep to the shallow, $\mathrm{ST}=$ nubbins transplanted from the shallow to the deep. 


\section{A2.2.2 Environmental parameters}

During the experimentation period, in situ data loggers (ONSET Hobo loggers) were attached securely to the seedling trays at each depth to record water temperature and irradiance at each depth at hourly intervals. The mean, maximum and minimum daily temperatures were to be calculated for each depth as well as the difference between the minimum and maximum temperature at each depth. Paired t-tests between sites were to be done on the raw data (daily average) to determine if the two depths experienced significantly different average daily temperatures. Data from the light loggers was only to be used for the first 5 days after deployment to exclude the effect of fouling on the light sensors

\section{A2.2.3 Genetic identification and physiological characteristics of Symbiodinium}

Samples were collected at the beginning of the experiment for identification of the original Symbiodinium type harboured by the colonies. The fragments were processed the following day according to Loh et al. (2001), and preserved using $20 \%$ DMSO solution. Symbiont identity was established using ITS2-DGGE, following protocols outlined in Chapter 3. Effective quantum yield of the colony $(\Delta \mathrm{F} / \mathrm{Fm}$ ', see Chapter 5 for details) was recorded using a Diving PAM fluorometer (Walz, Germany) at the beginning of the experiment, prior to sample collection. The yield was recorded at three different locations on the same coral fragment approximately $1 \mathrm{~cm}$ below the tip of the branch. Due to the difficulties of working at such a remote location, dark adapted maximum quantum yield could not be recorded, but effective quantum yield was deemed suffice for comparing photosynthetic 
efficiency between depths.

\section{A2.3 RESULTS}

Upon return to Lord Howe Island in September 2008, it was discovered that the experimental set-up had been destroyed by the worst storms experienced by the Island in 20 years. No transplants were remaining and the experiment could not be repeated due to time constraints. 


\section{Appendix 3}

Symbiodinium diversity by sampling effort

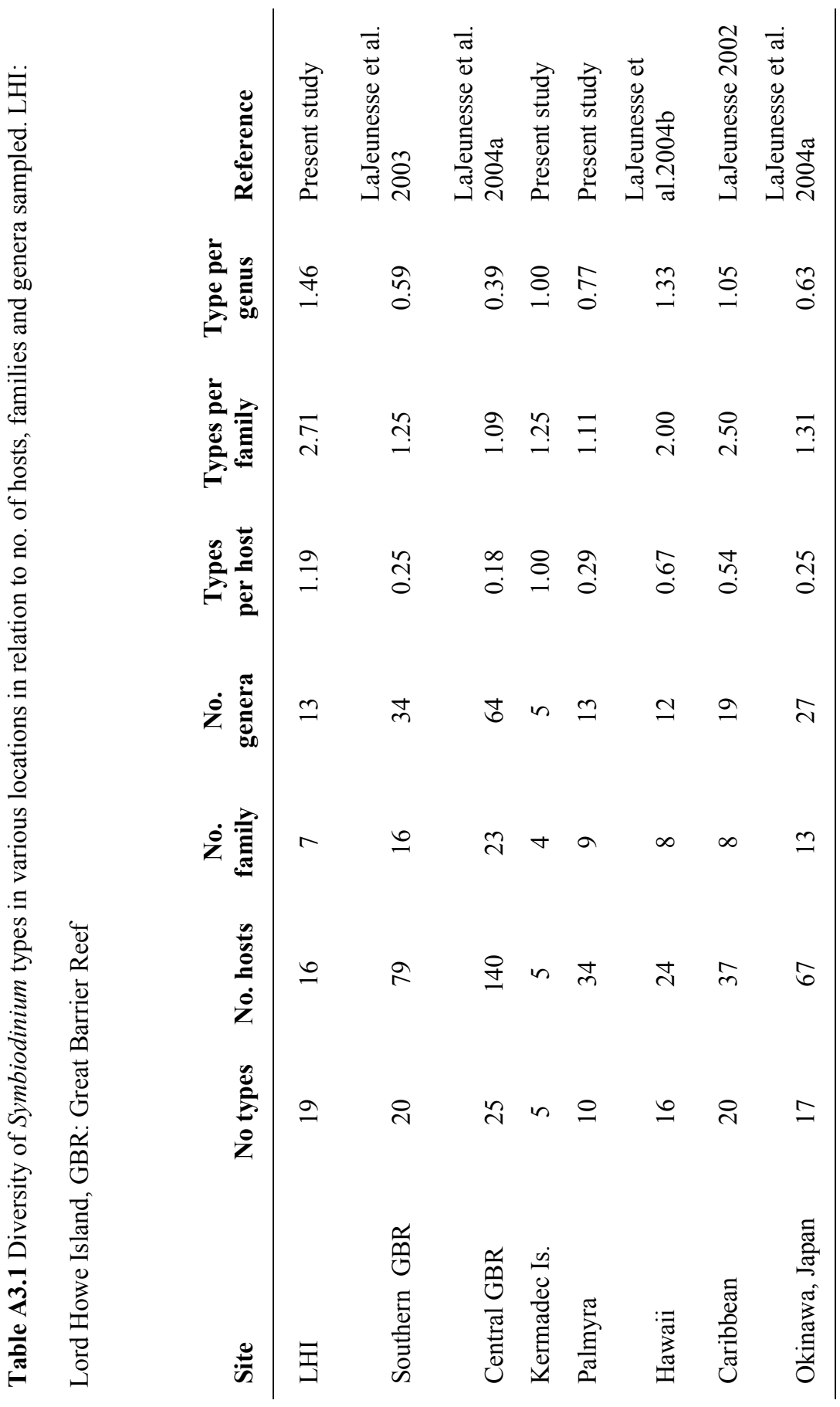




\section{Appendix 4}

\section{Palmyra Atoll coral diversity, distribution and photosynthetic health}

\section{A.4.1 Coral diversity at Palmyra Atoll}

Table A4.1 Species list of scleractinian cnidarians reported at Palmyra Atoll from 1987-2005 (Williams et al. 2008). ITS2-DGGE Symbiodinium types identified in coral species shown following reference. Montipora species identified to group level (Table A4.2) in survey therefore Symbiodinium type not shown.

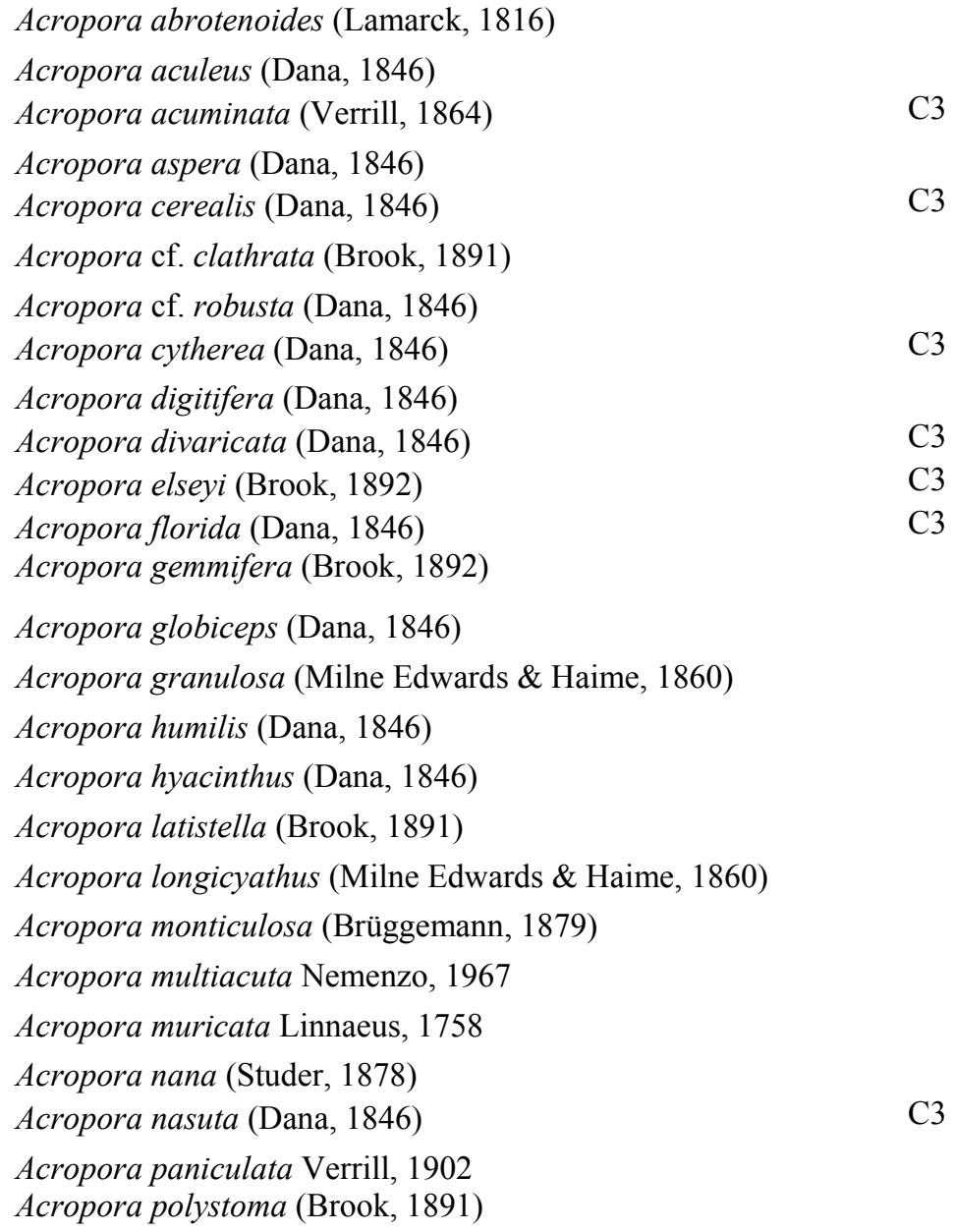


Acropora robusta (Dana, 1846)

Acropora rosaria (Dana, 1846)

Acropora samoensis (Brook 1891)

Acropora selago (Studer, 1878)

Acropora sp. Oken, 1815

Acropora spicifera (Dana, 1846)

Acropora squarrosa (Ehrenberg, 1834)

Acropora subulata (Dana, 1846)

Acropora tenuis (Dana, 1846)

Acropora valida (Linnaeus 1758)

Acropora variabilis (Klunzinger, 1879)

Acropora vaughani Wells, 1954

Acropora verweyi Veron \& Wallace, 1984

Alveopora verrilliana Dana, 1872

Astreopora expansa Brüggemann, 1877

Astreopora gracilis Bernard, 1896

Astreopora listeri Bernard, 1896

Astreopora myriophthalma (Lamarck, 1816)

Astreopora sp. Blainville, 1830

Astreopora suggesta Wells, 1954

Balanophyllia sp. [small cups] Searles, Wood, 1844

Ctenactis echinata (Pallas, 1766)

Cycloseris cyclolites (Lamarck, 1801)

Cycloseris patelliformis (Boschma, 1923)

Cycloseris sp. Milne Edwards \& Haime, 1849

Cyphastrea serailia (Forskål, 1775)

Echinophyllia aspera (Ellis \& Solander, 1788)

Echinophyllia sp. Klunzinger, 1879

D1 D1a

Edwards \& Haime 1848

Edwards \& Haime 1848

Favia favus (Forskål, 1775)

Favia matthaii Vaughan, 1918

Favia pallida (Dana, 1846)

Favia rotumana (Gardiner, 1899)

Favia rotundata (Veron \& Pichon, 1977)

Favia sp. Oken, 1815

Favia speciosa Dana, 1846

Favia stelligera (Dana, 1846)

Favites abdita (Ellis \& Solander 1786)

Favites chinensis (Verrill, 1866)

Favites flexuosa (Dana, 1846)

Favites halicora (Ehrenberg, 1834) 
Favites pentagona (Esper, 1794)

Favites russelli (Wells, 1954)

Favites sp. Link, 1807

Fungia concinna Verrill, 1864

Fungia danai Milne Edwards \& Haime, 1851

Fungia fungites (Linnaeus, 1758)

Fungia granulosa Klunzinger, 1879

Fungia horrida Dana, 1846

Fungia moluccensis Horst, 1919

Fungia paumotensis Stutchbury, 1833

$\mathrm{C} 1, \mathrm{C} 1_{\mathrm{xx}}$

Fungia repanda Dana, 1846

Fungia scutaria Lamarck, 1801

Gardineroseris planulata (Dana, 1846)

C1

Goniastrea edwardsi Chevalier, 1971

Goniastrea pectinata (Ehrenberg, 1834)

Goniastrea retiformis (Lamarck, 1816)

Halomitra pileus (Linnaeus 1758)

Herpolitha limax Esper, 1797

Heteractis crispa ${ }^{2}$ (Ehrenberg, 1834)

Heteractis malu ${ }^{2}$ (Haddon \& Shackleton, 1893)

Hydnophora exesa (Pallas, 1766)

Hydnophora microconos (Lamarck, 1816)

Hydnophora pilosa (Veron, 1985)

Hydnophora rigida (Dana, 1846)

Isopora brueggemanni (Brook, 1893)

Isopora cuneata (Dana, 1846)

Isopora palifera (Lamarck, 1816)

Leptastrea agassizi Vaughan 1907

Leptastrea bewickensis Veron \& Pichon, 1977

Leptastrea pruinosa Crossland, 1952

Leptastrea purpurea (Dana, 1846)

C1 C1b

Leptastrea sp. A [large angular calices] Milne

Leptastrea sp. B Milne Edwards \& Haime 1848

Leptastrea sp. C [small round calices] Milne

Leptastrea transversa Klunzinger, 1879

Leptoria phrygia (Ellis \& Solander, 1786)

Leptoseris mycetoseroides Wells, 1954

Lobophyllia corymbosa (Forskå1, 1775)

Lobophyllia hemprichii (Ehrenberg, 1834)

Merulina ampliata (Ellis \& Solander, 1786)

$\mathrm{C} 3_{\mathrm{xx}}$

Montastraea annuligera (Milne-Edwards \& Haime, 1849) 
Montastraea curta (Dana, 1846)

Montastraea sp. Blainville, 1830

Montipora aequituberculata Bernard, 1897

Montipora caliculata (Dana, 1846)

Montipora capitata (Dana, 1846)

Montipora cf. incrassata (Dana, 1846)

Montipora danae (Milne Edwards \& Haime, 1851)

Montipora dilatata Studer, 1901

Montipora efflorescens Bernard, 1897

Montipora flabellata Studer, 1901

Montipora foliosa (Pallas, 1766)

Montipora foveolata (Dana, 1846)

Montipora hoffmeisteri Wells, 1954

Montipora informis Bernard, 1897

Montipora millepora Crossland, 1952

Montipora monasteriata (Forskå1, 1775)

Montipora patula Verrill, 1864

Montipora peltiformis Bernard, 1897

Montipora sp. Blainville, 1830

Montipora spongodes Bernard, 1897

Montipora tuberculosa (Lamarck, 1816)

Montipora venosa (Ehrenberg, 1834)

Montipora verrilli Vaughan 1907

Pachyclavularia violacea ${ }^{1}$ (Quoy \& Gaimard 1833)

Pachyseris sp. Milne Edwards \& Haime 1849

Pavona cactus

Pavona chiriquiensis Glynn, Mate \& Stemann, 2001

Pavona clavus (Dana, 1846)

Pavona duerdeni Vaughan, 1907

Pavona explanulata (Lamarck, 1816)

Pavona frondifera (Lamarck, 1816)

Pavona maldivensis (Gardiner, 1905)

Pavona minuta Wells, 1954

Pavona varians Verrill, 1864

Platygyra daedalea (Ellis \& Solander, 1786)

Platygyra lamellina (Ehrenberg, 1834)

Platygyra pini Chevalier, 1973

Platygyra ryukyuensis Yabe \& Sugiyama, 1936

Platygyra sp. Ehrenberg, 1834

Platygyra sinensis (M. Edwards \& Haime, 1849)

Plesiastrea versipora (Lamarck, 1816)

Pocillopora brevicornis Lamarck, 1816 
Pocillopora damicornis (Linnaeus, 1758)

C1c, C42a

Pocillopora capitata Verrill, 1864

Pocillopora eydouxi Milne Edwards \& Haime 1860

C1c, C42a

Pocillopora meandrina Dana 1846

$\mathrm{Clc}$

Pocillopora sp. Lamarck, 1816

Pocillopora verrucosa (Ellis \& Solander, 1786)

$\mathrm{C} 1 \mathrm{c}, \mathrm{C} 42 \mathrm{a}$

Pocillopora zelli Veron 2000

Porites annae Crossland, 1952

Porites australiensis Vaughan, 1918

Porites evermanni Vaughan, 1907

Porites lichen Dana, 1846

Porites lobata Dana, 1846

Porites lutea Milne Edwards \& Haime, 1851

Porites murrayensis Vaughan, 1918

Porites rus (Forskå1, 1775)

Porites solida (Forskå1, 1775)

Porites sp. [nodular] Link, 1807

Porites sp. Link, 1807

Porites superfusa Gardiner, 1898

Porites vaughani Crossland, 1952

Psammocora contigua (Esper, 1797)

Psammocora haimeana Milne Edwards \& Haime, 1851

Psammocora nierstraszi Horst, 1921

C1

Psammocora profundacella Gardiner, 1898

Psammocora stellata Verrill, 1864

Psammocora verrilli Vaughan, 1907

Rhodactis howesii ${ }^{4}$ (Ehrenberg, 1834)

Sandalolitha robusta Quelch, 1886

Sarcophyton sp. ${ }^{1}$ Gosliner, Behrens \& Williams, 1996

Sinularia sp. ${ }^{1}$ Gosliner, Behrens \& Williams, 1996

Stereonephthya sp. ${ }^{1}$ Gosliner, Behrens \& Williams, 1996

Stichodactyla mertensii ${ }^{2}$ Brandt, 1835

Stylaster elegans. ${ }^{5}$ Verrill, 1864

Stylophora pistillata Esper, 1797

Symphyllia recta (Dana, 1846)

Tubastraea coccinea Lesson, 1831

Turbinaria reniformis Bernard 1896

D1a

Turbinaria frondens (Dana, 1846)

Turbinaria sp. Oken, 1815 
Table A4.2 Groups of Montipora species found at Palmyra Atoll, remote Central Pacific based on their growth-form and skeletal characters. Adapted from Veron (2000)

\begin{tabular}{cl}
\hline No. & \multicolumn{1}{c}{ Group Description } \\
\hline 2 & Laminar species without conspicuous coenosteum ridges \\
3 & Encrusting or massive species with prominent coenosteum tuberculae \\
4 & Encrusting or massive species with prominent thecal papillae \\
6 & Encrusting species with very small corallites \\
7 & Species with funnel-shaped (foveolate) corallites \\
8 & Species with large coenosteum tuberculae formin \\
\hline
\end{tabular}


A4.2 Coral distributions at Palmyra Atoll

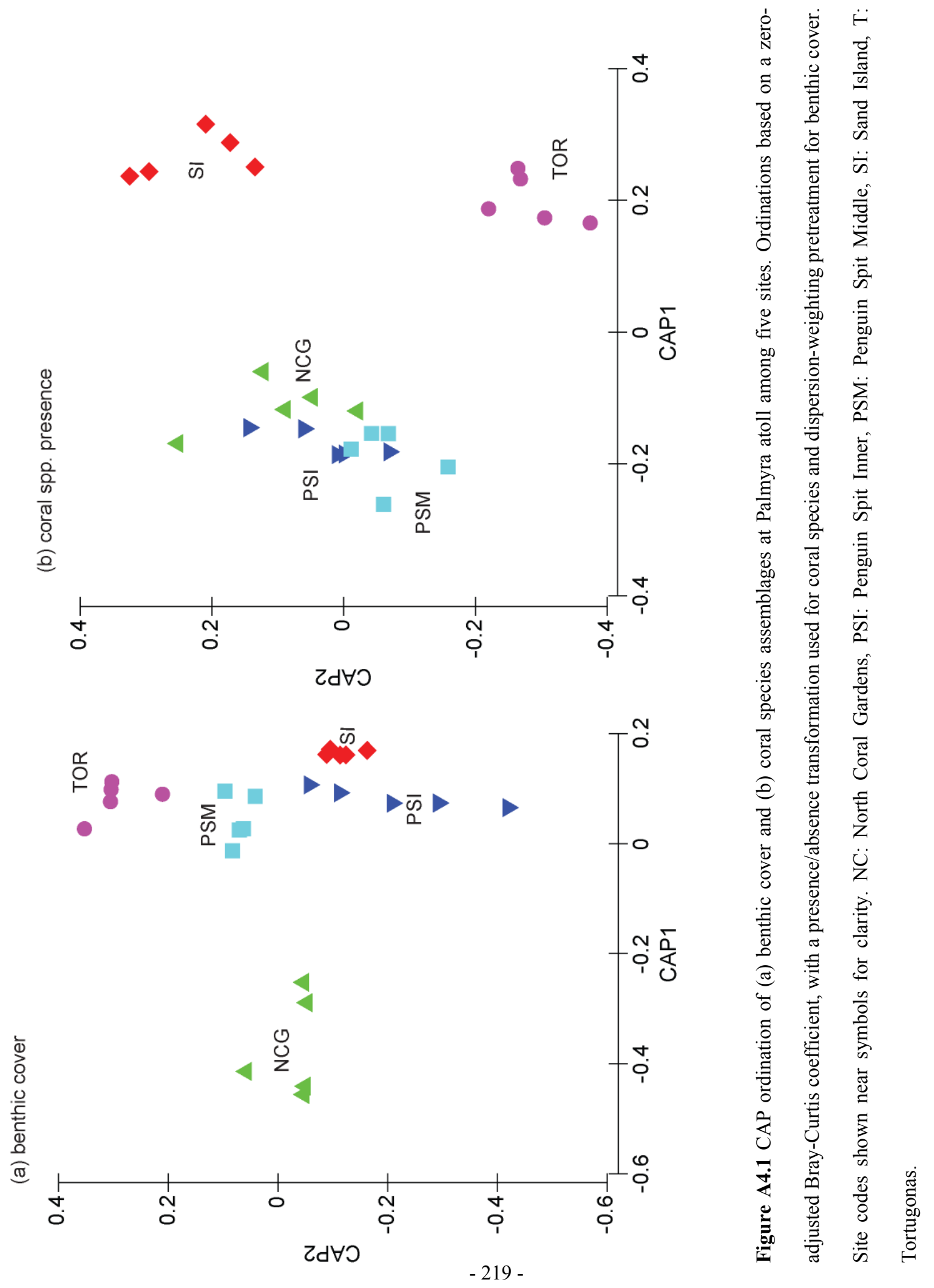




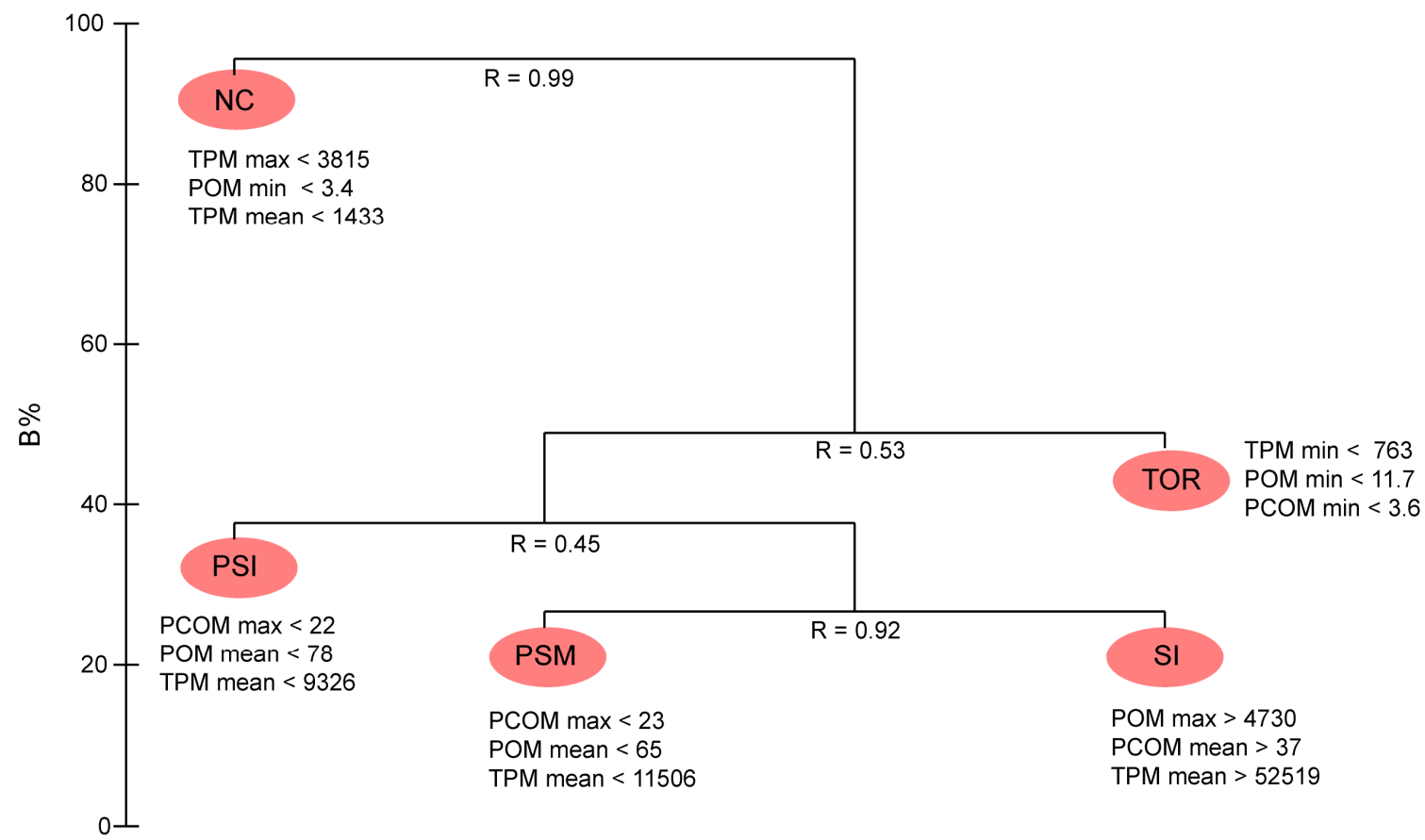

Figure A4.2 LINKTREE classification and regression tree analysis (with Simprof test of 1000 permutations) showing major splits in benthic cover between sites in link-tree dendrogram by most significant environmental variable(s). B\% is the absolute measure of group differences. For each split the ANOSIM test statistic R is shown. NC: North Coral Gardens, PSI: Penguin Spit Inner, PSM: Penguin Spit Mid, SI: Sand Island, T: Tortugonas. POM IN \%, TPM/POM in $\mathrm{mg} \mathrm{m}^{-2} \mathrm{~d}^{-1}$. 